Serviço de Pós-Graduşo EESC/USP

EXEMPLAR REVISADO

Data de entrada no Serviço:..........................

Ass: forn

\title{
ESTUDO DA GEOMETRIA DA ARESTA DE CORTE DE \\ FERRAMENTAS APLICADAS AO TORNEAMENTO \\ DE SUPERLIGAS À BASE DE NÍQUEL COM
}

ALTA VELOCIDADE DE CORTE

Eng. M.Sc. Leonardo Roberto da Silva

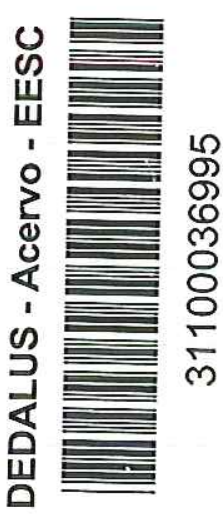

Tese apresentada à Escola de Engenharia de São Carlos, da Universidade de São Paulo, como parte dos requisitos para obtenção do título de doutor em Engenharia Mecânica

ORIENTADOR: Prof. Dr. Reginaldo Teixeira Coelho

São Carlos 


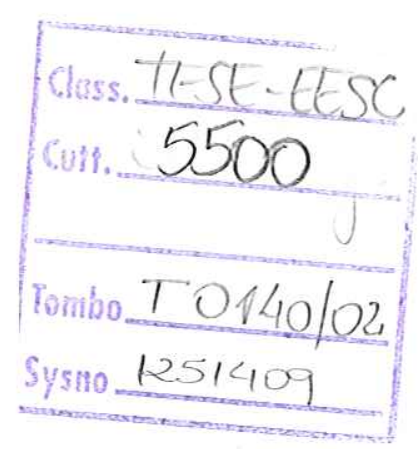

Ficha catalográfica preparada pela Seção de Tratamento da Informação do Serviço de Biblioteca - EESC/USP

Silva, Leonardo Roberto da

S586e Estudo da geometria da aresta de corte de ferramentas aplicadas ao torneamento de superligas à base de níquel com alta velocidade de corte / Leonardo Roberto da Silva. -- São Carlos, 2002.

Tese (Doutorado) -- Escola de Engenharia de São Carlos-Universidade de São Paulo, 2002.

Área: Engenharia Mecânica.

Orientador: Prof. Dr. Reginaldo Teixeira Coelho.

1. Usinagem com alta velocidade (HSM). 2. Corte a seco. 3. Mínima Quantidade de Lubrificante (MQL). 4. Ferramentas para HSM. 5. Temperatura e força de corte. 6. Superligas à base de níquel. 7. Preparação de arestas de corte. 8. Integridade superficial. I. Título. 
FOLHA DE JULGAMENTO

Candidato: Engenheiro LEONARDO ROBERTO DA SILVA

Tese defendida e julgada em 26-03-2002 perante a Comissão Julgadora:

Regunalo r.cello if $\operatorname{RoN} 100$

Prof. Assoc. REGINALDO TEIXEIRA COELHO (Orientador) (Escola de Engenhariayde São Carlos/USP)

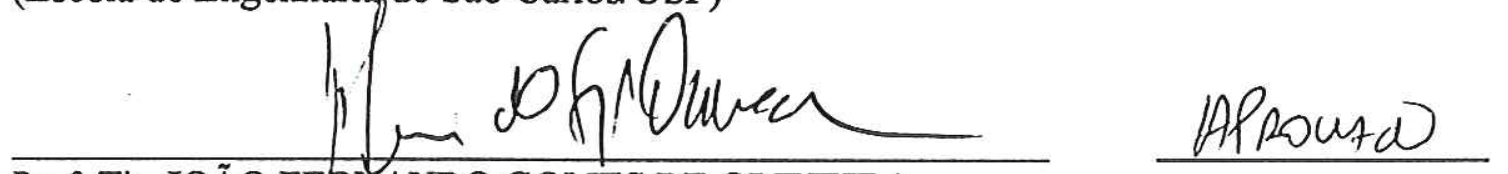

Prof. Tit. JOÃO FER ANDO GOMES DE OLIVEIRA

(Escola de Engenharia de São Carlos/USP)

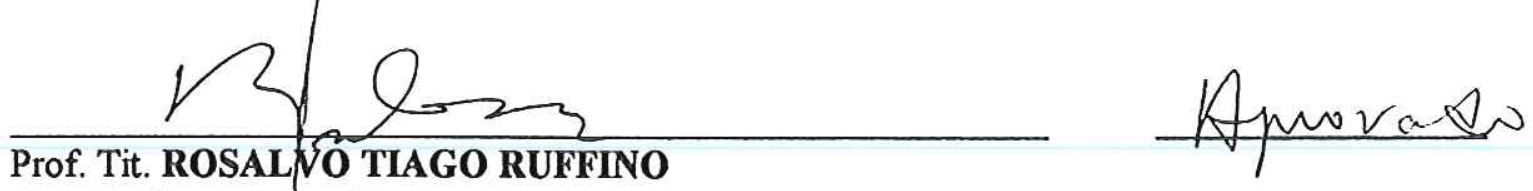

(Escola de Engenharia de São Carlos/USP)
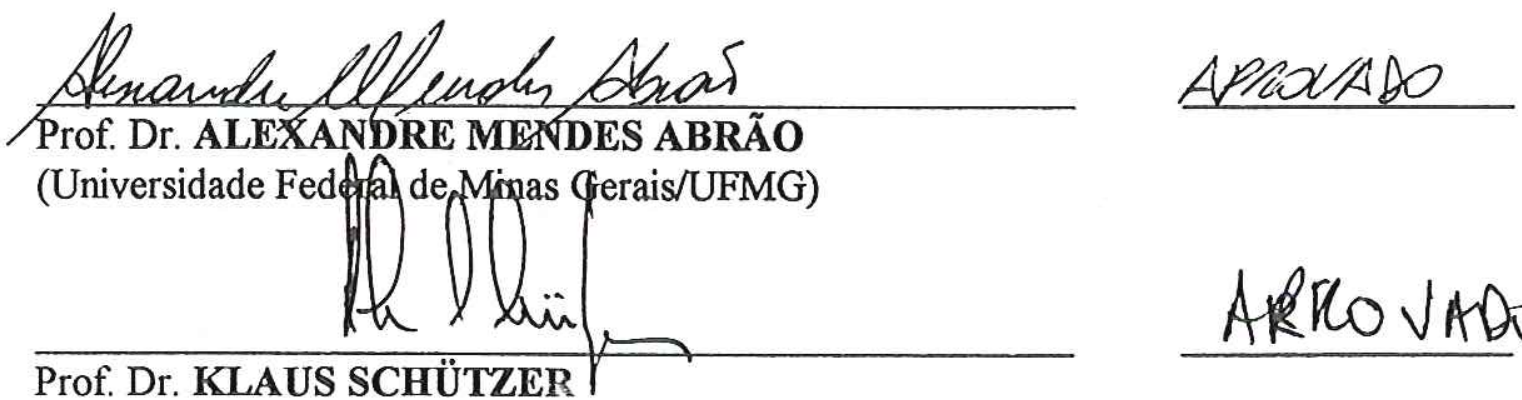

(Universidade Metodista de Piracicaba/UNIMEP)

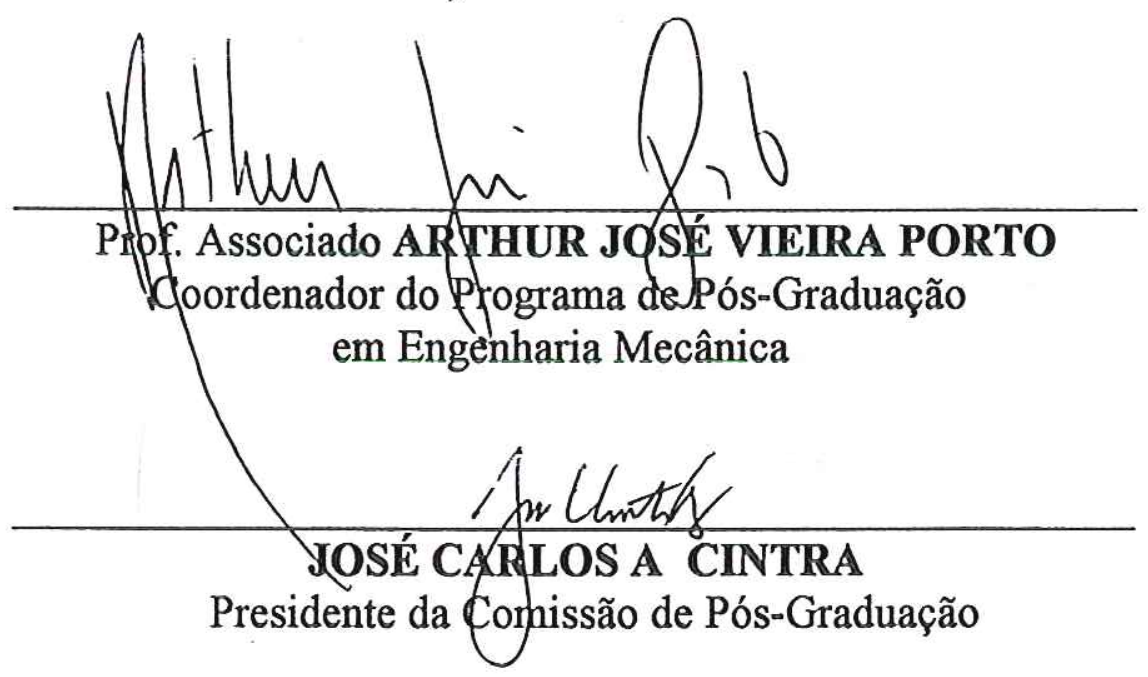


À Rosemary pelo incentivo e compressão nos momentos de ausência À minha filha Anna Beatriz um modesto exemplo de trabalho À minha mãe Conceição 


\section{AGRADECIMENTOS}

À Deus, por ter dado-me saúde, força e perseverança para alcançar mais este privilégio.

Ao professor Reginaldo Teixeira Coelho, pela excelente orientação fornecida durante a elaboração deste trabalho, pelas valiosas sugestões, pela amizade, paciência e ensinamentos transmitidos.

À Coordenadoria de Aperfeiçoamento de Pessoal de Nível Superior - CAPES, pelo financiamento da bolsa de estudo concedida pelo programa PICDT (CEFETMG)

Aos amigos Wilson Mendonça Gomes e Roberto Nereu, a todos funcionários da empresa Qualifer, pela grande colaboração na preparação das ferramentas e informações fornecidas.

À todos os colegas, professores e funcionários do Departamento de Engenharia Mecânica da EESC/USP pela colaboração na concretização deste trabalho.

À Coordenação do Curso Técnico de Mecânica (CEFET-MG) e aos colegas de trabalho, pelo constante apoio profissional.

Aos professores do curso de Pós Graduação pelos conhecimentos adquiridos.

Aos professores João Fernando Gomes de Oliveira, Rosalvo Tiago Ruffino e Luiz Carlos Casteletti pelas valiosas sugestões e aconselhamentos técnicos. 
Às minhas irmãs pelo estímulo ao estudo.

Aos técnicos, Ronaldo do grupo (OPF), Adão, Zé Carlos e Botelho (LAMAFE) e Tico (Departamento de Materiais) pela atenção e ajuda no desenvolvimento de todo trabalho.

Às secretárias da Pós Graduação deste departamento, Ana Paula, Beth e Irene e aos demais funcionários da secretaria do SEM pela atenção.

À FAPESP, pelo financiamento do projeto de auxilio a pesquisa, possibilitando a realização desta pesquisa.

Às empresa ITW - Chemical Products Ltda pelo doação do equipamento de mínima quantidade de lubrificante (MQL) e pelo fluido de corte usado nos ensaios. Sandvik Coromant pelo fornecimento de ferramentas cerâmicas.

Aos amigos do Grupo de Otimização de Processos de Fabricação (OPF): Aldo, Alexandre, Carlos Elias, Dinho, Douglas, Eraldo, Fábio, Giuliano, Jalon, João Chagas, Marcelo, Roger, Ronaldo e Tadeu pelo agradável convívio.

À Leila e família, que me abrigaram e com quem convivi nestes últimos anos.

À Cristiane pelo apoio e compressão nos momentos de ausência.

A todos aqueles que de alguma maneira contribuíram, direta ou indiretamente, com este trabalho, e que por ventura possa ter esquecido de citar. 


\section{SUMÁRIO}

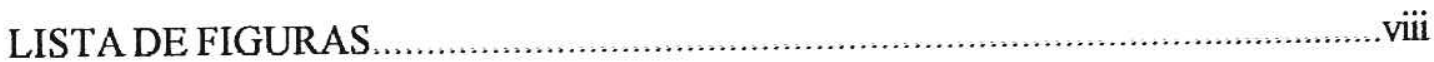

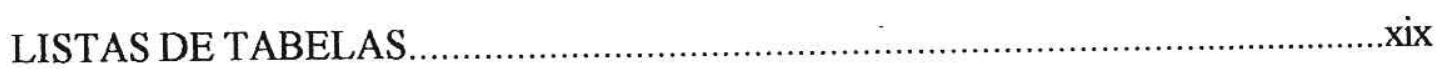

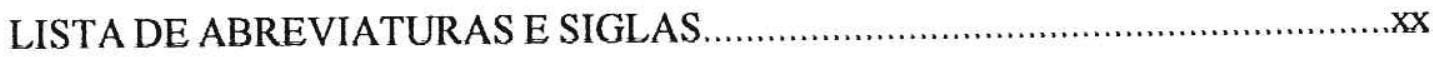

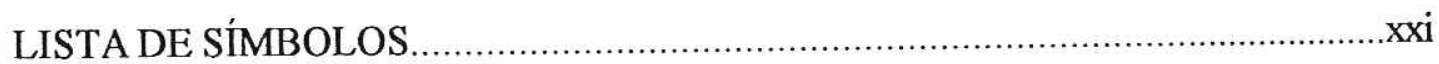

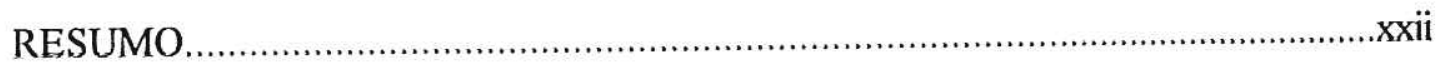

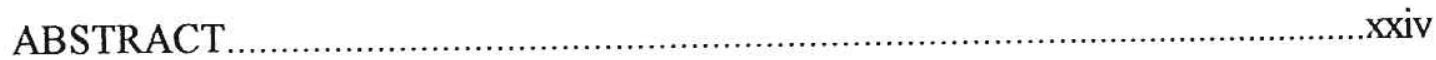

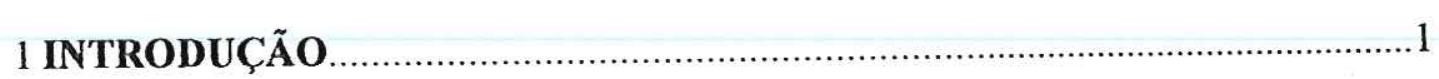

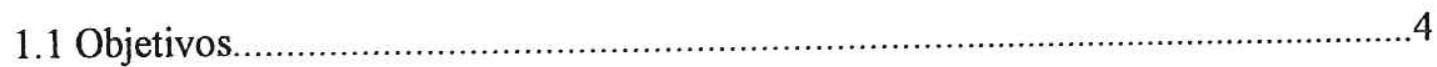

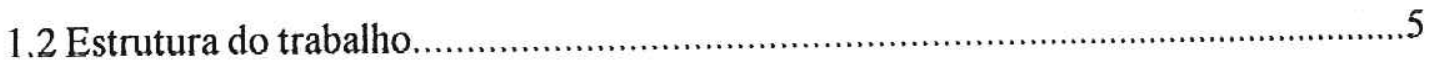

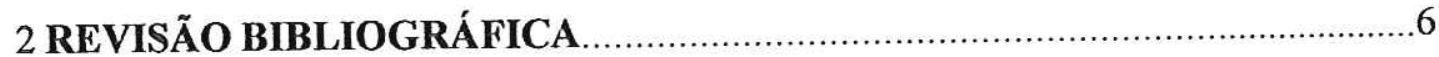

2.1 Tecnologia de usinagem com altas velocidades (HSM) ..............................6

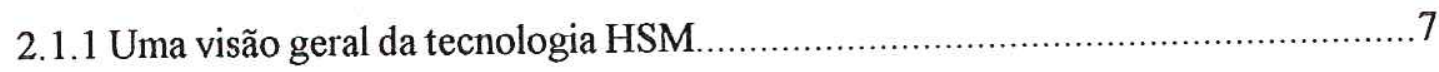

2.1.2 Vantagens econômicas da HSM ......................................................... 10

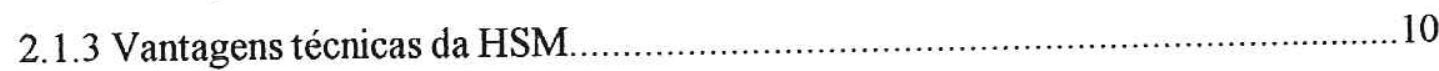

2.1.4 O estado da arte e tendências da tecnologia HSM ..................................11

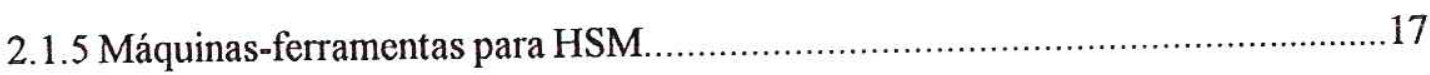

2.1.5.1 Características construtivas de máquinas HSM ...................................... 18

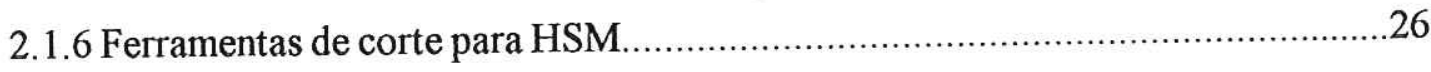

2.1.6.1 Projeto, aplicações e eficiência das ferramentas....................................... 31

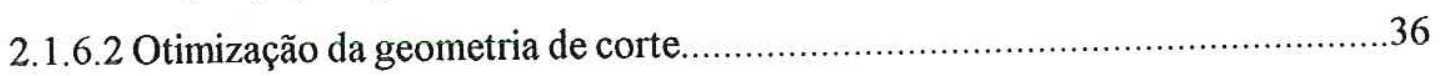

2.1.7 Monitoramento dos processos de usinagem............................................46

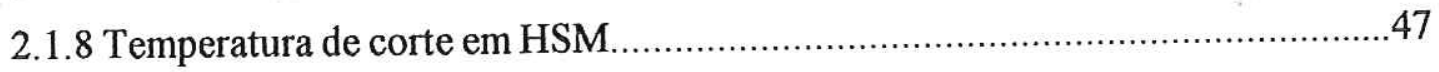

2.1 .9 Força de corte em HSM.............................................................. 51

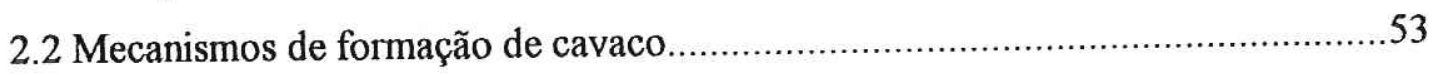

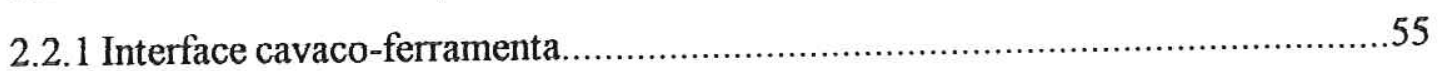

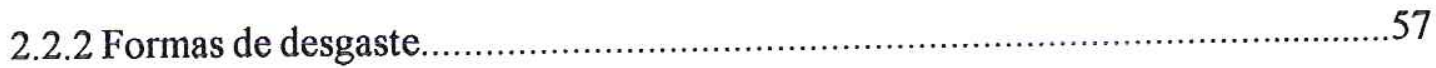




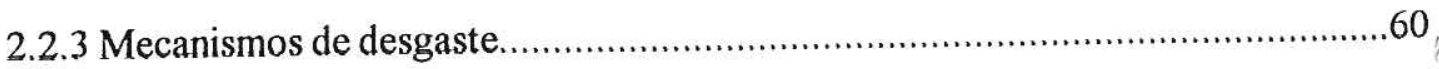

2.3 Usinagem de superligas à base de níquel.................................................... 70

2.3.1 Materiais de ferramentas para usinagem de superligas à base de níquel...........73

2.3.2 Integridade superficial na usinagem de superligas à base de níquel.................77

2.4 Aspectos da utilização de fluidos de corte em usinagem..............................83

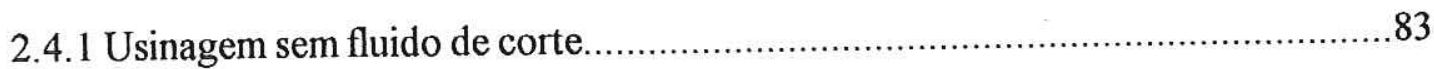

2.4.2 A técnica da Mínima Quantidade de Lubrificante (MQL) .........................89

2.4.3 Classificação e projeto de sistemas com mínima quantidade. de lubrificante. . .94

2.5 Conclusões da revisão bibliográfica .97

3 TRABALHO EXPERIMENTAL. .99

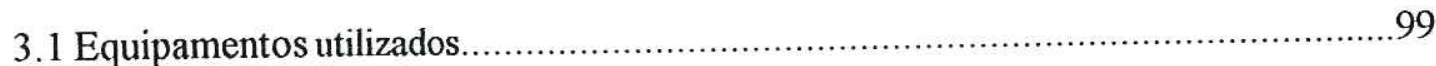

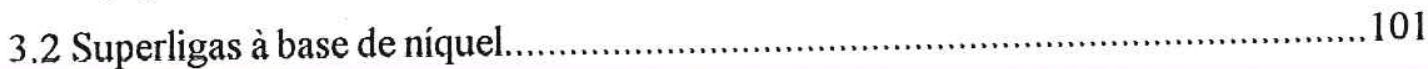

3.3 Ferramentas.

3.4 Planejamento e procedimento experimental........................................ 103

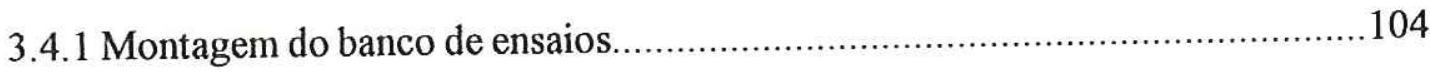

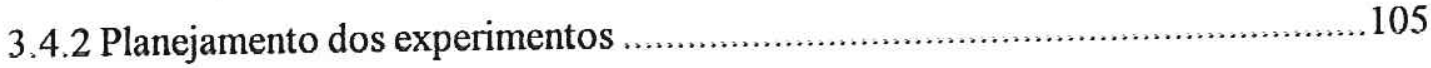

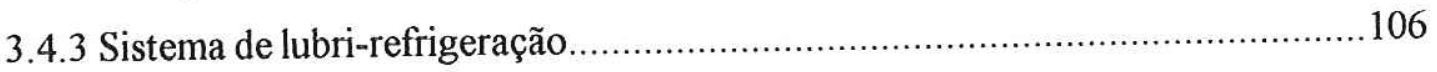

3.4.4 Preparação da geometria de aresta de corte............................................ 108

3.4.5 Avaliação dos mecanismos de desgaste ................................................... 110

3.4.6 Medição da rugosidade superficial...................................................... 110

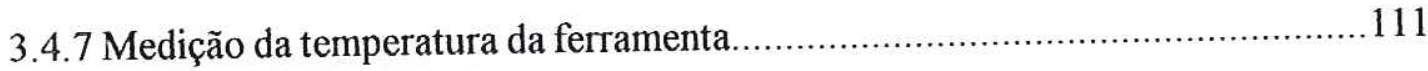

3.4.8 Medição da força de corte ............................................................ 114

3.4.9 Avaliação visual da microestrutura após a usinagem.....................................116

3.4.10 Medição da tensão residual ............................................................. 117

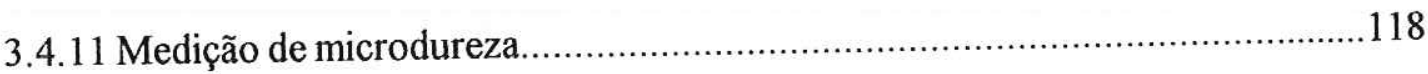

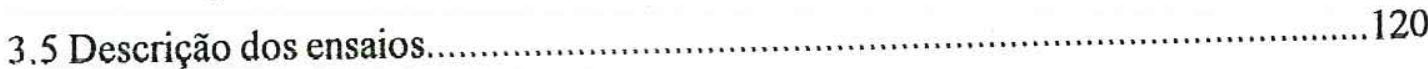

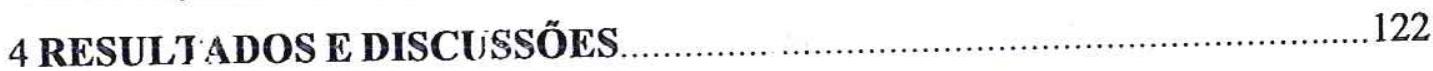

4.1 Medição da força de corte e temperatura.................................................. 122

4.1.1 Inconel 718...

4.1.2 Waspaloy.

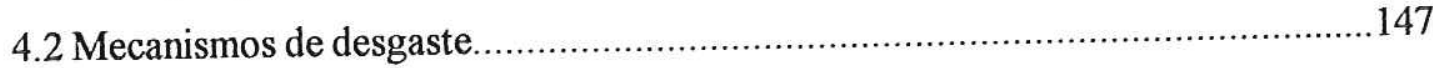




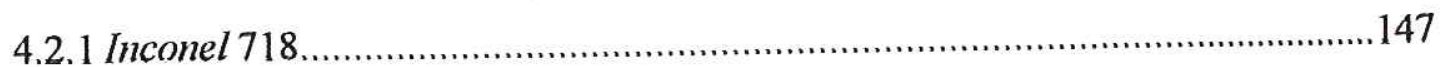

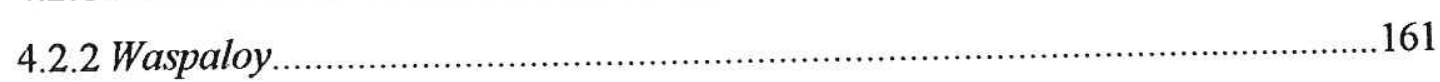

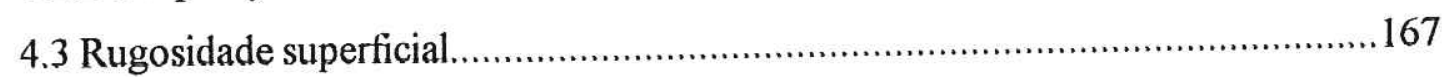

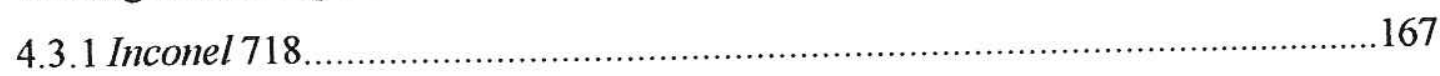

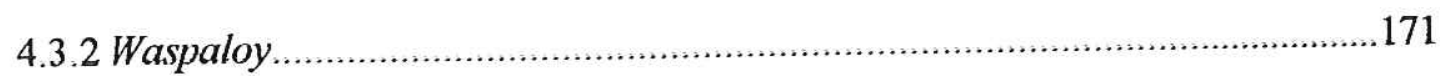

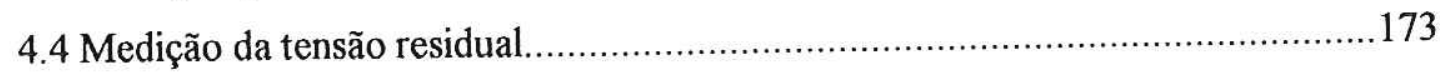

4.5 Avaliação visual da microestrutura após a usinagem ................................ 174

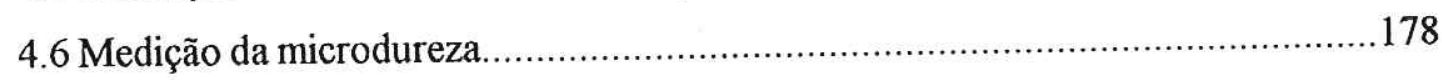

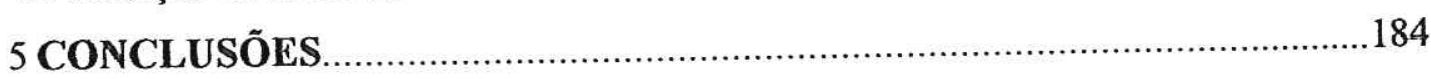

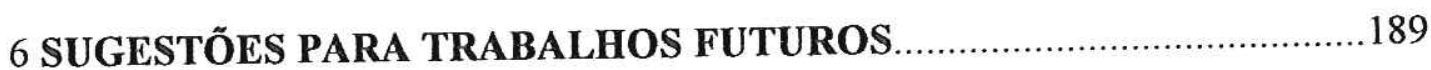

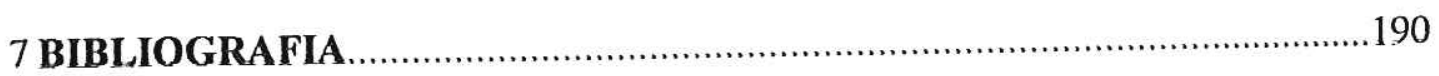

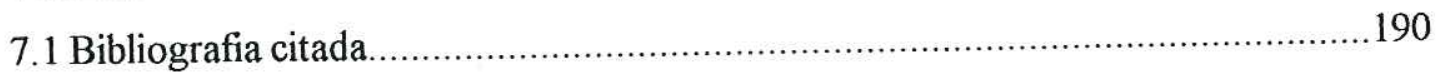

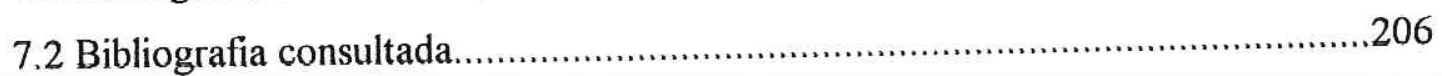

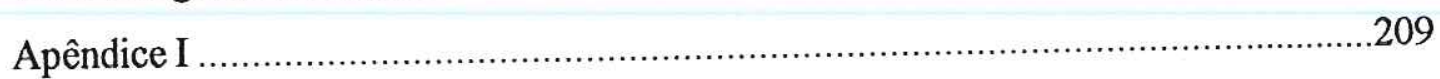

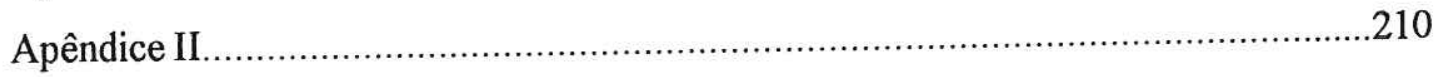




\section{LISTA DE FIGURAS}

FIGURA 2.1 - Velocidade de Corte Idealizada versus Temperatura de Corte Plotadas por Salomon (FLOM \& KOMANDURI, 1989) …............07

FIGURA 2.2 - Definição de Faixas de Valores para HSM (VIGNEAU, 1997)........09

FIGURA 2.3 - Influência da Tecnologia de Corte (SCHULZ, 1997) .......................12

FIGURA 2.4 - Tendência de Parâmetros de Corte em Usinagem com Alta Velocidade de Corte (BERT, 1997) ...........................................13

FIGURA 2.5 - Influência da Velocidade de Corte e Avanço sobre a Vida da Ferramenta em Aço de Alta Liga - SAE A2 (SCHULZ, 1997).........14

FIGURA 2.6 - Vida da Ferramenta Dependente de Diferentes Materiais

(SCHULZ, 1997) 14

FIGURA 2.7 - Uso de Diferentes Materiais de Corte (SCHULZ, 1997). 15

FIGURA 2.8 - Construção Típica de Motor para HSM

(NOVASKI \& CORRÊA, 1998)

FIGURA 2.9 - Propriedades dos Revestimentos (WECK et al. 1999) 20

FIGURA 2.10 - Comparação da Aceleração Praticável de um Acionamento de Fuso de Esferas Recirculantes e de um Motor Linear (SCHMITT, 1996)

FIGURA 2.11 - Componentes de uma Cabine de Segurança (SCHULZ, 1994) ......24

FIGURA 2.12 - Projeto de Sistema de Eixos-árvore para Altas Velocidades: Áreas Problemáticas (WECK et al. 1999). .25

FIGURA 2.13 - Linha de Fresas para HSM (STOCKINGER et al., 1998) .32

FIGURA 2.14 - Desempenho de Diferentes Ferramentas no Fresamento de Ferro Fundido (SCHULZ, 1996). .34

FIGURA 2.15 - Desempenho de Diferentes Ferramentas no Fresamento de Alumínio (SCHULZ, 1996). .34 
FIGURA 2.16 - Desgaste de Ferramenta de Metal Duro no Fresamento com Alta Velocidade de Diferentes Ligas de Alumínio e Cobre

(SAHM, 1996).

FIGURA 2.17 - Vida da Ferramenta versus Ângulo de Folga

(KALDOR et al., 1986)

FIGURA 2.18 - Efeito da Variação do Ângulo de Saída na Força de Corte (NOVASKI \& CORRÊA, 1998). .38

FIGURA 2.19 - Efeito do Ângulo de Inclinação na Vida da Ferramenta (SAHM, 1996) 39

FIGURA 2.20 - Evolução da Geometria de Corte (HAMANN et al., 1994) .40

FIGURA 2.21 - Efeito dos Parâmetros de Processo na Vida da Ferramenta no

Fresamento de Aço Ferramenta H13 Temperado - N = 10.000 rpm, $\mathrm{f}_{\mathrm{z}}=0,25 \mathrm{~mm} /$ dente e $\mathrm{a}_{\mathrm{p}}=0,625 \mathrm{~mm}$ (ELBESTAWI et al., 1997) $\ldots . .41$

FIGURA 2.22 - Dependência de Vida de Ferramenta $L_{1}$ (a) e $L_{2}$ (b) sobre o Chanfro de aresta (SHINTANI et al., 1989).....

FIGURA 2.23 - Dependência de Vida da Ferramenta para $L_{1}$ e $L_{2}$ sobre o Raio de Aresta (SHINTANI et al., 1989).

FIGURA 2.24 - Temperatura de Corte no Fresamento com Alta Velocidade

(SAHM, 1996).

FIGURA 2.25 - Total de Calor Introduzido nas Ferramentas de Metal Duro e Nitreto de Silício $-\mathrm{Si}_{3} \mathrm{~N}_{4}$ (LIN et al., 1992) ........................................5 50

FIGURA 2.26 - Diagrama da Cunha Cortante (MACHADO \& SILVA, 1999) ........53

FIGURA 2.27 = Áreas de Aderência e Escorregamento na Interface Cavaco-

Ferramenta (TRENT, 1984) .56

FIGURA 2.28 - Principais Áreas de Desgaste ( JACK, 1987). .58

FIGURA 2.29 - Parâmetros Utilizados para Medir os Desgastes das Ferramentas de Corte (ISO 3685-1993).

FIGURA 2.30 - Mecanis nos de Desgaste que Podem Acontecer nas Ferramentas de

Corte (TRENT, 1984)

FIGURA 2.31 - Desgaste de Cratera em Ferramentas de CBN em HSC

(KRAMER, 1987). .64 
FIGURA 2.32 - Dependência do Desgaste da Ferramenta $\left(\mathrm{Al}_{2} \mathrm{O}_{3}+\mathrm{TiC}\right)$ sobre a Velocidade de Corte à uma Distância de Corte de $50 \mathrm{~m}$ $\mathrm{V}_{\mathrm{C}}$ : Desgaste de Flanco no Raio; $\mathrm{V}_{\mathrm{N}}$ : Desgaste de Entalhe na Aresta Principal e $\mathrm{V}_{\mathrm{N}}$ : Desgaste de Entalhe na Aresta Secundária (KITAGAWA et al., 1997).

FIGURA 2.33 - Influência da Geometria da Ferramenta no Desgaste de Entalhe $\mathrm{V}_{\mathrm{N}}$ no Torneamento com Alta Velocidade do Inconel 718 com Ferramenta de $\mathrm{Al}_{2} \mathrm{O}_{3}+$ TiC (NARUTAKI et al., 1993) 68

FIGURA 2.34 - Temperatura de Corte versus Velocidade de Corte (VIGNEAU, 1997)

FIGURA 2.35 - Efeito do Torneamento com Alta Velocidade sobre as Tensões Residuais (VIGNEAU, 1997).

FIGURA 2.36 - Porcentagem dos Custos de Refrigeração, nos Custos de Fabricação

(NOVASKI \& DÖRR, 1999).

FIGURA 2.37 - Soluções Empregadas para a Utilização da Usinagem a Seco

(NOVASKI \& DÖRR, 1999).

FIGURA 2.38 - Vida da Ferramenta e Custo de Manufatura no Torneamento do Aço St 52-3/ABNT 5120 (DÖRR, 1999). .88

FIGURA 2.39 - Influência de Revestimentos e MQL no Fresamento de $\mathrm{AlZnMgCu}$

(KLOCKE \& EISENBLÄTTER, 1997).

FIGURA 2.40 - Otimização do Substrato e MQL na Furação de Aço

(SCHULZ, 1999)

FIGURA 2.41 - Diagrama Esquemático de um Sistema de Lubrificação de

Quantidade Mínima (HEISEL et al., 1998).

FIGURA 2.42 - Temperatura sob a Pastilha de Corte Indexável versus Desgaste e Tipo de Refrigerante $-V_{c}=200 \mathrm{~m} / \mathrm{min} ; \mathrm{f}=0,25 \mathrm{~mm} / \mathrm{rev}$.

e $a_{p}=1 \mathrm{~mm}$ (HEISEL et al., 1998).

FIGURA 3.1 - Banco de Ensaio Utilizido na Experimesiação no Monitoramento da Emissão Acústica, Temperatura e Força de Corte 104

FIGURA 3.2 - Sistema de Fixação do Corpo de Prova e Posicionamento do Bico Aspersor. 
FIGURA 3.3 - Esquema do Equipamento de Mínima Quantidade de Lubrificante MQL (Aplicador Accu-Lube ${ }^{\circledR}$ ).

FIGURA 3.4 - Bico Aspersor Utilizado para a Experimentação com a Técnica MQL. 108

FIGURA 3.5 - Principais Modificações no Inserto Quadrado e na Aresta de Corte 109

FIGURA 3.6 - Montagem do Termopar do Tipo K Fixado na Superfície de Saída da

Ferramenta, a uma Distância de $1,5 \mathrm{~mm}$ da Aresta de Corte.

FIGURA 3.7 - Circuito Eletrônico que Transforma Tensão (micro Volts) em

Corrente (mili Amper) e Novamente em Tensão (Volts)......

FIGURA 3.8 - Curva de Calibração do Termopar Tipo K

FIGURA 3.9 - Porta Ferramenta Especial para o Alojamento da Célula de Carga..115

FIGURA 3.10 - Montagem para Calibração Estática da Célula de Carga. 116

FIGURA 3.11 - Curva de Calibração Estática da Célula de Carga do

Dinamômetro.

FIGURA 3.12 - Dimensões e Forma do Corpo de Prova para Análise da Integridade Superficial.

FIGURA 3.13 - Representação da Amostra para a Medição da Microdureza.

FIGURA 3.14 - Vista Lateral da Amostra.

FIGURA 4.1 - Resultados da Força de Corte após 20 Segundos com Ferramentas

Triangular $\left(V_{c}=500 \mathrm{~m} / \mathrm{min} ; f=0,10 \mathrm{~mm} / \mathrm{rev}\right.$ e $\left.a_{p}=0,35 \mathrm{~mm}\right)$......

FIGURA 4.2 - Medição da Temperatura após 20 Segundos com Ferramentas

Triangulares a uma Distância de $1,5 \mathrm{~mm}$ da Aresta de Corte

$\left(\mathrm{V}_{\mathrm{c}}=500 \mathrm{~m} / \mathrm{min} ; \mathrm{f}=0,10 \mathrm{~mm} / \mathrm{rev}\right.$ e $\left.\mathrm{a}_{\mathrm{p}}=0,35 \mathrm{~mm}\right)$.

FIGURA 4.3 - Medição da Temperatura a uma Distância de 1,5mm da Aresta de

Corte e da Força de Corte em Função do Tempo com Ferramenta

Cerâmica CC670/Geometria 1 no Corte a Seco

$\left(V_{c}=500 \mathrm{~m} / \mathrm{min} ; \mathrm{f}=0,10 \mathrm{~mm} / \mathrm{rev}\right.$ e $\left.a_{p}=0,35 \mathrm{~mm}\right)$.

FIGURA 4.4 - Medição da Temperatura a uma Distância de 1,5mm da Aresta de

Corte e da Força de Corte em Função do Tempo com Ferramenta Cerâmica CC670/Geometria 2 Utilizando MQL

$\left(V_{c}=500 \mathrm{~m} / \mathrm{min} ; \mathrm{f}=0,10 \mathrm{~mm} / \mathrm{rev}\right.$ e $\left.a_{p}=0,35 \mathrm{~mm}\right)$. .124 
FIGURA 4.5 - Medição da Temperatura a uma Distância de 1,5mm da Aresta de Corte e da Força de Corte em Função do Tempo com Ferramenta de PCBN/Geometria 2 no Corte a Seco

$\left(\mathrm{V}_{\mathrm{c}}=500 \mathrm{~m} / \mathrm{min} ; \mathrm{f}=0,10 \mathrm{~mm} / \mathrm{rev}\right.$ e $\left.\mathrm{a}_{\mathrm{p}}=0,35 \mathrm{~mm}\right)$.

FIGURA 4.6 - Resultados da Força de Corte após 20 Segundos com Ferramentas

Redondas $\left(V_{c}=500 \mathrm{~m} / \mathrm{min} ; \mathrm{f}=0,10 \mathrm{~mm} / \mathrm{rev}\right.$ e $\left.\mathrm{a}_{\mathrm{p}}=0,35 \mathrm{~mm}\right)$.

FIGURA 4.7 - Medição da Temperatura após 20 Segundos com Ferramentas

Redondas a uma Distância de 1,5mm da Aresta de Corte

$\left(V_{c}=500 \mathrm{~m} / \mathrm{min} ; \mathrm{f}=0,10 \mathrm{~mm} / \mathrm{rev}\right.$ e $\left.a_{p}=0,35 \mathrm{~mm}\right)$.

FIGURA 4.8 - Medição da Temperatura a uma Distância de 1,5mm da Aresta de

Corte e da Força de Corte em Função do Tempo com Ferramenta

Cerâmica CC650/Geometria 1 no Corte a Seco

$\left(V_{c}=500 \mathrm{~m} / \mathrm{min} ; f=0,10 \mathrm{~mm} / \mathrm{rev}\right.$ e $\left.a_{p}=0,35 \mathrm{~mm}\right)$

FIGURA 4.9 - Medição da Temperatura a uma Distância de 1,5mm da Aresta de

Corte e da Força de Corte em Função do Tempo com Ferramenta

Cerâmica CC650/Geometria 2 no Corte a Seco

$\left(V_{c}=500 \mathrm{~m} / \mathrm{min} ; \mathrm{f}=0,10 \mathrm{~mm} / \mathrm{rev}\right.$ e $\left.\mathrm{a}_{\mathrm{p}}=0,35 \mathrm{~mm}\right)$

FIGURA 4.10 - Medição da Temperatura a uma Distância de 1,5mm da Aresta de

Corte e da Força de Corte em Função do Tempo com Ferramenta de PCBN/Geometria 2 no Corte a Seco

$\left(V_{c}=500 \mathrm{~m} / \mathrm{min} ; \mathrm{f}=0,10 \mathrm{~mm} / \mathrm{rev}\right.$ e $\left.a_{p}=0,35 \mathrm{~mm}\right)$

FIGURA 4.11 - Resultados da Força de Corte após 20 Segundos com Ferramentas

Quadradas $\left(V_{c}=500 \mathrm{~m} / \mathrm{min} ; \mathrm{f}=0,10 \mathrm{~mm} / \mathrm{rev}\right.$ e $\left.a_{p}=0,35 \mathrm{~mm}\right)$.....

FIGURA 4.12 - Medição da Temperatura após 20 Segundos com Ferramentas

Quadradas a uma Distância de $1,5 \mathrm{~mm}$ da Aresta de Corte

$\left(V_{c}=500 \mathrm{~m} / \mathrm{min} ; \mathrm{f}=0,10 \mathrm{~mm} / \mathrm{rev}\right.$ e $\left.a_{p}=0,35 \mathrm{~mm}\right)$

FIGURA 4.13 - Medição da Temperatura a uma Distância de 1,5mm da Aresta de

Corte e da Força de Corte em Função do Tempo com Ferramenta

Cerâmica CC650/Geometria 1 no Corte a Seco

$\left(V_{c}=500 \mathrm{~m} / \mathrm{min} ; \mathrm{f}=0,10 \mathrm{~mm} / \mathrm{rev}\right.$ e $\left.a_{p}=0,35 \mathrm{~mm}\right)$ 
FIGURA 4.14 - Medição da Temperatura a uma Distância de 1,5mm da Aresta de Corte e da Força de Corte em Função do Tempo com Ferramenta Cerâmica CC650/Geometria 2 no Corte a Seco

$\left(V_{c}=500 \mathrm{~m} / \mathrm{min} ; f=0,10 \mathrm{~mm} / \mathrm{rev}\right.$ e $\left.a_{p}=0,35 \mathrm{~mm}\right)$. 133

FIGURA 4.15 - Medição da Temperatura a uma Distância de 1,5mm da Aresta de Corte e da Força de Corte em Função do Tempo com Ferramenta de PCBN/Geometria 2 Utilizando MQL

$\left(V_{c}=500 \mathrm{~m} / \mathrm{min} ; \mathrm{f}=0,10 \mathrm{~mm} / \mathrm{rev}\right.$ e $\left.a_{p}=0,35 \mathrm{~mm}\right)$ 133

FIGURA 4.16 - Efeito da Velocidade de Corte Sobre a Temperatura, a uma

Distância de 1,5mm da Aresta de Corte com Ferramenta Cerâmica

CC650 Triangular $\left(V_{c}=\mathrm{m} / \mathrm{min} ; \mathrm{f}=0,10 \mathrm{~mm} / \mathrm{rev}\right.$ e $\left.a_{p}=0,35 \mathrm{~mm}\right) . .135$

FIGURA 4.17 - Efeito da Velocidade de Corte Sobre a Temperatura, a uma

Distância de 1,5mm da Aresta de Corte com Ferramenta Cerâmica

CC650 Redonda $\left(V_{c}=m / m i n ; f=0,10 \mathrm{~mm} /\right.$ rev e $\left.a_{p}=0,35 \mathrm{~mm}\right) \ldots 135$

FIGURA 4.18 - Efeito da Velocidade de Corte Sobre a Temperatura, a uma

Distância de 1,5mm da Aresta de Corte com Ferramenta Cerâmica

CC670 Triangular $\left(V_{c}=m / m i n ; f=0,10 \mathrm{~mm} /\right.$ rev e $\left.a_{p}=0,35 \mathrm{~mm}\right) . .136$

FIGURA 4.19 - Efeito da Velocidade de Corte Sobre a Temperatura, a uma

Distância de 1,5mm da Aresta de Corte com Ferramenta Cerâmica

CC670 Redonda $\left(V_{c}=\mathrm{m} / \mathrm{min} ; \mathrm{f}=0,10 \mathrm{~mm} / \mathrm{rev}\right.$ e $\left.a_{p}=0,35 \mathrm{~mm}\right) \ldots 136$

FIGURA 4.20 - Efeito da Velocidade de Corte Sobre a Temperatura, a uma

Distância de 1,5mm da Aresta de Corte com Ferramenta Cerâmica

CC670 Quadrada $\left(V_{c}=\mathrm{m} / \mathrm{min} ; f=0,10 \mathrm{~mm} / \mathrm{rev}\right.$ e $\left.a_{p}=0,35 \mathrm{~mm}\right) \ldots 137$

FIGURA 4.21 - Efeito da Velocidade de Corte Sobre a Força com Ferramenta

Cerâmica CC650 Triangular $\left(V_{c}=\mathrm{m} / \mathrm{min} ; \mathrm{f}=0,10 \mathrm{~mm} / \mathrm{rev}\right.$

e $\left.a_{p}=0,35 \mathrm{~mm}\right)$

FIGURA 4.22 - Efeito da Velocidade de Corte Sobre a Força com Ferramenta

Cerâmica CC650 Fiedonda $\left(\mathrm{V}_{\mathrm{c}}=\mathrm{m} / \mathrm{min} ; \mathrm{f}=0,10 \mathrm{~mm} / \mathrm{sev}\right.$

e $\left.a_{p}=0,35 \mathrm{~mm}\right)$

FIGURA 4.23 - Efeito da Velocidade de Corte Sobre a Força com Ferramenta

Cerâmica CC670 Triangular $\left(V_{c}=\mathrm{m} / \mathrm{min} ; f=0,10 \mathrm{~mm} / \mathrm{rev}\right.$

e $\left.a_{p}=0,35 \mathrm{~mm}\right)$ 
FIGURA 4.24 - Efeito da Velocidade de Corte Sobre a Força com Ferramenta

Cerâmica CC670 Redonda $\left(\mathrm{V}_{\mathrm{c}}=\mathrm{m} / \mathrm{min} ; \mathrm{f}=0,10 \mathrm{~mm} / \mathrm{rev}\right.$

e $\left.a_{p}=0,35 \mathrm{~mm}\right)$

FIGURA 4.25 - Resultados da Força de Corte após 20 Segundos com Ferramentas

Triangular $\left(V_{c}=500 \mathrm{~m} / \mathrm{min} ; \mathrm{f}=0,10 \mathrm{~mm} / \mathrm{rev}\right.$ e $\left.\mathrm{a}_{\mathrm{p}}=0,35 \mathrm{~mm}\right) \ldots \ldots 140$

FIGURA 4.26 - Medição da Temperatura após 20 Segundos com Ferramentas

Triangular a uma Distância de $1,5 \mathrm{~mm}$ da Aresta de Corte

$\left(V_{c}=500 \mathrm{~m} / \mathrm{min} ; \mathrm{f}=0,10 \mathrm{~mm} / \mathrm{rev}\right.$ e $\left.\mathrm{a}_{\mathrm{p}}=0,35 \mathrm{~mm}\right)$.

FIGURA 4.27 - Medição da Temperatura a uma Distância de 1,5mm da Aresta de

Corte e da Força de Corte em Função do Tempo com Ferramenta

Cerâmica CC650/Geometria $1\left(V_{c}=500 \mathrm{~m} / \mathrm{min} ; \mathrm{f}=0,10 \mathrm{~mm} / \mathrm{rev}\right.$

$\left.\mathrm{e} \mathrm{a}_{\mathrm{p}}=0,35 \mathrm{~mm}\right)$.

FIGURA 4.28 - Medição da Temperatura a uma Distância de 1,5mm da Aresta de

Corte e da Força de Corte em Função do Tempo com Ferramenta

Cerâmica CC650/Geometria $2\left(\mathrm{~V}_{\mathrm{c}}=500 \mathrm{~m} / \mathrm{min} ; \mathrm{f}=0,10 \mathrm{~mm} / \mathrm{rev}\right.$

e $\left.a_{p}=0,35 \mathrm{~mm}\right)$.

FIGURA 4.29 - Resultados da Força de Corte após 20 Segundos com Ferramentas

Redondas $\left(V_{c}=500 \mathrm{~m} / \mathrm{min} ; \mathrm{f}=0,10 \mathrm{~mm} / \mathrm{rev}\right.$ e $\left.\mathrm{a}_{\mathrm{p}}=0,35 \mathrm{~mm}\right) \ldots$

FIGURA 4.30 - Medição da Temperatura após 20 Segundos com Ferramentas

Redondas a uma Distância de $1,5 \mathrm{~mm}$ da Aresta de Corte

$\left(V_{c}=500 \mathrm{~m} / \mathrm{min} ; \mathrm{f}=0,10 \mathrm{~mm} / \mathrm{rev}\right.$ e $\left.a_{p}=0,35 \mathrm{~mm}\right)$

FIGURA 4.31 - Medição da Temperatura a uma Distância de 1,5mm da Aresta de

Corte e da Força de Corte em Função do Tempo com Ferramenta

Cerâmica CC670/Geometria $1\left(\mathrm{~V}_{\mathrm{c}}=500 \mathrm{~m} / \mathrm{min} ; \mathrm{f}=0,10 \mathrm{~mm} / \mathrm{rev}\right.$

e $a_{p}=0,35 \mathrm{~mm}$ )

FIGURA 4.32 - Medição da Temperatura a uma Distância de 1,5mm da Aresta de

Corte e da Força de Corte em Função do Tempo com Ferramenta

Cerâmica CC670/Geometria $2\left(\mathrm{~V}_{\mathrm{c}}=500 \mathrm{~m} / \mathrm{min} ; \mathrm{f}=0,10 \mathrm{~mm} / \mathrm{rev}\right.$

e $a_{p}=0,35 \mathrm{~mm}$ )

FIGURA 4.33 - Resultados da Força de Corte após 20 Segundos com Ferramentas

Quadradas $\left(V_{c}=500 \mathrm{~m} / \mathrm{min} ; \mathrm{f}=0,10 \mathrm{~mm} / \mathrm{rev}\right.$ e $\left.a_{p}=0,35 \mathrm{~mm}\right) \ldots \ldots .144$ 
FIGURA 4.34 - Medição da Temperatura após 20 Segundos com Ferramentas Quadradas a uma Distância de 1,5mm da Aresta de Corte $\left(V_{c}=500 \mathrm{~m} / \mathrm{min} ; \mathrm{f}=0,10 \mathrm{~mm} / \mathrm{rev}\right.$ e $\left.a_{p}=0,35 \mathrm{~mm}\right)$........ 145

FIGURA 4.35 - Medição da Temperatura a uma Distância de 1,5mm da Aresta de Corte e da Força de Corte em Função do Tempo com Ferramenta Cerâmica CC650/Geometria $1\left(\mathrm{~V}_{\mathrm{c}}=500 \mathrm{~m} / \mathrm{min} ; \mathrm{f}=0,10 \mathrm{~mm} / \mathrm{rev}\right.$ e $\left.a_{p}=0,35 \mathrm{~mm}\right)$

FIGURA 4.36 - Medição da Temperatura a uma Distância de 1,5mm da Aresta de Corte e da Força de Corte em Função do Tempo com Ferramenta Cerâmica CC650/Geometria $2\left(\mathrm{~V}_{\mathrm{c}}=500 \mathrm{~m} / \mathrm{min} ; \mathrm{f}=0,10 \mathrm{~mm} / \mathrm{rev}\right.$ e $\left.a_{p}=0,35 \mathrm{~mm}\right)$.

FIGURA 4.37 - Condição de Desgaste da Ferramenta Cerâmica CC650 Triangular sem Refrigeração $\left(V_{c}=500 \mathrm{~m} / \mathrm{min} ; \mathrm{f}=0,10 \mathrm{~mm} / \mathrm{rev}\right.$ e $\left.a_{p}=0,35 \mathrm{~mm}\right)$.

FIGURA 4.38 - Condição de Desgaste da Ferramenta Cerâmica CC650 Triangular Utilizando MQL $\left(\mathrm{V}_{\mathrm{c}}=500 \mathrm{~m} / \mathrm{min} ; \mathrm{f}=0,10 \mathrm{~mm} / \mathrm{rev}\right.$ e $\left.a_{p}=0,35 \mathrm{~mm}\right)$.

FIGURA 4.39 - Condição de Desgaste da Ferramenta Cerâmica CC670 Triangular sem Refrigeração $\left(V_{c}=500 \mathrm{~m} / \mathrm{min} ; f=0,10 \mathrm{~mm} / \mathrm{rev}\right.$ e $\left.a_{p}=0,35 \mathrm{~mm}\right)$. 148

FIGURA 4.40 - Condição de Desgaste da Ferramenta Cerâmica CC670 Triangular Utilizando MQL $\left(\mathrm{V}_{\mathrm{c}}=500 \mathrm{~m} / \mathrm{min} ; \mathrm{f}=0,10 \mathrm{~mm} / \mathrm{rev}\right.$ e $a_{p}=0,35 \mathrm{~mm}$ ).

FIGURA 4.41 - Condição de Desgaste da Ferramenta de PCBN Triangular $\left(V_{c}=500 \mathrm{~m} / \mathrm{min} ; f=0,10 \mathrm{~mm} / \mathrm{rev}\right.$ e $\left.a_{p}=0,35 \mathrm{~mm}\right)$.

FIGURA 4.42 - Condição de Desgaste da Ferramenta Cerâmica CC650 Redonda sem Refrigeração $\left(V_{c}=500 \mathrm{~m} / \mathrm{min} ; \mathrm{f}=0,10 \mathrm{~mm} / \mathrm{rev}\right.$ e $\left.a_{p}=0,35 \mathrm{~mm}\right)$.

FIGURA 4.43 - Condição de Desgaste da Ferramenta Cerâmica CC650 Redonda Utilizando MQL $\left(\mathrm{V}_{\mathrm{c}}=500 \mathrm{~m} / \mathrm{min} ; \mathrm{f}=0,10 \mathrm{~mm} / \mathrm{rev}\right.$ e $\left.a_{p}=0,35 \mathrm{~mm}\right)$. 
FIGURA 4.44 - Condição de Desgaste da Ferramenta Cerâmica CC670 Redonda sem Refrigeração $\left(V_{c}=500 \mathrm{~m} / \mathrm{min} ; \mathrm{f}=0,10 \mathrm{~mm} / \mathrm{rev}\right.$ e $\left.\mathrm{a}_{\mathrm{p}}=0,35 \mathrm{~mm}\right)$

FIGURA 4.45 - Condição de Desgaste da Ferramenta Cerâmica CC670 Redonda Utilizando MQL $\left(\mathrm{V}_{\mathrm{c}}=500 \mathrm{~m} / \mathrm{min} ; \mathrm{f}=0,10 \mathrm{~mm} / \mathrm{rev}\right.$ $\left.\mathrm{e} \mathrm{a}_{\mathrm{p}}=0,35 \mathrm{~mm}\right)$

FIGURA 4.46 - Condição de Desgaste da Ferramenta de PCBN Redonda

$\left(V_{c}=500 \mathrm{~m} / \mathrm{min} ; \mathrm{f}=0,10 \mathrm{~mm} / \mathrm{rev}\right.$ e $\left.\mathrm{a}_{\mathrm{p}}=0,35 \mathrm{~mm}\right)$.

FIGURA 4.47 - Condição de Desgaste da Ferramenta Cerâmica CC650 Quadrada sem Refrigeração $\left(V_{c}=500 \mathrm{~m} / \mathrm{min} ; \mathrm{f}=0,10 \mathrm{~mm} / \mathrm{rev}\right.$ e $\left.a_{p}=0,35 \mathrm{~mm}\right)$.

FIGURA 4.48 - Condição de Desgaste com Ferramentas de Cerâmicas Quadradas Utilizando MQL após 39 Segundos $\left(V_{c}=500 \mathrm{~m} / \mathrm{min}\right.$; $\mathrm{f}=0,10 \mathrm{~mm} / \mathrm{rev}$ e $\left.\mathrm{a}_{\mathrm{p}}=0,35 \mathrm{~mm}\right)$

FIGURA 4.49 - Condição de Desgaste da Ferramenta de PCBN Quadrada sem Refrigeração $\left(V_{c}=500 \mathrm{~m} / \mathrm{min} ; \mathrm{f}=0,10 \mathrm{~mm} / \mathrm{rev}\right.$ e $\left.\mathrm{a}_{\mathrm{p}}=0,35 \mathrm{~mm}\right) \ldots 159$ FIGURA 4.50 - Condição de Desgaste com Ferramentas Cerâmicas (CC650) com Geometria $1\left(V_{c}=500 \mathrm{~m} / \mathrm{min} ; \mathrm{f}=0,10 \mathrm{~mm} / \mathrm{rev}\right.$ e $\left.a_{p}=0,35 \mathrm{~mm}\right) \ldots 160$ FIGURA 4.51 - Condição de Desgaste de Ferramentas Cerâmicas (CC670) com Geometria $1\left(V_{c}=500 \mathrm{~m} / \mathrm{min} ; \mathrm{f}=0,10 \mathrm{~mm} / \mathrm{rev}\right.$ e $\left.a_{p}=0,35 \mathrm{~mm}\right) \ldots .161$

FIGURA 4.52 - Condição de Desgaste da Ferramenta Cerâmica CC650 Triangular

$$
\left(V_{c}=500 \mathrm{~m} / \mathrm{min} ; \mathrm{f}=0,10 \mathrm{~mm} / \mathrm{rev} \text { e } a_{p}=0,35 \mathrm{~mm}\right) \text {. }
$$

FIGURA 4.53 - Condição de Desgaste da Ferramenta Cerâmica CC670 Triangular

$$
\left(\mathrm{V}_{\mathrm{c}}=500 \mathrm{~m} / \mathrm{min} ; \mathrm{f}=0,10 \mathrm{~mm} / \mathrm{rev} \text { e } \mathrm{a}_{\mathrm{p}}=0,35 \mathrm{~mm}\right)
$$

FIGURA 4.54 - Condição de Desgaste da Ferramenta Cerâmica CC650 Redonda

$$
\left(V_{c}=500 \mathrm{~m} / \mathrm{min} ; \mathrm{f}=0,10 \mathrm{~mm} / \mathrm{rev} \text { e } a_{p}=0,35 \mathrm{~mm}\right) \text {. }
$$

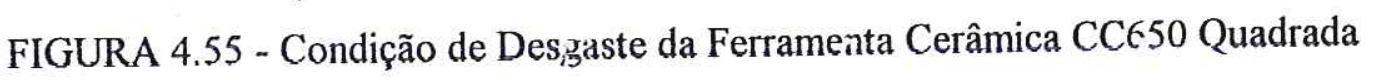

$$
\left(\mathrm{V}_{\mathrm{c}}=500 \mathrm{~m} / \mathrm{min} ; \mathrm{f}=0,10 \mathrm{~mm} / \mathrm{rev} \text { e } \mathrm{a}_{\mathrm{p}}=0,35 \mathrm{~mm}\right) \text {. }
$$

FIGURA 4.56 - Condição de Desgaste da Ferramenta de PCBN (CB7050) Quadrada

$$
\left(V_{c}=500 \mathrm{~m} / \mathrm{min} ; \mathrm{f}=0,10 \mathrm{~mm} / \mathrm{rev} \text { e } a_{p}=0,35 \mathrm{~mm}\right) \text {. }
$$


FIGURA 4.57 - Rugosidade Superficial $R_{a}$ Utilizando Ferramentas Cerâmicas CC650 - $\left(V_{c}=500 \mathrm{~m} / \mathrm{min} ; f=0,10 \mathrm{~mm} / \mathrm{rev}\right.$ e $\left.a_{p}=0,35 \mathrm{~mm}\right)$.

FIGURA 4.58 - Rugosidade Superficial $R_{a}$ Utilizando Ferramentas Cerâmicas CC670 - $\left(V_{c}=500 \mathrm{~m} / \mathrm{min} ; f=0,10 \mathrm{~mm} / \mathrm{rev}\right.$ e $\left.a_{p}=0,35 \mathrm{~mm}\right)$.

FIGURA 4.59 - Rugosidade Superficial $R_{a}$ Utilizando Ferramentas de PCBN

$\left(V_{c}=500 \mathrm{~m} / \mathrm{min} ; \mathrm{f}=0,10 \mathrm{~mm} / \mathrm{rev}\right.$ e $\left.\mathrm{a}_{\mathrm{p}}=0,35 \mathrm{~mm}\right)$. .168

FIGURA 4.60 - Rugosidade Superficial $R_{\mathrm{a}}$ Utilizando Ferramentas Cerâmicas

$\left(\mathrm{CC} 650\right.$ e CC670) $-\left(\mathrm{V}_{\mathrm{c}}=500 \mathrm{~m} / \mathrm{min} ; \mathrm{f}=0,10 \mathrm{~mm} / \mathrm{rev}\right.$ e $\left.a_{p}=0,35 \mathrm{~mm}\right)$

FIGURA 4.61 - Rugosidade Superficial $R_{a}$ Utilizando Ferramentas de PCBN $\left(V_{c}=500 \mathrm{~m} / \mathrm{min} ; f=0,10 \mathrm{~mm} / \mathrm{rev}\right.$ e $\left.a_{p}=0,35 \mathrm{~mm}\right)$.

FIGURA 4.62 - Resultado Comparativo da Tensão Residual com Ferramentas

Cerâmicas a uma Profundidade Abaixo da Superficie de

Aproximadamente $10 \mu \mathrm{m}$

$\left(V_{c}=500 \mathrm{~m} / \mathrm{min} ; f=0,10 \mathrm{~mm} / \mathrm{rev}\right.$ e $\left.a_{p}=0,35 \mathrm{~mm}\right)$.

FIGURA 4.63 - Microestruturas Subsuperficiais Obtidas com Ferramenta Cerâmica

Redonda CC670 sem Refrigeração (x100). 175

FIGURA 4.64 - Microestruturas Subsuperficiais Obtidas com Ferramenta Cerâmica

Redonda CC650 sem Refrigeração (x100)

FIGURA 4.65 - Microestruturas Subsuperficiais Obtidas com Ferramentas Redondas de Cerâmica/Geometria 2 Utilizando MQL (x100). 176

FIGURA 4.66 - Microestruturas Subsuperficiais Causadas com Ferramenta Cerâmica

CC650/Geometria 1 sem Refrigeração com

$\mathrm{V}_{\mathrm{c}}=70 \mathrm{~m} / \mathrm{min}(\mathrm{x} 100)$.

FIGURA 4.67 - Microestruturas Subsuperficiais Obtidas com Ferramenta Cerâmica

Triangular CC670 sem Refrigeração (x100).

FIGURA 4.68 - Variação da Microdureza em Função da Profundidade Abaixo da

Superficie com Ferramenta Cerâmica Redonda CC670 sem

Refrigeração $\left(V_{c}=500 \mathrm{~m} / \mathrm{min} ; \mathrm{f}=0,10 \mathrm{~mm} / \mathrm{rev}\right.$ e $\left.\mathrm{a}_{\mathrm{p}}=0,35 \mathrm{~mm}\right) \ldots 179$

FIGURA 4.69 - Variação da Microdureza em Função da Profundidade Abaixo da Superficie com Ferramenta Cerâmica Redonda CC650 sem

Refrigeração $\left(V_{c}=500 \mathrm{~m} / \mathrm{min} ; \mathrm{f}=0,10 \mathrm{~mm} / \mathrm{rev}\right.$ e $\left.\mathrm{a}_{\mathrm{p}}=0,35 \mathrm{~mm}\right) \ldots .179$ 
FIGURA 4.70 - Variação da Microdureza em Função da Profundidade Abaixo da Superficie com Ferramenta Cerâmica Redonda CC650/Geometria 1 sem Refrigeração $\left(V_{c}=70 \mathrm{~m} / \mathrm{min} ; \mathrm{f}=0,10 \mathrm{~mm} / \mathrm{rev}\right.$ e $\left.a_{p}=0,35 \mathrm{~mm}\right)$

FIGURA 4.71 - Variação da Microdureza em Função da Profundidade Abaixo da Superficie com Ferramentas Redondas de Cerâmica/Geometria2 Utilizando MQL $\left(\mathrm{V}_{\mathrm{c}}=500 \mathrm{~m} / \mathrm{min} ; \mathrm{f}=0,10 \mathrm{~mm} / \mathrm{rev}\right.$ e $\left.a_{p}=0,35 \mathrm{~mm}\right)$

FIGURA 4.72 - Variação da Microdureza em Função da Profundidade Abaixo da Superficie com Ferramenta Cerâmica Triangular CC670 $\left(V_{c}=500 \mathrm{~m} / \mathrm{min} ; \mathrm{f}=0,10 \mathrm{~mm} / \mathrm{rev}\right.$ e $\left.a_{p}=0,35 \mathrm{~mm}\right)$. 182 


\section{LISTA DE TABELAS}

TABELA 2.1 - Faixas de aplicações de usinagem com alta velocidade

(SCHULZ, 1997)

TABELA 2.2 - Velocidades de corte e taxas de avanços típicas para HSM

(SCHOCK, 1998).

TABELA 2.3 - Propriedades de ferramentas de corte cerâmicas comparadas com metal duro e PCBN (RICHARDS \& ASPINWALL, 1987 e ABRÃO et al. 1993) 30

TABELA 2.4 - Geometrias das ferramentas para HSC (DEWES \& ASPINWALL, 1995). 43

TABELA 2.5 - Composição química nominal (\% peso) e densidade das superligas à base de níquel forjadas (CHOUDHURY \& BARADIE, 1998 e EZUGWU et al., 1999).

TABELA 2.6 - Classificação da integridade superficial (MACHADO \& SILVA, 1999).

TABELA 3.1 - Composição química das superligas em \% 102

TABELA 3.2 - Propriedades mecânicas. 102

TABELA 3.3 - Material e geometria da ferramenta 103

TABELA 3.4 - Geometria dos conjuntos porta-ferramentas (padrão) 103

TABELA 3.5 - Matriz de experimentos com ferramentas cerâmicas (CC670 e CC650) de geometria quadrada na realização dos ensaios preliminares. 106

TABELA 3.6 - Modificações na geometria da aresta de corte em ferramentas cerâmicas (CC670 e CC650). 


\title{
LISTA DE ABREVIATURAS E SIGLAS
}

\author{
ABNT - Associação Brasileira de Normas Técnicas \\ AISI - American Iron and Steel Institute \\ CAD - Computer Aided Design \\ CAM - Computer Aided Manufacturing \\ CBN - Cubic Boron Nitride \\ CEN - Comité Européen de Normalisation \\ CIM - Manufatura Integrada por Computador \\ CNC - Comando Numérico Computadorizado \\ EA - Emissão Acústica \\ EDX - Energy-Dispersive Spectroscopy \\ HSC - High Speed Cutting \\ HSM - High Speed Machining \\ ISO - Internacional Organization for Standardization \\ JIS - Japanese Industrial Standard \\ MD - Metal Duro \\ MQL - Minimal Quantity of Lubricant \\ PCBN - Polycrystaline Cubic Boron Nitride \\ PCD - Polycrystaline Diamond \\ RMS - Root Mean Square \\ SAE - Society of Automotive Engineers
}




\section{LISTA DE SÍMBOLOS}

$\alpha_{0}$ - Ângulo de folga da ferramenta (graus)

$\gamma_{0}$ - Ângulo de saída da ferramenta (graus)

$\chi_{r}$ - Ângulo de posição (graus)

$\lambda_{\mathrm{r}}$ - Ângulo de inclinação

$\tau$ - Tensão residual (MPa)

$\mathrm{a}_{\mathrm{p}}$ - Profundidade de usinagem (mm)

$\mathrm{f}$ - Avanço ( $\mathrm{mm} / \mathrm{rev})$

$\mathrm{f}_{\mathrm{z}}$ - Avanço por dente $(\mathrm{mm} / \mathrm{rev})$

$\mathrm{H}_{\mathrm{v}}$ - Dureza Vickers (GPa)

KT - Desgaste de cratera (mm)

$P_{c}$ - Força de corte $(N)$

$\mathrm{R}_{\mathrm{a}}$ - Rugosidade superficial $(\mu \mathrm{m})$

$\mathrm{R}_{\delta}$ - Raio de ponta da ferramenta ( $\mathrm{mm}$ )

$\mathrm{t}$ - Tempo (s)

$\mathrm{T}$ - Temperatura da ferramenta $\left({ }^{\circ} \mathrm{C}\right)$

$\mathrm{VB}_{\mathrm{B}}$ - Desgaste de flanco médio ( $\mathrm{mm}$ )

$\mathrm{V}_{\mathrm{c}}$ - Velocidade de corte $(\mathrm{m} / \mathrm{min})$

$\mathrm{VB}_{\mathrm{N}}$ - Desgaste de entalhe $(\mathrm{mm})$ 
xxii

\section{RESUMO}

SILVA, L. R. (2002). Estudo da geometria da aresta de corte de ferramentas aplicadas ao torneamento de superligas à base de níquel com alta velocidade de corte. São Carlos, 2002. 211p. Tese (Doutorado) - Escola de Engenharia de São Carlos, Universidade de São Paulo.

Pesquisadores e indústrias de todo o mundo estão firmemente comprometidos com o propósito de fazer o processo de usinagem ser precisamente veloz e produtivo. A forte concorrência mundial gerou a procura por processos de usinagem econômicos, com grande capacidade de produção de cavacos e que produzam peças com elevada qualidade. Dentre as novas tecnologias que começaram a ser empregadas, e deve tornar-se o caminho certo a ser trilhado na busca da competitividade em curto espaço de tempo, está a tecnologia de usinagem com altas velocidades (HSM de High Speed Machining). A tecnologia HSM surge como componente essencial na otimização dos esforços para manutenção e aumento da competitividade global das empresas. Durante os últimos anos a usinagem com alta velocidade tem ganhado grande importância, sendo dada uma maior atenção ao desenvolvimento e à disponibilização no mercado de máquinas-ferramentas com rotações muito elevadas $(20.000-100.000 \mathrm{rpm})$. O processo de usinagem com alta velocidade está sendo usado não apenas para ligas de alumínio e cobre, mas também para materiais de difícil usinabilidade, como os aços temperados e superligas à base de níquel. Porém, quando se trata de materiais de dificil corte, têm-se observado poucas publicações, principalmente no processo de torneamento. Mas, antes que a tecnologia HSM possa ser empregada de uma forma econômica, todos os componentes envolvidos no processo de usinagem, incluindo a máquina, o eixoárvore, a ferramenta e o pessoal, precisam estar afinados com as peculiaridades deste novo processo. No que diz respeito às máquinas-ferramenta, isto significa que elas 
têm que satisfazer requisitos particulares de segurança. As ferramentas, devido à otimização de suas geometrias, substratos e revestimentos, contribuem para o sucesso deste processo. O presente trabalho objetiva estudar o comportamento de diversas geometrias de insertos de cerâmica $\left(\mathrm{Al}_{2} \mathrm{O}_{3}+\mathrm{SiC}_{\mathrm{w}}\right.$ e $\left.\mathrm{Al}_{2} \mathrm{O}_{3}+\mathrm{TiC}\right)$ e $\mathrm{PCBN}$ com duas concentrações de CBN na forma padrão, assim como modificações na geometria das arestas de corte empregadas em torneamento com alta velocidade em superligas à base de níquel (Inconel 718 e Waspaloy). Os materiais foram tratados termicamente para dureza de 44 e $40 \mathrm{HRC}$ respectivamente, e usinados sob condição de corte a seco e com utilização da técnica de mínima quantidade de lubrificante (minimal quantity lubricant - MQL) visando atender requisitos ambientais. As superligas à base de níquel são conhecidas como materiais de dificil usinabilidade devido à alta dureza, alta resistência mecânica em alta temperatura, afinidade para reagir com materiais da ferramenta e baixa condutividade térmica. A usinagem de superligas afeta negativamente a integridade da peça. Por essa razão, cuidados especiais devem ser tomados para assegurar a vida da ferramenta e a integridade superficial de componentes usinados por intermédio de controle dos principais parâmetros de usinagem. Experimentos foram realizados sob diversas condições de corte e geometrias de ferramentas para avaliação dos parâmetros: força de corte, temperatura, emissão acústica e integridade superficial (rugosidade superficial, tensão residual, microdureza e microestrutura) e mecanismos de desgaste. Mediante os resultados apresentados, recomenda-se à geometria de melhor desempenho nos parâmetros citados e confirma-se a eficiência da técnica MQL. Dentre as ferramentas e geometrias testadas, a que apresentou melhor desempenho foi a ferramenta cerâmica CC650 seguida da ferramenta cerâmica CC670 ambas com formato redondo e geometria 2 (chanfro em $\mathrm{T}$ de $0,15 \times 15^{\circ}$ com raio de aresta de $0,03 \mathrm{~mm}$ ).

Falavras-chave: usinagem com alta velocidade (HSN); corte a secis; mínima quantidade de lubrificante (MQL); ferramentas para HSM; força de corte; temperatura de corte; superligas à base de níquel; preparação de arestas de corte e integridade superficial. 


\begin{abstract}
SILVA, L. R. Study of the edge geometry of tools employed to high speed turning of nickel based superalloys. São Carlos, 2002. 211p. Tese (Doutorado) - Escola de Engenharia de São Carlos, Universidade de São Paulo.
\end{abstract}

Researchers and industry personnel around the world are firmly committed to the purpose of doing the machining process dramatically faster and more precise. The tough global competition has generated a search for more economical machining processes, with high ability for chip removal and, in this way, producing high quality workpieces. Among the new technologies available nowadays, the high speed machining (HSM) is pointed out as the main solution to obtain competitiveness in a short period of time. The HSM technology appears as an essential component to optimize the efforts for maintaining, and increasing, the global competitiveness. During the last years, high speed machining technology has received great attention, specially the development and availability in the market of machine tools with high rotational speeds $(20.000-100.000 \mathrm{rpm})$. The HSM has been used not only to machine aluminum and copper alloys, but also to difficult to machine materials, such as hardened steels and nickel based superalloys. However, for difficult to machine materials, the literature is very incipient, specially concerning the turning process. However, before the HSM technology be used in an economic way, all the components involved in the machining process, including the machine, the spindle, the tool and the operators, need to be tuned with the peculiarities of this new process. Concerning the tooling, they have to satisfy peculiar requirements of safety. Due to the optimization of their geometries, substrates and coatings, the cutting tools are contributing to the success of the process. The present work aims at the study of several insert geometries of ceramic tools $\left(\mathrm{Al}_{2} \mathrm{O}_{3}+\mathrm{SiCw}\right.$ and $\left.\mathrm{Al}_{2} \mathrm{O}_{3}+\mathrm{TiC}\right)$ and 
PCBN, with two concentrations of CBN, in the standard format and with modifications on the cutting edge geometry, working in the high speed turning of nickel based superalloys (Inconel 718 and Waspaloy). Materials were heat treated to hardness of 44 and $40 \mathrm{HRC}$, respectively, and machined under dry cutting condition and also with minimal quantity of lubricant (MQL) to attend environmental requirements. The nickel based superalloys are known as difficult to cut materials due to their high hardness, high mechanical strength at high temperature, chemical affinity to tool materials and lower thermal conductivity. The machining of superalloys affects negatively the integrity of the workpiece. For this reason, tool life and surface integrity of the machined component must be carefully analyzed throughout the control of the main machining parameters. Practical experiments were implemented using several cutting conditions and tool geometries to evaluate the following parameters: cutting force, temperature, acoustic emission and surface integrity (surface finishing, residual stress, microhardeness and microstructure) and wear mechanisms. Analyzing the results, the most suitable geometry for the mentioned parameters is recommended and the efficiency of the MQL technical is confirmed. Among all inserts and geometries tested, the CC650 ceramic tool presented better results, followed by the CC670 ceramic tool, both with round format and edge geometry number 2 (chamfer in $\mathrm{T} 0,15 \times 15^{\circ}$ with hone of $0,03 \mathrm{~mm}$ ).

Keywords: high speed machining (HSM); dry cutting; minimal quantity of lubricant (MQL); tools for HSM; cutting force; cutting temperature; nickel based superalloys; modification of cutting edges and surface integrity. 


\section{INTRODUÇÃO}

Nos meados da década de 80 , a globalização da competição mudou a forma de abordagem, pelas empresas, do processo de manufatura, em especial a usinagem de componentes metálicos. Os processos de usinagem têm uma importância significativa dentro dos atuais sistemas produtivos de fabricação mecânica. A forte concorrência mundial gerou a procura por processos de usinagem econômicos, com grande capacidade de remoção de cavacos e que produzam peças com elevada qualidade. Novas tecnologias, conceitos de automação e estratégias têm sido adotados e implementados, com o objetivo de incrementar o desempenho e a eficiência da máquina e do operador. Enfocam a redução dos custos e potencializam o aumento da produtividade, colocando o pessoal que desenvolve os produtos e as áreas de produção sob uma crescente pressão.

As transformações tecnológicas constituem o elemento-chave de sustentação e viabilização econômica da maioria das empresas no horizonte de negócios de médio e longo prazo, permitindo a melhoria da competitividade e a sustentabilidade da liderança de uma empresa.

Dentre as novas tecnologias que começaram a ser empregadas, e devem tornar-se o caminho certo a ser trilhado na busca da competitividade em curtíssimo espaço de tempo, está a tecnologia da usinagem com alta velocidade (HSM de High Speed Machining). Devido ao aspecto relativamente novo do termo, ao longo deste trabalho será empregada a abreviação em inglês HSC (High Speed Cutting) para designar apenas o corte em alta velocidade e HSM o processo, como um todo, de usinagem com altas velocidades. A HSM surge como componente essencial na otimização dos esforços para manutenção e aumento dà competitividade global das empresas e se credencia como instrumento indispensável para o enfrentamento dos novos desafios que se colocam.

Durante os últimos anos a usinagem com alta velocidade tem ganhado a importância que merece, o que quer dizer que tem sido dada uma maior atenção ao 
desenvolvimento e à disponibilização no mercado de tecnologias para velocidades e rotações muito elevadas. A $20^{\mathrm{a}}$ versão da Feira Internacional de MáquinasFerramentas do Japão (Jimtof, de Japan Internacional Machine Tool Fair) mostrou máquinas com eixos-árvore na faixa de rotação de 20.000 a $100.000 \mathrm{rpm}$ (mancais magnéticos ou aerostáticos), fusos de esferas recirculantes que permitem avanços rápidos de $100 \mathrm{~m} / \mathrm{min}$ e motores lineares que permitem alcançar deslocamento rápido de $120 \mathrm{~m} / \mathrm{min}$, com aceleração de 1,5 G (SIMON, 2001).

Mas, antes que a tecnologia HSM possa ser empregada de uma forma econômica, todos os componentes envolvidos no processo de usinagem, incluindo a máquina, o eixo-árvore, a ferramenta e o pessoal, precisam estar "afinados" com as condições especiais deste processo. No que diz respeito às máquinas, isto significa que elas devem satisfazer requisitos particulares de segurança. As ferramentas de corte, também devem estar à altura das condições térmicas mais severas que se originam com as altas velocidades de corte.

$\mathrm{O}$ corte com altas velocidades pode ser usado para todo processo de usinagem de metais leves, não-ferrosos e plásticos, mas para aços liga, ferro fundido e ligas de dificil usinabilidade ele é adequado apenas para o corte final. O material da ferramenta ainda é o fator limitante para usinagem com alta velocidade (SCHULZ, 1996; FALLBÖHMER et al. 2000 e CHRISTOFFEL, 2001).

Com o resultado dos avanços tecnológicos em máquinas-ferramentas e ferramentas de corte, a usinagem com alta velocidade (HSM) está sendo executada com um aumento progressivo nas velocidades de corte e de avanço. Os termos HSC e HSM estão sendo comumente utilizados nos anos recentes para descrever o fresamento de acabamento em altas rotações, entretanto no torneamento, roscamento e furação tem-se observado alguns poucos trabalhos publicados em comparação com o fresamento (ANDRAE, 1999).

Muitas vantagens de HSM têm sido citadas. De acordo com DEWES \& ASPINWALL (1997); SCHULZ (1997) e ANDRAE (1999) as mais comumente reivindicadas são: altas taxas de remoção, baixas forças de corte, mínima distorção da peça pela melhor dissipação do calor no processo e a capacidade de usinar peças de paredes finas. Adicionalmente à redução do tempo de produção, o uso da 
tecnologia HSM também produz peças com melhor qualidade superficial e dimensional.

As desvantagens do processo HSM têm sido também identificadas, tais como o elevado nível de desgaste das ferramentas, a carência de materiais de ferramentas avançadas e seu alto custo, balanceamento do ferramental, eixos-árvore caros com baixa durabilidade dos mancais (tipicamente $5.000-10.000 \mathrm{~h}$ na máxima velocidade rotacional), alto custo de máquina-ferramenta, sistema de controles especiais e sistemas de fixação especiais (DEWES \& ASPINWALL, 1997; SCHULZ, 1999; FALLBÖHMER et al. 2000 e CHRISTOFFEL, 2001).

Hoje em dia, a tecnologia HSM está ganhando enorme importância não apenas na área de fabricantes de moldes e matrizes, mas também em outras áreas de usinagem em geral. Isso tem aumentado a tendência em direção à substituição de métodos de produção convencionais, baseados em linhas "transfer" com usinagem multi-eixos, pelos centros de usinagem de alta performance com eixo-árvore único. Na Europa, Japão e EUA a tecnologia HSM deixou de ser apenas objeto de pesquisas em laboratórios e está sendo utilizada pela indústria com grande êxito, principalmente na fabricação de moldes e matrizes, prototipagem rápida, usinagem de ultra-precisão, entre outras (SCHÜTZER et al. 2000).

A usinagem HSM não deve estar relacionada somente ao parâmetro velocidade de corte, como regra absoluta, mas deve ser pensada também com base no material e processo, dos quais depende. Normalmente, a alta velocidade é definida como uma faixa que excede claramente os dados de corte em geral praticados, os quais ultrapassam os limites das máquinas-ferramentas convencionais ou das ferramentas.

As principais propriedades das superligas à base de níquel são alta resistência mecânica à temperaturas elevadas, alta resistência à fluência, alta resistência à fadiga e boa resistência à corrosão, características que tornam dificil a sua usinabilidade. A composição química com elevado teor de elementos de liga confere excelentes propriedades mecânicas e térmicas às superligas de níquel, mas dificultam demasiadamente a realização da usinagem desses materiais. No entanto, deve-se salientar que a literatura disponível é muito limitada em termos de informações para a usinagem das superligas à base de níquel, principalmente com altas velocidades. 
Definir as ferramentas mais adequadas e as respectivas condições operacionais para os diferentes processos de usinagem são questões básicas e fundamentais a serem resolvidas. A usinagem de superligas pode, ainda, afetar negativamente a integridade superficial da peça. Por essa razão, cuidados especiais devem ser tomados para assegurar a vida da ferramenta e a integridade superficial adequada de componentes usinado por intermédio de controle dos principais parâmetros de usinagem.

Nos últimos anos, o consumo de energia, a poluição do ar e os resíduos industriais têm despertado especial atenção por parte das autoridades públicas. Motivados pela pressão dos órgãos ambientais, os parlamentos têm elaborado leis cada vez mais rigorosas no sentido de proteger o meio ambiente e preservar os recursos energéticos. Até há poucos anos atrás, as indústrias tinham como objetivo principal a fabricação de produtos visando somente satisfazer aspectos tecnológicos e econômicos. A usinagem a seco e com Mínima Quantidade de Lubrificante (MQL) tem despertado a atenção de pesquisadores e técnicos da área de usinagem como alternativa aos fluidos tradicionais.

Hoje, raros eventos e publicações omitem o corte com alta velocidade e os fabricantes de ferramentas, máquinas-ferramentas e pacotes de programas CAD/CAM parecem estar desenvolvendo e vendendo apenas produtos com capacitação para alta velocidade. A obtenção de maiores velocidades de usinagem tem sido um desafio básico para fabricantes de máquinas-ferramentas (SINHOFF et al. 1999 e SIMON, 2001). Algumas empresas brasileiras e universidades estão começando a investir nesta tecnologia, adquirindo máquinas na faixa de transição para HSM e investindo em pesquisas científicas para auxiliar a implantação desta tecnologia no ambiente industrial. Atualmente existe carência de profissionais qualificados para suprir as necessidades de mercado brasileiro (SCHÜTZER et al. 2000 e COELHO et al. 2001).

\subsection{Objetivos}

O presente trabalho objetiva estudar o comportamento das diversas geometrias de ferramentas cerâmicas $\left(\mathrm{Al}_{2} \mathrm{O}_{3}+\mathrm{SiC}_{\mathrm{w}}\right.$ e $\mathrm{Al}_{2} \mathrm{O}_{3}+\mathrm{TiC}$ ) e PCBN (com duas concentrações de $\mathrm{CBN}$ ) na forma padrão, assim como modificações na 
geometria da aresta de corte, no torneamento com alta velocidade de corte em superligas à base de níquel endurecidas (Inconel 718 e Waspaloy).

Os principais objetivos que norteiam este trabalho são:

Avaliar o desempenho de diversas geometrias de inserto de ferramentas com aresta padrão;

- Desenvolver preparação de aresta de corte através de modificações de ferramentas normalizadas, com o propósito de obter a geometria de melhor desempenho;

* Propor a geometria para o torneamento com alta velocidade de corte em superligas à base de níquel com ferramentas cerâmicas $\left(\mathrm{Al}_{2} \mathrm{O}_{3}+\mathrm{SiC}_{\mathrm{w}}\right.$ e $\mathrm{Al}_{2} \mathrm{O}_{3}+$ TiC) e PCBN;

* Avaliar o desempenho da técnica de Mínima Quantidade de Lubrificante (MQL) na usinagem com alta velocidade de superligas à base de níquel, visando atender requisitos ambientais.

\subsection{Estrutura do trabalho}

O presente trabalho está dividido em capítulos, cujo conteúdo é descrito abaixo:

O Capítulo 2 refere-se à revisão bibliográfica, enfocando temas relevantes dentro do estágio atual da tecnologia envolvida no trabalho.

No Capitulo 3 é descrito o planejamento e o procedimento experimental dos ensaios.

O Capitulo 4 é dedicado exclusivamente à apresentação dos resultados e discussões dos gráficos obtidos nos ensaios para as diversas geometrias de ferramentas.

No Capítulo 5 são apresentadas as principais conclusões e considerações finais do presente trabalho.

No Capítulo 6 são apresentadas as sugestões para os futuros trabalhos que possam ampliar o conhecimento da tecnologia HSM de superligas à base de níquel e da técnica de MQL.

No Capítulo 7 são apresentadas as bibliografias citadas e consultadas, utilizadas para a escrita deste trabalho. 


\section{REVISÃO BIBLIOGRÁFICA}

Esta revisão bibliográfica visa apresentar e analisar os temas mais relevantes para a usinagem com alta velocidade, no que se refere a máquinas-ferramentas, ferramentas para HSM, força de corte, temperatura, integridade superficial e mecanismos de desgaste sob condição de corte a seco e com Mínima Quantidade de Lubrificante (MQL) visando atender requisitos ambientais. A usinagem com altas velocidades (HSM) sob condição de corte a seco e com mínima quantidade de lubrificante são novas tecnologias para custos de produção reduzidos e não agressão ao meio ambiente, principalmente nas áreas de fresamento, torneamento e furação. São termos genéricos para projetos de processos inovativos e de alto desempenho.

\subsection{Tecnologia de usinagem com altas velocidades (HSM)}

No final deste século, a tecnologia de usinagem com altas velocidades estabeleceu-se nos países industrializados. Isto também se deve ao fato de que as máquinas-ferramentas padrão tornaram-se mais rápidas e, portanto, permitem a aplicação de processos de usinagem com velocidades mais elevadas. A tecnologia HSM faz exigências muito particulares sobre a máquina-ferramenta. São necessárias altas rotações no eixo-árvore para atingir as velocidades de corte desejadas no processo. A utilização de construções leves permite aumentos significativos da aceleração, especialmente com a utilização de motores lineares. Comandos numéricos computadorizados (CNC) rápidos e modernos são absolutamente essenciais para a implementação de processos com altas velocidades (NOVASKI \& CORRÊA, 1998 e SCHULZ, 1999).

A alta velocidade de corte oferece novas e grandes vantagens em amplos campos de aplicação. Impulsiona o desenvolvimento de novas tecnologias em ferramentas, máquinas-ferramentas e componentes e altera sensivelmente as relações industriais e comerciais. 


\subsubsection{Uma visão geral da tecnologia HSM}

O conceito de usinagem com alta velocidade foi desenvolvido por Carl $\mathrm{J}$. Salomon durante uma série de experimentos de 1924 a 1931, quando em 1931 obteve a patente para usinagem com alta velocidade baseado nos efeitos da temperatura (KAHLES et al. 1978; FLOM \& KOMANDURI, 1989; DEWES \& ASPINWALL, 1997; AGBA, 1999 e SCHULZ, 1999b). Salomon reconheceu que em princípio as temperaturas e as forças de corte tendiam a decrescer em altas velocidades, no entanto, um longo percurso teve que ser trilhado até a introdução da tecnologia HSM comercialmente. Salomon baseou-se em uma série de curvas de velocidade de corte em função da temperatura de corte atingida. Estes experimentos foram desenvolvidos em aço, bronze, cobre e alumínio atingindo velocidades de corte respectivamente (440 $\mathrm{m} / \mathrm{min}, 1.600 \mathrm{~m} / \mathrm{min}, 2.840 \mathrm{~m} / \mathrm{min}$ e $16.500 \mathrm{~m} / \mathrm{min}$ ) no processo de fresamento utilizando uma serra circular de grande diâmetro. A FIGURA 2.1 mostra uma apresentação simplificada deste conceito (FLOM \& KOMANDURI, 1989).

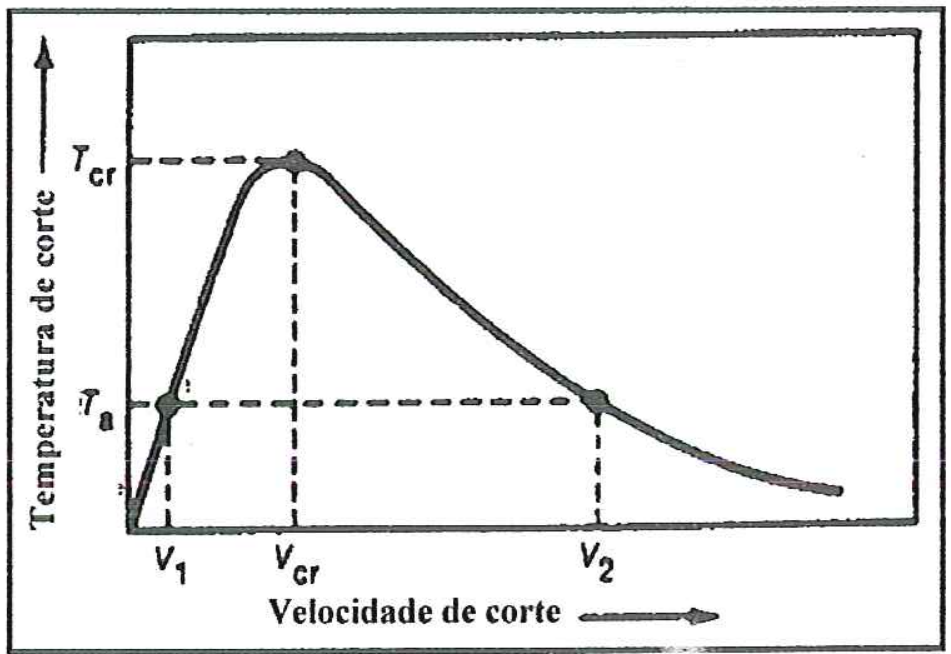

FIGURA 2.1 - Velocidade de Corte Idealizada versus Temperatura de Corte Demostrada por Salomon (FLOM \& KOMANDURI, 1989).

Somente com o desenvolvimento dos eixos-árvore de alta rotação no início dos anos 80, com os quais foi possível atingir altas velocidades, abriu-se a possibilidade de serem realizadas pesquisas tecnológicas de base nessa área.

O termo "corte com alta velocidade" não é de fácil definição. Por exemplo, o projeto da CEN (comité Européen de Normalisation) de 05 de outubro de 1995 - 
"Ferramentas de fresamento para usinagem por remoção de cavacos a velocidades periféricas elevadas em máquinas para corte de metais - Requisitos de segurança" define velocidades acima de $1.000 \mathrm{~m} / \mathrm{min}$ como usinagem com alta velocidade. Isso faz sentido sob o ponto de vista da segurança, mas certamente não é a melhor classificação. Para ser mais exato, devem ser considerados o material a ser usinado, a ferramenta de corte usada e o processo. Por exemplo, quando uma carcaça de alumínio é usinada com pastilhas de diamante, uma velocidade de $10.000 \mathrm{~m} / \mathrm{min}$ ainda pode ser considerada moderada. Por outro lado, se um aço endurecido é usinado com nitreto cúbico de boro $(\mathrm{CBN})$ como material de corte, a velocidade de corte de $200 \mathrm{~m} / \mathrm{min}$, isto certamente também pode ser considerado como usinagem HSC (STOCKINGER et al. 1998).

Segundo KITAGAWA et al. (1996); SCHULZ (1997) e FINZER apud NOVASKI \& CORRÊA (1998), a definição do que é alta velocidade de corte está intimamente associada ao tipo de material usinado, tipo de operação de corte e tipo de ferramenta, entre outros itens. VIGNEAU (1997) indica na FIGURA 2.2, a faixa de valores que definem a alta velocidade de corte para cada material específico.

$\mathrm{Na}$ Europa, normalmente fala-se em velocidade de corte, enquanto nos Estados Unidos emprega-se rotação do eixo-árvore. Muitos autores usam velocidade absoluta do eixo-árvore, sendo que a faixa mais real a ser considerada como definição inicial de usinagem com alta velocidade no fresamento, está em torno de 8000 rpm, ou maiores. Porém, isto é enganoso porque não indica o diâmetro do eixoárvore. É muito fácil alcançar alta rotação com eixos de pequeno diâmetro. Uma representação mais exata da alta velocidade do eixo-árvore, do ponto de vista de projeto é o número DN (diâmetro do eixo-árvore em "mm" multiplicado pela sua rotação, em "rpm"). Existem várias máquinas comerciais disponíveis com o número DN na faixa de 1,5 milhão e poucos eixos (principalmente em laboratório) com número DN que excedem à 2 milhões (SMITH \& TLUSTY, 1997). No processo de torneamento estas definições não são atendidas.

De acordo com HEISEL \& GRINGEL (1996); FINZER (1997); SCKOCK (1998) e SCHULZ (1999), entende-se por usinagem com alta velocidade, a usinagem de materiais com velocidades de corte e taxas de avanço aumentadas por um fator de 5 até 10 em relação às velocidades de corte e avanços tradicionais. 
ENDERLE \& KNUSZYNSKI (1998) e MÜLLER \& ICE (1999) afirmam que as definições da faixa de velocidade de HSC variam substancialmente conforme se muda de um tipo de usinagem para outro. Por exemplo, se no caso de fresamento uma aplicação de HSC envolve uma velocidade de corte da ordem de cinco a dez vezes maior que a velocidade convencional, o dobro da velocidade convencional já é suficiente para que os processos de furação e roscamento sejam considerados como HSM. Assim, no fresamento de metais leves, a faixa HSC é de velocidades de corte bem acima de $V_{c}=1.000 \mathrm{~m} / \mathrm{min}$, enquanto que na furação está dentro da faixa de $100 \mathrm{~m} / \mathrm{min}$ e no roscamento com machos, a usinagem com altas velocidades já pode ser referida a partir de $\mathrm{V}_{\mathrm{c}}=50 \mathrm{~m} / \mathrm{min}$. Dadas às características particulares de processo, as exigências que a usinagem de furos requer, tanto das ferramentas, quanto dos materiais de corte, são muito diferentes das de fresamento e torneamento. Especialmente quando se trata da furação de blocos sólidos, o material de corte estará submetido a todas as velocidades de corte possíveis entre $0 \mathrm{~m} / \mathrm{min}$ no centro até a velocidade máxima de corte no diâmetro externo da broca. Normalmente utilizam-se pastilhas indexáveis na usinagem com alta velocidade de corte em furos.



FIGURA 2.2 - Definição de Faixas de Velocidade de Corte para HSM

(VIGNEAU, 1997). 
De acordo com NOVASKI \& CORRÊA (1998), a tecnologia HSM envolve não apenas o simples aumento de rotação dos motores das máquinas, mas sim um novo conceito de:

Processo de usinagem;

Máquinas-ferramentas;

Ferramentas de corte.

As características mais relevantes do emprego e utilização das altas velocidades de corte estão nos aspectos econômicos e técnicos. Altas taxas de remoção de material e reduzido tempo de usinagem são de importância decisiva para o aspecto econômico do processo de corte (ANDRAE, 1999).

\subsubsection{Vantagens econômicas da HSM}

GRUNDLER (1994); NOVASKI \& CORRÊA (1998); FALLBÖHMER et al. (2000) e CHRISTOFFEL (2001) afirmam que o conhecimento de todas as vantagens proporcionadas pelo uso da HSM é de natureza complexa e dificil. Resumidamente, podem ser consideradas:

- Incremento na produtividade;

- Maior flexibilidade comercial (pedidos complexos atendidos em menor tempo);

$\because$ Redução dos custos do processo de fabricação;

* Baixos tempos inativos;

- Redução do ciclo de fabricação;

- Maior flexibilidade na alocação de mão de obra.

\subsubsection{Vantagens técnicas da HSM}

Segundo GRUNDLER (1994); SCHULZ (1996); DESTEFANI (1997); KIRSCHN!K (1997); NOVASKI \& CORRÊA (1998); ANDRAE (1999); FALLBÖHMER et al. (2000); CHRISTOFFEL (2001) e SCHULZ et al. (2001), o conhecimento da tecnologia HSM proporciona ganhos de ordem tecnológica, a exemplo de:

Melhoria na exatidão das peças, especialmente em usinagem de peças delgadas;

* Melhoria nos mecanismos de formação de cavaco; 
Incremento na qualidade superficial das peças, o que elimina muitas vezes operações posteriores;

* Diminuição das forças de corte, proporcionalmente ao aumento das velocidades de corte, com enormes vantagens na usinagem de peças de parede fina;

A usinagem ocorre sem vibrações, pois as excitações induzidas pelo corte da ferramenta são de baixa amplitude e de alta freqüência, acima das freqüências de ressonâncias normais dos sistemas mecânicos das máquinas-ferramentas;

Melhoria na dissipação de calor do processo, pois a maior parte da energia térmica gerada se concentra no cavaco, e como este é arrancado rapidamente devido à alta velocidade de corte, a transferência de calor para a peça é mínima, evitando distorção térmica;

* Alta taxa de remoção de material, ou seja, o volume específico de cavaco é pelo menos $30 \%$ superior comparado a usinagem convencional;

Usinagem de materiais endurecidos (moldes);

Possibilidade de emprego de usinagem sem fluido de corte.

\subsubsection{O estado da arte e tendências da tecnologia HSM}

Em comparação com as máquinas-ferramentas convencionais, a aplicação econômica das máquinas HSM é profundamente influenciada pela escolha da tecnologia de corte correta, por velocidades de corte ótimas e avanços adequados e por ferramentas otimizadas. Quanto às velocidades de corte otimizadas e os avanços, pode-se dizer que não há máquinas HSM de aplicação universal.

A usinagem com alta velocidade possibilita às empresas a obtenção de vantagens competitivas através do aprimoramento nos processos de fabricação, por meio da inovação das tecnologias existentes para usinagem de componentes e desenvolvimento de novas formas. O objetivo é o aumento da produtividade e da eficiência comercial, reduzindo custos e oferecendo alternativas às necessidades requeridas pelo setor produtivo, preservando a competitividade e a qualidade do trabalho, sem agredir o meio ambiente.

Para entender a tecnologia HSM é necessário uma interação de máquinas, ferramentas, material da peça e tecnologia de corte, para que se possa proporcionar um melhor resultado no projeto das máquinas HSM, seus componentes e os 
respectivos processos da manufatura conforme ilustra a FIGURA 2.3 (SCHULZ, 1997).

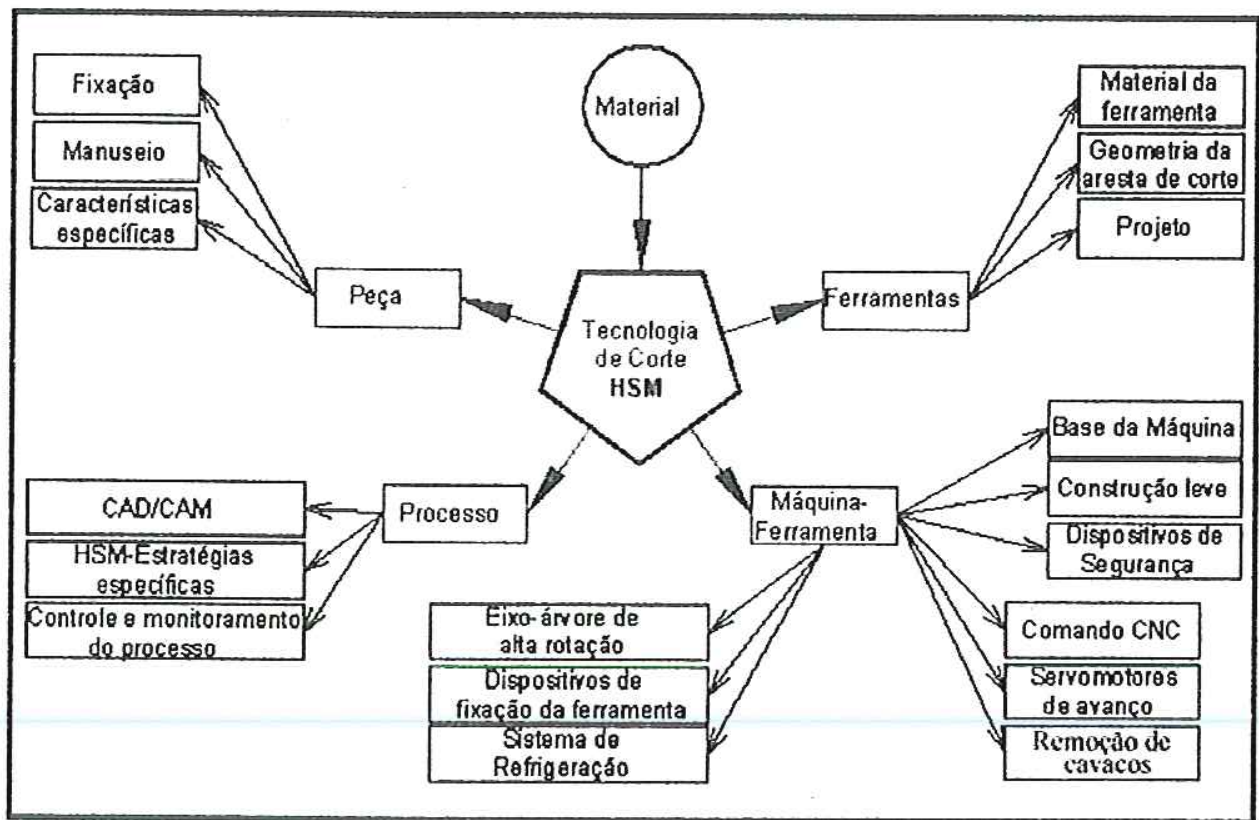

FIGURA 2.3 - Influência da Tecnologia de Corte (SCHULZ, 1997).

A TABELA 2.1 indica os principais campos de aplicações e exemplos de corte em que a alta velocidade fornece vantagens específicas. A maior economia alcançada com o uso de máquinas-ferramentas de alta velocidade, em comparação com a que se alcança com máquinas convencionais, é fortemente influenciada pela escolha correta da tecnologia de corte, das velocidades de corte, dos avanços, das ferramentas e principalmente da estabilidade do processo (SCHULZ, 1997).

A usinagem com alta velocidade não é destinada a cortes pesados em materiais ferrosos e superligas, mas sim a configurações próximas da forma final da peça, ou quando a operação é feita com pequeno sobremetal, visando a qualidade superficial. Em materiais não ferrosos, emprega-se operações de desbaste e acabamento visando altas taxas de remoção de material (SCHULZ, 1996; FALLBÖHMER et al. 2000; SCHÜTZER et al. 2000 e CHRISTOFFEL, 2001). 
TABELA 2.1 - Faixas de aplicações de usinagem com alta velocidade (SCHULZ, 1997).

\begin{tabular}{|c|c|c|}
\hline Vantagens da HSM & Campo de aplicação & Exemplos de aplicação \\
\hline $\begin{array}{c}\text { Alto volume de } \\
\text { remoção }\end{array}$ & $\begin{array}{c}\text { Aços ligas e ferro fundido } \\
\text { Ligas leves }\end{array}$ & $\begin{array}{c}\text { Fabricação de moldes e matrizes } \\
\text { Produção aeroespacial }\end{array}$ \\
\hline $\begin{array}{c}\text { Alta qualidade } \\
\text { superficial }\end{array}$ & $\begin{array}{c}\text { Usinagem de precisão } \\
\text { Peças especiais }\end{array}$ & $\begin{array}{c}\text { Indústria óptica } \\
\text { Peças para mecânica fina }\end{array}$ \\
\hline Baixas forças de corte & $\begin{array}{c}\text { Usinagem de peças com } \\
\text { paredes finas }\end{array}$ & $\begin{array}{c}\text { Indústria automotiva aeroespacial } \\
\text { Equipamentos domésticos }\end{array}$ \\
\hline $\begin{array}{c}\text { Alta taxa de condução } \\
\text { do calor da região de } \\
\text { corte pelos cavacos }\end{array}$ & $\begin{array}{c}\text { Usinagem de peças para } \\
\text { trabalho a frio e sensíveis ao } \\
\text { calor }\end{array}$ & $\begin{array}{c}\text { Mecânica de precisão } \\
\text { Ligas de magnésio }\end{array}$ \\
\hline
\end{tabular}

A FIGURA 2.4 mostra uma indicação da tendência dos parâmetros: volume de cavaco, qualidade superficial, força de corte e vida da ferramenta quando a velocidade de corte é aumentada (BERT, 1997).

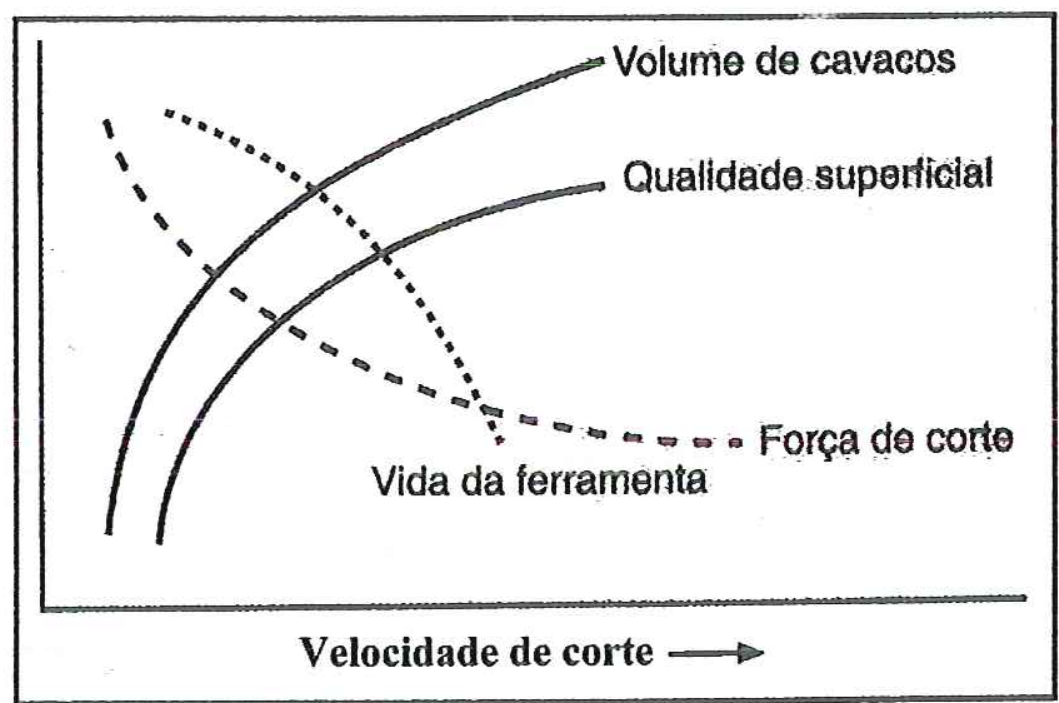

FIGURA 2.4 - Tendência de Parâmetros de Corte em Usinagem com Alta Valocidade de Corte (BERT, 1997).

Segundo SCHULZ (1997), a única desvantagem da HSM está na possível redução da vida da ferramenta causada pelo aumento da velocidade de corte (FIGURA 2.4). Entretanto ele afirma que, compensando-se esta desvantagem e aumentando-se a vida da ferramenta, determinando parâmetros de usinagem ótimo 
para cada aplicação e para cada material, haverá como conseqüência uma atenuação deste problema no desempenho da tecnologia HSM conforme ilustram as FIGURAS 2.5 e 2.6 .

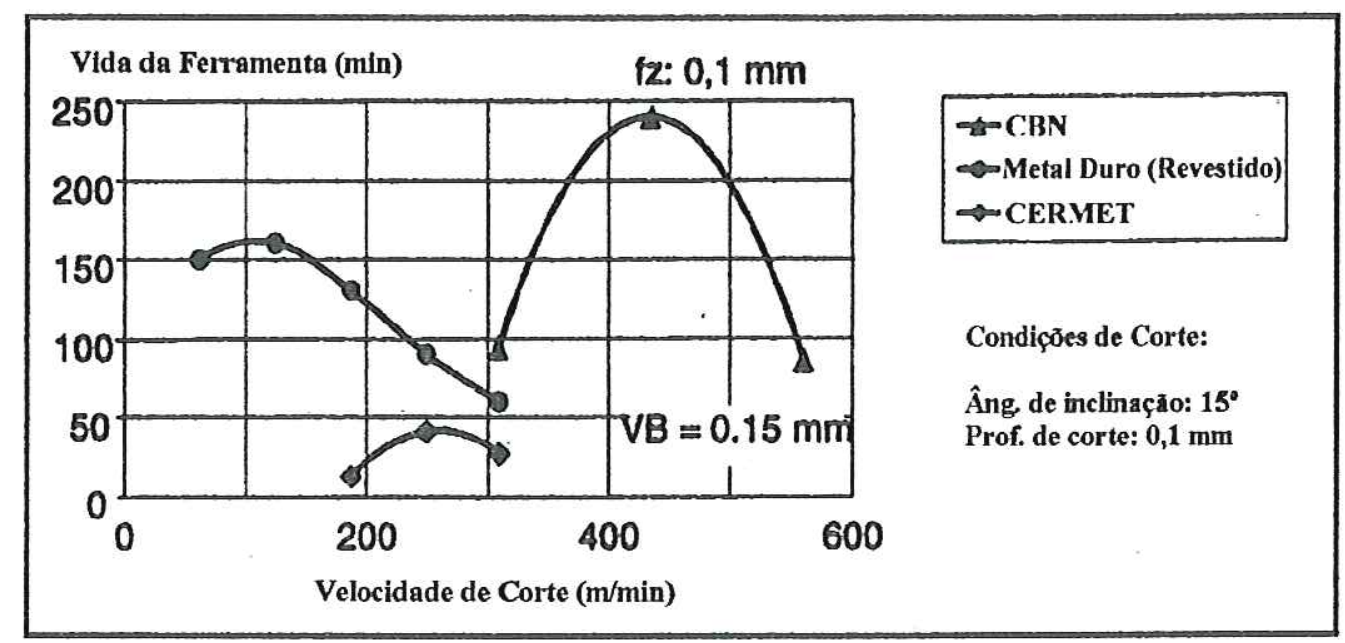

FIGURA 2.5 - Influência da Velocidade de Corte e Avanço sobre a Vida da Ferramenta em Aço de Alta Liga - SAE A2 (SCHULZ, 1997).

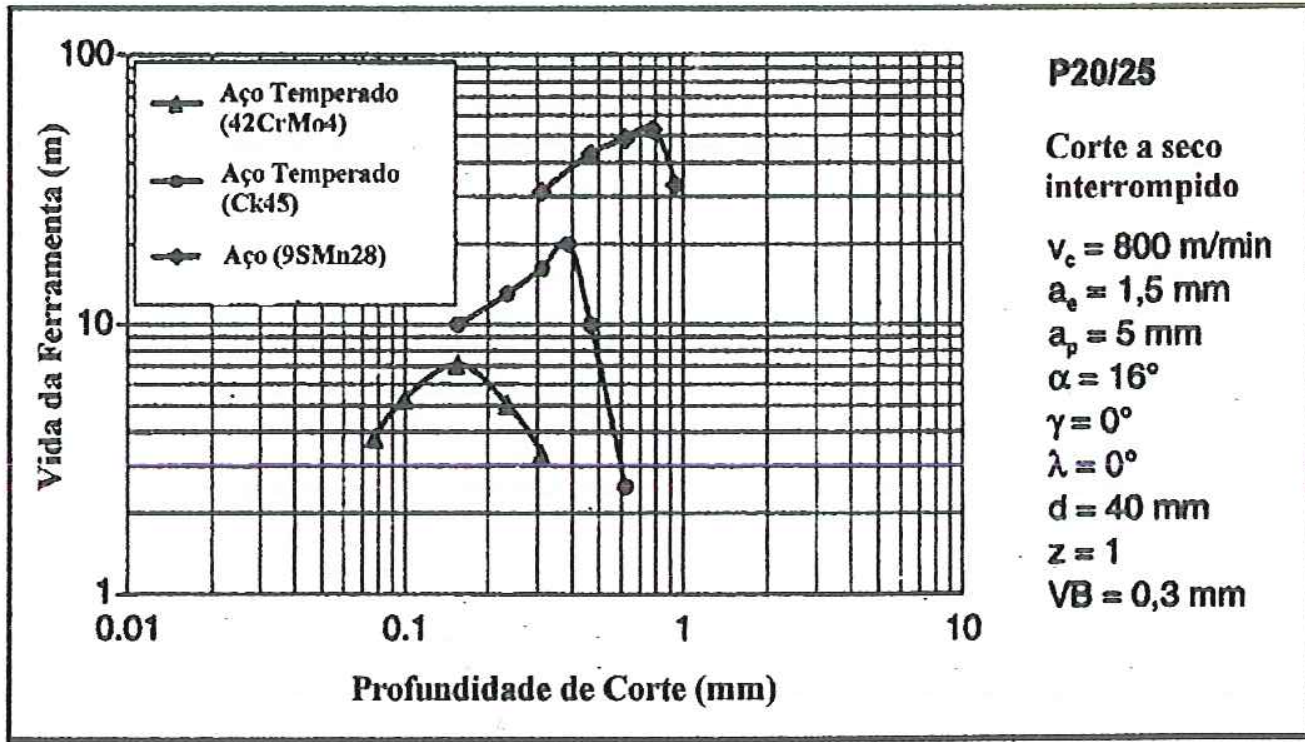

FIGURA 2.6 - Vida da Ferramenta Dependente de Diferentes Materiais (SCHULZ, 1997).

Por outro lado, a escolha das propriedades do material da ferramenta de corte é de extrema importância para a sua vida. De acordo com SCHULZ (1997), ferramentas de cermets proporcionam valores excelentes na usinagem do aço 40CrMnMo7. Usando este mesmo material de corte para o ferro fundido GG 
$25 \mathrm{CrMo}$, os testes conduziram a resultados completamente insatisfatórios conforme ilustra a FIGURA 2.7.

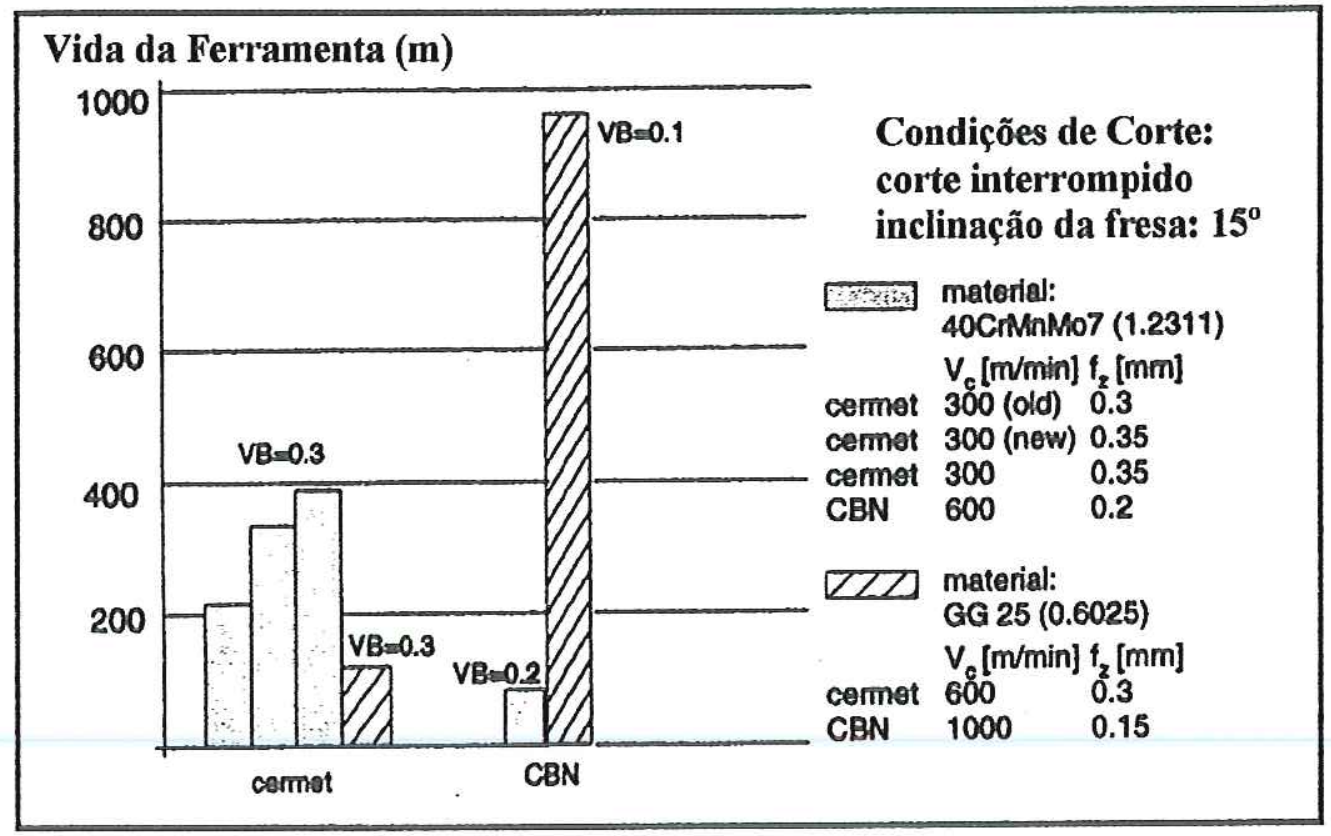

FIGURA 2.7 - Uso de Diferentes Materiais de Corte (SCHULZ, 1997).

No que se refere a aços endurecidos, a tecnologia HSM possibilita possíveis substituições de processos. Torneamento de aço endurecido (> $52 \mathrm{HRC}$ ) poderá substituir a retificação com qualidade de trabalho IT 7. Por outro lado, matrizes e moldes manufaturados pelo lento processo de eletroerosão poderá ser substituído pelo fresamento com alta velocidade em muitas aplicações. Entretanto, HSM em aço endurecido resulta em altas temperaturas e tensões na interface ferramenta-peça, necessitando de otimização dos parâmetros de corte (SCHULZ, 1999 e FALLBÖHMER et al. 2000).

SCHOCK (1998) apresenta os parâmetros típicos de produção de matrizes e moldes para HSM, resumidos na TABELA 2.2. Na usinagem com HSC é requerida uma espessura de corte mínima para a criação de condições de corte favoráveis. Portanto, uma realização tecnológica correta do processo de alťs velocidades de corte torna a adaptação do avanço absolutamente necessária. Assim, para uma ferramenta de até cerca de $20 \mathrm{~mm}$ de diâmetro, avanços de 0,05 a $0,2 \mathrm{~mm} /$ dente devem ser considerados como valores de referência. 
TABELA 2.2 - Velocidades de corte e taxas de avanços típicas para HSM (SCHOCK, 1998).

\begin{tabular}{|c|c|c|c|}
\hline Material & $\begin{array}{c}\text { Veloc. de corte } \\
(\mathrm{m} / \mathrm{min})\end{array}$ & $\begin{array}{c}\text { Avanços típicos } \\
(\mathrm{m} / \mathrm{min})\end{array}$ & $\begin{array}{c}\text { Ferramentas/ } \\
\text { Revestimentos }\end{array}$ \\
\hline Alumínio & \pm 2000 & $12-20$ & VHM - sem \\
\hline Cobre & \pm 1000 & $6-12$ & VHM - sem \\
\hline Aço (42-52HRC) & \pm 400 & $3-7$ & VHM/TiCN, TiAlN \\
\hline Aço (56-60HRC) & \pm 250 & $3-4$ & VHM/TiCN, TiAlN \\
\hline
\end{tabular}

FINZER (1997); ELBESTAWI et al. (1997); KLOCKE et al. (1999) e SCHULZ et al. (2001) revelam que com o uso da tecnologia HSM na fabricação de matrizes e moldes, pode-se obter redução do tempo de fabricação, produzir uma melhoria na qualidade superficial e proporcionar uma vida superior da ferramenta, além de eliminar operações típicas de acabamento manual. Porém, esta tecnologia é algo novo e a carência de conhecimento e geometria de corte apropriada tem impedido a aplicação mais ampla de HSM.

Muitas vantagens da HSM têm sido citadas. Entretanto, KRAMER (1987); DEWES \& ASPINWALL (1997); KIRSCHNIK (1997); SCHULZ (1999); ANDRAE (1999b) e CHRISTOFFEL (2001) comentam que existem também notáveis desvantagens que precisam ser consideradas, sendo estes os pontos principais:

Alto nível de desgaste da ferramenta;

* Necessidade de ferramentas e máquinas-ferramentas de maior custo (especiais);

* Eixos-árvore especiais, de alto custo e com baixa durabilidade dos mancais (tipicamente 5.000 - 10.000 horas na máxima velocidade rotacional);

$\therefore$ Balanceamento do ferramental;

Sistema de controles especiais e parâmetros tecnológicos para a usinagem otimizada, os quais ainda não são totalmente conhecidos e dominados.

É importante salientar que as desvantagens descritas, devem-se principalmente ao fato de que a usinagem com alta velocidade de corte é uma tecnologia recente. Com o passar do tempo, novos estudos adicionarão informações 
que permitirão a utilização cada vez mais freqüente desta tecnologia. Este trabalho complementa a literatura sobre o torneamento com alta velocidade de corte em superligas à base de níquel, uma vez que existem poucas publicações sobre o assunto, e revela importantes contribuições no que se refere ao comportamento da força de corte, temperatura, emissão acústica, mecanismos de desgaste e integridade superficial em condições de alta velocidade de corte.

\subsubsection{Máquinas-ferramentas para HSM}

As solicitações cinemáticas e dinâmicas a que são submetidas as máquinas e ferramentas durante o processo de usinagem com alta velocidade de corte exigem uma nova maneira de construção de máquinas-ferramentas, no que se refere ao projeto e características construtivas. São máquinas denominadas de alta velocidade (high speed machines - HSMach). Entre as novas concepções empregadas nestas máquinas, os novos eixos-árvore e motores de acionamento possibilitam acelerações significativamente maiores do que as máquinas convencionais. Isso requer das máquinas condições extremas de lubrificação e rigidez. Além disso, outra grande modificação empregada nestas máquinas é a utilização de motores lineares que possibilitam o alcance de altas velocidades de avanço sem perdas significativas de potência disponível no eixo-árvore. Tais motores constituem o elemento-chave de diferenciação de uma máquina HSM e estão intimamente relacionados ao emprego de um novo conceito de projeto de máquina, possibilitando uma grande flexibilidade associada aos recursos da tecnologia HSM.

Deve-se ainda ressaltar que o emprego destas máquinas impulsionou o desenvolvimento de comandos CNC especificamente adaptados à HSM, com alterações conceituais nos algoritmos de software e, é claro, alterações profundas de hardware.

Estes equiparnentos possuerî particularidades de concepção e construção singulares, onde tudo é planejado para a obtenção do máximo desempenho do processo em HSM. Os centros de usinagem de alto desempenho disponíveis no mercado oferecem rotações do eixo-árvore de 10.000 - $50.000 \mathrm{rpm}$, potência 7.5 - 40 $\mathrm{kW}$ e velocidade de avanço de 10-60 m/min (DEWES \& ASPINWALL, 1997). 


\subsubsection{Características construtivas de máquinas HSM}

O conceito que envolve a escolha de uma máquina HSM deve ser sedimentado no tipo de aplicação em que ela será utilizada e quais serão os requisitos mínimos desta aplicação. Pode-se afirmar que não existem máquinas HSM para aplicações universais. Para cada caso particular de usinagem deverão ocorrer modificações nos componentes da máquina, a fim de adequar o equipamento às novas exigências do processo. A seguir estão alguns tópicos resumidos sobre as características construtivas e operacionais destas máquinas:

Para obtenção de um bom desempenho dinâmico, em geral a base da máquina deverá ser fabricada em concreto polimérico, o que garante um componente para absorção em altas solicitações bastante favorável. O seu efeito de amortecimento estrutural, aproximadamente 10 vezes maior do que o ferro fundido ou de construções de aço soldadas, reduz os problemas de vibração. Outros fatores importantes na elaboração do projeto, concepção e escolha de um equipamento HSM são seus eixos-árvore, os carros de translação auxiliares, as guias, os fusos de avanço e os sistemas de controle CNC (LEWIS apud NOVASKI \& CORRÊA, 1998 e SCHULZ, 1999).

- Como regra geral, de acordo com WALZ (1996) e SCHULZ (1999), o projeto do eixo-árvore deve considerar um motor integrado, ou linear, cuja eliminação dos elos de transmissão cinética resulta na ausência total de elementos de transmissão mecânica na direção do movimento dos eixos de avanços. Depois do surgimento do motor de acionamento direto da árvore, o motor linear é o desenvolvimento lógico cuja idéia conceitual básica é substituir componentes mecânicos por eletrônicos integrados em máquinas-ferramentas para alta velocidade de corte. Desta maneira, o uso de construções compactas e rígidas permite o alcance de freqüências críticas elevadas, em comparação às máquinas normais. A capacidade de um eixo-árvore de alta velocidade é caracterizada pelos seguintes parâmetros essenciais: velocidade, capacidade de carga, precisão, rigidez e durabilidade. A FIGURA 2.8 apresenta esquematicamente um típico projeto de motor para máquinas HSM. 


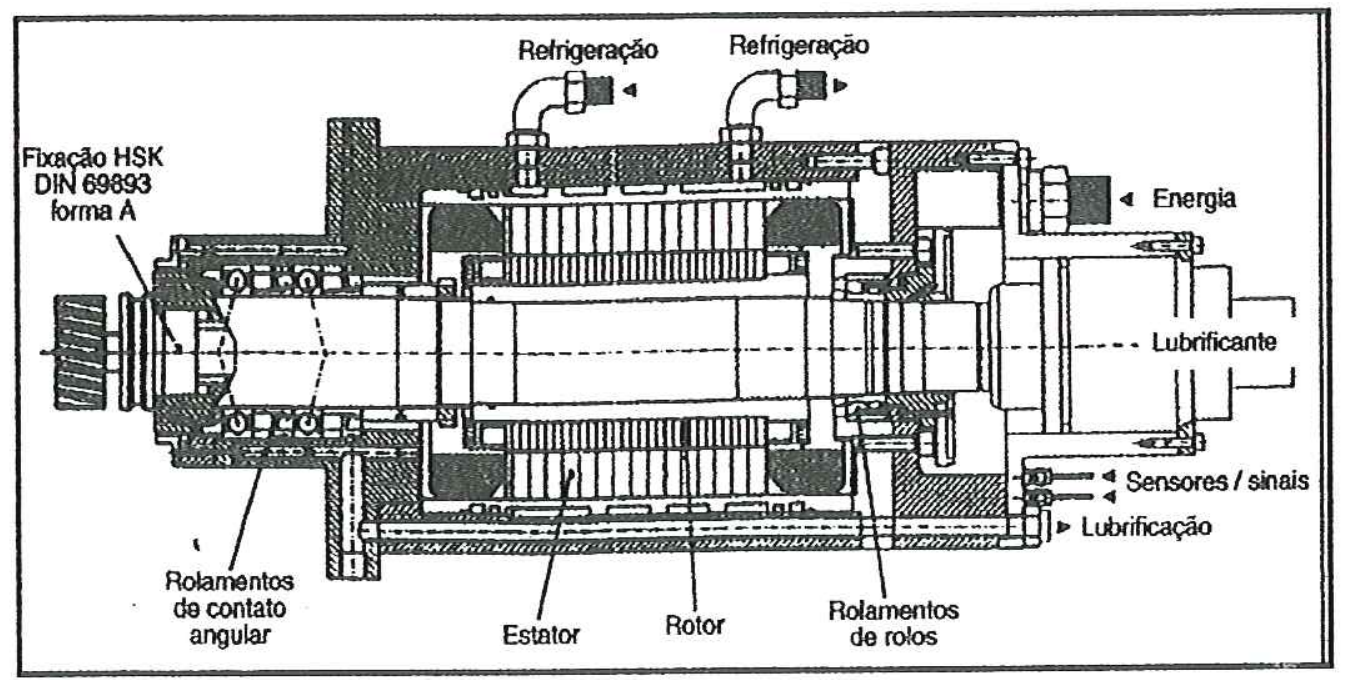

FIGURA 2.8 - Construção Típica de Motor para HSM (NOVASKI \& CORRÊA, 1998).

Nestes motores são encontrados mais comumente rolamentos de cerâmica, mas também podem ser utilizados rolamentos especiais, mancais magnéticos, hidrostáticos ou aerostáticos, buscando a maximização do torque, resultando em vibração e atrito mínimos, podendo alcançar um número $\mathrm{DN}$ de até $2,5 \times 10^{6}$ $\mathrm{mm} / \mathrm{min}$. As esferas de material cerâmico usadas para a construção destes mancais tem baixos coeficientes de expansão linear e expansão térmica, de tal forma que é pequena a faixa de aumento da temperatura sob rotação em alta velocidade. $\mathrm{O}$ material cerâmico também tem elevada resistência ao calor e à corrosão e baixa densidade, portanto, o engripamento do mancal pode ser melhor controlado (ASHLEY, 1995; DEWES \& ASPINWALL, 1995; MAJIMA, 1996; e DESTEFANI, 1997). Os rolamentos de esferas de contato angular tem sido usado com sucesso em eixos-árvore de alta velocidade, como resultado das suas propriedades, características de bom balanceamento. $\mathrm{O}$ diâmetro da montagem será limitado principalmente pela velocidade periférica (força de inércia ou centrífuga) e pelas características do material utilizado. WECK et al. (1999) apresentam uma melhoria no desempenho de rolamentos de rolos atrayés de revestimentos nas pistas. Fazendo isto, muda a combinação de materiais no "tribocontato", com um efeito positivo sobre o comportamento do desgaste e da temperatura. A FIGURA 2.9 apresenta um resumo e uma avaliação dos revestimentos testados. A avaliação dos revestimentos é baseada em testes com 
tribomáquinas padronizadas. Com relação à capacidade de carga, força de aderência, força de abrasão, dureza e resistência à fadiga, o revestimento de TiAlN apresenta os melhores resultados. Para esse revestimento metálico muito duro, bem conhecido do setor de revestimento de ferramentas, a FIGURA 2.9 mostra também uma fotografia de uma fratura feita com um microscópio eletrônico de varredura (SEM). A principal vantagem das pistas revestidas é o reduzido atrito no contato dos rolos. Esse atrito, em níveis mais elevados de velocidade, conduz a uma alta temperatura no mancal, o que se torna um fator limitante.

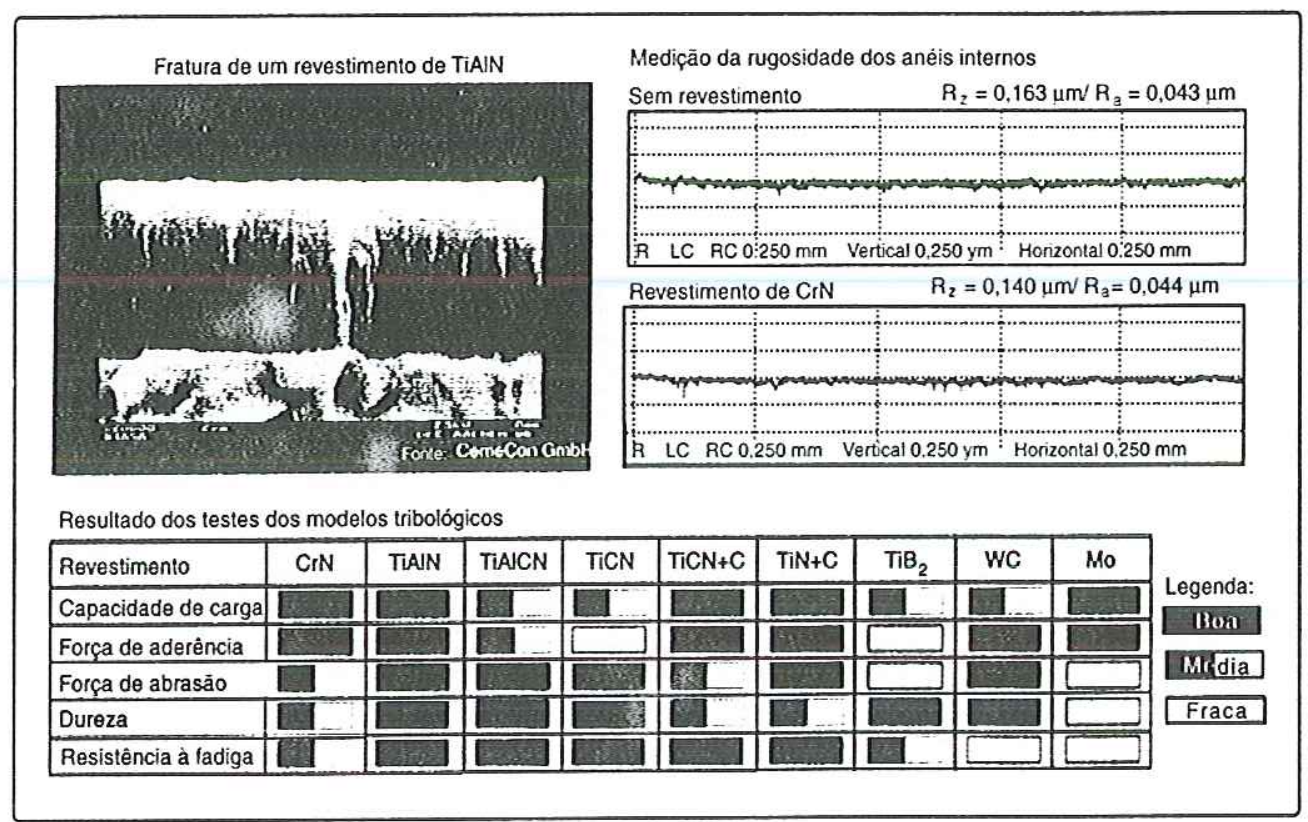

FIGURA 2.9 - Propriedades dos Revestimentos (WECK et al. 1999).

Além do torque fornecido pelo motor, outra exigência fundamental para máquinas HSM são as altas acelerações necessárias à manutenção das taxas de avanço constante, garantindo a precisão dinâmica do conjunto (HEISEL \& GRINGEL, 1996 e NOVASKI \& CORRÊA, 1998). Uma das mais eficientes maneiras para satisfazer estas duas exigências é através da redução da massa dos componentes móveis. A utilização de construções leves permitem aumentos significativos da aceleração, especialmente com a utilização de motores lineares. Visando esta condição, todos os componentes da máquina devem ser produzidos mantendo-se uma relação de peso bastante reduzida, possibilitado por novos materiais como o alumínio, titânio e plásticos reforçados. Alguns destes materiais 
proporcionarão uma redução no momento de inércia em torno de $40 \%$. Como as forças de corte são notoriamente reduzidas no corte a alta velocidade, as cargas devidas à inércia de massas tornam-se mais importantes para o projetista. Além do material, outros fatores que podem ser utilizados para este fim são a otimização da geometria estrutural, a melhoria conceitual do projeto e busca por melhores sistemas de fixação.

* Praticamente todos componentes móveis das máquinas HSM possuem guias lineares, porque elas apresentam redução do coeficiente de atrito e garantias de melhor precisão, em virtude da utilização de rolos e esferas. De acordo com VOLL apud NOVASKI \& CORRÊA (1998), pode-se afirmar que a opção de eixos-árvore de esferas recirculantes ocasiona a redução de folgas e do próprio momento de inércia, aumentando o avanço por rotação em até três vezes. As tecnologias dos servomotores de acionamento conjugado aos fusos de esferas recirculantes apresentam ótimas características dinâmicas. Oferecem controle de reversão com baixas constantes de tempo e torques elevados também em curtos espaços de tempo.

SCHMITT (1996) apresenta as influências das massas em movimento linear sobre o comportamento da aceleração, para o conceito de fusos de esferas recirculantes e de um motor linear, que são indicadas na FIGURA 2.10. Devido à transmissão de movimento do acionamento de parafuso, a aceleração do fuso de esferas recirculantes é relativamente independente do tamanho das massas em movimento linear. A potência de aceleração é comandada fundamentalmente pelos momentos de inércia dos eixos-árvore e do motor e pelo passo da rosca. $\mathrm{O}$ comportamento do motor linear é completamente diferente. A sua potência de aceleração é inversamente proporcional à massa em movimento linear, de forma que cada quilo de massa economizado na massa da mesa leva a um aumento direto das acelerações possíveis. Manter um corte com alta velocidade exige taxas de avanço substancialmente mais alı́as do que aquelas requeridas para a usinagem convencional. As máximas acelerações que hoje são possíveis nas máquinas-ferramentas construídas com motores lineares estão situadas na faixa de 20 a $30 \mathrm{~m} / \mathrm{s}^{2}$ (SCHULZ, 1999). De acordo com SCHMITT (1997), as velocidades de avanço dos sistemas hoje disponíveis no mercado, formados por 
motores de acionamento rotativo e seus sistemas de transmissão, são de 30 a 60 $\mathrm{m} / \mathrm{min}$. As velocidades de avanço úteis para a usinagem, no entanto, estão significativamente abaixo desses valores.

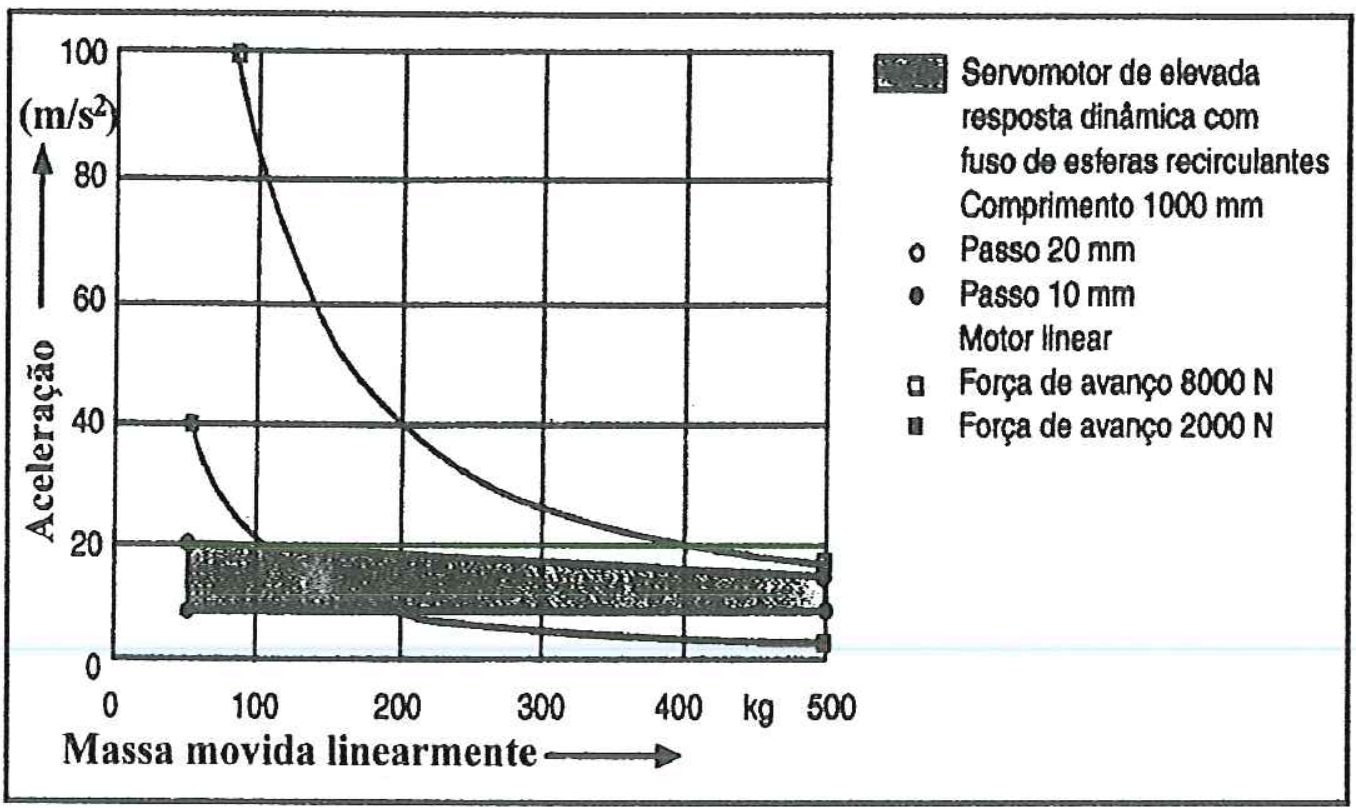

FIGURA 2.10 - Comparação da Aceleração Praticável de um Acionamento de Fuso de Esferas Recirculantes e de um Motor Linear (SCHMITT, 1996).

Devido às elevadas velocidades de avanço envolvidas em máquinas HSM, as exigências quanto à velocidade de processamento do comando são bastante severas. Limitações do processo convencional $\mathrm{CNC}$, que até então eram irrelevantes para o processo de usinagem, passam a ter um novo enfoque para a manufatura em HSM. DISTLER (1996); HOCK \& JAJENSKI (1996); GEIST (1999) e SCHÜTZER et al. (2001) afirmam que os atuais sistemas CNC são extremamente lentos para as taxas de avanço requeridas, uma vez que o tempo de processamento da sentença de comando é mais alto do que o tempo de acesso aos pontos programados para a trajetória de corte. O tempo de processamento de bloco (TPB) é o tempo médio necessário para o controle numérico processar uma linha de programa e enviar informações de comando para o acionamento dos servos-motores. Durante muitos anos os fabricantes de $\mathrm{CNC}$ acreditaram que seus produtos eram capazes de usinar em alta velocidade pelo fato de que processavam programas de usinagem com rapidez. Esta crença se devia a pouca 
experiència com essa tecnologia. Além disso, os programas $\mathrm{CNC}$ utilizam uma elevada quantidade de linhas de comando, o que exige programar muitos pontos de trajetória. Cada ponto corresponde a uma linha de programa, com uma instrução de posicionamento. A conseqüência direta desta lentidão dos atuais CNC é a parada das máquinas HSM para a espera do processamento da sentença de comando. Logo, os comandos em máquinas HSM devem possibilitar o processamento de muitas sentenças à frente dos movimentos das máquinas. Uma das soluções encontradas para viabilizar a introdução deste novo conceito de CNC é a utilização da interpolação flexível, recurso que agrupa diversas sentenças de interpolação linear em uma única sentença (ASHLEY, 1995). Assim, é reduzido o tempo de resposta para as acelerações e desacelerações decorrentes da modificação da trajetória e da alteração das velocidades de avanço. Por outro lado, os sistemas CAD-CAM existentes são também inadequadamente preparados para programação em HSM, sendo o mesmo particularmente importante na tecnologia do processo. Neste ponto, o suporte ao usuário carece de uma melhoria considerável, para que ele tenha liberdade, confiança e, consequentemente, coragem necessárias para projetar operações de usinagem mais revolucionárias e de maior desempenho principalmente no fresamento.

* A eliminação dos cavacos é outro item de grande importância em condições severas de usinagem, como as que ocorrem em máquinas HSM. Para facilitar a remoção dos cavacos, muitas máquinas HSM possuem sistemas que possibilitam fixar a peça verticalmente, facilitando a retirada dos cavacos da área de corte, mesmo que seja por gravidade. Em relação aos sistemas de refrigeração, a única grande alteração, passa a ser a obrigatoriedade de os mesmos serem submetidos a altas pressões (SCHULZ, 1994).

* Como conseqüência direta das altas velocidades envolvidas no processo de HSM, grandes volumes de cavacos são removidos e. lançados à distância e grande vazão de fluidos de corte é necessária, o que torna o encapsulamento do local de trabalho quase obrigatório. Neste aspecto, proteções contra a quebra de ferramenta são de extrema prioridade. As cabines de encapsulamento devem ter resistência suficiente para absorver energia de impacto, caso ocorram quebras ou 
lançamento de componentes em altas velocidades conforme ilustra a FIGURA 2.11. Se um inserto quebrar e soltar-se numa ferramenta de corte a alta velocidade, produzirá forças de intensidade suficiente para penetrar na área de proteção como se fosse uma bala de arma de fogo. Em casos extremos, a máquina inteira deve ser colocada numa área protegida, onde nenhuma pessoa possa entrar enquanto o equipamento estiver em operação. Além destas providências, deve haver sistemas de controle ativos (os chamados sistemas de controle durante o processo) que garantam um funcionamento perfeito nos processos com alta velocidade (SCHULZ, 1994 e NOVASKI \& CORRÊA, 1998).

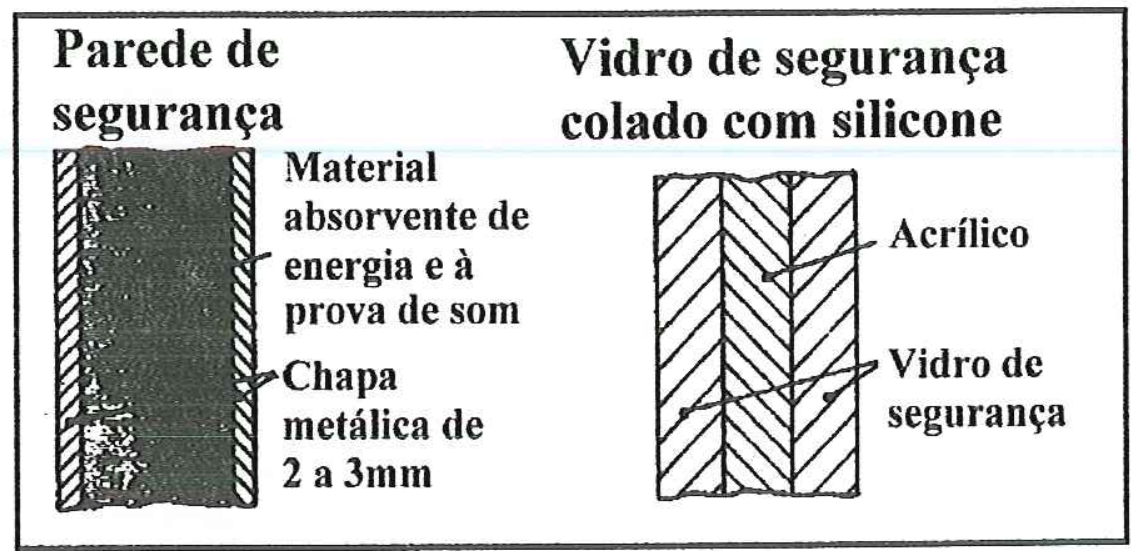

FIGURA 2.11 - Componentes de uma Cabine de Segurança (SCHULZ, 1994).

* Outro fator de bastante relevância em HSM são os mecanismos de fixação das ferramentas, onde a rigidez deve considerar o alto nível de solicitações. A interface ferramenta/eixo-árvore é o ponto onde ocorre a maior concentração de esforços entre a peça e a máquina. Esta interface deve garantir, além das condições usuais de rigidez e requisitos gerais de corte (transmissão de torque, por exemplo), ótimas condições geométricas (batimento e concentricidade) e principalmente possibilitar troca rápida de ferramentas. Uma boa conexão entre ferramenta HSC e máquina-ferramenta é a interface HSK DIN 69893 (cone de haste vazada), que foi projetada visando a usinagem com alta velocidade. Este sistema já provou, em testes, suportar até quatro vezes o esforço gerado na usinagem. Desta maneira, está atendida também a segurança (BECK, 1998). 
A FIGURA 2.12 resume os elementos problemáticos no projeto de um sistema de mancais de eixo-árvore adequado para o corte com alta velocidade. Eles podem ser identificados nos mancais, no eixo-árvore, no acionamento, na interface da ferramenta e na transmissão rotativa (WECK et al. 1999).

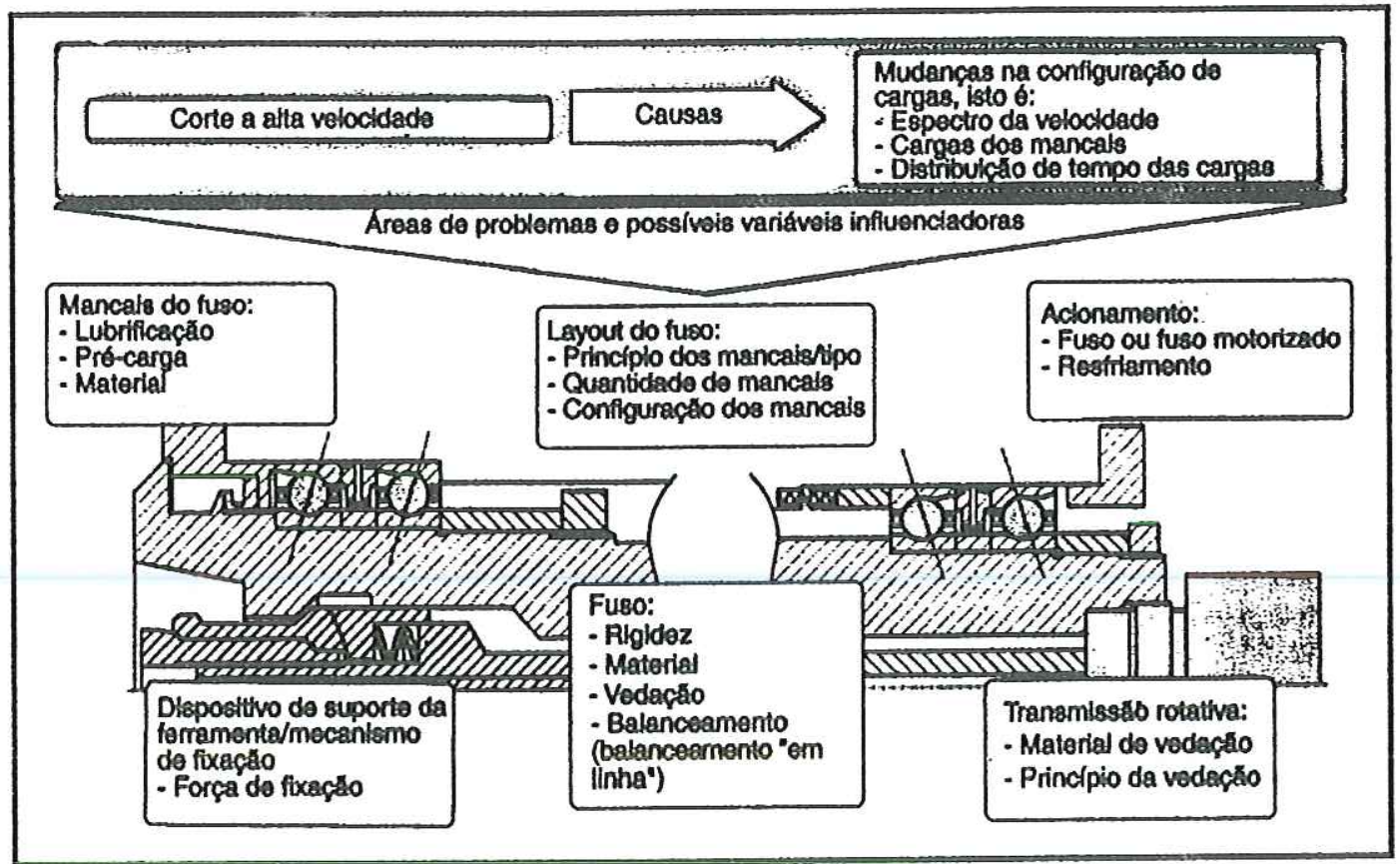

FIGURA 2.12 - Projeto de Sistema de Eixos-árvore para Altas Velocidades: Áreas Problemáticas (WECK et al. 1999).

Com o aumento das velocidades do eixo-árvore, o balanceamento insuficiente provoca problemas dinâmicos em níveis cada vez maiores. O eixo-árvore afeta o comportamento estático e dinâmico do sistema do fuso, principalmente por sua resistência à flexão e momento de inércia. Os materiais alternativos como fibras de carbono e cerâmicas irão desempenhar um papel mais importante no futuro. 


\subsubsection{Ferramentas de corte para HSM}

As ferramentas de corte a serem utilizadas em processos com HSM devem ter aspectos de projeto e confecção visando atuar basicamente em quatro aspectos: material da ferramenta, geometria da ferramenta, sistema ferramenta-máquina e design da ferramenta.

Os materiais mais apropriados para aplicação em usinagem com HSC são os diamantes policristalinos (PCD) para materiais não-ferrosos especialmente alumínio, atingindo-se vidas de ferramentas elevadas com altos níveis de qualidade superficial e precisão e o nitreto cúbico de boro $(\mathrm{CBN})$ para materiais ferrosos principalmente operações de acabamento. Os desgastes apresentados demostram que eles possuem maior resistência à abrasão em altas temperaturas, em comparação com as pastilhas recobertas por carboneto de titânio (TiC), nitreto de titânio (TiN), carbonitreto de titânio $[\mathrm{Ti}(\mathrm{C}, \mathrm{N})]$, óxido de alumínio $\left(\mathrm{Al}_{2} \mathrm{O}_{3}\right)$ e materiais cerâmicos cujos aperfeiçoamentos recentes levaram a um aumento da tenacidade. Este fato é de grande importância, porque na usinagem com HSC as temperaturas na interface são extremamente elevadas, devido às altas velocidades de corte empregadas, e do atrito entre peça e ferramenta. Assim, ferramentas de aço rápido, que em temperaturas da ordem de $400^{\circ} \mathrm{C}$ já começam a perder a dureza, são inadequadas. O comportamento destes materiais varia amplamente em função de sua composição e estrutura, bem como das características do material usinado (BECK, 2000).

As primeiras ferramentas de PCBN foram lançadas na metade dos anos 70, e atualmente existem no mercado, uma variedade de ferramentas com alta ou baixa concentração de $\mathrm{CBN}$, com aglomerantes de base metálica ou cerâmica.

A principal vantagem do PCBN é a sua dureza a quente extremamente alta (aproximadamente $1800 \mathrm{HV}$ a $1000^{\circ} \mathrm{C}$ ) combinado com a sua solubilidade no ferro relativamente baixa e sua boa tenacidade à fratura. Estas propriedades permitem seu uso eficaz para usinar aços temperados na faixa de 50 a 65 HRC. Com o advento das ferramentas de corte PCBN, tornou-se possível alterar a seqüência de operações tradicionalmente aplicada a aços temperados. Anteriormente, a peça era usinada próxima a sua geometria final na condição recozida, era tratada termicamente à dureza desejada e então usinada nas dimensões e tolerâncias finais através de operações de retificação. Usando ferramentas de PCBN é possível tornear e fresar 
aços no estado temperado até a forma final, eliminando desta forma as operações de retificação e os problemas associados à distorção da peça durante o tratamento térmico. Outra grande aplicação de PCBN está na fabricação de moldes para injeção de alumínio ou plástico usando-se fresamento de alta velocidade.

Diversas classes de PCBN podem ser encontradas de acordo com porcentagem de CBN presente (entre 30 e 98\%), e do material da segunda fase, que pode ser uma liga de Ni-Co-TiC-WC, ou ainda materiais cerâmicos como TiN ou $\mathrm{AlB}_{2} / \mathrm{AlN}$. O tamanho dos cristais de $\mathrm{CBN}$ varia entre 1 e $10 \mu \mathrm{m}$. Em geral, a medida em que o teor de CBN aumenta, a dureza da ferramenta aumenta também. Três são os principais produtores mundiais de PCBN: DeBeers, Sumitomo e General Electric (ABRÃO et al. 1993 e COELHO et al. 1995).

Segundo ELBESTAWI et al. (1997), fresas de acabamento com ponta esférica de PCBN tem sido usadas recentemente no fresamento de alta velocidade de matrizes e moldes. Os materiais das peças são aços ligados temperados de dureza 30 - 45 HRC. A recomendação para a velocidade de corte fica entre $500-1000 \mathrm{~m} / \mathrm{min}$.

Comumente, as ferramentas cermets são também utilizadas em HSM. SCHULZ \& MORIWAKI (1992) e TÖNSHOFF (1994) comentam que as vantagens das ferramentas cermets estão relacionadas à alta resistência ao desgaste, alta estabilidade química e dureza a quente e reduzida suscetibilidade na formação da aresta postiça de corte (APC). Este grupo é constituído por TiC, TiN e geralmente tem Ni-Co-Mo como elementos de ligação. Pode ocorrer também a presença de outros elementos, tais como $\mathrm{Al}, \mathrm{Co}$, Mo ou composto de $\mathrm{Mo}_{2} \mathrm{C}, \mathrm{TaC}, \mathrm{NbC}, \mathrm{WC}$, AIN, TaN e outros (KLOCKE \& PÖHLS, 1998 e MACHADO \& SILVA, 1999). Uma desvantagem dos cermets é a baixa tenacidade comparada aos carbetos de tungstênio. A tenacidade indica a capacidade da ferramenta suportar elevadas forças de corte e cargas de impacto causadas por cortes interrompidos, o que acarreta a fratura e o lascamento da aresta de corte da ferramenta. A estabilidade química esta relacionada à resistência ao desgaste químico da ferramenta por difusão ou dissolução, o que afeta basicamente a taxa de formação de crateras na aresta de corte (ABRÃO et al. 1993). Por esta razão, sua principal aplicação está em operações de acabamento em máquinas rígidas. 
O material cerâmico possui algumas propriedades que são muito interessantes para uma ferramenta de usinagem de alta velocidade, tais como: dureza à quente e a frio, resistência ao desgaste, alta resistência à deformação plástica, alta resistência à compressão e excelente estabilidade química, o que evita o desgaste por difusão, sendo muito importante quando se usina em altas velocidades e altas temperaturas. Algumas propriedades destes materiais, porém, fazem com que sua utilização na usinagem não seja tão fácil, que são: baixa condutividade térmica, o que logicamente dificulta a transferência de calor e principalmente, baixa tenacidade, o que facilita o trincamento e a quebra da ferramenta. Desde de 1970, o desenvolvimento de ferramentas cerâmicas tem progredido notavelmente. Estes desenvolvimentos têm habilitado as ferramentas cerâmicas para serem usadas na usinagem de vários tipos de aços, ferro fundido, não-ferrosos e superligas à base de níquel em altas velocidades e avanços (ABRÃO et al. 1993 e JIANXIN \& XING, 1997). As ferramentas cerâmicas exibem uma resistência à compressão que varia pouco com a temperatura, ao contrário das de metal duro, que mostram uma queda rápida na resistência à compressão quando a temperatura se eleva. As ferramentas cerâmicas devem ter ângulos negativos ou bordas arredondadas ou chanfradas para compensar a sua baixa resistência à tração e ao cisalhamento e para tirar vantagens da sua alta resistência à compressão e ao desgaste. As geometrias negativas são recomendadas porque os insertos com ângulos positivos não podem resistir ao choque mecânico e térmico de entrada e saída das peças. A geometria negativa coloca a ponta da ferramenta cerâmica sob força de compressão e elimina a formação de fissuras devido à tensão (EZUGWU \& WALLBANK, 1988).

De maneira geral, as ferramentas cerâmicas podem ser classificadas em dois grupos, onde no primeiro se enquadram os materiais a base de óxido de alumínio, tamúém conhecido como alumina. Fazem parte dessa categoria, alumina reforçada com zirconia $\left(\mathrm{Al}_{2} \mathrm{O}_{3}+\mathrm{ZrO}_{2}\right)$, alumina mista $\left(\mathrm{Al}_{2} \mathrm{O}_{3}+\mathrm{TiC}\right)$ e alumina reforçada com whiskers (fibras curtas e orientadas aleatoriamente) de carboneto de silício $\left(\mathrm{Al}_{2} \mathrm{O}_{3}+\right.$ $\mathrm{SiC}_{\mathrm{w}}$ - WRA). No segundo grupo são encontrados os materiais a base de nitreto de silício $\left(\mathrm{Si}_{3} \mathrm{~N}_{4}\right)$.

As ferramentas de alumina reforçada com zirconia apresentam dureza semelhante ao metal duro à temperatura ambiente $(\cong 1700 \mathrm{HV})$ além de boa 
estabilidade química comparada aos carbonetos e nitretos. As ferramentas de alumina possuem tenacidade de fratura bem inferior ao metal duro e baixa resistência ao choque tanto mecânico quanto térmico e, por isso, devem ser utilizadas sem fluido de corte. A adição da zirconia $\left(\mathrm{ZrO}_{2}\right)$ à matriz de alumina tem como objetivo principal melhorar a sua tenacidade.

Segundo TRENT (1984); VIGNEAU et al. (1987); RICHARDS \& ASPINWALL (1989); PASHBY \& KHAMSEHZADEH (1990); THANGARAJ \& WEINMANN (1992) e JIANXIN \& XING (1997), as pastilhas de cerâmica reforçada com whiskers de carbonetos de silício ( $\mathrm{SiC}$ ) foram desenvolvidas em meados dos anos 80 e são indicadas para usinagem com alta velocidade de superligas à base de níquel. Além de dar maior resistência, as inclusões de $\mathrm{SiC}$ aumentam a condutividade térmica e a dureza mas, infelizmente, a estabilidade química é reduzida, e há evidência de que isto influencia a taxa de desgaste quando se usinam superligas à base de níquel de diferentes composições. Bom desempenho tem também sido revelado no torneamento de alta velocidade de aço endurecido e ferro fundido. Em geral estas fibras apresentam um diâmetro de 0,5 a $1 \mu \mathrm{m}$ e um comprimento de 10 a $80 \mu \mathrm{m}$. As ferramentas são confeccionadas por pressão a quente da mistura de pó de alumina/whiskers de SiC por uma hora a temperatura de 1250$2000^{\circ} \mathrm{C}$ sob pressão de 28-29 MPa num forno a vácuo de 1,3 MPa. Sua adição à matriz aumenta principalmente a tenacidade de fratura e a resistência ao choque térmico. Elas não somente apresentam resistência à altas temperaturas, mas também tem baixo coeficiente de expansão térmica, uma propriedade que é muito desejável no material da ferramenta de corte.

Cerâmicas a base de nitretos de silício tem sido usadas como ferramentas de corte desde o princípio dos anos 80. Devido ao baixo coeficiente de expansão térmica (vide TABELA 2.3) estes materiais apresentam excelente resistência ao choque térmico sendo recomendadas para a usinagem de ferro fundido.

THANGARAJ \& WEINMANN (1 $(992)$ afirmam que, apesar das diversas melhorias nas propriedades fisicas e controle do processo das ferramentas cerâmicas, usinagem de superligas à base de níquel utilizando tais ferramentas, tem-se obtido sucesso limitado, particularmente nas condições de desbaste, corte interrompido e usinagem com alta velocidade. 
A TABELA 2.3, compilada por RICHARDS \& ASPINWALL (1989) e ABRÃO et al. (1993) mostra algumas propriedades destes materiais, comparadas a um metal duro classe ISO M20 e ferramenta de PCBN.

TABELA 2.3 - Propriedades de ferramentas de corte cerâmicas comparadas com metal duro e PCBN (RICHARDS \& ASPINWALL, 1989 e ABRÃO et al. 1993)

\begin{tabular}{|c|c|c|c|c|c|c|}
\hline & \multicolumn{6}{|c|}{ MATERIAL } \\
\hline $\begin{array}{c}\text { Proprieda- } \\
\text { des }\end{array}$ & $\begin{array}{c}\text { Metal duro } \\
\text { M20 }\end{array}$ & Alumina mista & $\begin{array}{l}\text { Alumina } \\
\operatorname{com} \mathrm{SiC}_{\mathrm{w}}\end{array}$ & Sialon & $\begin{array}{l}\text { Alumina } \\
\text { branca }\end{array}$ & PCBN \\
\hline $\begin{array}{l}\text { Composição } \\
\text { típica (\% } \% \mathrm{~cm} \\
\text { volume) }\end{array}$ & $\begin{array}{c}89,5 \% \text { WC } \\
10 \% \text { Co } \\
0,5 \% \text { outros }\end{array}$ & $\begin{array}{c}55-60 \% \mathrm{Al}_{2} \mathrm{O}_{3} \\
30 \% \mathrm{TiC} \\
5-10 \% \mathrm{ZrO}_{2}\end{array}$ & $\begin{array}{l}71 \% \mathrm{Al}_{2} \mathrm{O}_{3} \\
28 \% \mathrm{SiC}_{\mathrm{w}} \\
1 \% \text { outros }\end{array}$ & $\begin{array}{l}77 \% \mathrm{Si}_{3} \mathrm{~N}_{4} \\
13 \% \mathrm{~N}_{2} \mathrm{O}_{3} \\
10 \% \mathrm{Y}_{2} \mathrm{O}_{2}\end{array}$ & $\begin{array}{c}90-95 \% \\
\mathrm{Al}_{2} \mathrm{O}_{3} \\
5-10 \% \mathrm{ZrO}_{2}\end{array}$ & $\begin{array}{c}50-90 \% \mathrm{CBN} \\
50-10 \% \\
\mathrm{TiN} / \mathrm{TiC}\end{array}$ \\
\hline $\begin{array}{c}\text { Dureza a } \\
25^{\circ} \mathrm{C}(\mathrm{HV})\end{array}$ & 1600 & 1900 & 2000 & 1600 & 1700 & 4000 \\
\hline $\begin{array}{c}\text { Dureza a } \\
1000^{\circ} \mathrm{C} \\
(\mathrm{HV})\end{array}$ & $\cong 400$ & 850 & 900 & 900 & 650 & 1800 \\
\hline $\begin{array}{c}\text { Tenacidade à } \\
\text { fratura } \\
\text { MPa.m }^{0,5}\end{array}$ & 13 & 2 & $5-8$ & 6 & 1,9 & 10 \\
\hline $\begin{array}{l}\text { Condutivida- } \\
\text { de térmica } \\
\mathrm{W} / \mathrm{m}^{\circ} \mathrm{C}\end{array}$ & 85 & $12-18$ & $25-32$ & 23 & $8-10$ & 100 \\
\hline $\begin{array}{l}\text { Módulo de } \\
\text { elasticidade } \\
\mathrm{KN} / \mathrm{mm}^{2}\end{array}$ & 580 & 420 & 390 & 300 & 380 & 680 \\
\hline $\begin{array}{c}\text { Coeficiente } \\
\text { de expansão } \\
\text { térmica } \\
10^{-6} \mu \mathrm{C}\end{array}$ & 5,5 & 8 & 6,4 & 3,2 & 8,5 & 5 \\
\hline $\begin{array}{l}\text { Tamanho do } \\
\text { grāo }(\mu \mathrm{m})\end{array}$ & $1-2$ & 1.2 & - & 1 & $1-2$ & $1-3$ \\
\hline
\end{tabular}




\subsubsection{Projeto, aplicações e eficiência das ferramentas}

De acordo com LISBOA (apud NOVASKI \& CORRÊA, 1998) e CHRISTOFFEL (2001), as ferramentas de corte e seus acessórios constituem outro elemento-chave no desenvolvimento da HSM, tanto em relação aos materiais quanto ao projeto. Deve-se dar especial atenção aos sistemas de fixação da ferramenta nas máquinas, devido aos altos esforços a que são submetidas. Muitas vezes estas ferramentas atingem velocidades de corte acima de $8.000 \mathrm{~m} / \mathrm{min}$ o que exige delas características como alta rigidez na fixação, tenacidade no corte e tolerância às altas temperaturas geradas pelo corte durante a usinagem.

Em comparação com as máquinas-ferramentas convencionais, a aplicação econòmica das máquinas HSM é profundamente influenciada pela escolha da tecnologia de corte correta. A geometria da ferramenta e a geometria do material, além da própria máquina, devem ser levadas em consideração e projetadas para uma faixa específica de HSM. Em HSM, modificações na aresta de corte podem melhorar o desempenho da operação e reduzir as tensões de corte resultantes. Isto pode ser usado para a fabricação de componentes leves de paredes finas ou eletrodos e permitem o fresamento nas dimensões reais mesmo com ferramentas longas.

Enquanto no torneamento com alta velocidade, que é feito com ferramental fixo, não existem tensões mais elevadas na ferramenta (exceto na aresta de corte), são exigidos requisitos mais apertados das ferramentas rotativas para HSM, como as fresas, devido às altas velocidades de rotação e forças centrífugas. As operações de fresamento compõem a grande maioria das aplicações em HSM. Para citar um exemplo, uma fresa de $80 \mathrm{~mm}$ de diâmetro, operando a $24.000 \mathrm{rpm}$, produz uma velocidade de corte de cerca de $6.030 \mathrm{~m} / \mathrm{min}$.

A FIGURA 2.13 apresenta uma linha de fresas desenvolvida especialmente para HSM. O conceito das fresas é diferente daquele das fresas típicas do tipo pastilha de diamante. As fresas consistem do menor número de partes necessárias. $\mathrm{O}$ corpo da fresa é feito de alumínio de alta resistência à tração, que permite rotações mais elevadas do que o aço. A aresta de corte de diamante é soldada diretamente à cápsulas de aço, fixadas ao corpo por meio de parafusos. O tempo de preparação é extremamente curto, devido à simplicidade da fresa (STOCKINGER et al., 1998). 


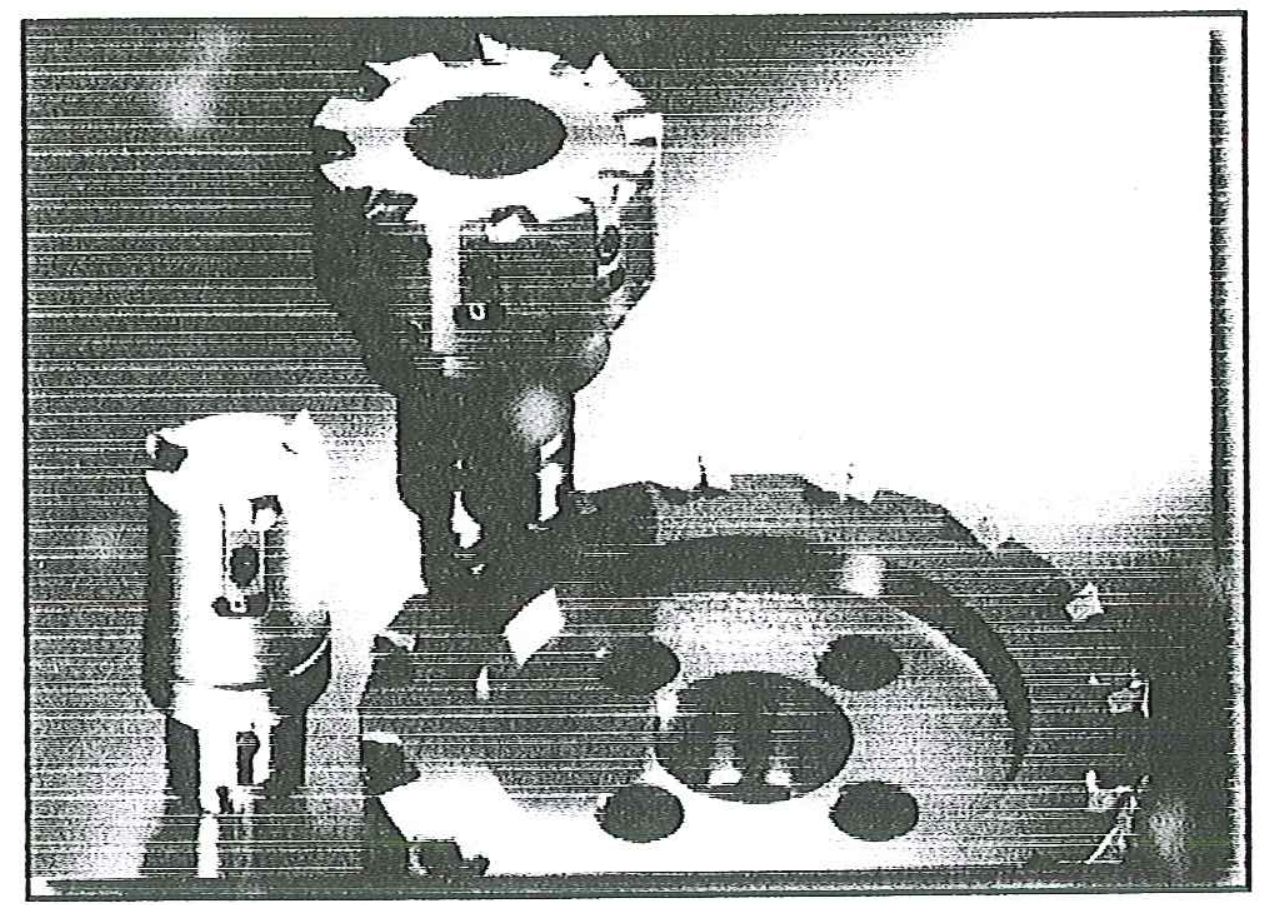

FIGURA 2.13 - Linha de Fresas para HSM (STOCKINGER et al., 1998).

De acordo com STOCKINGER et al. (1998) e CHRISTOFFEL (2001), o conceito das fresas para HSM foi analisado e otimizado de várias maneiras:

O projeto da ferramenta foi analisado através do método dos elementos finitos;

* A fresa foi operada até uma velocidade de rotação que a destruiu;

* A fresa foi operada até com 1,6 vezes a velocidade operacional aprovada e verificada quanto à deformação plástica;

* O movimento dinâmico das arestas de corte individuais foi medido durante a velocidade operacional aprovada;

* O nível de ruído em decibéis foi verificado na velocidade operacional aprovada.

O balanceamento das ferramentas é fundamental para a utilização da tecnologia com alta velocidade, e o PTW (Institut fuir Produktionsmanagement, Technologie und Werkzeugmaschinen), em Darmstadt, Alemanha, está desenvclvendo um projeto de pesquisa denominado "Balanceamento" para analisar detalhadamente esta questão, especialmente quanto aos seus efeitos sobre a qualidade superficial, a vida da ferramenta e a precisão dimensional que podem ser obtidas (KRESS, 1996). Para ferramentas compactas normalmente é suficiente o balanceamento estático, enquanto para ferramentas com grandes comprimentos em 
balanço, o balanceamento dinâmico é uma necessidade vital. É absolutamente recomendado que cada elemento: ferramenta, adaptador e eixo-árvore, sejam balanceados individualmente, rebalanceando-se a ferramenta e o adaptador em conjunto e, eventualmente, também rebalancear a ferramenta juntamente com o eixoárvore.

O resultado do desbalanceamento do suporte de ferramentas sobre a peça é a trepidação, ou ondulações na superficie do metal provocadas pelo movimento da ferramenta de corte. Trepidação de alta freqüência também pode resultar em acabamentos superficiais ruins e consequentemente a incapacidade de manter tolerâncias apertadas, o que significa mais peças refugadas. Os efeitos do desbalanceamento do suporte de ferramentas nas máquinas são ainda mais devastadores. As forças centrífugas provocarão tensões internas no eixo-árvore, normalmente resultando em falha prematura do mancal do eixo-árvore. Outro efeito negativo é a redução da vida da ferramenta de corte (LAYNE, 2001).

Um desafio para o futuro é a obtenção de ferramental com bom balanceamento, alta rigidez, alta precisão e sem folgas devido à rotação em alta velocidade. A classificação dos requisitos de qualidade de balanceamento para cada máquina rotativa é estipulado pela ISO 1940/1-1986. Outro fator de bastante relevância em HSM são os mecanismos de fixação das ferramentas, onde a rigidez deve considerar o alto nível de solicitações (WATANABE, 1996).

O calor gerado durante a formação de cavacos é principalmente eliminado junto com eles, o que quer dizer que o alto volume de cavacos que é produzido deve ser removido, de maneira que a ferramenta tem que ter canais de cavacos adequados. Além disso, a tecnologia HSM exige alta segurança tanto em termos de ferramenta quanto de máquina-ferramenta.

SCHULZ (1996) apresenta a performance de diversas ferramentas para HSC no fresamento de ferro fundido e alumínio conforme mostrado através das FIGURAS 2.14 e 2.15. Os metais duros (P40 e K10) com revestimento foram satisfatórios na usinagem do ferro fundido na faixa de velocidade de corte utilizada. Os revestimentos adquirem uma importância fundamental quando se pretende atender às exigências de elevada resistência ao desgaste em temperaturas altas e um baixo 
atrito. Isto exige dos revestimentos uma elevada dureza a quente, conduzindo ao desenvolvimento de novos materiais para revestimentos.

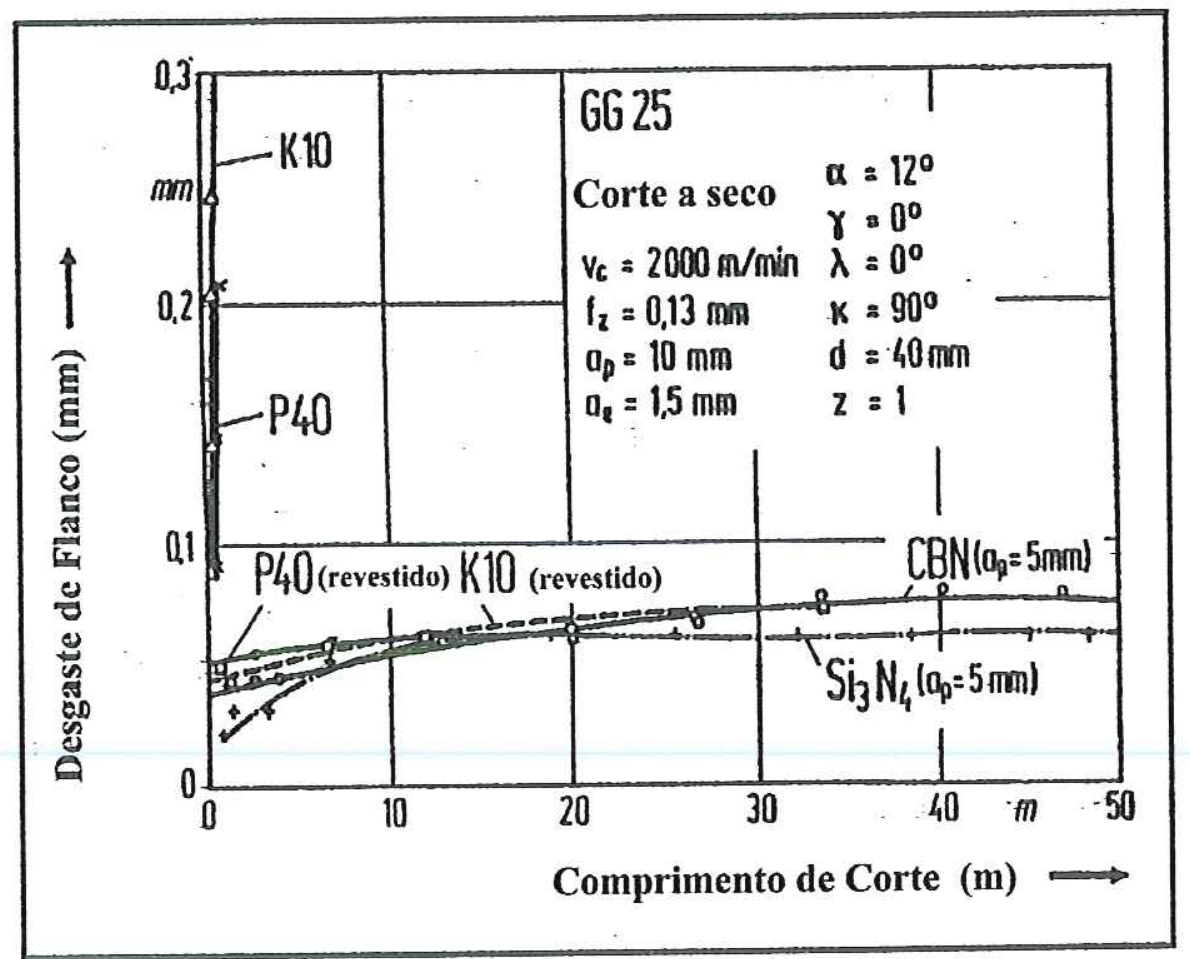

FIGURA 2.14 - Desempenho de Diferentes Ferramentas no Fresamento de Ferro Fundido (SCHULZ, 1996).

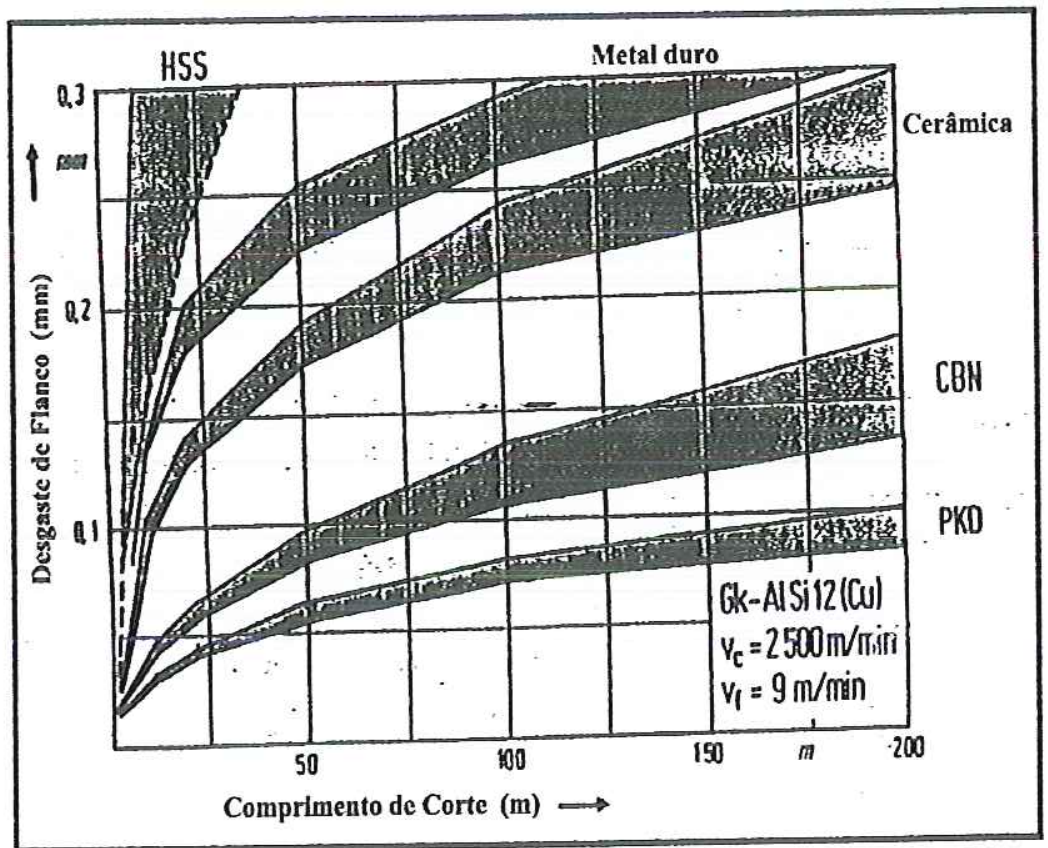

FIGURA 2.15 - Desempenho de Diferentes Ferramentas no Fresamento de Alumínio (SCHULZ, 1996). 
Ferramentas cerâmicas não são apropriadas no fresamento de alumínio devido à baixa resistência ao choque mecânico e térmico na entrada e saída da ferramenta, conduzindo para a quebra da aresta de corte. Diamantes policristalinos são indicados por ter alta resistência à abrasão, baixo coeficiente de atrito e boa condução térmica.

Por outro lado, SAHM (1996) afirma que o metal duro classe K 10 é material de corte padrão para usinagem com alta velocidade de ligas de alumínio e cobre, proporcionando vida da ferramenta satisfatória. Em ligas de alumínio-silício contendo mais que $12 \%$ de silício, a vida da ferramenta é reduzida bruscamente conforme ilustra a FIGURA 2.16. O silício é considerado um elemento abrasivo, e para estes materiais requer-se o uso de PCD. Em ligas de cobre, elementos como níquel, titânio e alumínio aumentam o desgaste da ferramenta.

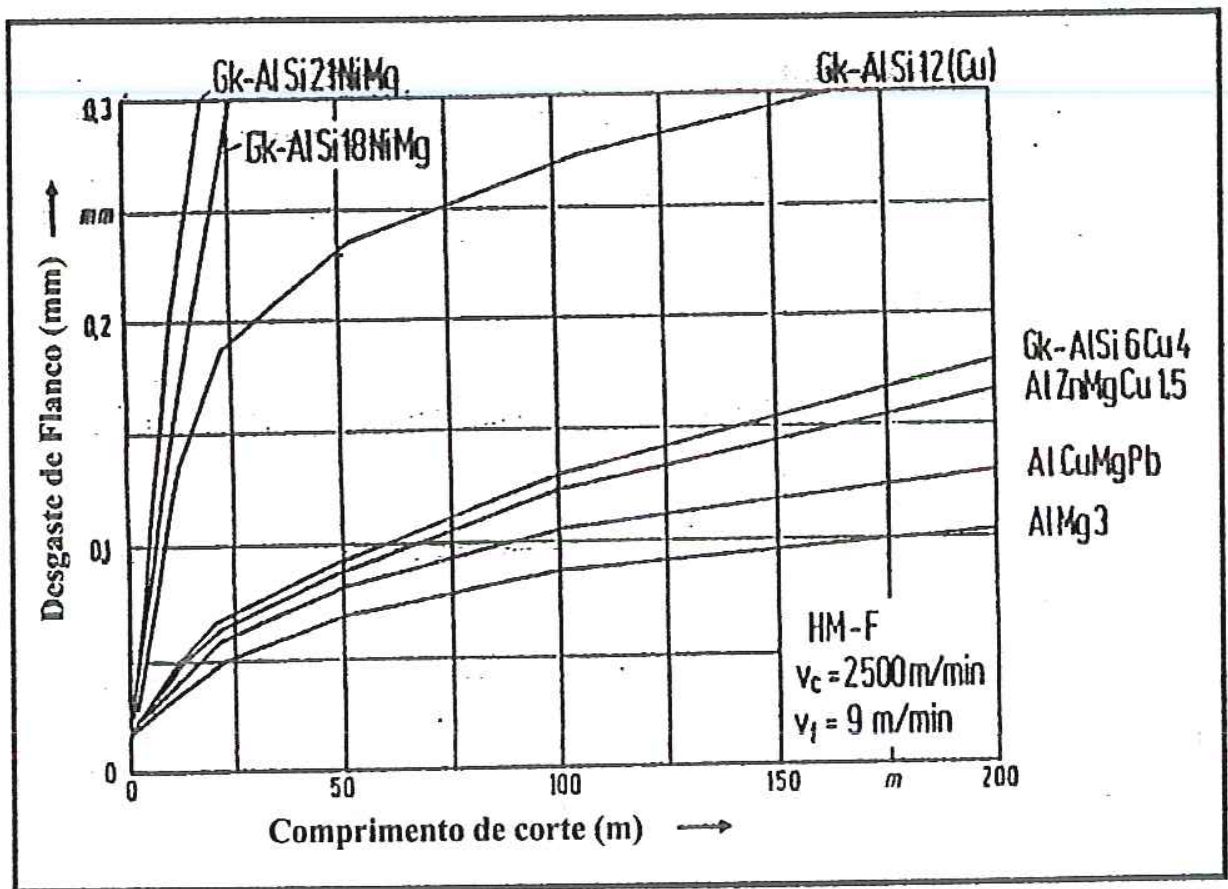

FIGURA 2.16 - Desgaste de Ferramenta de Metal Duro no Fresamento com Alta Velocidade de Diferentes Ligas de Alumínio e Cobre (SAHM, 1996). 


\subsubsection{Otimização da geometria de corte}

A geometria de corte das ferramentas utilizadas em usinagem tem influência decisiva no desempenho do processo. Muitos estudos já foram realizados principalmente em torneamento, fresamento e furação acerca da geometria das ferramentas e insertos utilizados nestes processos, com objetivo de se conseguir um melhor desempenho das mesmas. Maximização de vida da ferramenta é comumente objetivo no planejamento do processo de usinagem. Cinco parâmetros principais de processo introduzem influências na vida da ferramenta, sendo eles: material da peça, material da ferramenta, geometria da aresta de corte, condições de corte e tipo de operação. Todos estes fatores juntos afetam principalmente as forças de corte e a temperatura gerada durante a usinagem, sendo que estes irão determinar a vida da ferramenta (LO et al. 1998). Estes pesquisadores investigaram a influência dos ângulos de inclinação, folga e saída nos processos de furação e torneamento em aço SAE 1050 utilizando ferramentas de aço rápido, resultando em aumento de até $400 \%$ na vida da ferramenta (broca).

A otimização da seqüência de corte e dos parâmetros de usinagem é de grande importância no caso da usinagem de materiais dificeis de cortar. Entretanto, a geometria da aresta de corte tem também um significativo efeito no desempenho da usinagem. O processo de preparação de aresta, quando administrado corretamente, aumenta a resistência mecânica e de impacto da aresta de corte da ferramenta, prolonga a vida e melhora a qualidade superficial da peça. As opções de preparação de aresta atualmente utilizadas pelos fabricantes de ferramentas são: quina viva (sharp), raio de aresta (hone), aresta chanfrada (K-land) e aresta chanfrada com raio de aresta (K-land + hone). O raio de aresta pode variar de 0,0127 a $0,203 \mathrm{~mm}$ dependendo do tamanho do inserto e da aplicação de corte. O objetivo do raio de aresta é aumentar a resistência mecânica e de impacto da aresta de corte (STIER, 1988 e SHAFFER, 1999).

THIELE \& MELKOTE (1999) afirmam que, no torneamento do aço AISI 52100 endurecido utilizando insertos de PCBN, raio de aresta grande $(122 \mu \mathrm{m})$ geralmente produz camada branca contínua, enquanto que, raio de aresta pequeno 
$(23 \mu \mathrm{m})$ não produz camada branca. Por outro lado, usinagem com raio de aresta grande aumenta a tensão residual de compressão.

Geralmente é encontrada uma geometria de ferramenta ótima para uma máxima vida da ferramenta. Entre os vários parâmetros geométricos, o mais importante e freqüentemente negligenciado é o ângulo de folga. $\mathrm{O}$ comportamento geral do ângulo de folga está ilustrado na FIGURA 2.17 (KALDOR et al., 1986).

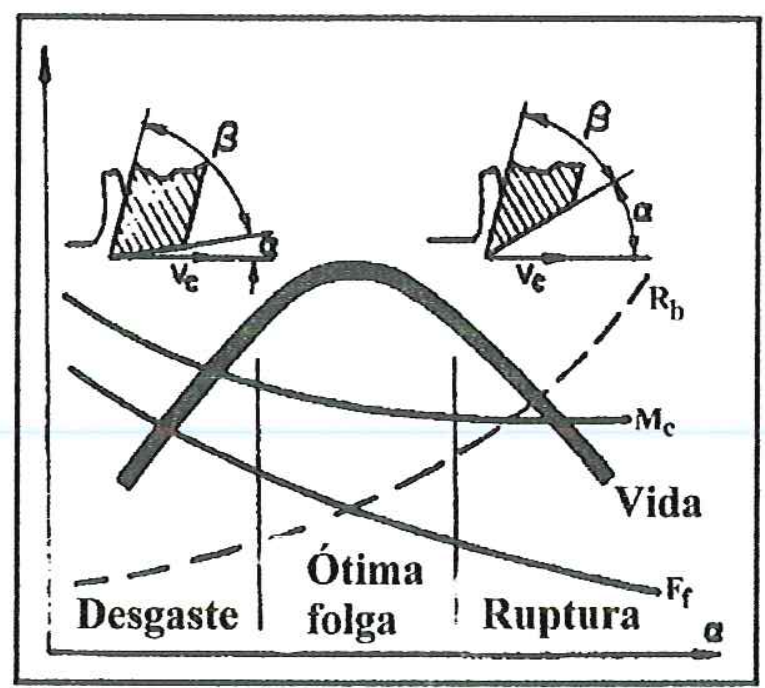

FIGURA 2.17 - Vida da Ferramenta versus Ângulo de Folga: $R_{b}$ - Resistência à ruptura; $\mathrm{M}_{\mathrm{c}}$ - Torque e $\mathrm{F}_{\mathrm{f}}$ - Força de avanço (KALDOR et al., 1986).

A inerente fragilidade das ferramentas de carbeto conduz a falhas prematuras por fratura frágil, especialmente no corte interrompido. Um pequeno chanfro negativo na aresta de corte pode reduzir a possibilidade de falha prematura ocasional por intermédio do fortalecimento da aresta, melhor dissipação do calor e distribuição de tensão favorável. SIKDAR et al. (1992) observaram em seus experimentos que as arestas de corte chanfradas são superiores às arestas arredondadas no que se refere ao lascamento, mas a força de avanço aumenta com o chanfro conduzindo a um maior desgaste de flanco. Eles demostraram que o chanfro pode ser otimizado para alcançar um compromisso entre o desgaste de flanco e o lascamento. Da mesma opinião, REN \& ALTINTAS (2000) demonstraram que a força de corte aumenta, o ângulo de cisalhamento e a temperatura na interface cavaco-ferramenta não sofrem alterações significativas quando o chanfro de aresta passa de $5^{\circ}$ para $40^{\circ}$ no torneamento com alta velocidade. $\mathrm{O}$ chanfro de aresta de $15^{\circ}$ proporcionou menor desgaste de flanco. 
Em HSM, os ângulos da ferramenta influenciam de forma significativa a magnitude dos esforços de corte durante a usinagem, à semelhança da usinagem convencional. Testes realizados no PTW (Institut für Produktionsmanagement, Technologie und Werkzeugmaschinen), permitiram chegar a alguns valores recomendáveis de forma genérica para otimização de geometrias de ferramentas, apesar de estarem relacionados a operações de fresamento e fresotorneamento em HSC (SCHULZ, 1997). Pode-se observar na FIGURA 2.18, que o resultado da variação do ângulo de saída efetivo em HSM é similar à variação encontrada na usinagem convencional.

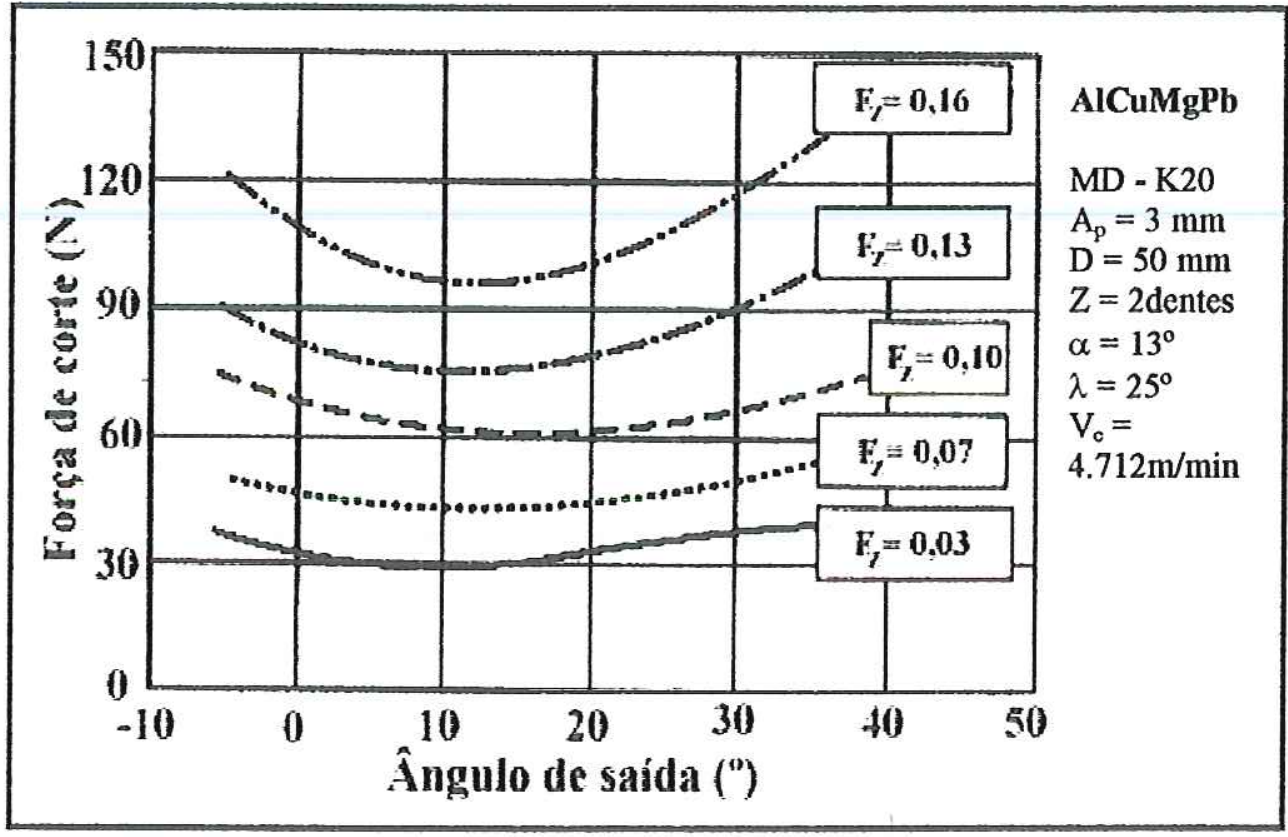

FIGURA 2.18 - Efeito da Variação do Ângulo de Saída na Força de Corte (NOVASKI \& CORRÊA, 1998).

SCHULZ \& HOCK (1995) e SAHM (1996) nos seus experimentos utilizando fresa de acabamento de forma esférica afirmam que a variação da velocidade de corte ao longo aresta traz conseqüências à integridade superficial. No centro da ferramenta, a velocidade de corte iguala a zero e o espaço do cavaco efetivo é muito pequeno. Isto causa lascamento na aresta de corte como também alta rugosidade superficial na peça, especialmente quando utiliza material de corte de alta qualidade. Estas condições de corte desfavoráveis podem ser aperfeiçoadas por uma inclinação no eixo da ferramenta em relação à superficie normal conforme ilustra a FIGURA 2.19 
(SAHM, 1996). Segundo os pesquisadores, a inclinação da fresa na extensão de $10^{\circ}$ $20^{\circ}$, representa uma estratégia ótima de usinagem para fresamento com alta velocidade em matrizes e moldes. Nesta faixa de inclinação, a geometria da formação de desgaste pode ser representada pelos parâmetros de corte de espessura e trajetória de corte inferior.

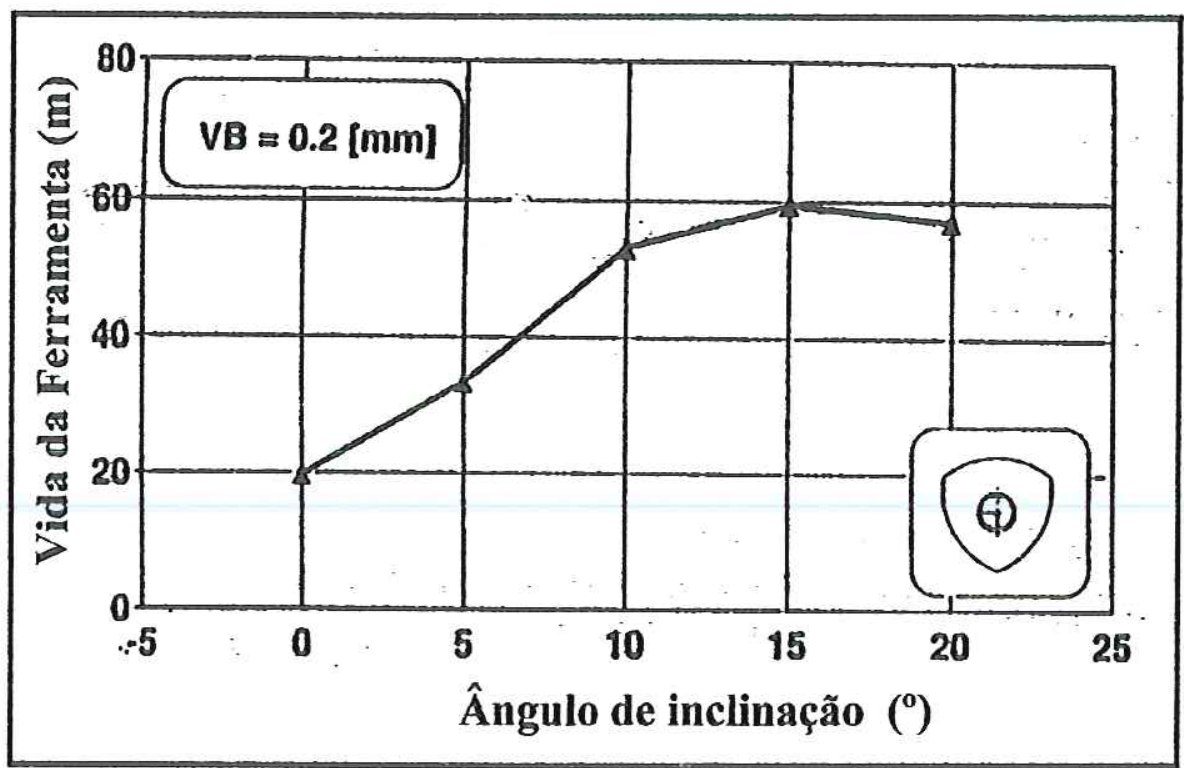

Material: $40 \mathrm{CrMnMo} 7$

Ferramenta: fresa esférica

P 40/50 com cobertura

$\mathrm{D}=20 \mathrm{~mm}-2$ dentes
Condições de corte:

corte interrompido

$\mathrm{a}_{\mathrm{p}}=1 \mathrm{~mm} ; \mathrm{a}_{\mathrm{e}}=0.7 \mathrm{~mm}$

$\mathrm{V}_{\mathrm{c}}=300 \mathrm{~m} / \mathrm{min} ; \mathrm{f}_{\mathrm{z}}=0.3 \mathrm{~mm}$

FIGURA 2.19 - Efeito do Ângulo de Inclinação na Vida da Ferramenta (SAHM, 1996).

HAMANN et al. (1994) afirmam com seus experimentos no torneamento do aço inoxidável utilizando alta velocidade de corte, que a geometria da ferramenta apropriada pode ser capaz de proteger as arestas de corte à medida que não foi afetada pelo desgaste de cratera por um tempo maior. Eles utilizaram dois tipos de quebra cavaco no inserto quadrado P25 revestido com TiC-TiN, conforme ilustrado na FIGURA 2.20, em velocidades de corte de 600 e $660 \mathrm{~m} / \mathrm{min}$. Como resultado, a vida da ferramenta foi dez vezes superior com a geometria modificada $\left(2^{\circ}\right.$ perfil) na velocidade de $660 \mathrm{~m} / \mathrm{min}$ e cinco vezes superior na velocidade de $600 \mathrm{~m} / \mathrm{min}$, apesar de o mecanismo de desgaste ter sido o mesmo. 


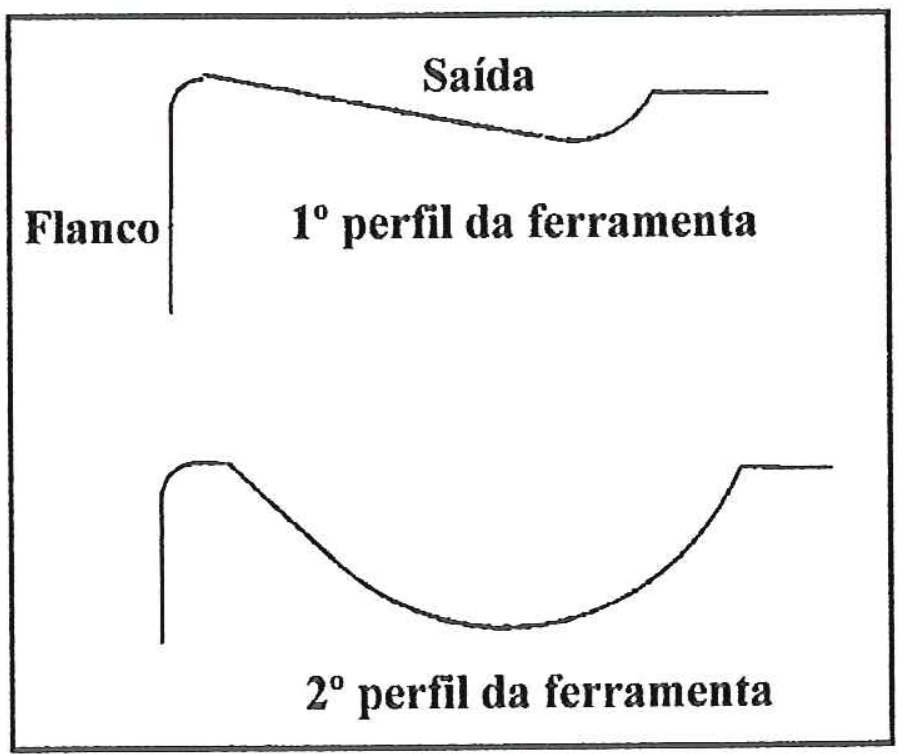

FIGURA 2.20 - Evolução da Geometria de Corte (HAMANN et al., 1994).

ELBESTAWI et al. (1997) apresentam o efeito da preparação de aresta de corte para o fresamento com alta velocidade em matrizes e moldes, nas condições a seco e refrigerado, usando duas concentrações de CBN (baixa e alta) no desempenho de ferramentas de PCBN mostrado na FIGURA 2.21. O melhor desempenho foi obtido com a ferramenta contendo alta concentração de CBN com preparação de aresta com quina viva. A alta concentração de $\mathrm{CBN}$ alcançou melhor desempenho do que a baixa sob determinadas condições, exceto quando fluido refrigerante foi usado. Como a ferramenta de alta concentração de CBN tem uma alta condutividade térmica $(100 \mathrm{~W} / \mathrm{mK})$, o calor gerado durante o corte pode ser dissipado rapidamente da zona de corte, assim diminuindo o seu efeito na usinagem deixando o material dificil de cortar. 


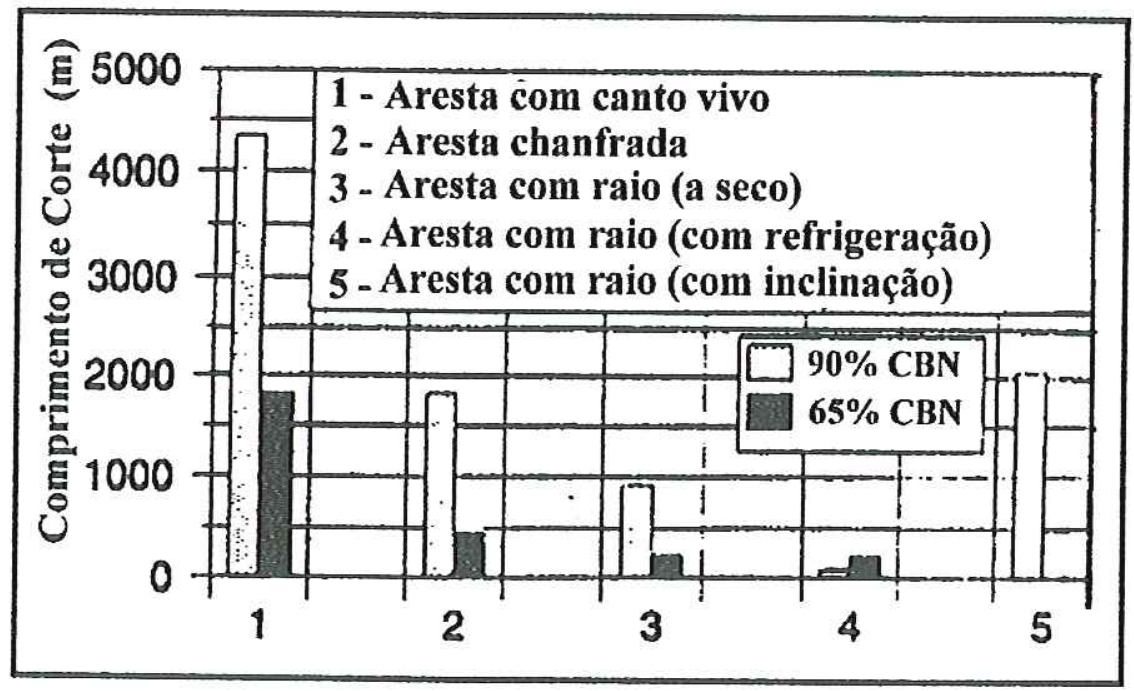

FIGURA 2.21 - Efeito dos Parâmetros de Processo na Vida da Ferramenta no

Fresamento de Aço Ferramenta H13 Temperado - N = $10.000 \mathrm{rpm}$, $\mathrm{f}_{\mathrm{z}}=0,25 \mathrm{~mm} /$ dente e $\mathrm{a}_{\mathrm{p}}=0,625 \mathrm{~mm}$ (ELBESTAWI et al., 1997).

SHINTANI et al. (1989) pesquisaram o efeito do chanfro de aresta de corte, largura do chanfro de aresta, raio de ponta e raio de aresta referente à vida da ferramenta e a rugosidade superficial, no torneamento do aço cromo-molibdênio cementado (JIS-SCM420 - SAE 4130) com ferramenta de PCBN brasada. O limite da vida da ferramenta foi determinado pelo comprimento de corte alcançado e foi definido como $L_{1}$. A dependência de $\mathrm{L}_{1}$ em relação ao chanfro de aresta é ilustrada na FIGURA 2.22 (a), indicando que o máximo comprimento usinado até atingir um desgaste de flanco de $0,25 \mathrm{~mm}$ é alcançado com o ângulo de $30-35^{\circ}$ negativo. A rugosidade superficial foi determinada também pelo comprimento de corte alcançado no limite de vida da ferramenta para $R_{a} \cong 0,8 \mu \mathrm{m}$, e foi definido como $L_{2}$. A relação entre $L_{2}$ e o chanfro de aresta é mostrado na FIGURA 2.22 (b) a qual exibe uma tendência similar à FIGURA 2.22 (a), a saber, que $\mathrm{L}_{2}$ também teve o melhor desempenho com o ângulo negativo em torno de $35^{\circ}$. $\mathrm{O}$ efeito do raio de aresta $\left(\mathrm{r}_{\mathrm{H}}\right)$ em $L_{1}$ e $L_{2}$ foi investigado para um raio de ponta de $0,8 \mathrm{~mm}$ e chanfro de aresta de $35^{\circ}$. Como mostra a FIGURA 2.23, a máxima vida para $L_{1}$ e $L_{2}$ foi indicado para $r_{H}=$ $0,05 \mathrm{~mm}$.

Segundo KOENIG (apud WEINGAERTNER et al., 1994) o raio de ponta não tem grande influência sobre as forças de usinagem, desde que a relação $2 r_{\varepsilon} \leq a_{p}$ seja satisfeita. 


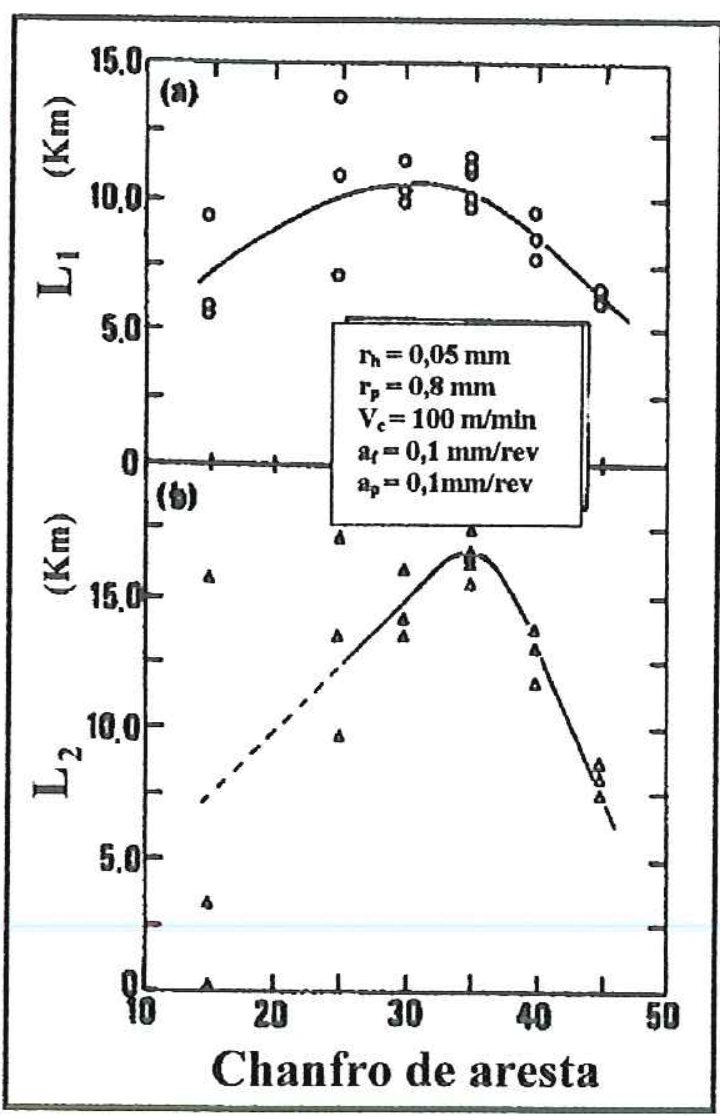

FIGURA 2.22 - Dependência de Vida de Ferramenta $L_{1}$ (a) e $L_{2}$ (b) sobre o Chanfro de aresta (SHINTANI et al., 1989).

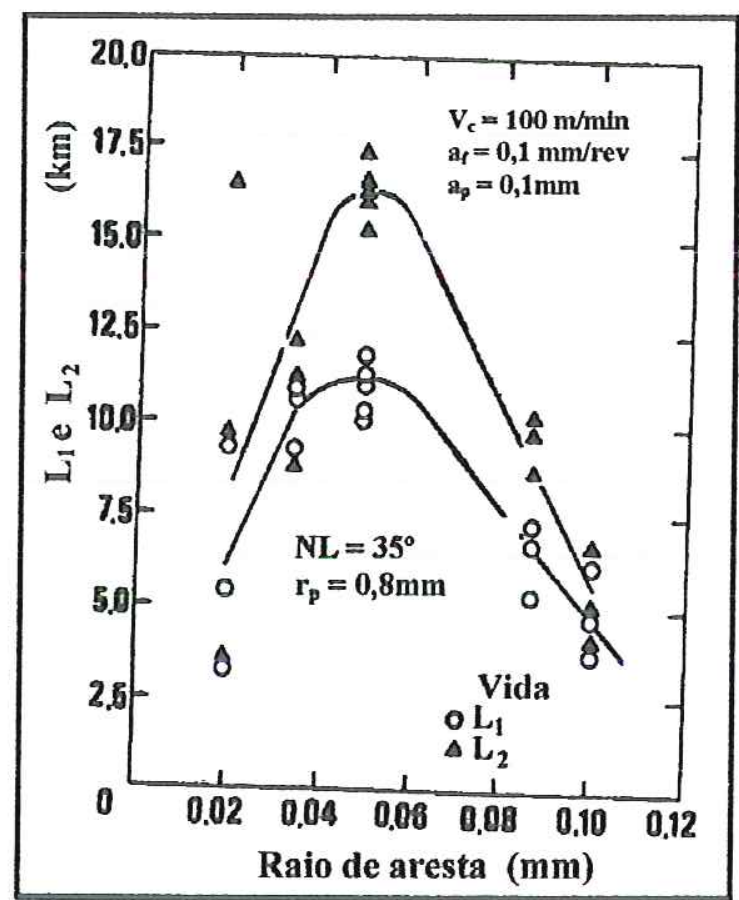

FIGURA 2.23 - Dependência de Vida da Ferramenta para $L_{1}$ e $L_{2}$ sobre o Raio de Aresta (SHINTANI et al., 1989). 
KANKAANPÄÄ \& KORHONEN (1987) apresentaram os efeitos da geometria da aresta de corte no desempenho de ferramentas HSS-PM (aço-rápido fabricado pela metalurgia do pó) sem e com revestimento de TiN no torneamento do aço (AISI 8620) endurecido por cementação. $\mathrm{O}$ ângulo de saída foi modificado de $5^{\circ}$ para $6^{\circ} \mathrm{com}$ simultânea diminuição do ângulo de folga de $6^{\circ}$ para $5^{\circ}$. Os resultados mostraram claramente que até mesmo pequenas modificações na geometria de corte podem influenciar no resultado de mecanismo de desgaste. Pequenas alterações no ângulo de saída podem resultar em mudanças profundas na vida da ferramenta, no torneamento. Os efeitos são maiores nas ferramentas com cobertura. De fato, foi verificado que pelo aumento do ângulo de saída de $5^{\circ}$ para $6^{\circ}$, a vida da ferramenta sem cobertura aumentou $40 \%$ e nas ferramentas com cobertura de TiN esse aumento foi de $200 \%$.

DEWES \& ASPINWALL (1995) apresentam as geometrias das fresas de topo que podem ser especificadas para a faixa de HSC detalhada na TABELA 2.4.

TABELA 2.4 - Geometrias das ferramentas para HSC (DEWES \& ASPINWALL, 1995).

\begin{tabular}{|l|l|l|}
\hline \multicolumn{1}{|c|}{ Material da peça } & \multicolumn{1}{|c|}{ Ferramenta } & \multicolumn{1}{c|}{ Ângulos } \\
\hline Ligas de alumínio & Metal duro - K 10 & $\begin{array}{l}\gamma=10-15^{\circ} ; \alpha=13-18^{\circ} \\
\text { Hélice }=>25^{\circ}\end{array}$ \\
\hline Aço carbono (0,5\%) & Cermet & $\gamma=-60^{\circ}$ \\
\hline Aço para matriz (57 HRC) & PCBN & $\gamma=-10^{\circ} ;$ Hélice $=-10^{\circ}$ \\
\hline Ligas de níquel & Metal duro K10 & $\gamma=>20^{\circ} ; \alpha=20^{\circ}$ \\
(TiN/TiC) & Hélice $=>0^{\circ}$ \\
\hline Ligas de titânio & Metal duro - K 10 & $\begin{array}{l}\gamma=>18^{\circ} ; \alpha=20^{\circ} \\
\text { Hélice }=0^{\circ} \\
\gamma=5^{\circ} ; \alpha=10^{\circ} \\
\text { Hélice }=30^{\circ}\end{array}$ \\
\hline Compósitos de polímero & Metal duro - K 10 & $\gamma=15^{\circ} ; \alpha=32^{\circ}$ \\
\hline
\end{tabular}


SCHULZ (1996) e ANDRAE (1999b) afirmam que na maioria dos casos as ferramentas atualmente disponíveis para HSC são perigosas quando operando em altas rotações. Com base na experiência conquistada em função das pesquisas atuais pode-se concluir que se deve:

\section{Usar materiais dúcteis;}

Minimizar o efeito de entalhe (notch) dependendo do espaço necessário para o cavaco;

Minimizar o efeito de entalhe dependendo do desenho do fio de corte;

Providenciar conexões que se adaptem à forma;

Manter as massas pequenas para todos os componentes da ferramenta;

Resistência ao desgaste em alta velocidade de corte;

Baixo erro de balanceamento;

Boa trajetória para deslocamento de cavacos;

Alto número de aresta de corte.

De acordo com SMITH (1994), a geometria de corte para uso com cerâmica reforçada com whiskers tem sido assunto de pesquisas e de experiências ao longo dos últimos anos. Já foi demonstrado conclusivamente que ferramentas com ângulo de inclinação negativo, com ângulo superior de $5^{\circ}$ e ângulo lateral de $10^{\circ}$, dão os melhores resultados em termos de corte mais livre e maior vida útil.

EZUGWU et al. (1999) comprovaram, com seus experimentos na usinagem de superligas à base de níquel, que a forma e a geometria das ferramentas de corte representam um importante papel na determinação da vida da ferramenta e na qualidade da superficie usinada. Ferramentas de cerâmica de forma romboidal (losangular) geralmente fornecem baixo desempenho na usinagem das superligas, entretanto os insertos de forma redonda e quadrada proporcionam alto desempenho como também um melhor acabamento superficial sob condições de corte semelhante. Isto é devido ao aumento nos ânģulos compreendidos dos insertos quadrado e redondo, o que tendem a aumentar a resistência da aresta dos insertos e a área de contato, resultando em baixas tensões e melhor distribuição de calor na aresta cortante. A variação no ângulo de posição $\left(\chi_{\mathrm{r}}\right)$ nos insertos de forma quadrada, romboidal e redondo, tem também efeitos sobre a vida da ferramenta na usinagem das superligas à base de níquel. $\mathrm{O}$ inserto de forma romboidal com ângulo de posição 
grande tende a aumentar a curvatura do cavaco durante a usinagem. Isto vai ter um efeito adverso sobre a resistência à fadiga na altura da profundidade de corte e consequentemente sobre a vida da ferramenta. Assim também pensa RAHMAN et al. (1997) sobre os efeitos do ângulo de posição sobre a vida da ferramenta no torneamento do Inconel 718. Observa-se que a vida aumenta à medida que o ângulo aumenta de $-5^{\circ}$ para $45^{\circ}$. A maior vida foi obtida quando o ângulo de posição foi de $45^{\circ}$ nas diversas condições de corte testadas.

KATTAN \& CURRIE (1996) demostram que todas as forças de corte decrescem quando o ângulo de posição fica acima de $95^{\circ}$. As medidas das forças de corte para a geometria com ângulo de posição de $107,5^{\circ}$ indicam valores inferiores aqueles com ângulo de posição de $90^{\circ} \mathrm{e} 95^{\circ}$. A cor da raiz do cavaco com ângulo de posição de $107,5^{\circ}$ foi marrom claro comparado com a cor do cavaco com ângulo de posição de $75^{\circ}$, que foi azul escuro, o que indica menor temperatura de corte com ângulo de posição de $107,5^{\circ}$. Obteve-se melhor qualidade superficial e precisão dimensional com o ângulo de posição de $95^{\circ}$.

Segundo SANCHEZ et al. (2000), o processo de lapidação da aresta de corte tem influência significativa na vida da ferramenta e na rugosidade superficial. Como resultado do mecanismo de desgaste mais brando sofrido pela pastilha de metal duro lapidada, sua geometria altera-se menos mantendo valores de rugosidades superficiais mais baixos do que no caso da pastilha não lapidada, ou seja, acabada pelo processo de retificação. Este comportamento pode ser explicado pela provável remoção, pela lapidação, da camada de material com defeitos anteriormente introduzidos no processo de retificação da pastilha e também pelas menores tensões residuais (compressivas) deixadas pelo processo de lapidação. 


\subsubsection{Monitoramento dos processos de usinagem}

Os recentes desenvolvimentos e tendências na tecnologia da usinagem e no projeto de máquinas-ferramentas, a exemplo de usinagem com alta velocidade, torneamento de peças endurecidas e nano-usinagem impuseram novas exigências aos sistemas de monitoramento no ambiente da manufatura. O monitoramento dos processos de usinagem é uma valiosa ferramenta de otimização dos mesmos e, portanto, vem despertando interesse crescente dos pesquisadores, engenheiros e técnicos da área. A motivação para isto tem sido a crescente busca por qualidade e produtividade industrial, que capacitam as empresas quanto à competitividade no mercado mundial. O monitoramento se aplica, segundo DORNFELD (1999), nos seguintes elementos do processo:

Nas máquinas, para diagnósticos e monitoramento de desempenho;

* Nas ferramentas, para verificar posicionamento, estado de afiação, alinhamento, lubrificação, etc.;

Nas peças, para monitoramento da geometria e dimensão, rugosidade superficial, tolerâncias e danos térmicos;

Nos processos propriamente ditos, para melhor compreensão do mecanismo de formação do cavaco, monitoramento das temperaturas, forças de usinagem e consumo de energia, entre outros.

As principais características de um bom sistema de monitoramento são: confiabilidade, baixo custo, simplicidade, suportar o ambiente industrial, não ser influenciado por ruídos externos, o parâmetro medido deve ser dependente somente do que se quer monitorar, tempo de resposta e ser pouco intrusivo, ou seja, o sensor não deve interferir na operação de usinagem. O monitoramento das máquinasferramentas tem como objetivo, aumentar a confiabilidade das mesmas, detectando tanto as falhas catastróficas, onde o processo precisa ser paralisado, quanto as degradações dos subsistemas que compõem o processo, gerando um indicador do momento em que tais degradações atinjam um nível crítico. A detecção da falha catastrófica da ferramenta (rebarbação e quebra da ferramenta de corte) constitui-se numa importante função para a melhoria da credibilidade e promoção da automação 
dos processos de fabricação (TÖNSHOFF et al. 1988; BYRNE et al. 1995; INASAKI, 1998 e JEMIELNIAK \& OTMAN, 1998).

Existem vários métodos de monitoramento dos processos de usinagem, sendo normalmente divididos em dois grandes grupos: monitoramento direto e monitoramento indireto. O presente trabalho abordará somente a medição de temperatura, emissão acústica e força de corte em HSM.

\subsubsection{Temperatura de corte em HSM}

O calor gerado na zona de cisalhamento e na ferramenta de corte durante a usinagem, tem sido extensivamente estudado usando-se uma variedade de técnicas experimentais, incluindo análise microestrutural, termopar cavaco-ferramenta, termopar implantado, métodos de radiação, técnicas analíticas, pós químicos etc. Termopares implantados podem ser posicionados em diferentes locais na ferramenta, fornecendo detalhes da distribuição do calor. Este método foi utilizado no presente trabalho.

Embora diversos trabalhos sobre temperatura de corte estejam disponíveis, são poucos os que se referem à usinagem com alta velocidade, principalmente em superligas à base de níquel.

Os efeitos de geração e transmissão do calor no corte de metais são muito complexos, pois com o aumento da temperatura mudam as características fisicas e mecânicas do metal em trabalho. Com o aumento da temperatura, além do ponto de transformação da estrutura do material, as ferramentas perdem a sua dureza, desgastam-se rapidamente e tornam-se improdutivas. Por outro lado, para aumentar a produtividade da ferramenta deve-se aumentar a velocidade, o avanço e a profundidade de corte. Todos estes três fatores aumentam a temperatura (FERRARESI, 1977).

Em usinagem praticamente toda a energia consumida é convertida em calor. Somente uma pequena porcentagem (1 a 3\%) não é convertida em energia térmica. Grande parte deste calor gerado é dissipado pelo cavaco, uma pequena porcentagem é dissipada pela peça e uma outra para a ferramenta de corte, o que representa apenas pequenos percentuais ( 8 a 10\%). O aumento da temperatura, associado a este 
calor, é significativo, podendo chegar, em certos casos, a $1.100^{\circ} \mathrm{C}$, o que compromete fortemente a resistência da ferramenta (MACHADO \& SILVA, 1999).

Muitos pesquisadores têm concluído que não existe redução de temperatura em HSM, e que a maior parte do calor é transferido para o cavaco. Consequentemente, baixa distorção térmica da peça pode ser observada, à medida que a maior parte do calor da usinagem ( 70 - 90\% aproximadamente) é transportado pelo cavaco (AGBA, 1999).

SINHOFF et al. (1999) afirmam que, uma grande vantagem do fresamento com alta velocidade é a redução no aquecimento da peça em conseqüência do aumento da dissipação do calor de corte via cavaco. Este efeito deve-se principalmente às pequenas seções transversais dos cavacos. O que significa que o processo de formação do cavaco causa menos deformação/compressão dos cavacos.

A carga térmica na aresta de corte, entretanto, permanece alta, da mesma forma, ou até cresce consideravelmente com o aumento da velocidade de corte. Isto provoca uma redução drástica na vida da ferramenta. Dobrando a velocidade de corte pode-se reduzir a vida da ferramenta para até um décimo ou menos, dependendo da combinação do material da peça e material da ferramenta de corte na operação específica (SINHOFF et al. 1999).

A usinagem com alta velocidade de corte em aços, ferro fundido e superligas causam temperaturas de corte extremamente altas, de modo que a tensão térmica da ferramenta é decisiva para o processo. Por outro lado, a baixa condutividade térmica de alguns materiais, tais como ligas de titânio e superligas à base de níquel dificultam a dissipação do calor, o qual conduz a uma substancial elevação na temperatura de corte (KITAGAWA et al. 1997). A FIGURA 2.24 apresenta a ascensão da temperatura com o aumento da velocidade de corte na usinagem do aço $\mathrm{Ck} 45$ (SAHM, 1996). 


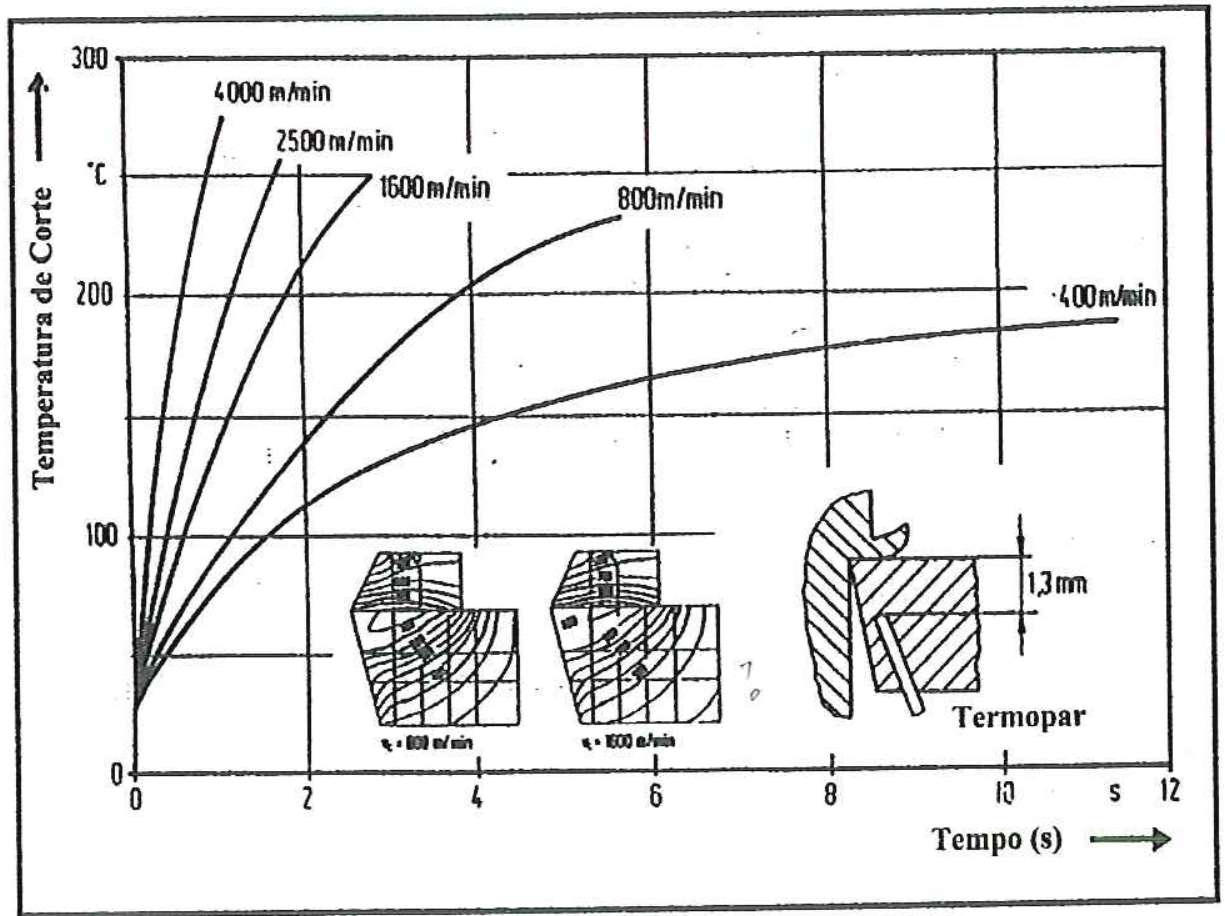

Material: Aço Ck 45

Condições de corte:

Ferramenta: $\phi=40 \mathrm{~m}$;

$\mathrm{a}_{\mathrm{p}}=5 \mathrm{~mm}$

Inserto: P 20

$a_{\mathrm{e}}=1,5 \mathrm{~mm}$

$\alpha=16^{\circ}$

$\mathrm{f}_{\mathrm{z}}=0,31 \mathrm{~mm}$

$\gamma=0^{\circ}$

corte interrompido

$\lambda=0^{\circ}$

corte a seco

FIGURA 2.24 - Temperatura de Corte no Fresamento com Alta Velocidade

(SAHM, 1996).

A temperatura foi medida utilizando termopar à uma distância de $1,3 \mathrm{~mm}$ da ponta da ferramenta. A temperatura medida foi usada para calcular a distribuição de calor na ferramenta. A máxima temperatura na ponta da ferramenta foi muito superior à medida, alcançando aproximadamente $750^{\circ} \mathrm{C}$ na velocidade de corte de $800 \mathrm{~m} / \mathrm{min}$ e perto de $1.100^{\circ} \mathrm{C}$ com a velocidade de $1.600 \mathrm{~m} / \mathrm{min}$. Metal duro mostra uma extrema perda de dureza a temperaturas acima de $800^{\circ} \mathrm{C}$, considerada como temperatura crítica. Consequentemente, velocidade de corte superior à $800 \mathrm{~m} / \mathrm{min}$ apresenta severos desgaste na ferramenta de carbeto. Por outro lado, LIN et al. (1992) apresentam valores de temperatura na interface em HSC (600 m/min) utilizando pirômetro infravermelho com fibra óptica no torneamento do aço carbono AISI 1045 com ferramentas de nitreto de silício $\left(\mathrm{Si}_{3} \mathrm{~N}_{4}\right)$ e metal duro (WC - K05). 
Baseado na temperatura medida na superfície de saída, a média da temperatura de corte e calor total era calculada pelo método inverso de elementos finitos. As temperaturas na interface cavaco-ferramenta foram $1.200^{\circ} \mathrm{C}$ e $1.050^{\circ} \mathrm{C}$ para o nitreto de silício e metal duro, respectivamente. $\mathrm{O}$ total de calor produzido na zona de corte foi calculado baseado em equações e ilustrado na FIGURA 2.25 .

A condutividade térmica do material da ferramenta é um fator importante para determinar a quantia de calor que é dissipado para a zona de corte. As temperaturas na interface de ambos materiais são similares, mas o calor transferido para as ferramentas é dramaticamente diferente. A diferença de calor introduzido entre as ferramentas de cerâmica e metal duro está perto de $30 \mathrm{~W}$ na velocidade de corte de $600 \mathrm{~m} / \mathrm{min}$ (LIN et al. 1992).

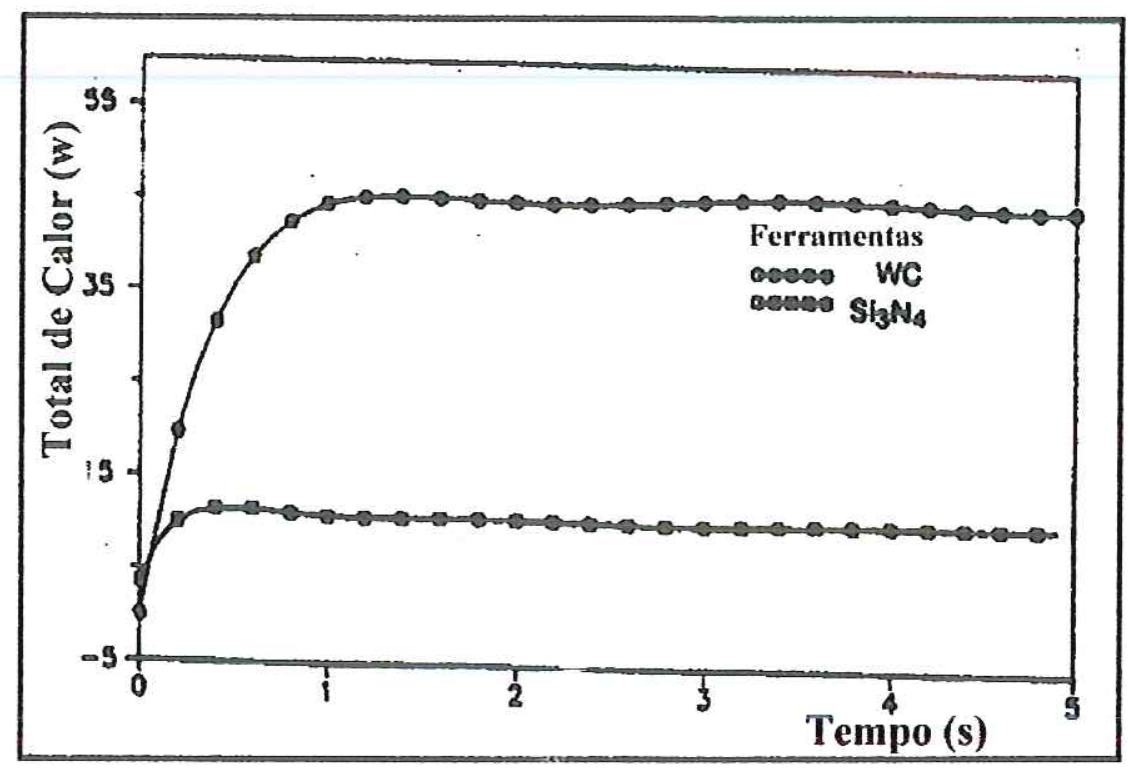

FIGURA 2.25 - Total de Calor Introduzido nas Ferramentas de Metal Duro e Nitreto de Silício - $\mathrm{Si}_{3} \mathrm{~N}_{4}$ (LIN et al., 1992).

ELWARDANY et al. (1996) encontraram resultados interessantes analisando o efeito da velocidade de corte sobre a temperatura na aresta de corte durante o torneamento do Inconel 718. Inicialmente, com o aumento da velocidade de corte de 110 para $510 \mathrm{~m} / \mathrm{min}$, a temperatura na aresta de corte é reduzida em aproximadamente $200^{\circ} \mathrm{C}$, mas com o avançar da velocidade de corte até $720 \mathrm{~m} / \mathrm{min}$, a temperatura na aresta de corte aumenta significativamente. Por outro lado, aumentando o raio de ponta reduziu a temperatura na aresta de corte. Os 
pesquisadores revelam através de microscópico eletrônico de varredura a presença de aderência de material, causado pela pressão de caldeamento entre a peça e ferramenta. $\mathrm{O}$ aumento da velocidade de corte é sempre acompanhado pela redução da espessura do cavaco, o qual conduz um aumento da energia de deformação plástica, de modo que se revela na aderência de cavaco na aresta de corte.

ELBESTAWI et al. (1993) observaram o comportamento da temperatura do Inconel 718 no torneamento contínuo e interrompido utilizando termopar Ni-Cr. O efeito do aumento da velocidade de corte sobre os dois casos foi diferente. No corte contínuo, aumentando a velocidade de corte resultou no aumento da temperatura da ferramenta. Por outro lado, aumentando a velocidade de corte no corte interrompido reduziu a temperatura da ferramenta.

\subsubsection{Força de corte em HSM}

O conhecimento da força de usinagem atuante na aresta de corte da ferramenta e o estudo do comportamento de suas componentes são de grande importância, não somente porque a potência requerida para executar o corte pode ser estimada, mas também, porque elas devem ser consideradas no projeto das máquinas-ferramentas, isto é, para o correto dimensionamento das estruturas, dos acionamentos, da fixação de ferramentas, das guias e de outros elementos. Além disso, a grandeza da força de usinagem é um critério para a determinação da usinabilidade de um material de peça, já que geralmente materiais que apresentam maiores forças de usinagem são também de usinagem mais dificil. $\mathrm{O}$ monitoramento das componentes das forças de usinagem também pode ser utilizado para detectar a quebra da ferramenta de corte ou até mesmo o desgaste da mesma. Para o emprego desta técnica é necessária a utilização de dinamômetros que são do tipo extensométrico ou piezoelétrico, e estes sensores podem ser acoplados ao suporte porta-ferramenta ou na própria mesa de trabalho da máquina-ferramenta. As limitações desta técnica ficam em função das dimensões dos dinamômetros e do seu elevado custo (DAN \& MATHEW, 1990; WEINGAERTNER et al. 1994; WILCOX et al. 1997 e MACHADO \& SILVA, 1999).

A atuação da força de usinagem depende de uma série de fatores: material da peça, área da seção de corte, espessura de corte, geometria da ferramenta e ângulo de 
posição, estado de afiação da ferramenta, material da ferramenta, lubri-refrigeração, processo de formação de cavaco e velocidade de corte (FERRARESI, 1977 e ANDREASEN \& CHIFFRE, 1993).

A análise das componentes da força de usinagem no torneamento com alta velocidade de corte em superligas à base de níquel é um assunto pouco explorado na literatura técnica, que fornece poucos dados sobre as forças específicas das diferentes superligas.

THANGARAJ \& WEINMANN (1992) afirmam que não encontraram variação expressiva na força de corte quando a velocidade de corte passa de $456 \mathrm{~m} / \mathrm{min}$ para $762 \mathrm{~m} / \mathrm{min}$ utilizando ferramentas cerâmicas de geometria redonda no torneamento do Inconel 718. Segundo os pesquisadores, a força de corte é independente da velocidade de corte nas condições testadas, enquanto que a força de avanço aumenta com o aumento da velocidade de corte. De uma maneira geral, existe um consenso entre os diversos pesquisadores de que as forças na usinagem tendem a ser menores quando aumenta a velocidade de corte e não há desgaste da ferramenta. KRAMER (1987) relata que o aumento da velocidade de corte não está necessariamente associado com o aumento da força de corte e a tendência de fratura da ferramenta. Pelo contrário, aumentando a velocidade de corte freqüentemente resulta na diminuição da espessura do cavaco e correspondente diminuição na força de corte. ELBESTAWI et al. (1993) indicaram redução da força de corte com o aumento da velocidade de corte de $500 \mathrm{~m} / \mathrm{min}$ para $700 \mathrm{~m} / \mathrm{min}$ na usinagem do Inconel 718. A redução da força de corte com o aumento da velocidade de corte pode ser explicado com o desenvolvimento do processo de formação de cavaco na região do corte. SCHULZ et al. (2001) comprovaram a diminuição da força de corte quando aumenta a velocidade de corte de $1.000 \mathrm{~m} / \mathrm{min}$ para $8.000 \mathrm{~m} / \mathrm{min}$ para diferente formação de cavacos (segmentados e contínuos) quando da usinagem da liga $\mathrm{AlZnMgCu} 1.5$.

Devido ふ̀ diminuição da força de corte, proporcionalmente ao aumento das velocidades de corte, usinagem com alta velocidade pode ser utilizada com enormes vantagens na usinagem de peças de paredes finas. Além disso, a diminuição da força de usinagem tem uma influência positiva sobre a integridade superficial da peça (ANDRAE, 1999). 


\subsection{Mecanismos de formação de cavacos}

Para um estudo das diferentes grandezas relacionadas a usinagem dos metais, tais como, desgaste da ferramenta e suas causas, forças de corte, aresta postiça de corte, etc, é necessário um estudo mais abrangente do processo de formação de cavacos. Em geral o mecanismo da deformação do cavaco pode ser explicado considerando o volume de metal "klmn", da FIGURA 2.26, movendo-se em direção à cunha cortante (MACHADO \& SILVA, 1999).

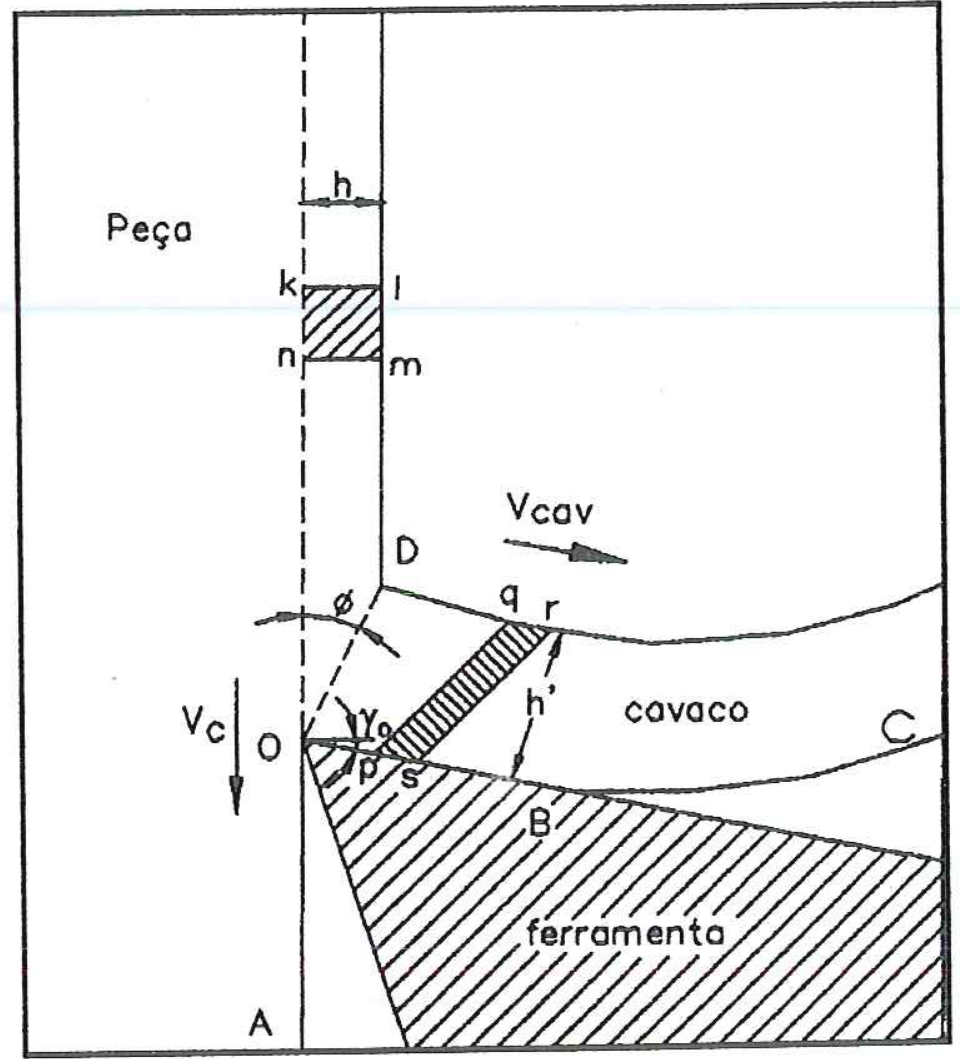

FIGURA 2.26 - Diagrama da Cunha Cortante (MACHADO \& SILVA, 1999).

A ação da ferramenta recalca o volume "klmm". Neste ponto, o metal começa a sofrer deformação elástica. Com o prosseguimento do processo, o limite de escoamento é vencido e o maierial passa a se deformar plasticarìente. Deformações plásticas continuam acontecendo até que as tensões não são mais suficientes para manter este regime. Assim fica definida uma zona de cisalhamento primária, sendo que, para facilitar o estudo, ela é representada por apenas um plano, definido pela linha OD da FIG. 2.26. 
Após o material entrar em regime plástico, o avanço da ferramenta faz com que as tensões ultrapassem o limite de resistência do material, ainda dentro da zona de cisalhamento primária, promovendo a ruptura, que se inicia com a abertura de uma trinca no ponto "O" e que pode se estender até o ponto "D", segundo o plano "OD". A extensão de propagação da trinca, que depende principalmente da ductilidade ou fragilidade do material da peça, vai determinar a classe de cavaco, isto é, contínuo ou descontínuo.

Após passar pela região primária de cisalhamento, ao volume de material "klmm" só resta movimentar-se por sobre a superficie de saida da ferramenta e sair como um componente, ou lamela de cavaco. Entretanto, ao atravessar a zona primária de cisalhamento ela se deforma plasticamente para um novo formato "pqrs" da FIGURA 2.26. O entendimento das condições dessas interfaces cavacoferramenta é de importância fundamental para análise do processo de corte.

Segundo FLOM \& KOMANDURI (1989), dois tipos de formação de cavaco têm sido observados na usinagem a alta velocidade, dependendo do tipo de material da peça a ser usinada e das condições metalúrgicas. Eles são cavacos do tipo contínuo e segmentado. Cavacos contínuos são mais prováveis de ocorrer na usinagem com alta velocidade de metais ou ligas com arranjo celular de corpo centrado, estrutura cúbica de face centrada, alta difusividade térmica e baixa dureza tais como ligas de alumínio e aço de baixo carbono. O cavaco segmentado acontece na usinagem de materiais como ligas de titânio e super ligas à base de níquel, considerado material com pobres propriedades térmicas. Os cavacos segmentados são caracterizados por grandes deformações continuadas em estreitas bandas entre segmentos com muito pouca, ou quase nenhuma deformação no interior destes segmentos. O cisalhamento para formar o cavaco começa a ocorrer em um plano de cisalhamento particular, quando as tensões, impostas pelo movimento da ferramenta contra a peça, excedem o limite do escoamento do material. Com o prosseguimento da deformação, existe uma rotação no plano de cisalhamento, que comę̧a a se afastar da ponta da ferramenta e se movimentar por sobre a superficie de saída. HAMANN et al. (1994) produziram cavaco segmentado no torneamento com alta velocidade de aço inoxidável austenítico em diferentes condições de corte. 
Segundo ELBESTAWI et al. (1997), nos experimentos realizados em HSM na fabricação de matrizes e moldes foram produzidos cavacos curtos, completamente segmentados em espessuras variáveis em peça com dureza de 45 HRC a uma rotação de eixo-árvore de $10000 \mathrm{rpm}$. Quando a rotação foi aumentada para $60000 \mathrm{rpm}$, produziram-se cavacos em forma de pequenas esferas fundidas, devido ao alto calor gerado no processo nesta velocidade.

KOMANDURI \& SCHROEDER (1986); WAYNE \& BULJAN (1990); THANGARAJ \& WEINMANN, (1992); GATTO \& IULIANO (1994); ELWARDANY et al. (1996) e VIGNEAU (1997) encontraram também a presença de cavacos segmentados no torneamento com altas velocidades do Inconel 718 (440 HV) devido às condições de corte de cisalhamento adiabático. Observaram que o tamanho dos cavacos segmentados aumenta com o aumento do avanço e da velocidade de corte. Macroscopicamente, este fenômeno corresponde à segmentação do cavaco e pode ser explicado pelo aumento da temperatura na área de corte, sendo o mesmo responsável pela redução da força de corte. Os pesquisadores concluíram que superligas à base de níquel têm propriedades que podem causar a transição de cavacos contínuos para cavacos segmentados, à medida que se aumenta a velocidade de corte. Uma grande vantagem do torneamento com alta velocidade é que os cavacos segmentados podem ser removidos fáceis e automaticamente da zona de corte.

Em recente trabalho, ANDRAE (1999) revela a presença de cavacos segmentados no torneamento sem refrigeração de aço temperado (AISI 1045) e cementado (AISI 1015) com velocidade de corte variando de 200 a $4000 \mathrm{~m} / \mathrm{min}$. A medida que a velocidade de corte aumenta, o ângulo de cisalhamento aumenta, entretanto a espessura do cavaco diminui e consequentemente a relação de espessura do cavaco $\left(h^{\prime} / h\right)$ é reduzida. Ao mesmo tempo as forças de usinagem decrescem.

\subsubsection{Irterface cavaco-ferramenta}

Um dos principais problemas em usinagem é saber o que realmente ocorre na região da interface cavaco ferramenta, pois nesta região, não é possível a visualização. A formação do cavaco é um processo periódico, com cada ciclo dividido em 4 etapas distintas: (recalque ou deformação elástica, deformação 
plástica, ruptura e movimento ou escorregamento sobre a superficie de saída da ferramenta). Segundo TRENT (1984), as condições em que este escorregamento acontece influencia marcantemente todo o processo, particularmente, no próprio mecanismo de formação do cavaco, na força de usinagem, no calor gerado durante o corte, e consequentemente na temperatura de corte e nos mecanismos e taxa de desgaste das ferramentas de corte, e consequentemente na vida das mesmas. É preciso, contudo, entender como se processa o movimento do cavaco ao longo da superficie de saída da ferramenta.

As condições da interface cavaco-ferramenta são, portanto, uma das áreas de estudo mais importantes em usinagem. Isto, entretanto, tem sido um desafio grande, porque são poucas as conclusões que podem ser tiradas de observações diretas durante o corte, principalmente em altas velocidades. A maioria das teorias disponíveis foram derivadas de estudos desta interface, após o corte ter sido interrompido (utilizando-se dispositivos de parada rápida, também chamados "quickstops") e de medições de deformações e temperatura naquela região.

Uma das teorias mais difundidas nos meios científicos nos dias de hoje, é a existência de uma zona de aderência entre o cavaco e a ferramenta, defendida por Trent em 1963. Na periferia desta zona de aderência existe a zona de escorregamento. A FIGURA 2.27 identifica estas duas zonas: linha $\mathrm{BC}=$ aderência e linha $\mathrm{CD}=$ escorregamento (TRENT, 1984).

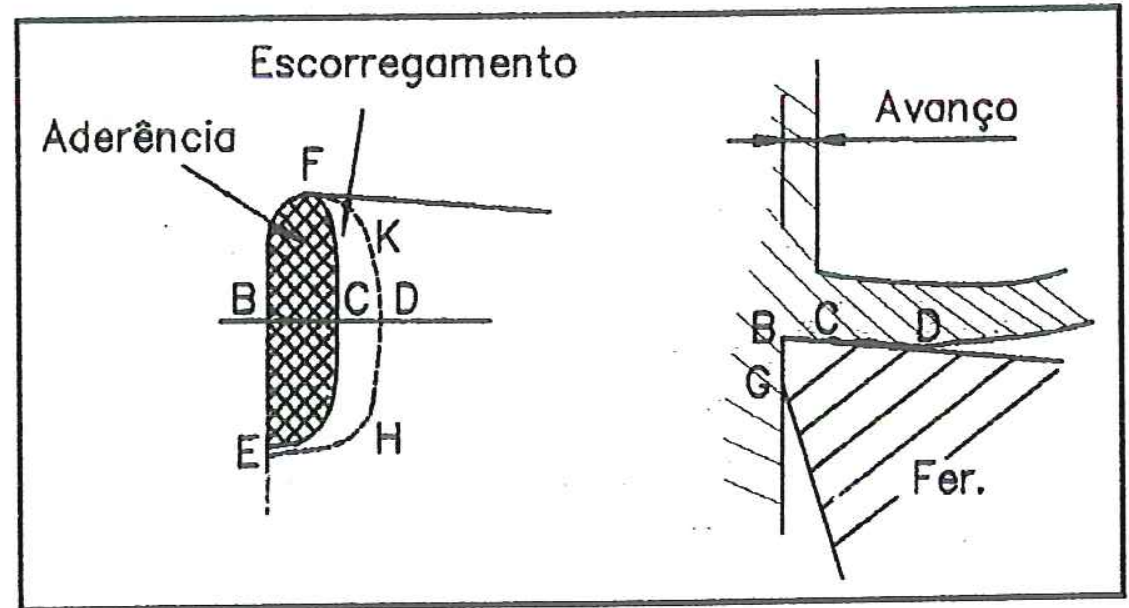

FIGURA 2.27 - Áreas de Aderência e Escorregamento na Interface CavacoFerramenta (TRENT, 1984). 
Em determinadas condições especiais, a zona de aderência pode ser suprimida, prevalecendo apenas às condições de escorregamento.

Uma outra situação diferente é a existência da aresta postiça de corte, APC, que é um fenômeno que pode ocorrer a baixas velocidades de corte e avanços e na usinagem de materiais que contenham $2^{\mathrm{a}}$ fase. A presença da APC vai alterar completamente a geometria da cunha cortante, com efeitos em todo o processo de usinagem (força e temperatura de corte, desgaste das ferramentas e acabamento superficial) (MACHADO \& SILVA, 1999).

A formação da APC tem efeito negativo sobre a qualidade superficial, precisão de peça manufaturada e sobre o desgaste da ferramenta, devido às partículas instáveis de material da peça o qual migra para cima da superficie de saída e flanco da ferramenta (KLOCKE \& PÖHLS, 1998). Como mostram numerosos estudos, aumentando a velocidade de corte tem-se efeito decisivo sobre a formação da APC. A força de corte diminui com a formação da aresta postiça, pois o ângulo efetivo de saída aumenta.

Segundo LIAO \& SHIUE (1996), quando Inconel 718 é usinado sob condição de alta velocidade de corte é muito freqüente que a APC apareça na aresta de corte. A ocorrência da APC implica que existe alta afinidade química e altas tensões devido à alta temperatura existente na interface cavaco-ferramenta.

\subsubsection{Formas de desgaste}

Durante a usinagem dos metais a ação do corte muda a forma e, portanto, a geometria original da ferramenta de corte. Verifica-se um desgaste progressivo tanto na superfície de folga quanto na superficie de saída da ferramenta. A FIGURA 2.28 apresenta as principais áreas deste desgaste (JACK, 1987). 


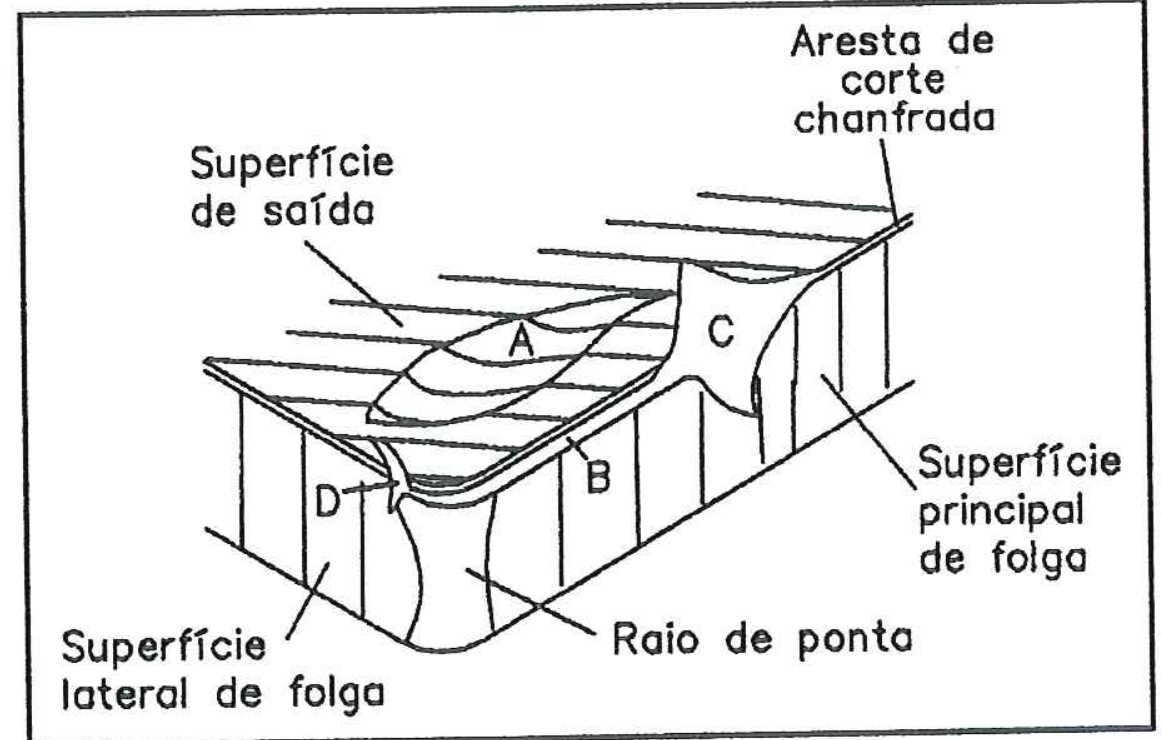

FIGURA 2.28 - Principais Áreas de Desgaste (JACK, 1987).

Pelo menos três formas de desgaste podem ser identificadas:

Desgaste de cratera (área A da FIGURA 2.28);

Desgaste de flanco (área B da FIGURA 2.28);

Desgaste de entalhe (áreas C e D da FIGURA 2.28).

Antes que um desses desgastes atinja grandes proporções, de maneira a colocar o processo de corte em risco, a ferramenta deverá ser reafiada ou substituída.

A FIGURA 2.29 mostra alguns dos parâmetros utilizados pela norma ISO 3685 (1993) para quantificar esses desgastes. Os principais desgastes são:

* Profundidade de cratera (KT);

$\therefore$ Desgaste de flanco médio $\left(\mathrm{VB}_{\mathrm{B}}\right)$;

- Desgaste de flanco máximo (VB $\mathrm{VBax}_{\mathrm{Bmax}}$;

- Desgaste de entalhe $\left(\mathrm{VB}_{\mathrm{N}}\right)$. 


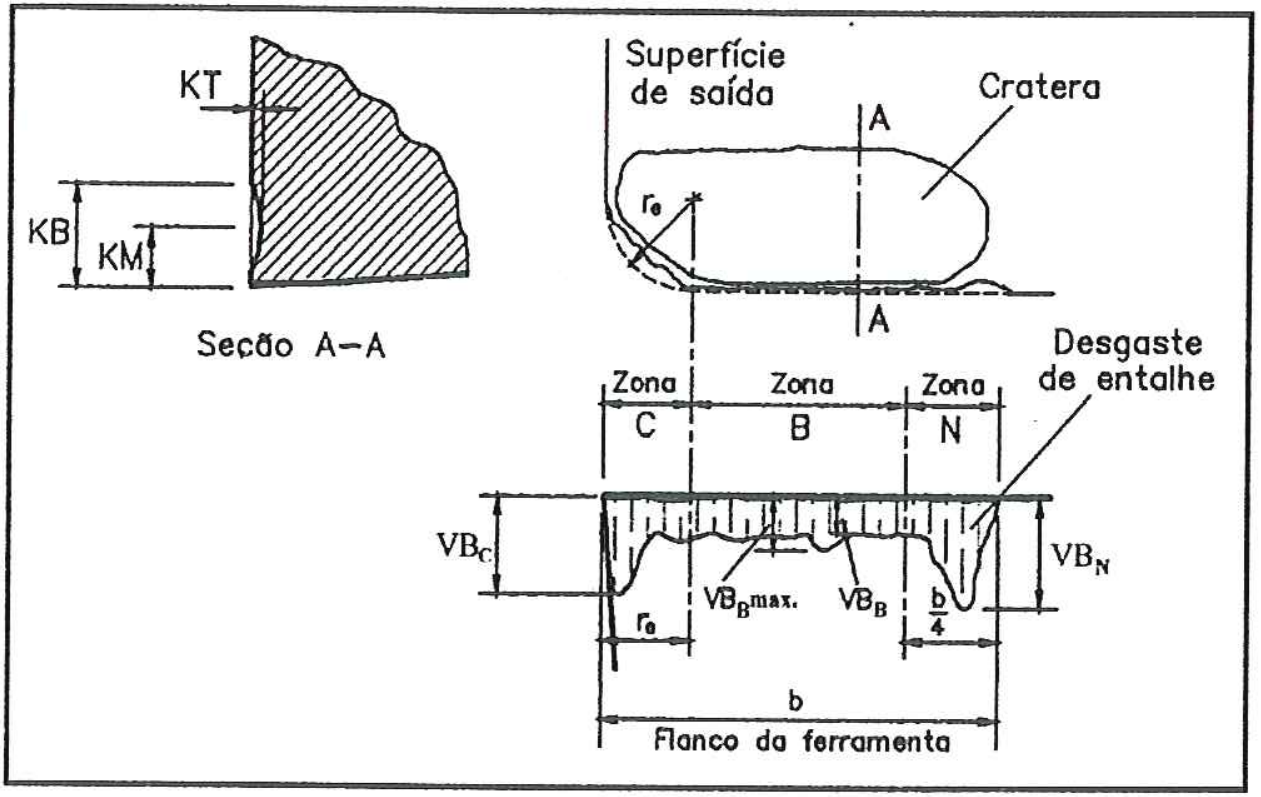

FIGURA 2.29 - Parâmetros Utilizados para Medir os Desgastes das Ferramentas de Corte (ISO 3685, 1993).

O critério recomendado pela ISO 3685 (1993) para ferramentas de aço rápido, metal duro e cerâmicas é:

Desgaste de flanco médio, $\mathrm{VB}_{\mathrm{B}}=0,3 \mathrm{~mm}$;

Desgaste de flanco máximo, $\mathrm{VB}_{\mathrm{Bmax}}=0,6 \mathrm{~mm}$;

Profundidade da cratera, $\mathrm{KT}=0,06+0,3 \mathrm{f}$ onde $\mathrm{f}$ é avanço em $\mathrm{mm} / \mathrm{rev}$;

Falha catastrófica.

Quando o desgaste de entalhe predomina, como no caso da usinagem de ligas de Ni com metal duro ou cerâmicas, a norma recomenda usar um valor de $\mathrm{VB}_{\mathrm{N}}=1,0$ $\mathrm{mm}$ como critério também. Desta maneira, quando qualquer um dos limites for ultrapassado, recomenda-se a reafiação ou substituição da ferramenta de corte.

É importante salientar que estes valores sugeridos pela ISO 3685 são para testes de vida de ferramentas, e industrialmente esses parâmetros podem assumir valores diferentes, pois eles dependem de vários fấores tais como: rigidez da máquina-ferramenta, precisão requerida na peça, etc., que são diferentes para os diversos processos de fabricação. Uma maneira prática muito utilizada industrialmente é permanecer usando a aresta de corte até que as peças produzidas saiam das especificações de tolerância e/ou acabamento de projeto. 
Sistemas modernos de usinagem utilizam hoje em dia o controle automático do desgaste, indiretamente por meio de monitoramento das componentes de forças, potência ou vibrações do sistema ou diretamente por emissão acústica.

\subsubsection{Mecanismos de desgaste}

Os mecanismos de desgaste resultam de processos físicos e químicos durante a operação de desgaste. Em condições normais de corte, uma das formas de desgaste apresentada na FIGURA 2.28 irá prevalecer, e eles se desenvolvem por vários mecanismos de desgaste. A literatura apresenta variações na classificação dos mecanismos de desgaste, porém, grande parte dos trabalhos existentes, consideram pelo menos seis mecanismos diferentes (PALMAI apud MACHADO \& SILVA, 1999). Diferentes mecanismos de desgaste podem ser observados em HSC, devido à grande quantidade de calor gerada e dissipada durante o corte.

O conhecimento dos fenômenos de desgaste no material de corte selecionado para utilização em ferramentas é um dos principais fatores de seleção. Em usinagem convencional, o mecanismo por abrasão é o mais preocupante. $\mathrm{Na}$ usinagem com altas velocidades de corte, o mecanismo por abrasão torna-se apenas mais um componente a ser considerado. Em HSM, o aumento da temperatura causada pelo aumento da velocidade de corte tende a acelerar a ocorrência de outros fenômenos de desgaste entre a peça e a ferramenta, a exemplo da difusão e da oxidação, e deste modo, necessita de materiais de ferramentas mais refratário tais como as cerâmicas (KRAMER, 1987; ADDHOUM \& BROUSSAUD, 1989; SCHULZ \& MORIWAKI, 1992 e LIWIS apud NOVASKI \& CORRÊA, 1998).

De acordo com LÉON (1997), os diferentes tipos de mecanismos de desgaste que acontecem em HSC são: desgaste abrasivo, mecanismo de difusão, desgaste por aderência e APC, desgaste por deslizamento, deformação plástica, fadiga térmica e mecânica e lascamento. Segundo ADDHOUM \& BROUSSAUD (1989), os mecanismos de desgaste podem ser classificados em duas categorias: desgaste mecânico e desgaste químico. Desgaste mecânico inclui abrasão, adesão e deformação plástica. Desgaste químico acontece principalmente em altas temperaturas (altas velocidades) e envolve processos de difusão e reações químicas entre ferramenta e cavacos e oxidação com a atmosfera. 
TRENT (1984) classifica alguns destes mecanismos na FIGURA 2.30.

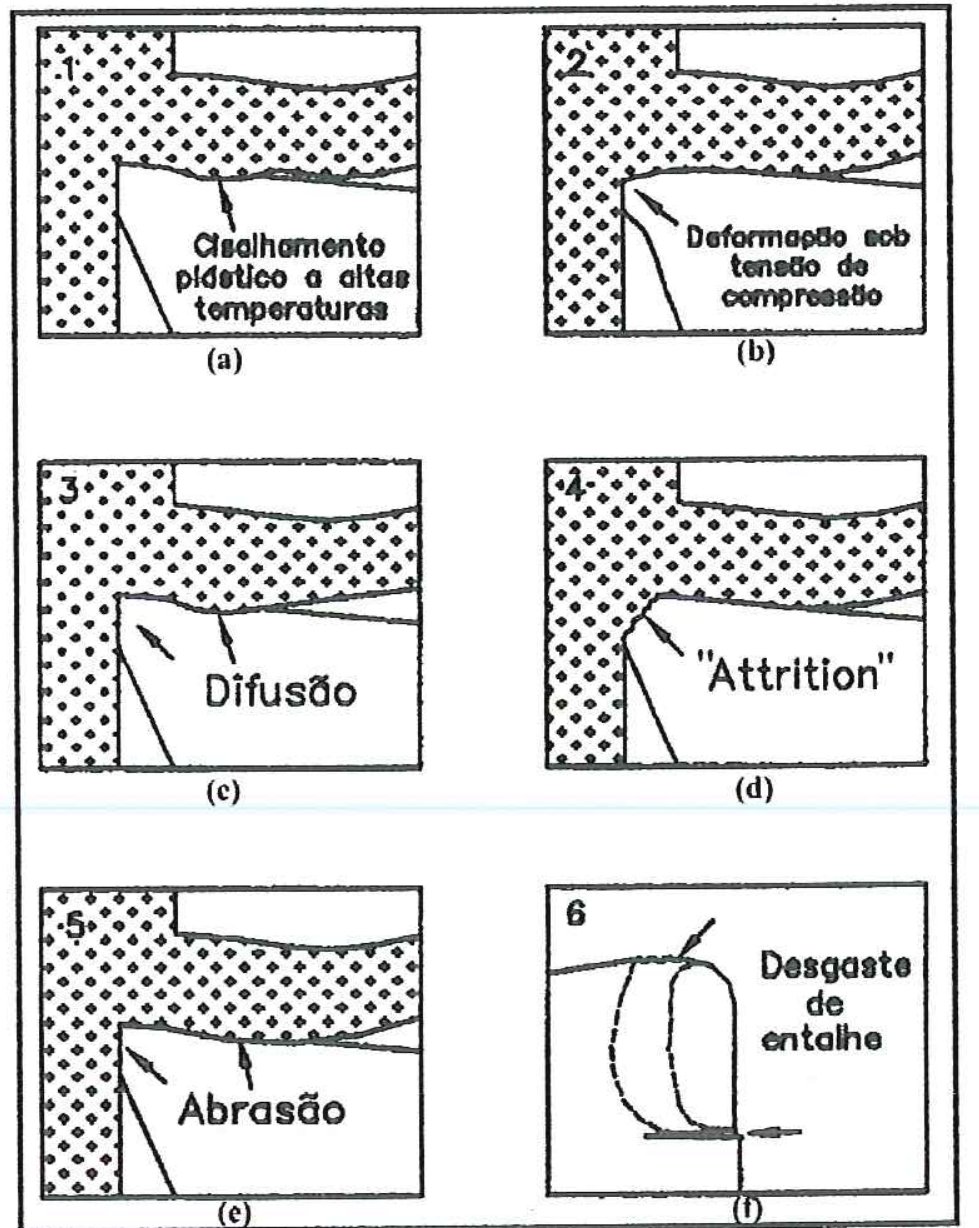

FIGURA 2.30 - Mecanismos de Desgaste que Podem Acontecer nas Ferramentas de Corte (TRENT, 1984).

A seguir, cada um destes mecanismos é definido em separado:

a) Deformação plástica superficial por cisalhamento a altas temperaturas

Ocorre mais provavelmente na usinagem de metais com alto ponto de fusão, utilizando ferramentas de aço-rápido. As tensões cisalhantes na interface cavacoferramenta são suficientes para causar deformação plástica superficial. Devido às altas temperaturas ali deseııvolvidas, a resistência ao escoamento do material da ferramenta, próximo à interface, é reduzida. Como conseqüência, material é arrancado da superficie da ferramenta, formando-se assim uma cratera (FIGURA 2.30.a). 
b) Deformação plástica da aresta de corte sob altas tensões de compressão

Este desgaste ocorre na usinagem dos materiais de alta dureza. A combinação de altas tensões de compressão, com altas temperaturas na superficie de saida, pode causar a deformação plástica da aresta de corte das ferramentas de aço-rápido ou metal duro. O crescimento desta deformação pode gerar a quebra da aresta de corte. É evitada pelo emprego de uma ferramenta com maior dureza a quente e maior resistência à deformação plástica, ou pela mudança das condições de usinagem e/ ou geometria da ferramenta, visando a diminuição dos esforços e da temperatura de corte. Geralmente, ocorre a altas velocidades de corte e avanço e leva a uma falha catastrófica (FIGURA 2.30.b) e na usinagem de aços endurecidos é eventualmente observado quando da utilização de ferramentas cerâmicas (LÉON, 1997). ELBESTAWI et al. (1997) observaram o desenvolvimento da deformação plástica na superficie de saída e presença de lascamento na aresta de corte no fresamento de alta velocidade em peças com dureza de 45 - 55 HRC. JUN et al. (1997) afirmam que a fratura da ferramenta $\mathrm{Al}_{2} \mathrm{O}_{3}+\mathrm{SiC}_{\mathrm{w}}$ quando na usinagem de superligas à base de níquel foi causada por ambos: mecanismo de fratura frágil e deformação plástica. Geralmente fratura frágil acontece em baixas velocidades, sinal que começa a ser observado como lascamento perto da superficie de saída e ponta da ferramenta.

\section{c) Mecanismo por difusão}

Este mecanismo envolve a transferência de átomos de um material para outro e é fortemente dependente da temperatura e da solubilidade dos elementos envolvidos na zona de fluxo (zona de cisalhamento secundário). Quando se empregam velocidades de corte elevadas, o aumento da temperatura de corte é importante e a ferramenta deve, então, demonstrar qualidades suplementares: estabilidade química e pouca afinidade com o material usinado para evitar os mecanismos de degradação por difusão. Segundo TRENT (1984), as velocidades relativas entre ferramenta-peça ou ferramenta-cavaco são altas e o tempo de contato entre esses materiais é muito pequeno. Isto praticamente levaria o mecanismo de difusão a ser desprezível, se não fosse a existência de uma zona de aderência (zona morta ou zona de fluxo) na interface cavaco-ferramenta. As temperaturas na zona de fluxo são também elevadas o suficiente para promover o processo de difusão. A renovação constante da zona de aderência, promovida pela alta taxa de deformação, 
garante um fluxo difusivo também constante. TRENT (1984) afirma que o mecanismo de desgaste poderá atuar tanto na superficie de saída como na superficie de folga, e a taxa de desgaste irá aumentar com o aumento da velocidade de corte e do avanço. Um exemplo típico de mecanismo por difusão é aquele que acontece na ferramenta de diamante quando se usinam ligas ferrosas. A partir de temperaturas não muito altas (em torno de $600^{\circ} \mathrm{C}$ ), devido à alta afinidade entre o carbono do diamante e o ferro do cavaco, o processo de difusão é grandemente incentivado. Segundo ABRÃO et al. (1995) nos testes realizados no torneamento do aço AISI 52100 com dureza de 62 HRC utilizando ferramenta DBC50 e cerâmica mista (CC650), a difusão resultante de altas temperaturas de corte foi o mecanismo predominante de desgaste observado. A mesma conclusão, apresenta SILVA (1998) no torneamento com alta velocidade $\left(V_{c}=400 \mathrm{~m} / \mathrm{min}\right)$ do aço ABNT 4340 temperado utilizando ferramentas de cerâmica mista (CC650) e PCBN (DBC50 e DBC80).

A difusão é responsável principalmente pelo desgaste de cratera em altas velocidades de corte, pois é na superficie de saída da ferramenta que se tem às condições necessárias para a difusão, isto é, alta temperatura (devido às altas velocidades e à zona de aderência) e o tempo de contato cavaco-ferramenta devido à zona de aderência, onde a velocidade de saída do cavaco é zero (DINIZ et al. 1999).

JUN et al. (1997) observaram por análises EDX, a seção entre a ferramenta de $\mathrm{Al}_{2} \mathrm{O}_{3}+\mathrm{SiC}_{\mathrm{w}}$ e a superficie acabada da superliga de níquel (GH169) em altas velocidades de corte, e estas indicam que dois modos de difusão podem acontecer. Níquel e ferro difundindo para dentro do material da ferramenta reagem quimicamente com $\mathrm{SiC}_{\mathrm{w}}$, produzindo $\mathrm{FeSi}$ e $\mathrm{NiSi}$. Esta diminui a resistência à abrasão e a dureza da ferramenta. Além disso, as fibras de $\mathrm{SiC}$ são oxidadas, levando à formação de fase vítrea de dióxido de silício através da interface da $\mathrm{Al}_{2} \mathrm{O}_{3}+\mathrm{SiC}_{\mathrm{w}}$. Esta oxidação poderá ser agravada pelo aumento da velocidade de corte e avanço, causando severos desgastes na ferramenta. NARUTAKI et al. (1993) afirmam também mecanismo de difusão nas ferramentas $\mathrm{Al}_{2} \mathrm{O}_{3}+\mathrm{SiC}_{1}$. e $\mathrm{Si}_{3} \mathrm{~N}_{4}$ no torneamento com alta velocidade do Inconel 718. Por outro lado, utilizando ferramenta cerâmica mista $\left(\mathrm{Al}_{2} \mathrm{O}_{3}+\mathrm{TiC}\right)$ o mecanismo de difusão não acontece revelando melhor estabilidade na usinagem do Inconel 718. 
Segundo KRAMER (1987), a difusividade aumenta exponencialmente com a temperatura conforme os resultados apresentados na FIGURA 2.31 no torneamento de superliga à base de níquel (Inconel 718 - 400HB) com insertos de CBN.

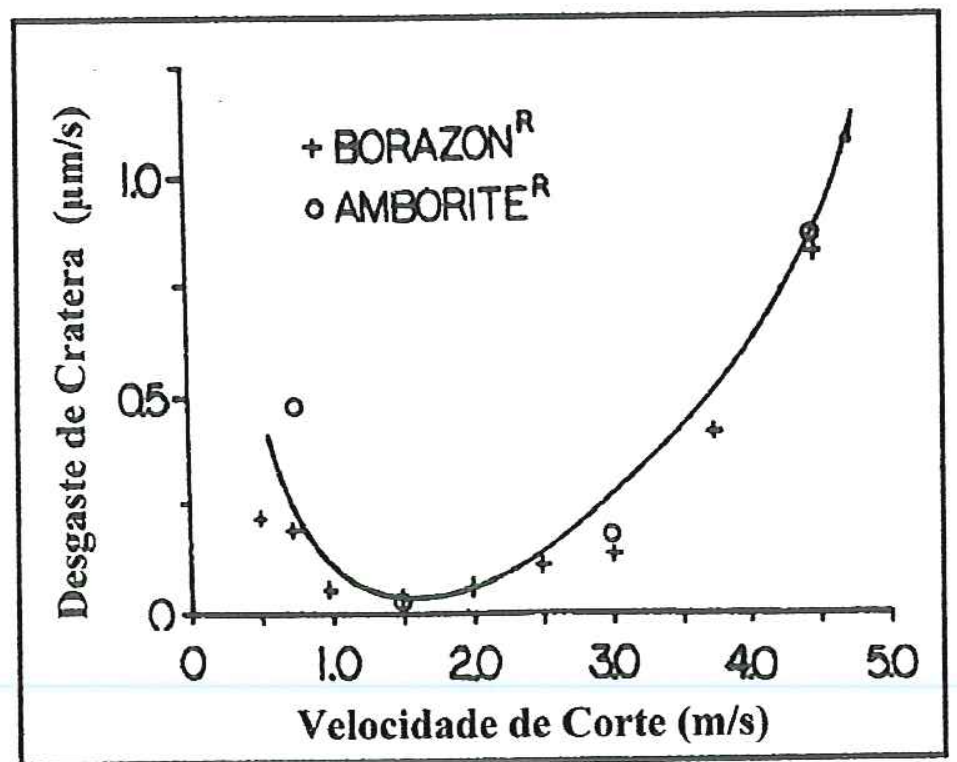

FIGURA 2.31 - Desgaste de Cratera em Ferramentas de CBN em HSC (KRAMER, 1987).

No microscópio as áreas desgastadas por difusão têm uma aparência lisa (FIGURA 2.30.c).

d) Mecanismo por aderência e arrastamento - "attrition"

Este mecanismo ocorre, geralmente, a baixas velocidades de corte, onde 0 fluxo de material sobre a superficie de saida da ferramenta se torna irregular. $O$ fenômeno da aderência está presente na formação da aresta postiça de corte, mas pode-se ter desgaste por aderência mesmo sem a formação da aresta postiça. Sob estas condições, fragmentos microscópicos (na forma de grãos) são arrancados da superficie da ferramenta e arrastados junto ao fluxo de material adjacente à interface (EZUGWU et al. 1999a e MACHADO \& SILVA, 1999).

Segundo DINIZ et al. (1999), uma grande influência na diminuição deste tipo de desgaste é a utilização adequada do fluido de corte (principalmente com efeito lubrificante) e o recobrimento da ferramenta com materiais de baixo coeficiente de atrito como o nitreto de titânio. JUN et al. (1997) afirmam que o desgaste adesivo e "attrition" foram os principais mecanismos de desgaste no torneamento das 
superligas à base de níquel com ferramenta de $\mathrm{Al}_{2} \mathrm{O}_{3}+\mathrm{SiC}_{\mathrm{w}}$ em baixas velocidades. Da mesma opinião é SHARMAN et al. (1999), quando no fresamento com alta velocidade do Inconel 718 com ferramenta de metal duro com cobertura de TiAIN. Assim também pensa EZUGWU et al. (1999a), revelando que o mecanismo de desgaste por "attrition" foi dominante em baixas velocidades no torneamento do Inconel 718 com ferramenta de metal duro com coberturas múltiplas, onde há alta desigualdade de tensões devido a adesão intermitente entre a ferramenta e a peça como resultado do fluxo de cavaco irregular e a quebra parcialmente da aresta postiça de corte estável.

No microscópio, as áreas desgastadas por "attrition" têm uma aparência áspera (FIGURA 2.30.d).

e) Desgaste abrasivo

O desgaste abrasivo envolve a perda de material por microsulcamento ou microcorte causado por partículas de elevada dureza relativa. Estas partículas podem estar contidas no material da peça (carbonetos e carbonitretos), ou podem, principalmente, ser partículas da própria ferramenta que são arrancadas por “attrition”, por exemplo. Segundo MACHADO \& SILVA (1999), este mecanismo de desgaste é muito importante na usinagem com ferramentas de aço rápido, ferramentas revestidas, cerâmicas puras e cerâmicas mistas (FIGURA 2.30.e). Na utilização de ferramentas cerâmicas e PCBN, a presença deste tipo de desgaste se dá principalmente pelo arrastamento de partículas duras de carbonetos do material da peça com o deslocamento dos grãos de CBN que se soltam do material ligante (LUO \& LIAO 1996). No torneamento do aço AISI 4340 com dureza de 50 HRC eles observaram a presença de desgaste abrasivo e aderência. Esta camada de aderência serve como ação protetora, reduzindo o desgaste e consequentemente aumentando a vida da ferramenta.

\section{f) Desgaste de entalhe}

$O$ desgaste de entalhe não é propriamente um mecanismo, mas sim uma forma de desgaste localizado (áreas C e D da FIGURA 2.28). Porém, ainda não existe um consenso na literatura que explique exatamente o mecanismo que provoca o desgaste de entalhe. Por esta razão, é comum tratar esta forma de desgaste como 
um mecanismo. Ele ocorre principalmente na usinagem de materiais resistentes a altas temperaturas (tais como: ligas de níquel, titânio, cobalto e aço inoxidável). Geralmente, nas regiões onde ocorrem estes tipos de desgaste, as condições de escorregamento prevalecem e o mecanismo de desgaste, provavelmente, envolve abrasão e transferência de material (difusão e "attrition") e eles são bastante influenciados pelas interações com a atmosfera (MACHADO \& SILVA, 1999) (FIGURA 2.30.f). É geralmente reconhecido que o desgaste de entalhe é afetado pelos seguintes fatores: geometria de corte, tipo de quebra cavaco, avanço e velocidade de remoção de metal, propriedades termomecânicas da peça, compatibilidade química do material da ferramenta e peça e fatores externos que afetam transformações em reações químicas (WAYNE \& BULJAN, 1990).

KITAGAWA et al. (1997) encontraram presença de desgastes severos do tipo entalhe no torneamento de alta velocidade do Inconel 718 com ferramentas de alumina mista $\left(\mathrm{Al}_{2} \mathrm{O}_{3}+\mathrm{TiC}\right)$ conforme ilustra a FIGURA 2.32. HANASAKI et al. (1996) também observaram a presença em grande escala do desgaste de entalhe no torneamento de uma superliga de níquel contendo $50 \% \mathrm{Ni}, 25 \% \mathrm{Cr}$ e $6 \% \mathrm{Mo}$, utilizando pastilhas de metal duro K10, M10 e P20 de geometria triangular com diversas velocidades de corte na operação de acabamento. O desgaste de entalhe concentrou-se na altura da profundidade de corte, e era o responsável pela fratura da ferramenta principalmente em altas velocidades. Semelhantes resultados apresentaram EZUGWU et al. (1990) no torneamento com refrigeração de alta pressão do Incoloy 901 com ferramentas de metal duro e cerâmica reforçada com whiskers $\left(\mathrm{Al}_{2} \mathrm{O}_{3}+\mathrm{SiC}_{\mathrm{w}}\right)$.

ZHANG (1986) revela que a mudança nos parâmetros de corte tais como: avanço, velocidade de corte e profundidade, exercem influência direta sobre o desgaste de entalhe no torneamento de níquel puro $(99,5 \% \mathrm{Ni})$. Como regra, o desgaste de entalhe é acelerado pelo aumento da velocidade de corte. É aconselhável profundidade de corte inferior à $0,5 \mathrm{~mm}$. Em contraste, JUN et al. (1997) comprovaram que aumentando a velocidade de corte ocorre uma redução na profundidade do desgaste de entalhe, porém um aumento no desgaste de flanco e da ponta da ferramenta no torneamento da superliga GH169 (similar ao Inconel 718) com ferramenta de $\mathrm{Al}_{2} \mathrm{O}_{3}+\mathrm{SiC}_{\mathrm{w}}$. 
Tentativas de usinagem a alta velocidade nas ligas de Inconel 718 e Incoloy 901 demonstraram que o desgaste de entalhe pode ser suprimido pelo emprego da técnica de torneamento cônico. A técnica de torneamento cônico (ou rampamento) é alcançada pela variação da profundidade de corte durante a usinagem. Esta técnica tende para constantemente a troca da profundidade de corte ao longo da aresta cortante, deste modo distribuindo a concentração do esperado desgaste de entalhe. Esta técnica, também resulta na significante redução ou eliminação completa da fratura da aresta de corte causada primeiramente pelo excesso do entalhamento na ponta da ferramenta e ou no fim da região da profundidade de corte. Idealmente, esta conicidade em ligas de níquel deveria estar na faixa de relações de $0,050 \mathrm{~mm}$ em 100 $\mathrm{mm}$ ou de $0,012 \mathrm{~mm}$ em $25 \mathrm{~mm}$. Isto gera uma taxa de variação aceitável da superficie da peça ao longo da aresta de corte. A técnica descrita é vantajosa, independente do material da ferramenta de corte (SMITH, 1994 e EZUGWU et al., 1999).

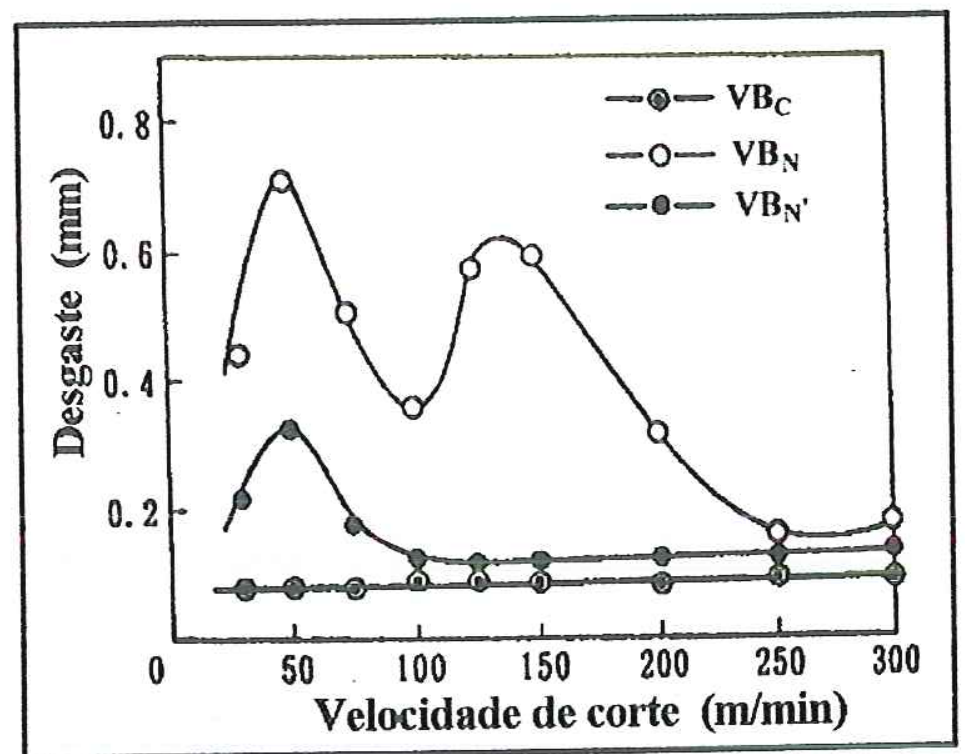

FIGURA 2.32 - Dependência do Desgaste da Ferramenta $\left(\mathrm{Al}_{2} \mathrm{O}_{3}+\mathrm{TiC}\right)$ sobre a Velocidade de Corte à uma Distância de Corte de 50m - VBC: Desgaste de Flanco no Raio; $\mathrm{VB}_{\mathrm{N}}$ : Desgaste de Entalhe na Aresta Principal e $\mathrm{VB}_{\mathrm{N}}$ : Desgaste de Entalhe na Aresta Secundária (KITAGAWA et al., 1997).

Segundo NARUTAKI et al. (1993), com a otimização da geometria da ferramenta pode-se reduzir este tipo de desgaste no torneamento com alta velocidade 
no Inconel 718. Os autores testaram três tipos de formato de pastilhas: quadrada, redonda e especial tipo "S". A FIGURA 2.33 mostra o desempenho do desgaste de entalhe $\left(\mathrm{VB}_{\mathrm{N}}\right)$ para os diversos tipos de ferramentas de $\mathrm{Al}_{2} \mathrm{O}_{3}+\mathrm{TiC}$ após 30 segundos de usinagem. A ferramenta redonda e a tipo " $\mathrm{S}$ " apresentaram pequeno desgaste de entalhe comparadas com a pastilha quadrada. A ferramenta quadrada apresentou maior probabilidade de predominar o desgaste de entalhe. Porém, a ferramenta do tipo redondo tem alguns problemas, como alta força de corte e rigidez. RICHARDS \& ASPINWALL (1989) recomendam para minimizar o desgaste de entalhe na usinagem de superligas de níquel, o uso de ângulo de posição baixo e ângulo de saída negativo. A ferramenta restringe o fluxo de cavaco e obriga o cavaco a se mover ao longo da superficie do ângulo de saída. Isto mostra que a força compressiva na interface cavaco-ferramenta, uma situação o qual, embora não favoreça o mecanismo de formação de desgaste de entalhe, encoraja o mecanismo pồ đifữão. Emi contraste, RAHMAN et al. (1997) comprovaram que a vida da ferramenta é significativamente aumentada com o aumento do ângulo de posição de $5^{\circ}$ para $15^{\circ}$ e $45^{\circ}$. Excelente resistência demostrou quanto ao desgaste de cratera com ângulo de posição de $15^{\circ} \mathrm{e} 45^{\circ}$.

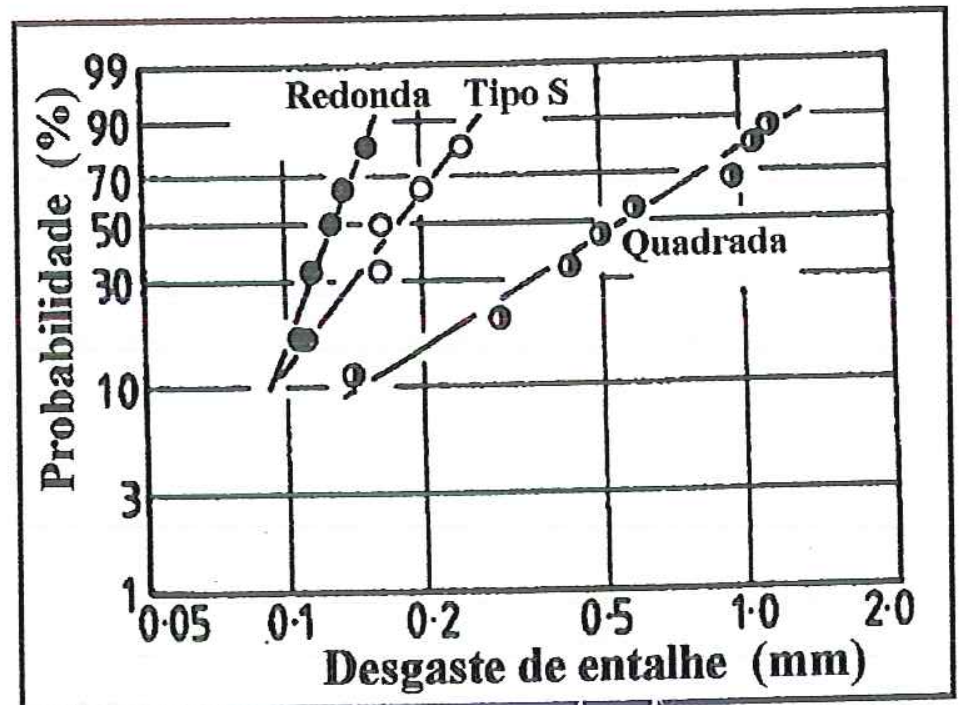

FIGURA 2.33 - Influência da Geometria da Ferramenta no Desgaste de Entalhe $\mathrm{VB}_{\mathrm{N}}$ no Torneamento com Alta Velocidade do Inconel 718 com Ferramenta de $\mathrm{Al}_{2} \mathrm{O}_{3}+$ TiC (NARUTAKI et al., 1993). 
Em resumo, todos estes mecanismos de desgaste são observados na prática, mas certamente um prevalecerá sobre os demais, dependendo principalmente do material da peça e da ferramenta, da operação de usinagem, das condições de corte, da geometria da ferramenta de corte e do emprego do fluido de corte.

GATTO \& IULIANO (1994) revelam que no torneamento com alta velocidade $(250-450 \mathrm{~m} / \mathrm{min})$ do Inconel $718(440 \mathrm{HV})$ com ferramentas de cerâmica $\left(\mathrm{Al}_{2} \mathrm{O}_{3}+\mathrm{SiC}_{\mathrm{w}}\right)$ diferentes tipos de desgaste foram evidentes. No raio de aresta, houve considerável lascamento e a presença de material soldado, como se APC tivesse sido formada. Desgaste devido ao efeito abrasivo do cavaco e a presença notável de desgaste de entalhe também estavam presentes. $\mathrm{O}$ lascamento foi dominante sobre os outros mecanismos de desgaste.

Segundo EZUGWU \& WANG (1996), no torneamento do Inconel 718 com ferramentas de metal duro com coberturas múltiplas, os modos de falhas foram associados aos mecanismos de desgaste de difusão, "attrition", abrasão e deformação plástica atuando individualmente ou em combinação devido à altas temperaturas e altas tensões geradas durante a usinagem, endurecimento da superficie usinada da peça, presença de carbetos abrasivos da superliga e reatividade com o material da ferramenta em altas temperaturas. 


\subsection{Usinagem de superligas à base de níquel}

Em termos gerais, usinabilidade pode ser definida como uma grandeza que indica a facilidade ou dificuldade de se usinar um material. Pode ser usada também para quantificar o desempenho de ferramentas de corte, de fluidos de corte e geometrias de ferramentas. Para obter as melhores condições de usinagem é fundamental que se tenha um bom conhecimento da microestrutura, das propriedades dos materiais envolvidos e dos seus efeitos sobre o comportamento das ferramentas de corte e sobre a eficiência dos processos de usinagem.

Forças de corte, energia requerida na usinagem, vida da ferramenta, acabamento superficial, taxa de desgaste, temperatura de corte, controle de cavaco e mesmo algumas propriedades fisicas, são variáveis que podem ser consideradas como medida da usinabilidade.

A maioria dos resultados de teste de usinabilidade publicada na literatura foram de testes de torneamento, e apesar de que algumas características, possam ser comuns a mais de um processo, é aconselhável não fazer extrapolações para diferentes processos.

O torneamento com alta velocidade de corte aplicado a superligas usando ferramentas de corte foi desenvolvido na última década, em função de melhoramentos das classes cerâmicas: $\mathrm{Al}_{2} \mathrm{O}_{3}$ (particulado), Sialon e $\mathrm{Al}_{2} \mathrm{O}_{3}+\mathrm{SiC}_{\mathrm{w}}$ (whiskers). Atualmente, a cerâmica $\mathrm{Al}_{2} \mathrm{O}_{3}+\mathrm{SiC}_{\mathrm{w}}$ tem melhor desempenho com relação à resistência ao desgaste e à tenacidade (VIGNEAU, 1997).

As principais propriedades das ligas de níquel são alta resistência mecânica à temperaturas elevadas, alta resistência à fluência, alta resistência à fadiga e boa resistência à corrosão. As principais aplicações são na indústria aeronáutica, marítima, nos componentes que trabalham a altas temperaturas $\left(>500^{\circ} \mathrm{C}\right)$, como pás e discos de turbinas, estruturas de aeronaves, câmaras de combustão, válvulas de adrịssão/escape, aplicações médicas, indústrias química e petroquímica, reatores nuclear, foguetes e etc. As superligas representam cerca de 55\% dos materiais usados para construção de motores aeroespaciais (KOMANDURI \& SCHROEDER, 1986; WAYNE \& BULJAN, 1990; GATTO \& IULIANO, 1994; VIGNEAU, 1997; CHOUDHURY \& BARADIE, 1998 EZUGWU et al. 1999a e MACHADO \& SILVA, 1999). 
As superligas de níquel são endurecidas pela precipitação de $\mathrm{Ni}_{3}$ (Al-Ti) fase (gama) e pela solução sólida de elementos refratários na matriz, e a resistência mais alta à temperatura é obtida pelo aumento da fração de volume desta fase.

A família das superligas de níquel (Inconel) apresenta uma composição química numa faixa relativamente ampla de percentuais, destacando-se os seguintes elementos: níquel até $79,6 \%$; cromo até $23 \%$ e molibdênio até $9 \%$ (BOEHS et al. 1995). Se por um lado a composição química com elevado teor de elementos de liga confere excelentes propriedades mecânicas e térmicas às superligas de níquel, por outro lado, elas dificultam demasiadamente a realização da usinagem desses materiais.

CHOUDHURY \& BARADIE (1998) e EZUGWU et al. (1999) apresentam a classificação, a composição química e a densidade das principais superligas à base de níquel, compilada na TABELA 2.5 .

TABELA 2.5 - Composição química nominal (\% peso) e densidade das superligas à base de níquel forjadas (CHOUDHURY \& BARADIE, 1998 e EZUGWU et al., 1999).

\begin{tabular}{|l|c|c|c|c|c|c|c|c|c|c|c|c|c|}
\hline $\begin{array}{c}\text { Designação } \\
\text { da liga }\end{array}$ & Ni & Cr & Co & Mo & W & Al & Ti & Fe & Mn & Si & C & Nb & $\begin{array}{c}\text { Densi- } \\
\text { dade } \\
\left(\mathbf{K g} / \mathbf{m}^{3}\right)\end{array}$ \\
\hline Astroloy & 55.1 & 15.0 & 17.0 & 5.25 & - & 4.0 & 3.5 & - & - & - & 0.06 & - & 7.91 \\
\hline Hastelloy X & 47.3 & 22.0 & 1.5 & 9.0 & 0.6 & - & - & 18.0 & 0.50 & 0.50 & 0.10 & - & 8.22 \\
\hline Inconel 600 & 76.6 & 15.8 & - & - & - & - & & 7.2 & 0.20 & 0.20 & 0.04 & - & 8.33 \\
\hline Inconel 625 & 61.6 & 22.0 & - & 9.0 & - & 0.2 & 0.2 & 3.0 & 0.15 & 0.15 & 0.05 & 4.0 & 8.44 \\
\hline Inconel 706 & 41.5 & 16.0 & 0.5 & 0.5 & - & 0.2 & 1.7 & 40.0 & 0.18 & 0.18 & 0.03 & 2.9 & 8.08 \\
\hline Inconel 718 & 53.0 & 18.6 & - & 3.1 & - & 0.4 & 0.9 & 18.5 & 0.20 & 0.30 & 0.04 & 5.0 & 8.19 \\
\hline Inconel X-750 & 73.0 & 15.0 & - & - & - & 0.8 & 2.5 & 6.8 & 0.70 & 0.30 & 0.04 & 0.9 & 8.30 \\
\hline IN-102 & 67.9 & 15.0 & - & 3.0 & 3.0 & 0.4 & 0.6 & 7.0 & - & - & 0.06 & 3.0 & 8.55 \\
\hline IN-853 & 74.6 & 20.0 & - & - & - & 1.5 & 2.5 & - & - & - & 0.05 & - & 8.09 \\
\hline M-252 & 55.2 & 20.0 & 10.0 & 10.0 & - & 1.0 & 2.6 & - & 0.50 & 0.50 & 0.15 & - & 8.25 \\
\hline Nimonic 75 & 78.8 & 20.0 & - & - & - & - & 0.4 & - & 0.10 & 0.75 & 0.01 & - & 8.37 \\
\hline Nimonic 80A & 74.7 & 19.5 & 1.1 & - & - & 1.3 & 2.5 & - & 0.10 & 0.70 & 0.06 & - & 8.22 \\
\hline Nimonic 90 & 57.4 & 19.5 & 18.0 & - & - & 1.4 & 2.4 & - & 0.50 & 0.70 & 0.07 & - & 8.18 \\
\hline Nimonic 115 & 57.3 & 15.0 & 15.0 & 3.5 & - & 4.0 & 4.0 & - & - & - & 0.15 & - & 7.85 \\
\hline Nimonic 120 & 63.8 & 12.5 & 10.0 & 3.7 & - & 4.5 & 3.5 & - & - & - & 0.04 & - & 7.95 \\
\hline Pyromet 860 & 43.0 & 12.6 & 4.0 & 6.0 & - & 1.2 & 3.0 & 30.0 & 0.05 & 0.05 & 0.05 & - & 8.23 \\
\hline René 41 & 55.3 & 19.0 & 11.0 & 10.0 & - & 1.5 & 3.1 & - & - & - & 0.09 & - & 8.25 \\
\hline René 95 & 61.3 & 14.0 & 8.0 & 3.5 & 3.5 & 3.5 & 2.5 & - & - & - & 0.15 & - & 8.23 \\
\hline TRW -NASA & 61.0 & 6.1 & 7.5 & 2.0 & 5.8 & 5.4 & 1.0 & - & - & - & 0.13 & 0.5 & 8.66 \\
\hline Unimet 500 & 53.6 & 18.0 & 18.5 & 4.0 & - & 2.9 & 5.9 & - & - & - & 0.08 & - & 8.02 \\
\hline Unimet 710 & 54.9 & 18.0 & 15.0 & 3.0 & 1.5 & 2.5 & 5.0 & - & - & - & 0.07 & - & 8.08 \\
\hline Waspaloy & 58.3 & 19.5 & 13.5 & 4.3 & - & 1.3 & 3.0 & - & - & - & 0.08 & - & 8.19 \\
\hline & & & & & & & & & & \\
\end{tabular}


De acordo com SHAW (1984); WAYNE \& BULJAN (1990); DARWISH (1997); MACHADO \& SILVA (1999); KÖNIG \& GERSCHWILER (1999); SHARMAN et al. (1999) e EZUGWU et al. (1999), os principais problemas na usinagem das superligas à base de níquel, devido às características e propriedades citadas, são:

a) Possuem matrizes austeníticas (CFC) e como os aços inoxidáveis, eles encruam rapidamente durante a usinagem, produzindo um severo endurecimento da peça. Isto pode causar problemas em passes subsequentes, contribuindo principalmente para a progressão do desgaste de entalhe na ponta da ferramenta e/ou na altura da profundidade de corte;

b) A alta resistência dessas ligas é mantida a elevadas temperaturas, e isto se opõe ao processo de deformação plástica necessária para formar o cavaco, mesmo a temperaturas de corte elevadas;

c) Esses materiais têm a tendência de reagirem com as ferramentas, em determinadas condições atmosféricas, conduzindo para alta taxa de desgaste do tipo difusão;

d) Tendências desses materiais se aderirem às superficies das ferramentas. Isto é mais crítico no processo de fresamento, pois a ferramenta ao sair do corte, mantém consigo o cavaco aderido à sua superficie de saida, o que além de prejudicar o acabamento superficial, causa lascamento de ferramenta na reentrada do corte;

e) Tendências das ligas formarem APC a velocidades de corte baixas, o que causa pobres acabamentos superficiais;

f) A presença de carbonetos duros e abrasivos na matriz dessas superligas aumenta a presença de desgaste abrasivo severo nas ferramentas;

g) A condutividade térmica é baixa, o que contribui para o desenvolvimento de altas temperaturas na ponta da ferramenta como também alto gradiente térmico na ferramenta.

Todos estes fatores operando juntos ou em combinação causam altas temperaturas de corte (podem chegar a $1000^{\circ} \mathrm{C}$ ) e alta tensão de compressão na superficie de saída (pode chegar a $3450 \mathrm{MPa}$ ) o que leva ao desenvolvimento rápido do desgaste de flanco, cratera ou desgaste de entalhe, dependendo do material da 
ferramenta e das condições de corte (EZUGWU et al. 1990; GATTO \& IULIANO, 1994 e CHOUDHURY \& BARADIE, 1998). Devido à estas condições desfavoráveis, as velocidades convencionais de corte com ferramentas de carbeto são de $80 \%$ a $90 \%$ mais baixas que as de aços comuns. No geral, as taxas de remoção de material são baixas, independente do processo de corte (VIGNEAU, 1997).

\subsubsection{Materiais de ferramentas para usinagem de superligas à base de} níquel

Das diversas variáveis que afetam o bom desempenho das operações de usinagem, a ferramenta de corte, embora pequena e de relativo baixo custo, é a mais crítica. GATTO \& IULIANO (1994) e EZUGWU et al. (1999) afirmam que a vida de ferramenta obtida na usinagem das superligas à base de níquel é severamente inadequada, tendo como conseqüência o aumento do custo de produção. Na maior parte, os principais parâmetros que compreendem o processo e que mais prejudicam um melhor desempenho são: seleção do material da ferramenta, geometria da ferramenta, método de usinagem, velocidade de corte, avanço, profundidade de corte, e etc. Com esses parâmetros bem controlados, pode-se conseguir tempo de vida adequado para as ferramentas durante a usinagem. Algumas ligas à base de níquel podem atingir valores de dureza na faixa de 250 a $440 \mathrm{HV}$.

As exigências para as ferramentas empregadas na usinagem das superligas abrangem aos seguintes aspectos: excelente resistência ao desgaste, alta resistência e tenacidade em alta temperatura, alta dureza a quente, resistência ao choque térmico, alta condutividade térmica e suficiente estabilidade química em altas temperaturas (ADDHOUM \& BROUSSAUD, 1989; THANGARAJ \& WEINMANN, 1992; JUN et al. 1997; GATTO \& IULIANO, 1997 e EZUGWU et al. 1999).

As superligas à base de níquel são normalmente usinadas com metal duro (WC - Co) com velocidades de corte na faixa de 10-30 m/min. Porém, ferramentas de metal duro não podem ser utilizadas na usinagem com alta velocidade, porque elas não resistem às altas temperaturas e tensões na zona de corte. A FIGURA 2.34 mostra as velocidades de corte de ferramentas de carbeto e de cerâmica de acordo com sua resistência à temperatura. Observa-se que a temperatura aumenta quando a velocidade de corte aumenta (VIGNEAU, 1997). 


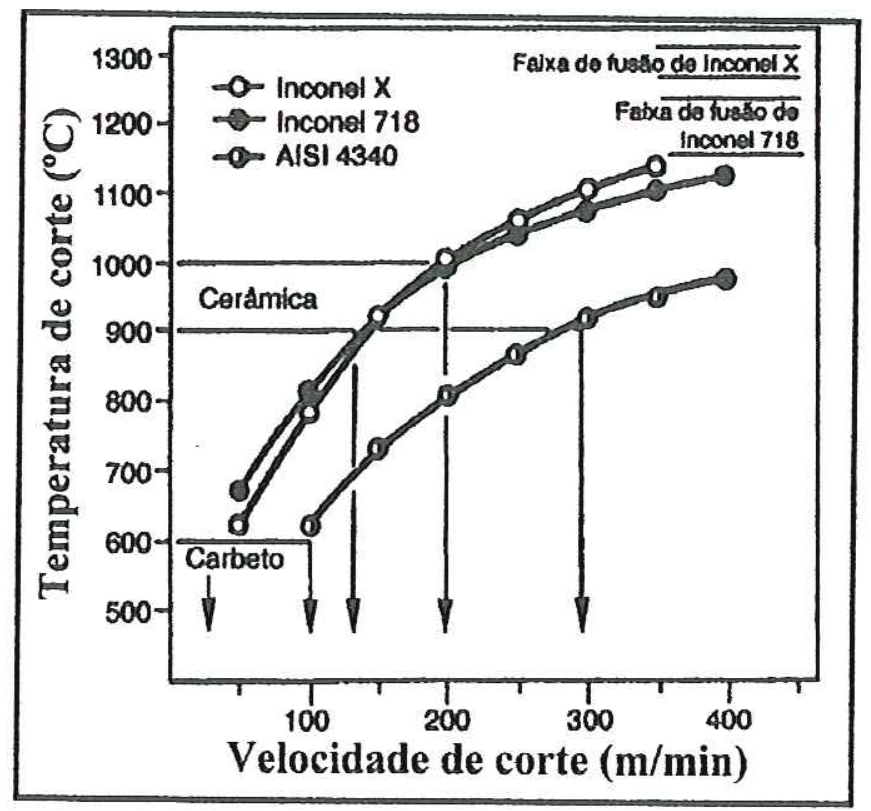

FIGURA 2.34 - Temperatura de Corte versus Velocidade de Corte (VIGNEAU, 1997).

Ferramentas cerâmicas são mais satisfatórias para o uso em altas velocidades de corte. Com a introdução das cerâmicas do tipo sialon (a base de $\mathrm{Si}_{3} \mathrm{~N}_{4}$ ) é possível multiplicar a velocidade de corte pelo fator de 5 e mais recentemente, ferramenta de alumina reforçada com whiskers $\left(\mathrm{Al}_{2} \mathrm{O}_{3}+\mathrm{SiC}_{\mathrm{w}}\right.$ - contendo $\left.25 \% \mathrm{SiC}\right)$, possibilita utilizar velocidade de corte de até 10 vezes comparada com as ferramentas de metal duro. $\mathrm{O}$ último material tem o custo muito alto, sendo o mesmo fundamentalmente importante para automatizar os parâmetros de corte, de forma que finalmente é possível reconciliar as exigências da produção, o qual iria sempre demandar o corte a alta velocidade, tendo como benefício uma maior vida da ferramenta e a confiabilidade do processo de corte. Os aços rápido são empregados principalmente nas operações de corte interrompido à baixas velocidades (BRANDT et al. 1990; VIGNEAU, 1997; CHOUDHURY \& BARADIE, 1998 e EZUGWU et al. 1999).

RICHARDS \& ASPINWALL (1989) apresentaram uma revisão sobre a aplicação de cerâmicas na usinagem das ligas de níquel. Foi destacado que com o emprego de alumina reforçada com Whiskers $\left(\mathrm{SiC}_{\mathrm{w}}\right)$, velocidades de corte podem chegar à $750 \mathrm{~m} / \mathrm{min}$ na usinagem de algumas ligas. $O$ desgaste de entalhe, muitas vezes pode predominar e neste caso, são recomendados pequenos valores do ângulo de posição $\left(\cong 45^{\circ}\right)$ e ângulos de saídas negativos. Da mesma opinião, KÖNIG \& 
GERSCHWILER (1999) revelaram que o ângulo de posição $\cong 45^{\circ}$ demostrou ser favorável às operações de torneamento com ferramentas cerâmicas e PCBN. A alta condutividade térmica e a baixa expansão térmica dos whiskers também aumenta a resistência ao choque térmico.

As ferramentas de alumina mista $\left(\mathrm{Al}_{2} \mathrm{O}_{3}+\mathrm{TiC}\right)$ são também adequadas para usinagem com alta velocidade e altos valores de avanços. Apesar da inferioridade da tenacidade, as mesmas apresentam excelente resistência ao desgaste e à difusão química. A introdução de TiC melhora as propriedades térmicas quando da usinagem das superligas à base de níquel (NOAKER, 1991).

Segundo EZUGWU et al. (1999), a utilização de ferramentas de metal duro com múltiplas camadas $(\mathrm{TiN}+\mathrm{TiCN}+\mathrm{TiN})$ manufaturadas pela técnica de deposição de vapor físico (PVD) têm também mostrado notável melhora na usinagem das superligas à base de níquel. GATTO \& IULIANO (1997) tem a mesma opinião no que se refere ao revestimento com $\mathrm{CrN}$ e $(\mathrm{Ti}, \mathrm{Al}) \mathrm{N}$ em cerâmicas reforçadas com whiskers $\left(\mathrm{Al}_{2} \mathrm{O}_{3}+20 \% \mathrm{SiC}_{\mathrm{w}}\right)$ proporcionando maior vida e minimizando os efeitos de temperatura. Por outro lado, CHOUDHURY \& BARADIE (1998) revelam que ferramentas sem cobertura têm melhor desempenho que as ferramentas com cobertura para usinagem do Inconel 718. Aparentemente, a camada não melhora o desempenho das ferramentas cobertas.

Os mecanismos e formas de desgaste das ferramentas cerâmicas são complexos e geralmente são influenciados por: difusão, lascamento, abrasão na superficie de folga, adesão na superfície de saída, abrandamento térmico, fratura catastrófica, cratera e desgaste de entalhe no flanco e na aresta secundária e deformação plástica. $\mathrm{O}$ mecanismo por difusão é determinado principalmente pela reação química e dissolução no material da peça. As superligas à base de níquel têm alta afinidade química com muitos materiais de ferramenia e, como tal, freqüentemente forma uma camada de aderência conduzindo aos desgastes de difusão e arrastamento (attrition). O gradiente químico indica difusão de $\mathrm{Ni}$, Cr e Fe do Inconel e $\mathrm{Si}$ do material da ferramenta (WAYNE \& BULJAN, 1990; THANGARAJ \& WEINMANN, 1992; GATTO \& IULIANO, 1994; JUN et al., 1997; CHOUDHURY \& BARADIE, 1998 e SHARMAN et al., 1999). Geralmente, encontra-se o desgaste de entalhe na altura da profundidade de corte, como o 
responsável pela rejeição da ferramenta de corte à baixas velocidades de corte. Com altas velocidades de corte, o desgaste de flanco compete com o desgaste de entalhe, dependendo do tipo de cerâmica utilizada. Para WAYNE \& BULJAN (1990), a profundidade do desgaste de entalhe em ferramentas cerâmicas é conseqüência da interação química entre a ferramenta e o cavaco possibilitando a formação da aresta postiça de corte (APC). Se a profundidade do desgaste de entalhe é um mecanismo de desgaste químico, então a expectativa é que o desgaste de entalhe seja dependente da temperatura e aumente em altas velocidades de corte. A essa consideração, acrescentam JUN et al. (1997), que deformação plástica, difusão e desgaste por aderência e "attrition" contribuem muito para com o desgaste de flanco e fratura catastrófica da aresta em altas velocidades devido à altas tensões, removendo agregados dos grãos.

Em fresamento em Inconel 718 utilizando cerâmica reforçada com whiskers, geometria redonda e quadrada, mostra-se que os insertos suportam com eficiência três tipos de desgaste: desgaste de flanco, entalhe e abrasão. $\mathrm{O}$ desgaste de entalhe foi predominante em todas condições de corte. Insertos com geometria redonda apresentaram melhor desempenho em comparação com a quadrada, devido à maior resistência na aresta auxiliando na resistência ao desgaste de entalhe (ELBESTAWI et al., 1993). Estes desgastes foram observados também por THANGARAJ \& WEINMANN (1992) no torneamento com alta velocidade utilizando cerâmica reforçada com whiskers de geometria redonda.

De acordo com GATTO \& IULIANO (1994), para uma otimização dos parâmetros de usinagem e a construção de modelo de vida da ferramenta deve-se levar em consideração a análise de formação de cavaco e o mecanismo de desgaste. Uma análise macroscópica e microscópica criteriosa é necessária para destacar, na mudànça dos parâmetros de corte, quais os vários mecanismos de desgaste envolvidos é mais importante que os outros e condições de vida da ferramenta.

RICHAFDS \& ASPINWALL (1989); KÖNIG \& GERSCHWIL'R (1999) e MACHADO \& SILVA (1999) afirmam que algumas superligas à base de níquel podem ser usinadas eficazmente com o emprego de ferramenta de PCBN, principalmente no torneamento de acabamento, proporcionando um menor nível de desgaste, mas o alto custo destas ferramentas torna sua aplicação economicamente 
inviável. TAKATSU apud EZUGWU et al. (1999) afirmam que nos testes de torneamento do Inconel 718 utilizando ferramentas de PCBN com concentração de $30-95 \%$ PCBN, o desgaste de entalhe se reduz significativamente com o aumento da concentração de PCBN, enquanto que a média do desgaste de flanco apresentou pequena variação, obtendo o mínimo na concentração de 55\% de PCBN. Por outro lado, ELBESTAWI et al. (1993) afirmam que ferramentas de PCBN são também suscetíveis às altas taxas de desgaste por difusão e subsequente perda de cristais. A essa consideração, acrescentam KÖNIG \& GERSCHWILER (1999) revelando que a resultante das propriedades química, física e mecânica tem uma decisiva influência sobre o desgaste e o comportamento do desempenho de ferramentas de PCBN. Classes de PCBN com constituição estimada de 30-50\% em volume de TiC ou TiN são satisfatórias para operação de acabamento em Inconel 718 e Waspaloy.

Para BILLMAN apud ABRÃO et al. (1993), a ferramenta de cerâmica reforçada com whiskers (WRA) é o material de ferramenta mais adequado para usinagem de superligas à base de níquel. Em velocidades de corte entre $100-250$ $\mathrm{m} / \mathrm{min}$, ferramentas de WRA e sialon $\left(\mathrm{Si}_{3} \mathrm{~N}_{4}\right)$ tem-se vida comparável, contudo, em altas velocidades $(250-420 \mathrm{~m} / \mathrm{min})$, a vida de WRA foi mais que o dobro que a ferramenta de sialon. Assim também pensa BRANDT et al. (1990), afirmando praticamente as mesmas conclusões quando da comparação das ferramentas cerâmicas CC670 e CC680 no torneamento do Inconel 718.

Segundo ERRICO \& CALZAVARINI (1995), as cerâmicas reforçadas com whiskers $\left(\mathrm{Al}_{2} \mathrm{O}_{3}+\mathrm{SiC}_{\mathrm{w}}\right)$ podem não ser consideradas como alternativa econômica em comparação com as outras cerâmicas no torneamento contínuo e descontínuo de ferro fundido e aço temperado. Por outro lado, elas não necessitam de refrigeração e são consideradas as mais apropriadas no torneamento de superligas à base de níquel.

\subsubsection{Integridade superficial na usinagem de superligas à base de níquel}

A questão da qualidade de componentes usinados é hoje em dia fortemente discutida e cada vez mais se exige componentes mecânicos com alta eficiência, não só pelo aspecto funcional, mas também pelo lado da segurança. Quando se produz qualquer componente através de operações que envolvam o cisalhamento do material da peça, deve-se ter em mente que a sua superficie apresenta irregularidades 
resultantes da ação inerente ao processo de produção, além de fatores tais como: deflexão, vibração ou trepidação da máquina ou peça. $\mathrm{O}$ controle da rugosidade superficial é necessário para dar a máxima condição satisfatória ao componente usinado, para que o mesmo tenha vida longa, resistência à fadiga, máxima eficiência e intercambiabilidade funcional. A textura superficial pode ter uma influência decisiva na aplicação e desempenho do componente usinado (EZUGWU \& TANG, 1995). Segundo SADAT (1987) e ANDRAE (1999), o aumento da velocidade de corte afeta positivamente a integridade superficial de peças assim como a qualidade do componente.

Entre os fatores que afetam a integridade superficial da peça nas operações de usinagem, os mais críticos provavelmente referem-se a desgaste da ferramenta, velocidade de corte, profundidade de corte e avanço. $\mathrm{O}$ desgaste da ferramenta aumenta o atrito entre a ferramenta e a superficie usinada, aumentando a temperatura que induz tensões normais e de cisalhamento, conduzindo à deformação superficial e subsuperficial que podem causar tensões residuais, e velocidades baixas podem resultar no desenvolvimento de danos causados pela presença de aresta postiça de corte. O efeito da velocidade de corte sobre a tensão residual induzida depende, em grande parte das propriedades do material da peça e da ferramenta. $\mathrm{O}$ aumento da espessura do cavaco permite muito mais dissipação de calor através dos cavacos, o qual reduz a tensão de tração interna gerada na peça pela tensão térmica. A distribuição da tensão residual é afetada pela mudança da profundidade de corte. Assim, as fontes que ocasionam tensão residual na superfície usinada podem ser: transformação de fase, tensão térmica devido às irregularidades de aquecimento e resfriamento da camada superficial e deformação mecânica (BRINKSMEIER et al. 1982; MATSUMOTO et al. 1986; ABRÃO \& ASPINWALL, 1996; CAPELLO et al. 1999 e ELWARDANY et al. 2000).

No que se refere à metalurgia superficial do componente usinado, o calor gerado durante o corte é a maior fonte de danos, particularmente no caso da retificação, que é um processo menos eficiente energeticamente do que o corte por geometria definida e gera temperaturas mais elevadas. No caso do torneamento, a superficie usinada é gerada principalmente pelo raio de ponta da ferramenta e pela aresta de corte secundária e, apesar de algum calor ser gerado devido ao atrito, a 
maior parte do calor desenvolvido na zona de cisalhamento flui para os cavacos e não para a peça. Quando a ferramenta não é chanfrada, a deformação plástica da camada superficial da peça é a principal causa da tensão residual. O campo térmico representa a menor parte, apesar da crescente importância com o aumento do desgaste de flanco. No torneamento, o conhecimento da correlação entre rugosidade superficial, tensão residual e parâmetros de processos não estão bem definidos, necessitando de um estudo mais amplo (CAPELLO et al. 1999). EZUGWU \& WALLBANK (1988) relataram que as geometrias negativas podem levar a uma força de compressão residual favorável e aumentar a resistência à fadiga dos componentes usinados por ferramentas cerâmicas.

A TABELA 2.6 mostra uma classificação da integridade superficial, que é subdividida em irregularidades geométricas da superficie e alterações metalúrgicas na subsuperficie (MACHADO \& SILVA, 1999).

TABELA 2.6 - Classificação da integridade superficial (MACHADO \& SILVA, 1999).

\begin{tabular}{|l|l|}
\hline \multicolumn{1}{|c|}{ Acabamento superficial } & \multicolumn{1}{|c|}{ Alterações sub-superficiais } \\
\hline Rugosidade superficial & Deformação plástica \\
Ondulações & Rebarbas deformadas plasticamente \\
Marcas indicando a direção das & Micro ou macrotrincas \\
irregularidades & Tensões residuais \\
Falhas & Alterações metalúrgicas \\
& Recristalização e crescimento de \\
& grãos \\
\hline
\end{tabular}

De acordo com EZUGWU \& WANG (1996); VIGNEAU (1997) e EZUGWU et al. (1999), a usinagem de superligas induz efeitos na integridade da superficie, os quais incluem:

Alta rugosidade superficial;

Modificações na dureza da camada superficial devido ao endurecimento da peça;

Microtrincas ou macrotrincas particularmente em retificação;

Deformação plástica;

* Transformações metalúrgicas atribuídas à alta temperatura; 
Tensões residuais (tração ou compressão);

Alterações químicas incluindo alta temperatura de oxidação e difusão entre a peça e o material da ferramenta.

Por essa razão, deve-se tomar cuidados especiais para assegurar a vida da ferramenta e a integridade superficial adequada a componentes usinados por intermédio de controle dos principais parâmetros, incluindo escolha do material e geometria da ferramenta, método de usinagem, velocidade de corte, valores de avanço, profundidade de corte e etc., principalmente em superligas à base de níquel, uma vez que suas aplicações são mais extensas em aeronaves e usinas de energia nuclear, onde as sensíveis superficies podem afetar as propriedades (fadiga, fratura/trinca por tensão de corrosão e fluência) tendo um grande impacto na vida em serviço dos componentes (BRINKSMEIER et al. 1982; SADAT, 1987; EZUGWU \& WANG, 1996 e EZUGWU et al. 1999a). De acordo com CAPELLO et al. (1999), os fatores que mais afetam a tensão residual são principalmente influenciados pelo raio de ponta e pelo avanço, enquanto que velocidade de corte e ângulo de saída representam papel secundário no torneamento dos aços $\mathrm{C} 45$ e 39NiCrMo3. Por outro lado, MATSUMOTO et al. (1999) comprovaram que os valores de avanço e profundidade de corte não afetam significativamente o perfil da tensão residual na subsuperficie. Os pesquisadores testaram ferramentas com geometrias de aresta de corte com quina viva, raio de aresta e duplo chanfro, e manifestaram que a geometria da aresta de corte é o fator dominante, determinando o perfil da tensão residual no torneamento do aço ABNT 52100 temperado.

A iniciação de trincas em componentes pode, muitas vezes, estar correlacionada a tensões residuais de tração. Como as trincas se expandem, a resistência da seção é reduzida e, então, a seção poderá não mais resistir à carga aplicada e uma falha poderá ocorrer. Portanto, é importante conhecer exatamente os efeitos do processo de usinagem sobre a integridade da superficie, e também, ter certeza da capacidade de reprodução destes efeitos quando um parâmetro de usinagem é modificado, ainda que levemente, para manter as tensões residuais sob controle. No torneamento de superligas à base de níquel, o aumento da velocidade de corte, da convencional para a alta, leva a diminuir o pico de tensão de tração na superficie e a aumentar o pico de tensão de compressão, o que é benéfico nas 
propriedades de resistência mecânica, conforme mostra a FIGURA 2.35. Os efeitos do fresamento a alta velocidade ainda não são muito bem conhecidos, mas já se sabe que algumas de suas condições induzem a altas tensões de tração (VIGNEAU, 1997). Em contraste, VIGNEAU \& BOULANGER (1982) afirmam que o aumento da velocidade de corte não efetua mudança significativa no limite de fadiga no torneamento de superligas à base de níquel $(\mathrm{NC} 19 \mathrm{FeNb})$ com ferramentas de metal duro e cermet.

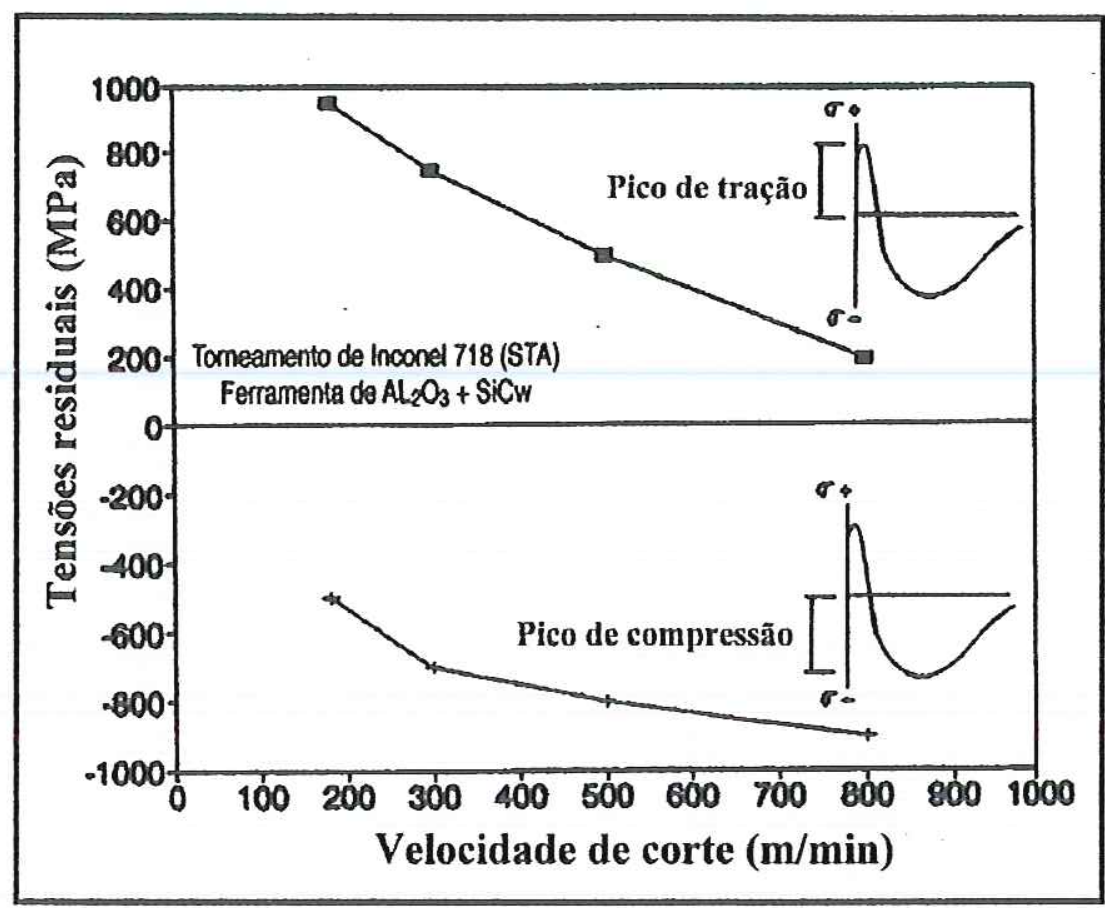

FIGURA 2.35 - Efeito do Torneamento com Alta Velocidade sobre as Tensões Residuais (VIGNEAU, 1997).

EZUGWU et al. (1999) revelaram que o torneamento com ferramenta nova que possua aresta afiada e ângulo de saída positivo tende a minimizar o valor da tensão residual, da deformação plástica e do endurecimento da peça. A geometria da ferramenta de corte pode também afetar a superficie usinada. Melhoria do acabamento superficial e mínima camada danificada podem ser obtidos com a utilização de insertos redondos. Usinagem prolongada tende a aumentar a dureza da camada da superfície e também deteriorar a superfície usinada. Isto pode ser atribuído ao desgaste de flanco severo, e consequentemente ao aumento das componentes de forças e da temperatura de corte devido ao aumento da área de 
contato relativo ao movimento entre o desgaste de flanco e a ponta da ferramenta. Condições de usinagem que introduzem altas tensões sobre a superficie usinada devem sempre ser evitadas e esforços devem ser feitos para assegurar a tensão de compressão sempre que possível. Efeitos desagradáveis na superfície usinada podem ser minimizados pelo uso de métodos e condições de usinagem apropriadas. LIU \& BARASH (1976), pesquisando o efeito do desgaste de flanco da ferramenta de usinagem sobre a integridade superficial de peças usinadas, constataram que o aumento do desgaste de flanco faz aumentar o atrito superficial entre a ferramenta e a superficie usinada e, como conseqüência, um aumento na temperatura afeta a tensão residual.

Deformação plástica excessiva ocorre após usinagem prolongada devido à ação combinada do aumento das componentes de forças, assim como a pressão e temperatura de corte superior na interface entre a ferramenta e a superficie usinada (EZUGWU et al. 1999a).

KÖNIG \& GERSCHWILER (1999) revelaram que o desgaste de entalhe na aresta de corte secundária conduz a um pobre acabamento superficial e na aresta principal resulta em formação de rebarbas na peça. Os pesquisadores afirmam também que deformação plástica da microestrutura acontece na superfície da peça por causa da operação de usinagem, causando endurecimento e aumentando a dureza final da peça (encruamento). A extensão da deformação e o valor da dureza aumentam dependendo dos parâmetros de corte, geometria e desgaste da ferramenta. A deformação plástica da superficie pode estar associada à mudança na forma do grão. Deformação plástica é visível com microscópico óptico e geralmente estendese acima de $20 \mu \mathrm{m}$ da superficie. Medida da microdureza mostra um significante aumento da dureza na superficie causada pela deformação plástica. Alterações induzidas na superficie pelo processo de fabricação podem afetar substancialmente as propriedades do componente.

Segundo DARWISH (1997), no tornesmento de superligas à base de níquel, a ferramenta cerâmica (Sandvik CC680) obteve menor valor de rugosidade superficial comparado com os insertos de PCBN (Sandvik CB50) na faixa de avanço de 0,075 $0,6 \mathrm{~mm} / \mathrm{rev}$. 
Estudos comparativos de componentes produzidos com ferramentas de PCBN e de cerâmica utilizando alta velocidade não mostram efeitos negativos significantes dos parâmetros de corte na microestrutura e nos testes de fadiga, quando comparados com a usinagem com ferramentas de carbetos.

\subsection{Aspectos da utilização de fluidos de corte em usinagem}

Os fluidos refrigerantes para usinagem baseados em emulsão ainda são usados em grande quantidade na indústria de processamento metal-mecânica, gerando elevados custos de consumo e de descarte, além do prejuízo ambiental. Recentemente, os aspectos ambientais têm-se tornado cada vez mais importante dentro dos processos produtivos, somando-se aos aspectos econômicos e tecnológicos.

A necessidade cada vez maior de uma técnica de produção não agressiva ao meio ambiente e o crescimento rápido dos custos de disposição dos fluidos refrigerantes tem justificado a demanda por uma alternativa ao processo de usinagem com fluido refrigerante. Na última década, porém, as pesquisas tiveram como meta restringir ao máximo o uso de fluidos refrigerante e/ou lubrificante na produção metalmecânica (MACHADO \& DINIZ, 2000).

Para que a utilização do fluido de corte seja minimizada, duas técnicas têm sido intensamente experimentadas: o corte completamente sem fluido (corte a seco) e o corte com mínima quantidade de lubrificante (MQL), pelo qual uma quantidade mínima de óleo é pulverizada em um fluxo de ar comprimido.

\subsubsection{Usinagem sem fluido de corte}

A usinagem a seco tem despertado a atenção de pesquisadores e técnicos que trabalham no âmbito da remoção de material, e, para os que a usam, ela apresenta vantagens econômicas e ecológicas. Analisando-se tecnicamente o corte a seco, ele só é viável quando o tempo de usinagem, o tempo de vida da ferramenta e qualidade superficial da peça for pelo menos semelhantes às conseguidas com a usinagem usando-se fluidos de corte tradicionais (SAHM \& SCHNEIDER, 1996; DUNLAP, 1997 e KLOCKE et al. 1998). O desenvolvimento da usinagem com alta velocidade 
geralmente se dá na condição a seco, principalmente na usinagem de materiais endurecidos.

O fluido de corte tem a tarefa de resfriar a peça e a ferramenta além de reduzir o atrito entre elas através de um efeito lubrificante, impedindo a formação de arestas postiças e adesão de cavacos sobre as ferramentas principalmente na usinagem de ligas de alumínio. Uma função importante do fluido de corte não muito considerada, mas que representa um papel decisivo na prática, é a sua utilidade no transporte dos cavacos (limpeza). Em altas velocidades de corte, as condições não são favoráveis para penetração do fluido de corte na interface para que ele exerça o papel lubrificante. Nestas condições, a refrigeração torna-se mais importante e deve ser utilizado um fluido de corte à base de água. Obviamente, os fluidos de corte são um importante parâmetro tecnológico na usinagem, tendo como beneficios: aumento de vida da ferramenta, melhoria no acabamento superficial, precisão dimensional e auxilia na quebra do cavaco (KLOCKE \& EISEMBLATTER, 1997; BROCKHOFF \& WALTER, 1998 e MACHADO \& DINIZ, 2000).

Embora tenham características positivas, os fluidos de corte têm, naturalmente, também o seu lado negativo, impondo necessidade de soluções alternativas. Prejuízos à saúde dos trabalhadores e ao meio ambiente colocam estas substâncias na mira dos órgãos ambientais. Eles podem provocar doenças de pele, irritações oculares e doenças respiratórias geradas pela inspiração dos seus vapores, aumento do risco de câncer, além de outros distúrbios. Saliente-se, no entanto, que os danos ao meio ambiente e à saúde não podem ser totalmente eliminados, pois na usinagem a seco é apontado o surgimento de problemas provocados pelas poeiras produzidas pela operação a seco. Existem exemplos clássicos na usinagem onde a aplicação do fluido de corte prejudica o processo. Usinagem com ferramentas cerâmicas deve normalmente ser feità a seco, pois o fluido pode promover choques térmicos com eventual fratura das ferramentas (SAHM \& SCHNEIDER, 1996; YOUNG et al 1997 e MACHADO \& DINIE, 2600).

Apesar dos argumentos sobre a proteção ambiental e a diminuição dos riscos para a saúde, as vantagens econômicas têm sido, naturalmente, o principal motivo para a redução ou a renúncia aos fluidos de corte. Mas justamente este potencial de economia é avaliado de modo bastante diferenciado pelos usuários. Segundo SAHM 
\& SCHNEIDER (1996) e KLOCKE \& EISEMBLATTER (1997), uma análise de custo na fábrica da Mercedes Benz AG (Alemanha) relativa às peças mostrou que, nos casos extremos, até $17 \%$ dos custos de fabricação com a produção de cavacos eram referentes aos fluidos de corte. Comparativamente nestes casos, os custos das ferramentas somavam de $2 \%$ a $3 \%$ dos custos da produção. Além disso, para que não se cometa o erro de generalizar estes índices, é preciso conhecer as demais condições de produção. Na Mercedes Benz o fator de custo mais importante é o investimento nas instalações de preparação, carga e descarga de máquinas e recuperação dos fluidos de corte. Ainda nesta linha de pensamento, NARUTAKI et al. (1997) relatam que nos Estados Unidos os fluidos de corte também representam 16\% dos custos de usinagem.

A FIGURA 2.36 mostra em um comparativo que a porcentagem dos custos referentes ao sistema de refrigeração não pode mais ser negligenciada. Pode-se observar que os gastos relacionados com a ferramenta representam apenas de 2 a $4 \%$ (custos variáveis) contra $17 \%$ em refrigeração (KLOCKE \& EISEMBLATTER, 1997; YOUNG et al. 1997 e NOVASKI \& DÖRR, 1999).

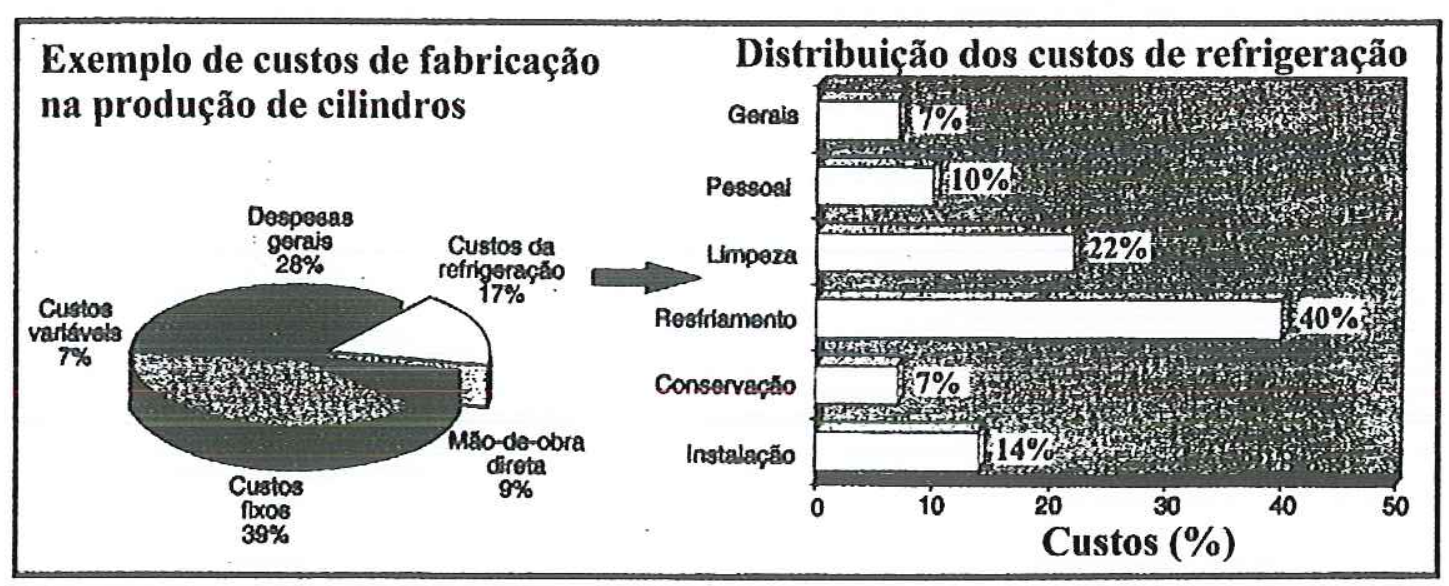

FIGURA 2.36 - Porcentagem dos Custos de Refrigeração nos Custos de Fabricação (NOVASKI \& DÖRR, 1999).

Este conjunto de situações torna cada vez mais indesejável o uso de sistemas de refrigeração na produção. A usinagem a seco surge como um imperativo, na busca de redução de custos, aumento da produtividade e atendimento aos requisitos ecológicos. 
Dependendo da qualidade das peças a serem fabricadas, o sistema de refrigeração também atende, de forma simples, à climatização da máquina e da peça. Na mudança para a operação a seco é preciso, portanto, encontrar novas soluções para estas funções. O processo de usinagem é influenciado por três aspectos: precisão, qualidade da superficie e tensões residuais em regiões próximas à superficie (KLOCKE \& EISENBLÄTTER, 1997 e DÖRR, 1999).

Segundo SAHM \& SCHNEIDER (1996), os primeiros sucessos obtidos no campo do ferro fundido cinzento estimularam uma pesquisa sobre a usinagem a seco para os processos de furação e mandrilamento realizadas em empresas alemãs. No geral, ferros fundidos cinzentos são particularmente bem sucedidos na usinagem a seco, em virtude dos seus cavacos curtos, baixas temperaturas e forças de corte como também o efeito lubrificante da grafita presente neste tipo de material. Adicionando elementos de liga, é possível também aperfeiçoar a usinabilidade de outros materiais e deste modo sua conveniência para a usinagem a seco. Todavia, o emprego da usinagem a seco depende do tipo de operação de usinagem e da tecnologia usada (KLOCKE \& EISENBLÄTTER, 1997; YOUNG et al. 1997; HEISEL et al. 1998 e DÖRR, 1999).

Ao lado da usinagem de fundidos, a usinagem de metais endurecidos com ferramentas de arestas geometricamente definidas, também é um campo no qual a operação a seco poderá ser introduzida. As exigências para as ferramentas resultam basicamente do aumento da temperatura de corte na usinagem a seco, sendo necessário observar duas características essenciais dos materiais de corte: a dureza a quente e a tenacidade. $\mathrm{O}$ nitreto cúbico de boro policristalino (PCBN) se adapta bem à usinagem a seco de materiais endurecidos e à usinagem de materiais fundidos totalmente perlíticos. Nestes materiais não há tendências à adesão e, então, pode-se renunciar à função de lubrificação do fluido de corte. Já as ferramentas de diamante policristalino (PCD) têm um melhor desempenho para usinar alumínio devido a sua baixa tendência de adesão. Até mesmo na usinagem do aço carbono já see emprega, em algumas empresas, o processo de usinagem a seco.

NOVASKI \& DÖRR (1999) e DÖRR (1999) afirmam que, para a operação a seco ter sucesso deve-se avaliar a interação no sistema ferramenta-máquina-peçaprocesso representado na FIGURA 2.37. 


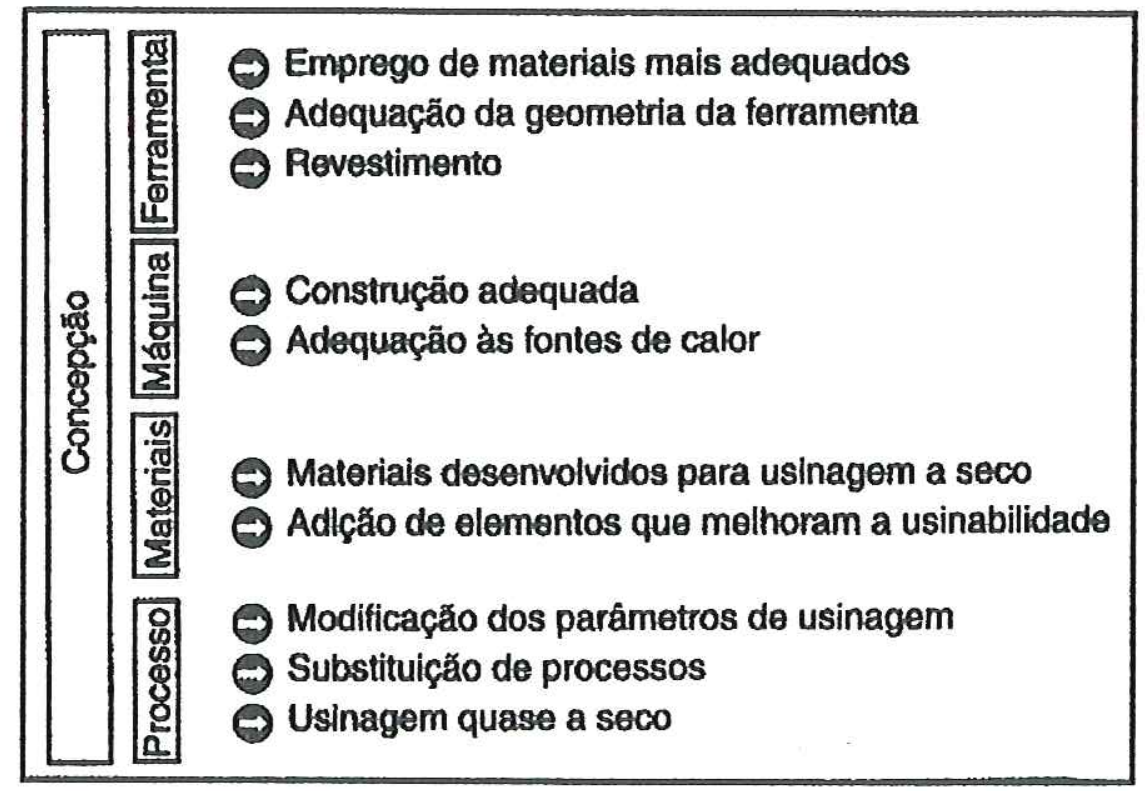

FIGURA 2.37 - Soluções Empregadas para a Utilização da Usinagem a Seco (NOVASKI \& DÖRR, 1999).

No caso das ferramentas, os revestimentos desempenham um papel central, junto com outros materiais e geometrias. Segundo KALHÖFER (1997) e SCHULZ (1999), as modificações na geometria da ferramenta e a aplicação de revestimentos resistentes a altas temperaturas, tal como TiAIN podem reduzir os efeitos de temperatura sobre a ferramenta, melhorando a conveniência das ferramentas para a usinagem a seco. Por outro lado, como a distribuição de calor é afetada, deve-se pensar em uma concepção mais adequada para a máquina-ferramenta. Em alguns casos, inclusive, a usinagem a seco deve ser pensada já na fase de desenvolvimento dos materiais a serem usinados. DÖRR (1999) afirma que a melhor seleção possível de revestimentos depende do material a ser usinado como também do processo de usinagem. O pesquisador apresenta através da FIGURA 2.38 os resultados dos experimentos no torneamento do aço St 52-3 (ABNT 5120) na condição a seco e refrigerada utilizando ferramenta cermet com e sem revestimento de TiN. Com a eliminação cia refrigeração e o uso de revestintento, possibilitou um ganho de $200 \%$ na vida da ferramenta e permitiu uma redução de $10 \%$ no custo de manufatura. 


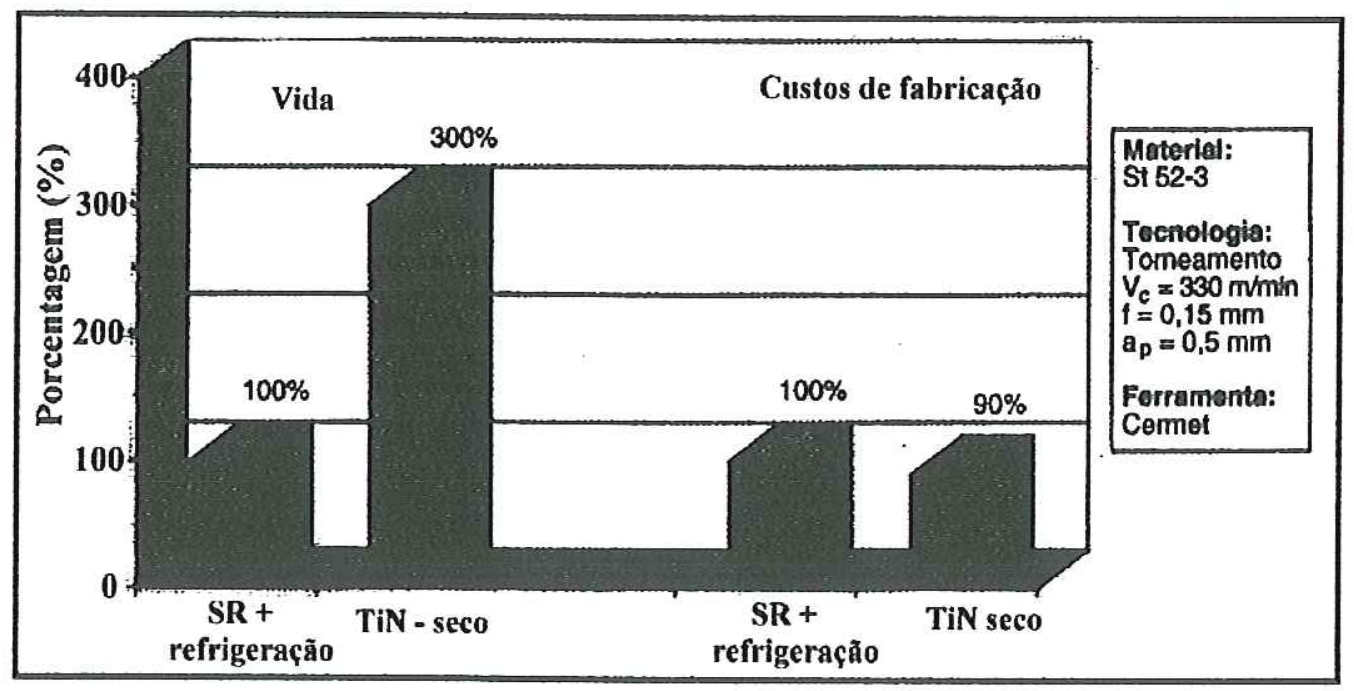

FIGURA 2.38 - Vida da Ferramenta e Custo de Manufatura no Torneamento do Aço St 52-3/ABNT 5120 (DÖRR, 1999).

A tecnologia Near-Net-Shape (usinagem de peças forjadas pelo processo de manufatura próximo da forma final) oferece a oportunidade de minimizar o volume de metal removido e deste modo a energia dissipada, favorecendo o corte a seco.

Outro ponto a ser levado em conta são as modificações dos parâmetros do processo. Sempre se tem a idéia que sem a utilização do fluido de corte os parâmetros de usinagem devem ser reduzidos. Este é um pensamento errôneo. Os resultados têm mostrado que tanto para o torneamento quanto para o fresamento gasta-se menos energia de atrito por volume de cavacos usinados, quando se utilizam avanços mais elevados e, consequentemente, espessuras de corte maiores. Além disto, o equilíbrio térmico faz com que mais calor seja transferido para o cavaco. Em alguns casos, a utilização da usinagem a seco conduz à utilização de processos alternativos (NOVASKI \& DÖRR, 1999).

Durante a usinagem a seco, as exigências nas ferramentas são decorrentes principalmente da elevação da temperatura do processo. A dureza a quente e a resistência ao desgaste a quente das ferramentas desempenham um papel fundamental nestes casos. Por esta razão, as ferramentas de HSS com sua baixa dureza substancialmente já na temperatura acima de $400^{\circ} \mathrm{C}$ são na maior parte inadequadas. Em contraste com esta afirmação, materiais de corte tais como, metal duro, cermets, cerâmicas, PCBN e PCD, tem alta dureza em temperaturas elevadas e são muito bem adaptados para usinagem a seco. Entretanto, corte a seco pode 
também apresentar efeitos positivos como redução de choque térmico e deste modo a formação de trincas em peças usinada por corte interrompido em ferramentas de metal duro, cerâmicas ou cermets (SAHM \& SCHNEIDER, 1996; KLOCKE \& EISENBLÄTTER, 1997 e DÖRR, 1999).

Quando não for possível a usinagem a seco das superligas à base de níquel por questões técnicas, recomenda-se a utilização de óleos minerais sulfurados. Um importante aspecto a ser considerado no caso de usinar liga com alto teor de níquel é que o fluido de corte deve ser removido completamente da peça usinada, antes de ser submetida a altas temperaturas. Isto é necessário para impedir a corrosão intergranular que poderia ser provocada pelo enxofre usado como aditivo de extrema pressão no fluido de corte (RUFFINO, 1995).

Em resumo, os resultados obtidos por diversos autores até o presente momento, mostram que a usinagem a seco pode ser aplicada com vantagens em muitos casos. Deve-se lembrar, no entanto, que apesar de todos resultados otimistas, a refrigeração convencional está longe de ser eliminada dos processos de usinagem, principalmente nos processos abrasivos. Para se promover a usinagem a seco também nos processos críticos, será indispensável implementar esforços conjuntos entre usuários, fabricantes de ferramentas e fabricantes de máquinas.

Para as operações: furação, alargamento, roscamento e fresamento de topo para obter-se sucesso em ligas de alumínio, é essencial o uso de ferramentas com sistemas de cobertura satisfatória e uso de mínima quantidade de lubrificante (MQL). Esta técnica assume particular importância no contexto de usinagem a seco sendo o centro das atenções nos últimos anos, como tecnologia para substituir o uso intensivo de fluidos refrigerantes (KLOCKE et al. 1998).

\subsubsection{A técnica da Mínima Quantidade de Lubrificante (MQL)}

Apesar das insistentes tentativas de eliminar completamente os fluidos refrigerantes, em muitos casos a refrigeração ainda é essencial para que se obtenham vidas econômicas de ferramentas e as qualidades superficiais requeridas. Isto é particularmente válido quando há exigência de tolerâncias estreitas e alta exatidão dimensional e de forma, ou quando se trata de usinagem de materiais críticos, de corte dificil. Isso faz da mínima quantidade de lubrificante uma alternativa 
interessante, porque combina a funcionalidade da refrigeração com um consumo extremamente baixo de fluidos (geralmente $<80 \mathrm{ml} / \mathrm{h}$ ). Estas mínimas quantidades de óleo são suficientes em muitos casos, para reduzir o atrito da ferramenta e ainda evitar a aderência de materiais. A minimização de fluido de corte tem adquirido relevância nos últimos dez anos (DÖRR \& SAHM, 2000).

As limitações das operações a seco podem ser superadas, em muitos casos, através da introdução de sistemas de lubrificação em quantidades mínimas (NearDry machining - MQL) que agem com base no princípio de utilização total, sem resíduos, aplicando fluxos de lubrificantes de 10 até no máximo $100 \mathrm{ml} / \mathrm{h}$ a uma pressão de 4,0 a 6,0 Kgf/cm² (KLOCKE \& EISENBLÄTTER, 1997; YOUNG et al. 1997; SCHULZ, 1999; DÖRR, 1999 e DINIZ, 1999). O que importa é que, ainda assim, os cavacos sejam liberados praticamente secos, evitando custos resultantes da reciclagem do fluido de corte. O objetivo é tornar os processos mais usados em centros de usinagem isentos de fluido de corte.

Nesta tecnologia, a função de lubrificação é assegurada pelo óleo e a de refrigeração principalmente pelo ar comprimido. Esta pequena quantidade de fluido pode ser suficiente para reduzir o atrito no corte, diminuindo a tendência à aderência em materiais com tais características. De sua comparação com a refrigeração convencional resultam numerosas vantagens: (KLOCKE \& EISENBLÄTTER, 1997; KLOCKE et al. 1998; HEISEL et al. 1998; e DÖRR, 1999).

- A quantidade de fluido de corte em relação ao volume da peça usinada é muitas vezes menor do que no caso da refrigeração por inundação convencional;

Baixo consumo de fluido de corte e eliminação de um sistema de circulação;

* Fluidos de corte não consumidos aumentam a necessidade de manutenção e problemas de despejo;

* Podem ser evitados materiais de filtragem e reciclagens da manutenção dos fluidos de corte;

* As jeças usinadas ficam quase secas, de maneira que em muitos casos é desnecessária uma operação de lavagem subsequente;

* O baixo conteúdo de óleo que permanece nos cavacos não justifica a sua recuperação; 
A aplicação de biocidas e preservativos pode ser enormemente eliminada, porque apenas a quantidade de fluido de corte que será usada em um turno de trabalho deve ser colocada no reservatório do sistema de mínima quantidade.

Por outro lado, comparado com a técnica convencional, MQL causa custos adicionais para pressurizar o ar e suportes tecnológicos, o quais são necessários no processo para superar as restrições tecnológicas da técnica MQL. Por exemplo, técnicas especiais para o transporte do cavaco podem ser necessárias, e talvez a produtividade seja reduzida devido ao impacto térmico nos componentes usinados. $\mathrm{O}$ vapor, a névoa e a fumaça de óleo gerados durante o uso da mínima quantidade de lubrificante na usinagem podem ser considerados subprodutos indesejáveis, pois contribuem para aumentar o índice de poluentes em suspensão no ar e tornaram-se fator de preocupação, necessitando de um bom sistema de exaustão na máquina. $\mathrm{Na}$ pulverização é utilizada uma linha de ar comprimido que funciona intermitentemente durante o processo. Essas linhas de ar geram um barulho que geralmente ultrapassa os limites admitidos pela legislação (MACHADO \& DINIZ, 2000). Com o conhecimento dos custos da usinagem úmida e os da usinagem com MQL, foi feita uma comparação de custos dos investimentos e dos custos fixos e proporcionais anuais na BMW. A confrontação dos custos totais de investimento na linha "transfer", inclusive do equipamento para limpeza de cavacos, comprovou vantagens financeiras de $22 \%$ na usinagem com a tecnologia MQL (DÖRR \& SAHM, 2000).

Esta técnica já é usada com sucesso há muitos anos em vários processos de corte, serramento e conformação de metais. As suas vantagens levam à previsão de que sua faixa de aplicações seja crescente, mas apesar de tudo, as variáveis de influência a serem consideradas e os efeitos sobre o resultado do processo têm sido matéria para apenas alguns poucos estudos. Nos sistemas de mínima quantidade são usados principalmente fluidos de corte não solúveis em água, principalmente óleos minerais. Deve-se considerar que, devicio às quantidade's muito pequenas de fluidos de corte usadas, os custos não deveriam impedir o uso de composições de alta tecnologia no campo dos óleos básicos e aditivos. Não é recomendável o uso de fluidos de corte que são desenvolvidos para sistemas convencionais, porque pode haver forte atomização e vaporização, o que é prejudicial à saúde dos operários. Quanto maior a velocidade de corte que juntamente à temperatura do processo, 
causam maiores problemas deste tipo, de maneira que, recomenda-se o uso de óleos básicos com uma viscosidade mais alta e adaptações no campo dos aditivos (antinévoa). Os materiais derivados de origem vegetal estão sendo cada vez mais empregados. Estes óleos, inalados com a formação do aerossol, diminuem os riscos à saúde (HEISEL et al. 1998).

KLOCKE \& EISENBLÄTTER (1997) apresentam o comportamento da formação da aresta postiça de corte (APC) de uma fresa de $16 \mathrm{~mm}$ de diâmetro com diversas coberturas na condição a seco e com a utilização da técnica MQL representado pela FIGURA 2.39. Nesta mesma linha SCHULZ (1999) afirma que no processo de furação utilizando aço, a técnica de quantidade mínima de refrigeração também forneceu excelentes vantagens conforme mostra a FIGURA 2.40. O efeito lubrificante reduz a força de atrito e deste modo prolonga a vida da ferramenta consideravelmente. Melhores resultados podem ser alcançados pelas atividades adicionais simultâneas, por exemplo, a otimização do substrato, ou seja, aumentando a quantidade de $\mathrm{TiC} / \mathrm{TaC}$.



$V_{c}=1000 \mathrm{~m} / \mathrm{min} ; F_{z}=0,07 \mathrm{~mm} /$ dente; $a_{p}=6 \mathrm{~mm}$

Ferramenta: Fresa inserto; $Z=1$ dente; $D=16 \mathrm{~mm}$

FIGURA 2.39 - Influência de Revestimentos e MQL no Fresamento de $\mathrm{AlZnMgCu}$ (KLOCKE \& EISENBLÄTTER, 1997). 
Observa-se que a técnica MQL proporcionou uma redução substancial na formação da APC. Aumentando o volume de fluxo de $10 \mathrm{ml} / \mathrm{h}$ para $40 \mathrm{ml} / \mathrm{h}$ não foi verificado nenhum benefício, demonstrando que pequenos volumes de fluxo são suficientes para suprimir a aresta postiça de corte completamente.

WAKABAYASHI et al. (1998) demonstraram resultados semelhantes no torneamento do aço $\mathrm{S} 45 \mathrm{C}$ utilizando diversas quantidades de lubrificante $(0,01 ; 0,03$; 0,$06 ; 0,10$ e $0,16 \mathrm{~cm}^{3} / \mathrm{min}$ ) a uma pressão de $6,0 \mathrm{kgf} / \mathrm{cm}^{2}$. A aresta postiça de corte foi totalmente eliminada com a técnica MQL comparando-se com o corte a seco e refrigerado (emulsão 5\%). Obteve-se melhor rugosidade superficial com a técnica MQL $\left(R_{a} \cong 0,4 \mu \mathrm{m}\right.$ contra $R_{a} \cong 0,8 \mu \mathrm{m}$ na condição a seco e refrigerado). $O$ desgaste de flanco variou-se conforme a quantidade de lubrificante, sendo que o maior volume de lubrificante proporcionou menor nível de desgaste.

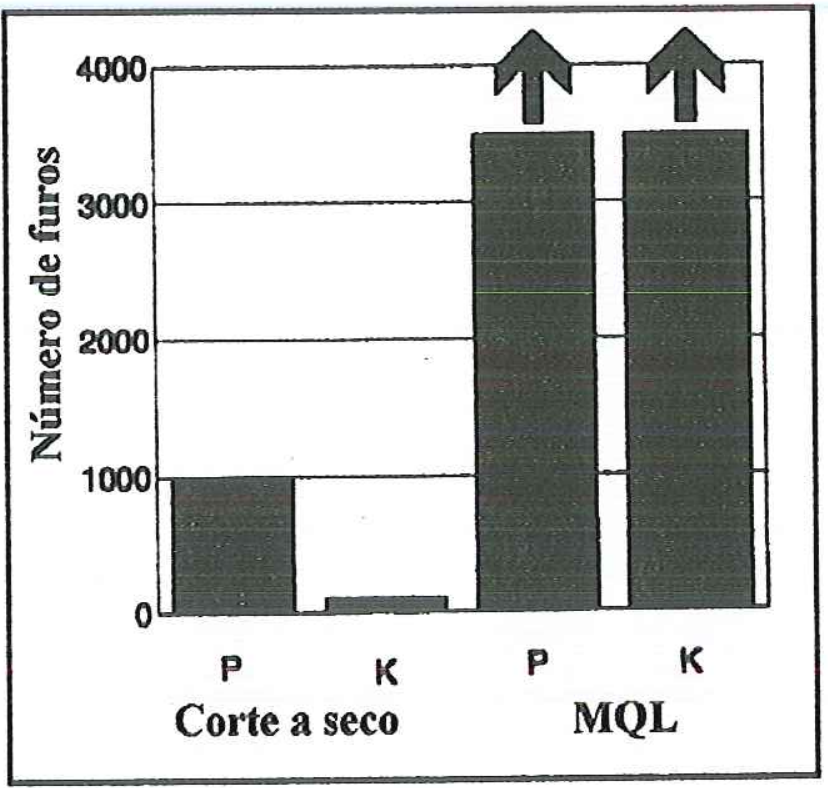

Ferramenta: $\mathrm{P}=11 \% \mathrm{Co}-12 \% \mathrm{TiC} \& \mathrm{TaC} ; \quad \mathrm{K}=9,5 \%$ Co

Revestimento: TiN; Diâmetro: $11,8 \mathrm{~mm}$

Material da peça: Ck45K - Furo cego: $22 \mathrm{~mm}$

Condiçǒes de corte: $V_{c}:=80 \mathrm{~m} / \mathrm{min} ; f=0,18 \mathrm{~mm} / \mathrm{rev}$

Ferramenta: Pressão do ar: 5 bar; Quantidade de óleo: $25 \mathrm{ml} / \mathrm{h}$

FIGURA 2.40 - Otimização do Substrato e MQL na Furação de Aço (SCHULZ, 1999). 
Recentemente, DINIZ (1999) revela resultados significativos na viabilidade da utilização da técnica MQL no processo de furação da liga alumínio-silício (7\% $\mathrm{Si}$ ) comparada com a refrigeração emulsionável, no que refere-se a qualidade do furo, desgaste de flanco, potência consumida e força de corte utilizando brocas de metal duro e com cobertura de diamante.

\subsubsection{Classificação e projeto de sistemas com mínima quantidade de} lubrificante.

Como afirma BROCKHOFF \& WALTER (1998) e HEISEL et al. (1998) existem principalmente três tipos diferentes de sistemas de mínima quantidade. De um lado estão os sistemas de pulverização de baixa pressão, onde o refrigerante é aspirado por uma corrente de ar e levado à superfície ativa com uma mistura. Esses sistemas se distinguem por um fluxo volumétrico de refrigerante de aproximadamente 0,5 a $10 \mathrm{l} / \mathrm{h}$. Eles são usados principalmente para a refrigeração com emulsões, produzem uma otimização notável e somente podem ser dosados grosseiramente. O segundo tipo de sistema usa bombas dosadoras com alimentação pulsatória de uma quantidade definida de lubrificante para a superficie ativa, sem ar. As taxas de fluxos são ajustáveis numa faixa entre 0,1 e $1 \mathrm{ml}$ por ciclo, com até 260 ciclos por minuto. Estes sistemas são utilizados principalmente em processos intermitentes. O terceiro e mais usado tipo de sistema de refrigeração de quantidade mínima é o de pressão, em que o refrigerante é bombeado para o bocal através de uma tubulação de suprimento em separado. Ali ele é misturado com ar comprimido fornecido separadamente, de forma que as quantidades de ar e lubrificante podem ser ajustadas independentemente. Este tipo de sistema é uma alternativa particularmente interessante, porque combina a funcionalidade da refrigeração com um consumo extremamente baixo, na faixa 10 a $100 \mathrm{ml} / \mathrm{h}$. Ao mesmo tempo, a mistura coaxial de refrigerante e ar no bocal previre enormemente a nebulosidade. Todas as investigações descritas neste trabalho se referem ao emprego da técnica do sistema de refrigeração de quantidade mínima por pressão e na condição a seco.

HEISEL et al. (1998) apresentam um diagrama esquemático de um sistema de refrigeração de quantidade mínima com o princípio de pressão descrito e os seus 
componentes ilustrados na FIGURA 2.41. O know-how desta tecnologia consiste na otimização do projeto do bocal.

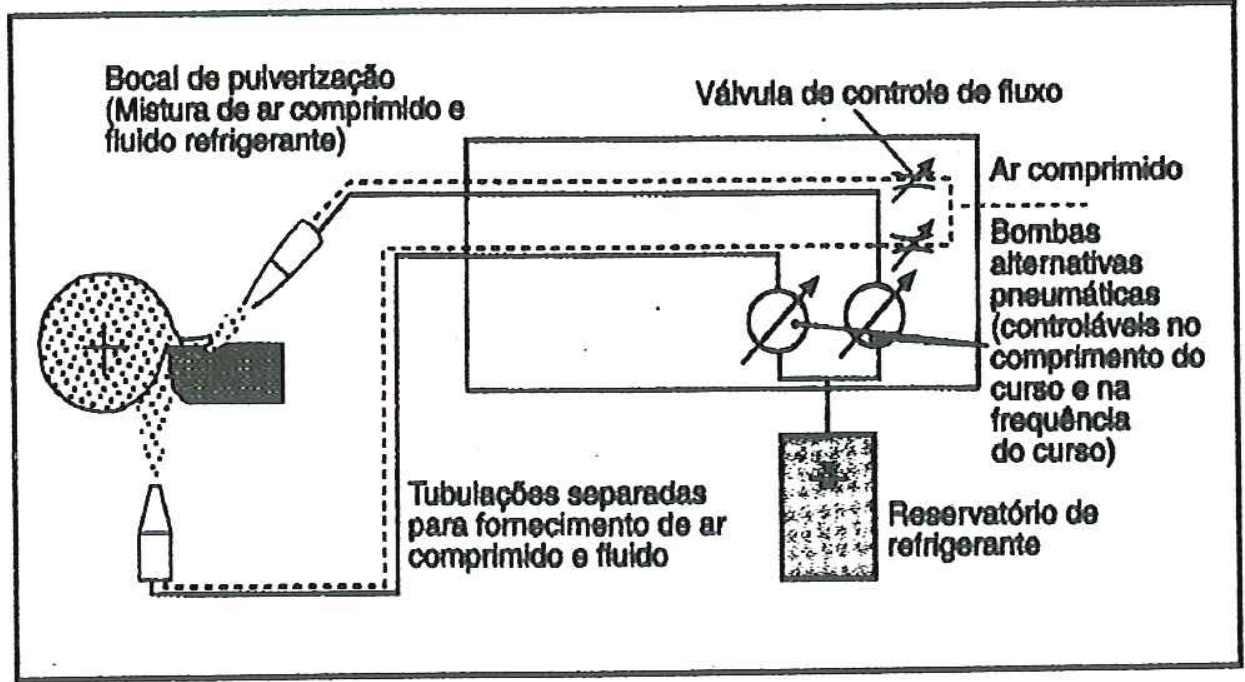

FIGURA 2.41 - Diagrama Esquemático de um Sistema de Lubrificação de Quantidade Mínima (HEISEL et al., 1998).

A estabilidade do jato, que significa a convergência da mistura ar-fluido, é muito importante para a aplicação prática nas máquinas de produção, porque ela determina a distância até a superficie ativa e, portanto, o perigo de colisões entre os sistemas de refrigeração e ferramentas, máquinas ou peça. Segundo HEISEL et al. (1998), a distância entre o bocal e a área de corte, ângulo de pulverização ou ajuste relativo à superficie de saída e flanco da ferramenta parecem ser parâmetros de menor importância. Isto torna mais fácil o uso da refrigeração de quantidade mínima nas máquinas de produção.

A refrigeração de quantidade mínima não é efetiva quanto ao transporte de cavacos, de forma que isso tem que ser compensado por máquinas-ferramentas cujo projeto já contemple esta necessidade ou por meios adicionais de limpeza.

De acordo com HEISEL et al. (1998), pelos resultados obtidos a partir de experiências de torneamento do aço $100 \mathrm{Cr} 6$ com pastilha de ccite classe $\mathrm{P} 25$, as medições de temperatura com termoelementos debaixo das pastilhas de corte da ferramenta mostraram efeitos notáveis de refrigeração conforme indica a FIGURA 2.42 . 


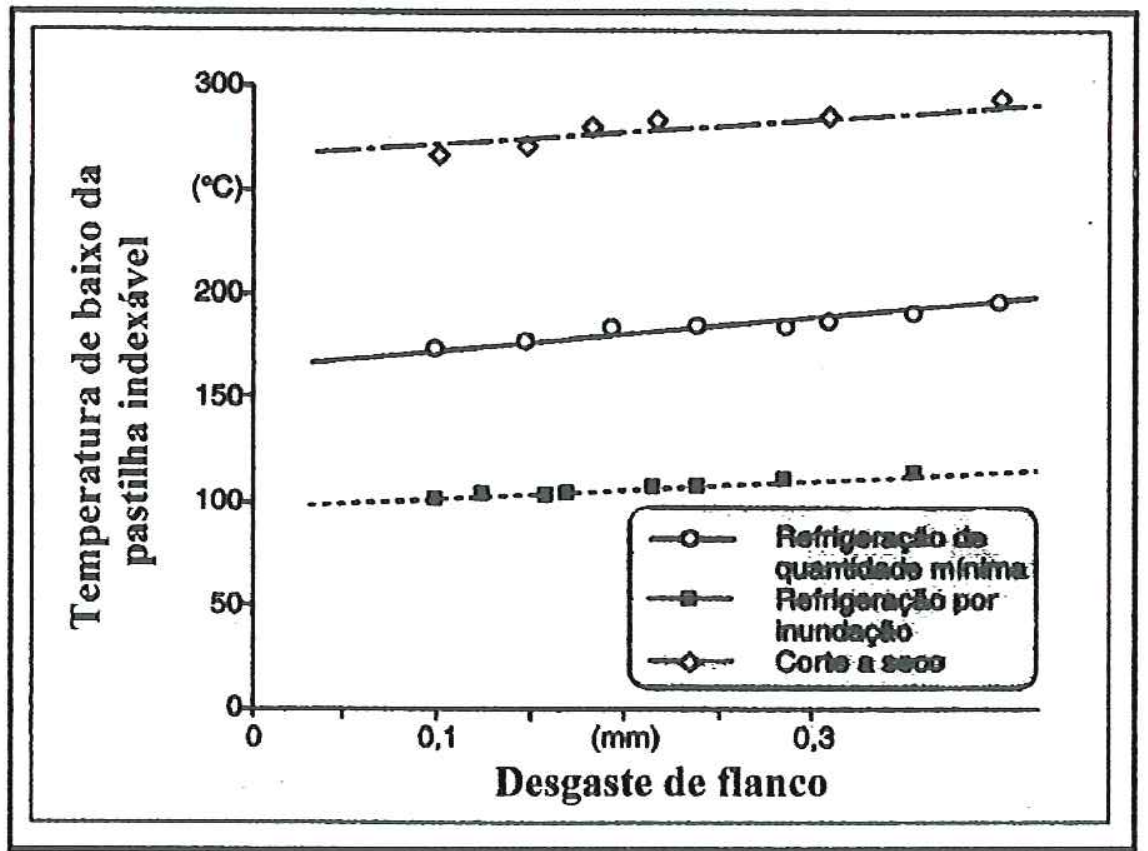

FIGURA 2.42 - Temperatura sob a Pastilha de Corte Indexável versus Desgaste e Tipo de Refrigerante $-V_{c}=200 \mathrm{~m} / \mathrm{min} ; \mathrm{f}=0,25 \mathrm{~mm} / \mathrm{rev}$. e $a_{p}=1 \mathrm{~mm}$ (HEISEL et al., 1998).

Como já era esperado, as temperaturas medidas ficaram entre as da usinagem a seco e as obtidas a partir de experiências com lubrificação por inundação, que significa esguichar um fluxo de líquido ou gás a baixa pressão na direção da área de corte a partir do topo, ou usando um bico direcionado à superficie de folga da ferramenta (WERTHEIM et al. 1997).

Com base na teoria de que as temperaturas na superficie ativa são mais elevadas do que as observadas debaixo da pastilha indexável, pode-se concluir que as ferramentas usadas com mínima quantidade de fluido de corte têm uma vida relativamente longa. Um dos motivos da ocorrência deste fenômeno é que, no caso da inundação de fluido de corte, não é possível atingir as temperaturas que são necessárias para amolecer o material na superfície ativa. Portanto, o material é muito duro para usinar e calsa um desgasie mais elevado da ferramenta. 


\subsection{Conclusỗes da revisão bibliográfica}

Segundo diversos autores (SCHULZ, 1997; ANDRAE, 1999; SINHOFF et al. 1999; SCHULZ, 1999 e SIMON, 2001) HSM é uma promissora tecnologia na atualidade e para o futuro visando redução dos custos, tempos de produção e garantindo qualidade ao produto final;

Segundo SCHULZ (1997), a tecnologia HSM, no caso de muitos materiais, conduz simultaneamente à redução de vida da ferramenta;

ANDRAE (1999) afirma que a força de usinagem e potência requerida em HSM podem ser reduzidas em aproximadamente $30 \%$;

* HSM requer máquinas-ferramentas com alto desempenho (DEWES e ASPINWALL, 1997; KIRSCHNIK, 1997; SCHULZ, 1999 e ANDRAE, 1999b);

* O corte HSC pode ser usado para todo processo de usinagem de metais leves, não-ferrosos e plásticos, mas para aço, ferro fundido e ligas de dificil usinabilidade ele é adequado apenas para o acabamento (SCHULZ, 1996; FALLBÖHMER et al. 2000 e CHRISTOFFEL, 2001);

* Pesquisadores e indústrias de todo o mundo estão firmemente comprometidos com o propósito de fazer o processo de usinagem ser dramaticamente veloz e precisamente produtivo (ANDRAE, 1999 e SIMON, 2001);

* Segundo diversos autores (KRAMER, 1987; ADDHOUM \& BROUSSAND, 1989; SCHULZ \& MORIWAKI, 1992 e LÉON, 1997), os mecanismos de formação de cavaco em diferentes zonas de cisalhamento são modificados pelo aumento da velocidade de corte;

* Com o aumento da velocidade de corte, cavacos segmentados são preferencialmente gerados (KOMANDURI \& SCHROEDER, 1986; FLOW \& KOMANDURI, 1989; WAYNE \& BULJAN, 1990; GATTO \& IULIANO, 1994; ELWARDANY et al. 1996; VIGNEAU, 1997 e SCHULZ et al. 2001);

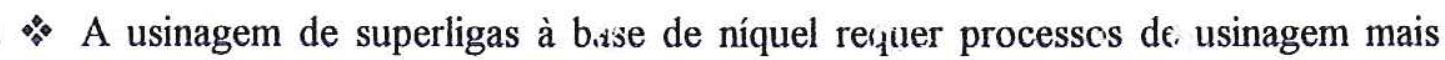
avançados, de forma a obter um alto nível de produtividade com relação à qualidade das superfícies usinadas e vida da ferramenta (RICHARDS \& ASPINWALL, 1989; GATTO \& IULIANO, 1994; DARWISH, 1997; 
VIGNEAU, 1997; KÖNIG \& GERSCHWILER, 1999; SHARMAN et al. 1999; EZUGWU et al. 1999 e CHRISTOFFEL, 2001);

SADAT, 1987 e ANDRAE, 1999 afirmam que HSM afeta positivamente a integridade superficial da peça como também a qualidade dos componentes usinados;

Apesar de todos resultados otimistas em relação à técnica MQL, a refrigeração convencional está longe de ser eliminada em alguns processos de usinagem, principalmente nos processos abrasivos (KLOCKE \& EISENBLATTER, 1997 e DÖRR, 1999);

* Atualmente, o comportamento da indústria para com o meio ambiente tem-se modificado bastante, mantendo o compromisso de dar passos positivos para reduzir o impacto ambiental dos processos de fabricação (SAHM \& SCHNEIDER, 1996; DUNLAP, 1997; HEISEL et al. e KLOCHE et al. 1998);

* Os resultados obtidos até o momento mostram que a usinagem a seco pode ser aplicada com vantagens em muitos casos (SAHM \& SCHNEIDER, $1996 \mathrm{e}$ YOUNG et al. 1997);

* Os resultados mostram que a tecnologia de MQL já está perfeitamente apta para os processos de produção (KLOCKE \& EISENBLÄTTER, 1997; KLOCKE et al. 1998; HEISEL et al. 1998 e DÖRR, 1999);

* Diversos pesquisadores demostram que os sistemas de mínima quantidade de lubrificante (MQL) resultam em vida mais longa para a ferramenta, velocidades de corte mais altas e melhor qualidade de acabamento superficial (KLOCKE \& EISENBLÄTTER, 1997; HEISEL et al. 1998; WAKABAYASHI et al. $1998 \mathrm{e}$ DÖRR, 1999). 


\section{TRABALHO EXPERIMENTAL}

Este capítulo tem a finalidade de descrever todos os equipamentos e materiais utilizados, assim como também a descrição dos procedimentos e planejamento utilizados durante a experimentação. $O$ trabalho experimental foi realizado no laboratório de Otimização de Processos de Fabricação (OPF) do Departamento de Engenharia Mecânica, e os resultados analisados no Departamento de Engenharia de Materiais da EESC-USP, no Instituto de Física de São Carlos (IFSC), na empresa QUALIFER responsável pelas modificações das arestas de corte e no Laboratório de Difração de Raios-X, do Centro de Caracterização e Desenvolvimento de materiais (CCDM) na Universidade Federal de São Carlos (UFSCAR). As análises metalográficas e a medição da macro/microdureza foram executadas no laboratório do Departamento de Engenharia de Materiais. A microscopia eletrônica de varredura para análise dos mecanismos de desgaste foi realizada no IFSC. As medições de tensão residual foram efetuadas no CCDM.

\subsection{Equipamentos utilizados}

Os experimentos foram executados no torno INDEX GU600, equipado com comando numérico computadorizado SIEMENS $810 \mathrm{D}$ com potência do motor no eixo-árvore de $22 \mathrm{~kW}$ e faixa de rotação de 50-5000 RPM. Um programa CNC foi elaborado para a usinagem dos corpos de prova (vide Apêndice I).

As formas e mecanismos de desgastes foram analisados através do microscópio eletrônico de varredura ZEISS modelo DSM 960 (Digital Scanning Microscope).

A rugosidade superficial foi medida utilizando-se um rugosímetro portátil marca TAYLOR HOBSON modelo Surtronic 3P, ajustado para um comprimento de amostragem (cut-off) de 0,8 $\mathrm{mm}$. Os valores de rugosidade foram medidos utilizando o parâmetro $R_{a}$. 
Os valores da microdureza foram obtidos usando um microdurômetro digital BUEHLER modelo MMT-3 com carga de 100 gramas aplicada durante 10 segundos na escala HV e HRC.

A análise microestrutural foi avaliada através do microscópio óptico ZEISS com ampliação máxima de 1000 vezes acoplado a uma câmera ADAPTOR modelo CMA-D2 gerenciada por um microcomputador que utiliza o software Ultimage/Pro versão 2.6 para captação da imagem.

A dureza durante os testes foi medida utilizando um durômetro digital modelo RT 240 com carga de $150 \mathrm{kgf}$ aplicada durante 30 segundos na escala HRC.

Para o monitoramento da emissão acústica, foi utilizado um sensor de EA SENSIS com unidade de tratamento de sinal BM-12 contendo um filtro passa-alta de $5 \mathrm{kHz}$ interligado a um sistema de aquisição de dados gerenciado por um microcomputador que utiliza o software LabView 5.1. O sistema SENSIS BM-12 é um aparelho totalmente analógico, basicamente composto por um circuito para a amplificação do sinal bruto da emissão acústica, onde podem ser acoplados diferentes tipos de filtros, definindo-se a faixa de freqüência que se deseja trabalhar. O circuito principal do sistema é responsável pelo cálculo do valor médio quadrático RMS (Root Mean Square) do sinal de emissão acústica, já filtrado e amplificado.

O equipamento utilizado para o controle da Mínima Quantidade de Lubrificante (MQL) foi o Accu-lube, fornecido pela empresa ITW Chemical Products Ltda, o qual usa sistema pulsante de fornecimento de óleo e permite a regulagem da vazão de ar comprimido e lubrificante de maneiras separadas. O lubrificante indicado foi LB-1000, utilizado para usinagem média e pesada. A vazão de ar comprimido foi monitorada com auxílio de um rotâmetro modelo K12V DIGIFLOW, com campo de medição entre 6 e $60 \mathrm{~m}^{3} / \mathrm{h}$ e pressão de calibração de $8 \mathrm{kgf} / \mathrm{cm}^{2}$. Inicialmente, foram realizados alguns ensaios preliminares para detenninar a melhor vazão de lubrificante e ar.

A temperatura da ferramınta foi medida pelo método de termopar implantado do tipo K (níquel-alumínio/níquel-cromo), cuja união entre os dois fios produziu uma forma de esfera de diâmetro variando entre 0,5 a $0,6 \mathrm{~mm}$. Para a calibração do termopar foi utilizado um multímetro digital FLUKE modelo 89 IV que possui um termopar do tipo K calibrado. 
A força de corte foi medida utilizando uma célula de carga piezoeléctrica Kistler modelo 5007 montada sob o suporte da ferramenta. O amplificador de carga foi conectado a uma placa de aquisição A/D e interligado ao software LabView 5.1.

Para a execução da preparação das arestas de corte foi utilizada uma afiadora universal marca SULMECÂNICA com rebolo especial diamantado e um projetor de perfil com ampliação máxima de 500X.

A tensão residual foi determinada utilizando-se um difratômetro de quatro círculos, marca SIEMENS, modelo D5000, utilizando-se radiação de cobalto.

\subsection{Superligas à base de níquel}

As superligas à base de níquel são classificadas como materiais que proporcionam alta resistência mecânica em temperaturas elevadas, alta resistência à fluência, alta resistência à fadiga e boa resistência à corrosão. Por outro lado, as características destes materiais (frágil, baixa condutividade térmica e presença de carbetos) ocasionam intenso desgaste da ferramenta.

As superligas utilizadas nos ensaios foram Inconel 718, na dimensão $\phi 3$ " x $200 \mathrm{~mm}$ e Waspaloy com $\phi 41 \times 200 \mathrm{~mm}$, produzidas pelo processo de laminação e endurecidas pelo tratamento térmico de solubilização seguido de precipitação/envelhecimento com a dureza final de 44 e $40 \mathrm{HRC}$ respectivamente, cuja composição química e propriedades mecânicas foram fornecidas pelo fabricante, a empresa MULTIALLOY - Engenharia de Materiais Ltda, mediante certificado de qualidade da análise química e dureza, conforme TABELAS 3.1 e 3.2. As superligas Inconel 718 e Waspaloy foram selecionadas como material de corpos de prova (CDP) devido à abrangente aplicação em indústrias aeronáutica, marítima, química $\mathrm{e}$ nuclear e ainda em componentes que trabalham à altas temperaturas, requerendo excelente resistência mecânica, onde as propriedades da superficie são suscetíveis à fadiga, tensão residual e corrosão tendo um grande impacto na vida dos componentes em serviço. $\mathrm{O}$ presente trabalho focaliza principalmente a integridade superficial sob condição a seco e com utilização da técnica MQL. 
TABELA 3.1 - Composição química das superligas em \%.

\begin{tabular}{|l|c|c|c|c|c|c|c|c|c|c|c|}
\hline Superligas & Ni & $\mathbf{C r}$ & $\mathbf{F e}$ & $\mathbf{M o}$ & $\mathbf{T i}$ & $\mathbf{C u}$ & $\mathbf{C o}$ & $\mathbf{A l}$ & $\mathbf{S i}$ & $\mathbf{C}$ & $\mathbf{M n}$ \\
\hline Inconel 718 & 53,70 & 18,42 & 17,62 & 2,98 & 0,98 & 0,03 & 0,15 & 0,52 & 0,13 & 0,03 & 0,07 \\
\hline Waspaloy & 58,00 & 19,16 & - & 4,23 & 3,00 & 0,01 & 13,40 & 1,37 & 0,02 & 0,04 & 0,02 \\
\hline
\end{tabular}

TABELA 3.2 - Propriedades mecânicas

\begin{tabular}{|l|cc|cc|c|c|}
\hline Superligas & \multicolumn{2}{|c|}{$\mathrm{L}_{\mathrm{R}}(\mathrm{MPa})$} & \multicolumn{2}{c|}{$\mathrm{L}_{\mathrm{E}}(\mathrm{MPa})$} & $\mathrm{A}$ & Dureza \\
& $21^{\circ} \mathrm{C}$ & $650^{\circ} \mathrm{C}$ & $21^{\circ} \mathrm{C}$ & $650^{\circ} \mathrm{C}$ & $(\%)$ & $(\mathrm{HRC})$ \\
\hline Inconel 718 & 1351 & 1230 & 1179 & 1020 & 17 & 44 \\
\hline Waspaloy & 1275 & 1120 & 795 & 690 & 25 & 40 \\
\hline
\end{tabular}

A medição da dureza foi monitorada durante a redução do diâmetro do corpo de prova, no intervalo de $5 \mathrm{em} 5 \mathrm{~mm}$ ao longo do comprimento, utilizando o método de dureza Rockwell, na escala "C" com carga de $150 \mathrm{~kg}$, durante 30 segundos. As medidas se mantiveram entre 41-44 HRC para o Inconel 718 e 38-40 HRC para o Waspaloy. Os testes foram mais concentrados para o Inconel 718.

\subsection{Ferramentas}

As ferramentas utilizadas nos ensaios conforme indicação dos fabricantes e da literatura foram as pastilhas de cerâmica reforçada com whiskers $\operatorname{CC} 670\left(\mathrm{Al}_{2} \mathrm{O}_{3}+\right.$ $\mathrm{SiC}_{\mathrm{w}}$ - contendo $\left.25 \% \mathrm{SiC}\right)$, cerâmica mista $\mathrm{CC} 650\left(\mathrm{Al}_{2} \mathrm{O}_{3}+28 \% \mathrm{TiC}\right)$ e PCBN (CB 7050; CB7020 e CB50 contendo 20 e 50\% de CBN respectivamente) fabricadas pela Sandvik Coromant nos formatos: quadrado, redondo e triangular.

A especificação ISO das pastilhas é indicada na TABELA 3.3. As ferramentas incorporam na sua forma comercial (padrão) um chanfro em $\mathrm{T}$ de $0,1 \mathrm{~mm}$ x $20^{\circ}$ na aresta de corte, exceto na ferramenta de PCBN com geometria redonda que apresenta aresta sem chanfro. As ferramentas foram utilizadas nas geometrias de corte padrão e com modificações das arestas de corte conforme ilustra a TABELA 3.6. 
TABELA 3.3 - Material e geometria da ferramenta

\begin{tabular}{|c|c|}
\hline Material & Geometria da pastilha \\
\hline Cerâmica - CC670/CC650 & RNGN 120400 T 01020 \\
\hline Cerâmica - CC670/CC650 & SNGN 120408 T 01020 \\
\hline Cerâmica - CC670/CC650 & TNGN 160408 T 01020 \\
\hline PCBN - CB7050/CB7020 & SNGN 120408 T 01020 \\
\hline PCBN - CB50 & RNGN 120400 F \\
\hline PCBN - CB7050/CB7020 & TNGA 160408 T01020 \\
\hline
\end{tabular}

Os conjuntos porta-ferramentas proporcionaram as seguintes geometrias, conforme ilustra a TABELA 3.4. As ferramentas foram utilizadas nas geometrias de corte padrão e com modificações das arestas de corte.

TABELA 3.4 - Geometria dos conjuntos porta-ferramentas (padrão)

\begin{tabular}{|l|c|c|c|}
\hline \multicolumn{1}{|c|}{ Geometria } & Quadrada & Triangular & Redonda \\
\hline Ângulo de posição $\left(\chi_{r}\right)$ & $45^{\circ}$ & $91^{\circ}$ & - \\
\hline Ângulo de saída $\left(\gamma_{0}\right)$ & $-6^{\circ}$ & $-6^{\circ}$ & $-6^{\circ}$ \\
\hline Ângulo de folga $\left(\alpha_{0}\right)$ & $6^{\circ}$ & $6^{\circ}$ & $6^{\circ}$ \\
\hline Âng. de inclinação $\left(\lambda_{s}\right)$ & $0^{\circ}$ & $-4^{\circ}$ & $-6^{\circ}$ \\
\hline
\end{tabular}

Após as modificações das arestas de corte, as ferramentas quadradas foram testadas também com o ângulo de posição de $25^{\circ}$ e $35^{\circ}$ e as ferramentas triangulares com o ângulo de posição de $71^{\circ}$ e $81^{\circ}$.

\subsection{Planejamento e procedimento experimental}

A avaliação do desempenho das diversas geometrias de aresta de corte foi através da medição de força de corte, temperałura, emissão acúcrica, mecanismos de desgaste e integridade superficial (rugosidade superficial, microdureza, microestrutura e tensão residual). Diversas condições de corte foram testadas com vários materiais de ferramentas, tais como $\mathrm{Al}_{2} \mathrm{O}_{3}+\mathrm{SiC}_{\mathrm{w}}, \mathrm{Al}_{2} \mathrm{O}_{3}+\mathrm{TiC}$ e $\mathrm{PCBN}$ (com duas concentrações de $\mathrm{CBN}$ ). 
Para alcançar uma confiabilidade aceitável na análise dos resultados, foram realizadas de duas a quatro repetições para as geometrias de melhor desempenho. $\mathrm{O}$ tratamento estatístico para a construção dos gráficos foi baseado no conceito de erro experimental. Quando um experimento é repetido sob as mesmas condições, os resultados não são idênticos. A flutuação que ocorre de uma repetição para outra é chamada de "erro experimental" (CARPINETTI, 2000).

\subsubsection{Montagem do banco de ensaios}

Foi montado um banco de ensaio para a realização dos experimentos, composto basicamente de um torno $\mathrm{CNC}$, um sensor de emissão acústica, uma unidade de tratamento de sinal de EA, bloco de conectores BNC, placa e programa de aquisição de sinais, circuito eletrônico para medição da temperatura, célula de carga para a medição de força de corte, amplificador de carga, fonte de tensão digital e microcomputador com o apoio do software LabView 5.1 para aquisição do sinal de EA, força de corte e temperatura da ferramenta conforme mostra a FIGURA 3.1.

A FIGURA 3.2 mostra o sistema de fixação da peça no torno e o posicionamento do bico aspersor.

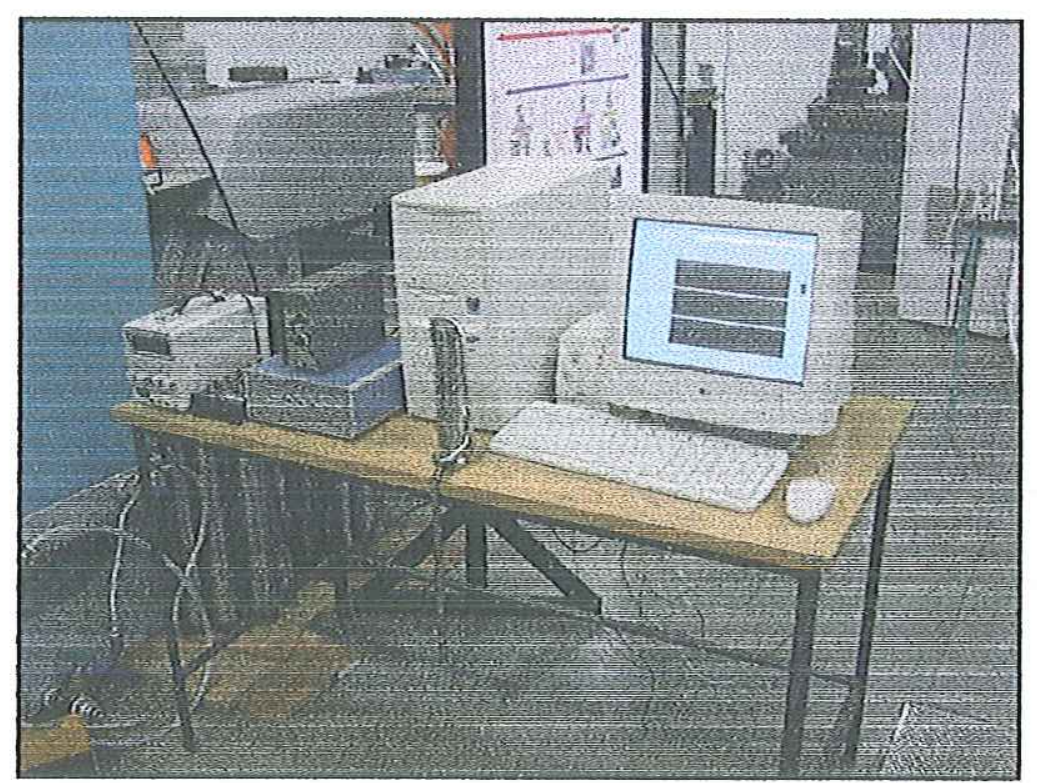

FIGURA 3.1 - Banco de Ensaio Utilizado na Experimentação no

Monitoramento da Emissão Acústica, Temperatura e Força de Corte. 

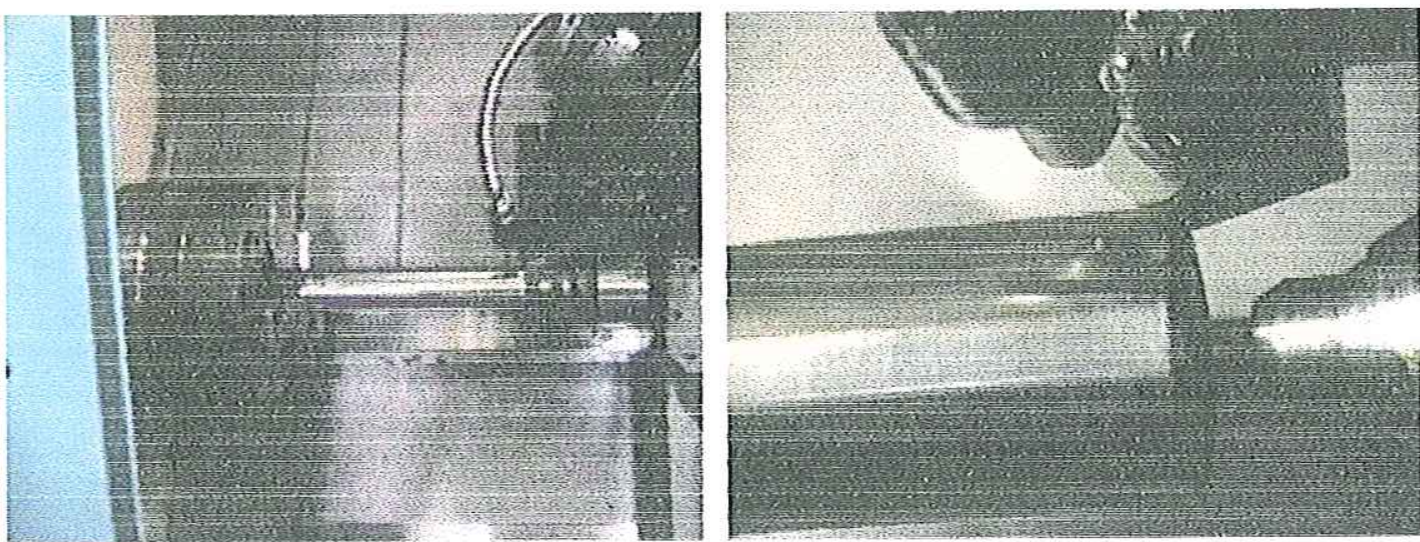

FIGURA 3.2 - Sistema de Fixação do Corpo de Prova e Posicionamento do Bico

Aspersor.

\subsubsection{Planejamento dos experimentos}

Os parâmetros de corte [velocidade de corte $\left(\mathrm{V}_{\mathrm{c}}\right)$, avanço $(\mathrm{f})$ e profundidade de usinagem $\left(\mathrm{a}_{\mathrm{p}}\right)$ ] foram selecionados mediante recomendação da literatura técnica e ensaios preliminares. Os mesmos foram ajustados de acordo com a máxima rotação do eixo-árvore e faixas de aplicações industriais na operação de acabamento utilizando alta velocidade de corte em peças de superligas à base de níquel.

As condições de corte selecionadas para a realização dos testes preliminares na usinagem do Inconel 718 com ferramentas cerâmicas (CC670 e CC650) de geometria quadrada foram: $V_{c}=300,400,500,600$ e $800 \mathrm{~m} / \mathrm{min} ; \mathrm{f}=0,05 ; 0,10$ e $0,15 \mathrm{~mm} / \mathrm{rev}$; e $a_{\mathrm{p}}=0,35 \mathrm{~mm}$, sob condição a seco e com mínima quantidade de lubrificante (MQL) com vazões de 15 e $30 \mathrm{ml} / \mathrm{h}$. A velocidade de corte de $800 \mathrm{~m} / \mathrm{min}$ apresentou fusão superficial na maior parte do comprimento usinado. A geometria quadrada foi escolhida para os testes preliminares por ser a mais utilizada mediante literatura técnica. Com os parâmetros de corte definidos, pôde-se planejar a matriz de experimentos para os testes preliminares, conforme mostra a TABELA 3.5. Os ensaios preliminares foram realizados com o objetivo de determinar a melhor condição de mínima quantidade de lubrificante e a máxima velocidade de corte a ser utilizada nos ensaios definitivos. Devido ao custo elevado das ferramentas de PCBN, optou-se em não testá-las nos testes preliminares. As velocidades de corte utilizadas nos ensaios preliminares estão na faixa de valores que definem a alta velocidade de corte para as superligas, segundo o gráfico da FIGURA 2.2. 
A técnica MQL foi utilizada com as ferramentas de melhor desempenho no corte a seco. A maior velocidade de corte que proporcionou melhor acabamento e menor taxa de desgaste foi a de $500 \mathrm{~m} / \mathrm{min}$ com avanço de $0,10 \mathrm{~mm} / \mathrm{rev}$., a qual foi selecionada para a realização dos testes definitivos na análise dos mecanismos de desgaste; medição da temperatura, emissão acústica e da força de corte; medição da rugosidade superficial; análise da microestrutura, microdureza e tensão residual. As demais velocidades foram utilizadas somente para medição da temperatura, força de corte e emissão acústica.

TABELA 3.5 - Matriz de experimentos com ferramentas cerâmicas (CC670 e CC650) de geometria quadrada na realização dos ensaios preliminares.

\begin{tabular}{|c|c|c|c|}
\hline $\mathbf{V}_{\mathbf{c}}(\mathbf{m} / \mathbf{m i n})$ & Avanço (mm/rev.) & Prof. de usinagem $\mathbf{( m m )}$ & Lubrificação \\
\hline 200 & 0,10 & 0,35 & Seco \\
\hline 300 & 0,10 & 0,35 & Seco \\
\hline 400 & 0,10 & 0,35 & Seco \\
\hline 500 & 0,10 & 0,35 & Seco \\
\hline 600 & 0,10 & 0,35 & Seco \\
\hline 800 & 0,10 & 0,35 & Seco \\
\hline 500 & 0,05 & 0,35 & Seco \\
\hline 500 & 0,15 & 0,35 & Seco \\
\hline 500 & 0,10 & 0,35 & $15 \mathrm{ml} / \mathrm{h}$ \\
\hline 500 & 0,10 & 0,35 & $30 \mathrm{ml} / \mathrm{h}$ \\
\hline
\end{tabular}

\subsubsection{Sistema de lubri-refrigeração}

O sistema MQL é composto basicamente de: compressor, regulador de pressão, rotâmetro, dosador e bico aspersor. A vazão inicial de lubrificante foi de $15 \mathrm{ml} / \mathrm{h}$ e do ar de $9 \mathrm{~m}^{3} / \mathrm{h}$. A vazão de $30 \mathrm{ml} / \mathrm{h}$ apresentou desempenho similar para a mesma vazão de ar, sendo assim, a vazão de $15 \mathrm{ml} / \mathrm{h}$ foi escolhida para a realização dos ensaios definitivos, pois é a condição de menor consumo de óleo. A vazão de lubrificante é medida com auxílio de uma proveta gradiada. O equipamento de mínima quantidade de lubrificante permite uma fina regulagem do volume de lubrificante/ar separadamente, por meio de um registro tipo agulha, atomizando-o em um fluxo de ar à pressão constante de $6,0 \mathrm{kgf} / \mathrm{cm}^{2}$. A FIGURA 3.3 mostra a unidade de controle do equipamento de MQL, onde é feita a dosagem do lubrificante e a regulagem da vazão de ar comprimido. Cada parte que compõe o equipamento foi 
numerado para facilitar a descrição e função. Na FIGURA 3.4 encontra-se o bico aspersor desenvolvido e utilizado na experimentação. $O$ modelo permite um ajuste fino da velocidade do ar para a formação de névoa com diferentes valores de vazão. O bico aspersor foi colocado a cerca de $25 \mathrm{~mm}$ da ferramenta direcionado para a superficie de saída/interface.

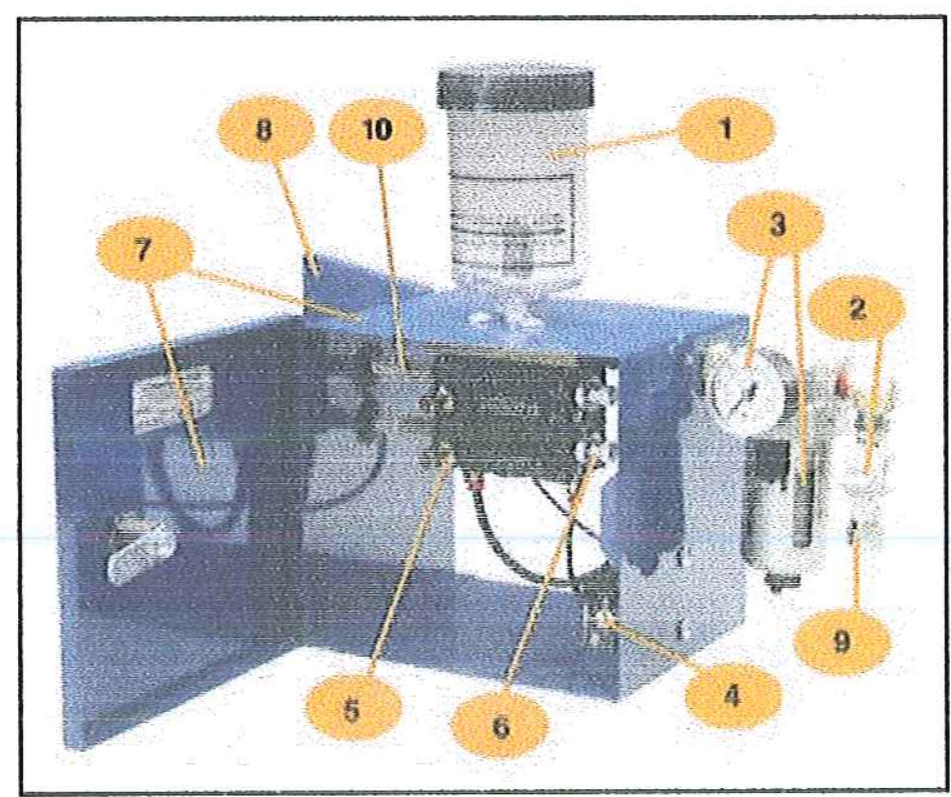

1. Reservatório $300 \mathrm{ml}$;

2. Registro de acionamento;

3. Manômetro e filtro de ar (deve atuar entre 80 e 150 psi ou 5,6 e $10,5 \mathrm{kgf} / \mathrm{cm}^{2}$ );

4. Gerador de frequêencia (sentido horário aumenta freqüência);

5. Bomba pneumática de ajuste individual;

6. Ajuste do fluxo de lubrificante;

7. Caixa metálica;

8. Furos de montagem ou bases magnéticas para fixação rápida;

9. Entrada de ar (mínimo $80 \mathrm{psi}$ ou $5,6 \mathrm{kgf} / \mathrm{cm}^{2}$ );

10. Saída para o bocal aplicador.

FIGURA 3.3 - Esquema do Equipamento de Mínima Quantidade de Lubrificante MQL (Aplicador Accu-Lube ${ }^{\circledR}$ ). 


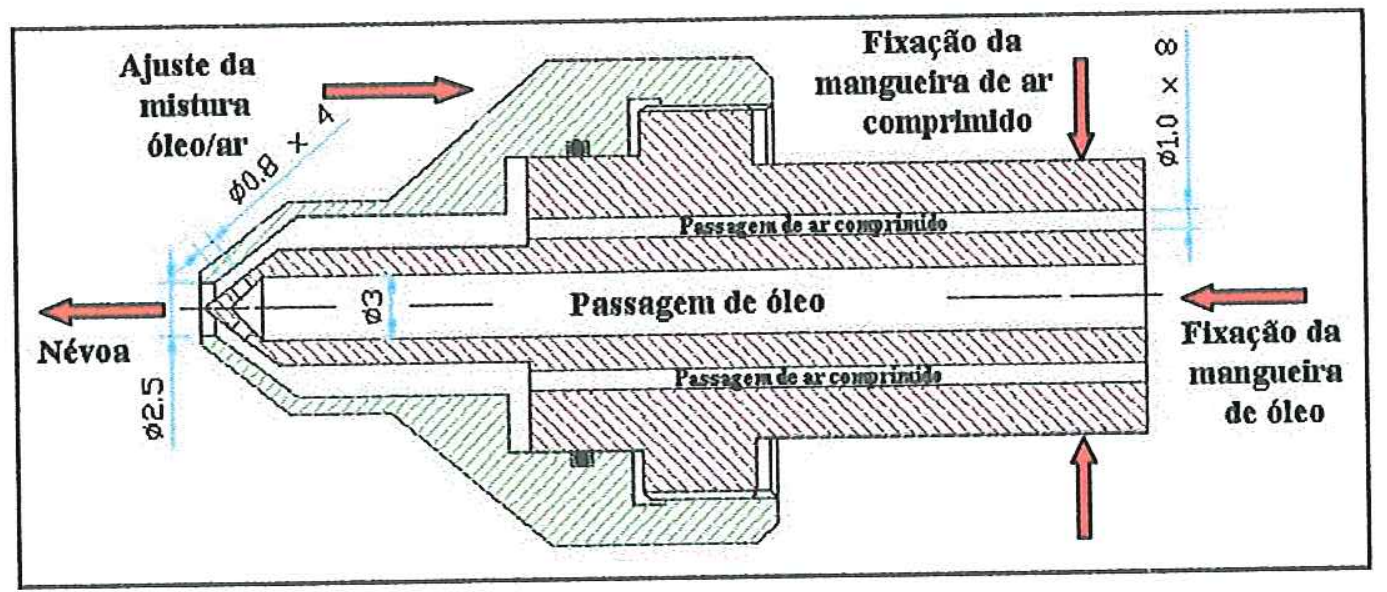

FIGURA 3.4 - Bico Aspersor Utilizado para a Experimentação com a Técnica MQL.

\subsubsection{Preparação da geometria de aresta de corte}

Os insertos foram modificados um de cada vez, fixados à mesa da afiadora universal, através de dispositivo específico. A preparação das arestas de corte consistiu na modificação de chanfro/raio de aresta, raio de ponta e ângulo de posição totalizando em 21 modificações nos formatos (quadrado, triangular e redondo) nas ferramentas de cerâmicas (CC670 e CC650), conforme ilustra a TABELA 3.6. Devido ao alto custo das ferramentas de PCBN, optou-se em testar as modificações nas ferramentas de cerâmicas, e empregar as geometrias de aresta de corte de melhor desempenho nas ferramentas de PCBN.

Após a preparação, os insertos foram levados para um projetor de perfil para serem avaliados dimensionalmente. A FIGURA 3.5 indica as modificações na geometria da aresta de corte para o inserto quadrado. Essas modificações foram reproduzidas para os insertos triangular e redondo. $O$ critério adotado para as modificações na geometria das arestas de corte foi a partir do chanfro de aresta existente na ferramenta comercial $\left(0,10 \mathrm{~mm} \times 20^{\circ}\right)$. As ferramentas quadradas e triangulares foram modificadas também no ângulo de posição e no raio de ponta. 

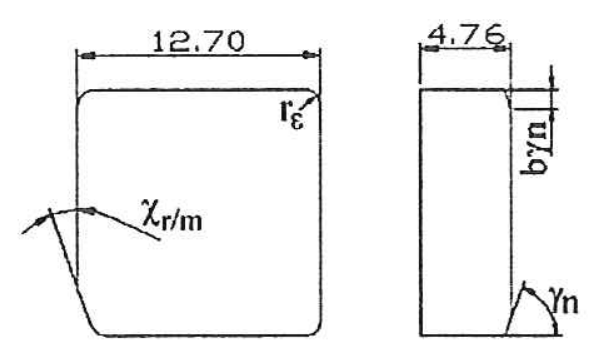

(a) Dimensões modificadas

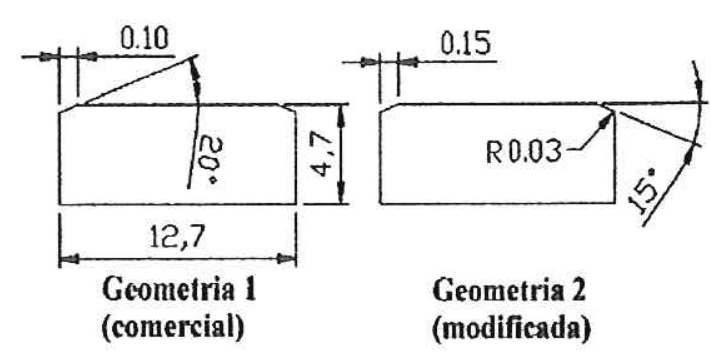

(b) Detalhe da geometria de aresta

FIGURA 3.5 - Principais Modificações no Inserto Quadrado e na Aresta de Corte.

TABELA 3.6 - Modificações na geometria da aresta de corte em ferramentas cerâmicas (CC670 e CC650).

\begin{tabular}{|c|c|c|c|c|c|c|}
\hline $\begin{array}{c}\text { Geometria } \\
\text { de aresta }\end{array}$ & $\begin{array}{c}\text { Chanfro } \\
(\gamma \mathbf{n})\end{array}$ & $\begin{array}{c}\text { Largura } \\
(\mathbf{b} \gamma \mathbf{n})\end{array}$ & $\mathbf{r}_{\mathbf{8}}$ & $\chi_{\mathbf{r} / \mathbf{m}}$ & $\begin{array}{c}\text { Raio de } \\
\text { aresta }\end{array}$ & $\begin{array}{c}\text { Formato } \\
\text { (classe) }\end{array}$ \\
\hline $1^{*}$ & $20^{\circ}$ & 0,10 & $*$ & $*$ & sharp & $\mathrm{Q}-\mathrm{T}-\mathrm{R}$ \\
\hline 2 & $15^{\circ}$ & 0,15 & $*$ & $*$ & $\mathrm{D}$ & $\mathrm{Q}-\mathrm{T}-\mathrm{R}$ \\
\hline 3 & $15^{\circ}$ & 0,15 & $*$ & $10^{\circ}$ & $\mathrm{D}$ & $\mathrm{Q}-\mathrm{T}$ \\
\hline 4 & $10^{\circ}$ & 0,20 & $*$ & $*$ & $\mathrm{D}$ & $\mathrm{Q}-\mathrm{T}-\mathrm{R}$ \\
\hline 5 & $20^{\circ} / 45^{\circ}$ & $0,10 / 0,15$ & $*$ & $*$ & $\mathrm{E}$ & $\mathrm{Q}(\mathrm{CC} 670)$ \\
\hline 6 & $20^{\circ}$ & 0,20 & $*$ & $*$ & $\mathrm{D}$ & $\mathrm{Q}-\mathrm{T}-\mathrm{R}$ \\
\hline $7^{*}$ & $0^{\circ}$ & - & - & - & sharp & $\mathrm{R}(\mathrm{PCBN})$ \\
\hline 8 & $15^{\circ}$ & 0,15 & $*$ & $20^{\circ}$ & $\mathrm{D}$ & $\mathrm{Q}-\mathrm{T}$ \\
\hline 9 & $20^{\circ}$ & 0,10 & $*$ & $10^{\circ}$ & $\mathrm{A}$ & $\mathrm{Q}$ \\
\hline 10 & $30^{\circ}$ & 0,25 & $*$ & $*$ & $\mathrm{E}$ & $\mathrm{Q}(\mathrm{CC} 670)$ \\
\hline 11 & $15^{\circ}$ & 0,20 & 1,2 & $*$ & $\mathrm{E}$ & $\mathrm{Q}-\mathrm{T}(\mathrm{CC670})$ \\
\hline 12 & $20^{\circ}$ & 0,10 & 1,2 & $*$ & $\mathrm{E}$ & $\mathrm{Q}-\mathrm{T}(\mathrm{CC670})$ \\
\hline 13 & $45^{\circ}$ & 0,20 & $*$ & $*$ & $\mathrm{E}$ & $\mathrm{Q}(\mathrm{CC} 670)$ \\
\hline 14 & $25^{\circ} / 45^{\circ}$ & $0,15 / 0,15$ & $*$ & $*$ & $\mathrm{~A}$ & $\mathrm{Q}(\mathrm{CC} 670)$ \\
\hline 15 & $20^{\circ}$ & 0,10 & 1,2 & $10^{\circ}$ & $\mathrm{A}$ & $\mathrm{Q}-\mathrm{T}(\mathrm{CC} 670)$ \\
\hline 16 & $15^{\circ}$ & 0,15 & $*$ & $*$ & $\mathrm{~A}$ & $\mathrm{Q}-\mathrm{T}-\mathrm{R}$ \\
\hline 17 & $20^{\circ}$ & 0,10 & $*$ & $*$ & $\mathrm{~A}$ & $\mathrm{~T}-\mathrm{R}$ \\
\hline 18 & $15^{\circ}$ & 0,15 & 1,2 & $*$ & $\mathrm{~A}$ & $\mathrm{Q}-\mathrm{T}$ \\
\hline 19 & $10^{\circ}$ & 0,20 & $*$ & $*$ & $\mathrm{~A}$ & $\mathrm{Q}-\mathrm{T}-\mathrm{R}$ \\
\hline 20 & $15^{\circ}$ & 0,15 & $*$ & $*$ & sharp & $\mathrm{Q}-\mathrm{T}-\mathrm{R}$ \\
\hline 21 & $20^{\circ}$ & 0,10 & $*$ & $*$ & $\mathrm{D}$ & $\mathrm{T}-\mathrm{R}$ \\
\hline
\end{tabular}

(* Padrão - vide TAB. 3.3; $\mathrm{A}=0,0381-0,0635 \mathrm{~mm} ; \mathrm{D}=0,0127-0,0381 \mathrm{~mm} ; \mathrm{E}=0,0635$ -

$0,088.9 \mathrm{~mm}$; Sharp $\leq 0,0127 \mathrm{~mm}$; by $=$ largura do chanfro; $r_{8}=$ raio de ponta;

$\chi_{\mathrm{s} / \mathrm{m}}=$ ângulo de posição modificado; $\mathrm{Q}=$ quadrado; $\mathrm{R}=$ redondo; $\mathrm{T}=$ triangular). 
As geometrias de aresta de corte de melhor desempenho foram: geometria 1 (chanfro em T de $0,1 \mathrm{~mm} \times 20^{\circ}$ - comercial) e geometria 2 (chanfro em $\mathrm{T}$ de $0,15 \mathrm{~mm}$ x $15^{\circ}$ com raio de aresta de $0,03 \mathrm{~mm}$ - modificada), sendo a última a melhor opção para os parâmetros avaliados. A geometria 7 (aresta do tipo sem chanfro - comercial) foi utilizada somente na ferramenta redonda de PCBN, por falta de opção do fabricante.

Deve-se salientar que, as geometrias de aresta de corte propostas pelos fabricantes de ferramentas cerâmicas e de PCBN, são utilizadas para diversos tipos de materiais usinados, necessitando de otimização para um melhor desempenho em materiais específicos.

\subsubsection{Avaliação dos mecanismos de desgaste}

A análise dos mecanismos de desgaste envolvidos foi realizada com a finalidade básica de comparar os tipos de desgastes das ferramentas CC670, CC650 e CB7050/CB7020/CB50. As ferramentas desgastadas foram posteriormente analisadas e fotografadas no microscópio eletrônico de varredura (SEM) na tentativa de encontrar evidências que pudessem identificar os mecanismos de desgaste atuantes. As ampliações das fotografias foram ajustadas de maneira que permitisse uma melhor visão da região do desgaste.

\subsubsection{Medição da rugosidade superficial}

A medição da rugosidade superficial foi realizada ajustando o rugosímetro para o comprimento de amostragem (cut-off) de $0,8 \mathrm{~mm}$, verificando e ajustando o mesmo junto ao padrão do fabricante no decorrer dos testes.

A cada passada, foram medidos os valores da rugosidade média $R_{a}$ em três pontos eqüidistantes do comprimento usinado $(185 \mathrm{~mm})$, sendo efetuado três medições em cada ponto e em seguida calculou-se a média dos valores para a confecção dos gráficos. O objetivo da medição de rugosidade foi avaliar o desempenho das diversas geometrias de arestas de corte quanto ao acabamento gerado, mais especificamente sobre o parâmetro $R_{a}$. 


\subsubsection{Medição da temperatura da ferramenta}

A temperatura da ferramenta foi medida pelo método de termopar implantado do tipo $\mathrm{K}$ com diâmetro da cabeça variando entre 0,5 a $0,6 \mathrm{~mm}$, fixado por um dispositivo (grampo com rasgo para alojamento da cabeça do termopar) construído especialmente para esse fim, na superficie de saída da ferramenta, a uma distância de 1,5 mm da aresta de corte, conforme ilustra a FIGURA 3.6.

Os termopares geram tensão da ordem de $\mu \mathrm{V}$, portanto, muito sensíveis a ruídos elétricos. Termopares muito longos poderiam está sujeito a ruído, interferindo na leitura. Por este motivo, utilizou-se termopar de aproximadamente $250 \mathrm{~mm}$ de comprimento. Este termopar foi ligado a um circuito eletrônico que transforma a tensão gerada pelos termopares em uma corrente de $\mathrm{mA}$ e novamente em tensão, mas em V. A tensão com ordem de grandeza em V é muito menos sensível a ruídos elétricos, assim o cabo blindado leva o sinal da placa de circuito eletrônico até o bloco de conectores $\mathrm{BNC}$, podendo ter o tamanho necessário sem comprometer a qualidade do sinal. A FIGURA 3.7 mostra a placa de circuito eletrônico utilizada nos experimentos.

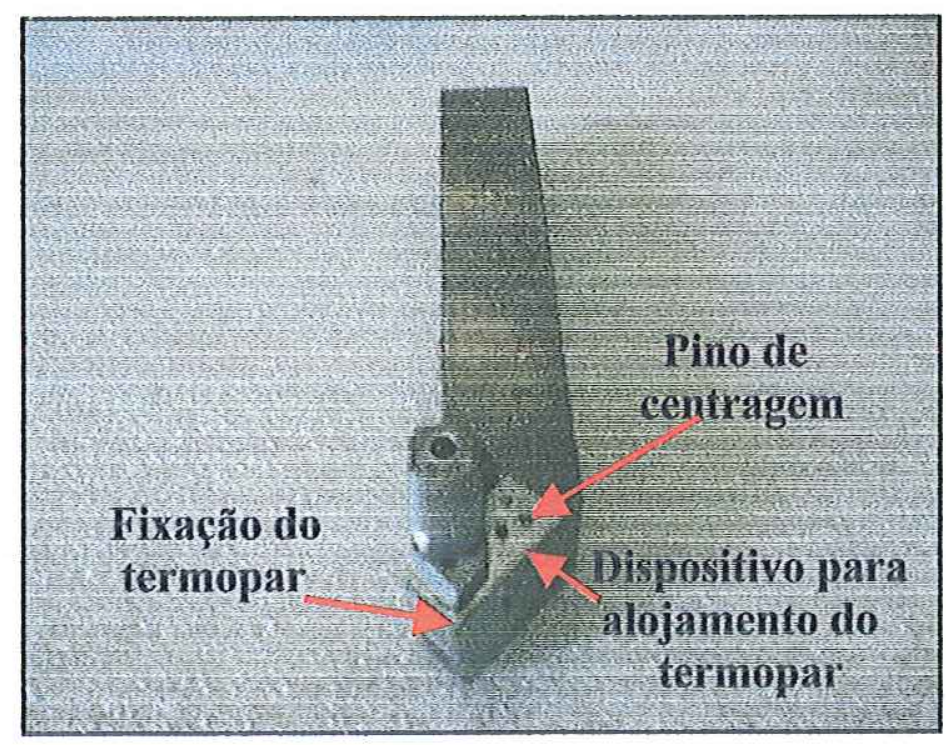

FIGURA 3.6 - Montagem do Termopar do Tipo K Fixado na Superficie de Saída da

Ferramenta, a uma Distância de 1,5 mm da Aresta de Corte. 


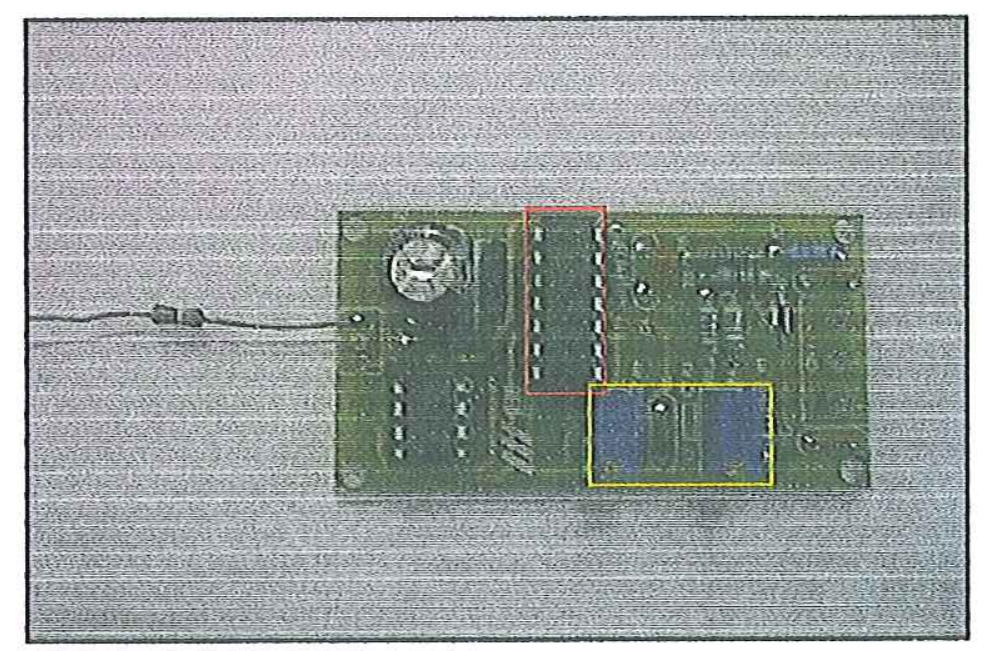

FIGURA 3.7 - Circuito Eletrônico que Transforma Tensão $(\mu \mathrm{V})$ em Corrente (mA) e Novamente em Tensão (V).

De todos os componentes eletrônicos que foram utilizados neste circuito, chama-se a atenção para 3 deles. $\mathrm{O}$ circuito integrado, dentro do retângulo vermelho, cuja função é transformar a tensão do termopar em corrente. Os outros componentes são os 2 potenciômetros, dentro do retângulo amarelo, cuja a função de um é ajustar a corrente mínima $(4 \mathrm{~mA})$ e a do outro é ajustar a corrente máxima $(20 \mathrm{~mA})$. A alimentação do circuito eletrônico é feita por uma fonte digital ajustada em uma tensão de alimentação de $12 \mathrm{~V}$.

Para medir a temperatura, utilizou-se também um módulo de entrada e saída de sinais modelo BNC-12 e uma placa de conversão e aquisição de sinais modelo AT-MIO-16XE-50, ambos da NATIONAL INSTRUMENTS instalada em um computador PC com o suporte do software LabView 5.1. A referida placa foi utilizada também na medição de força de corte e emissão acústica.

A calibração do termopar foi realizada em duas etapas. Na primeira fez uso de um calibrador de termopares (Altek - modelo 322-1) que funciona da seguinte maneira: seleciona-se o tipo do termopar, no caso tipo $\mathrm{K}$, em seguida escolhe-se uma temperatura de calibração no equipamento para ajuste da corrente mínima (4 mA), escolheu-se $0^{\circ} \mathrm{C}$. $\mathrm{O}$ calibrador faz o papel do termopar, gerando uma tensão para a temperatura escolhida. Uma vez o calibrador de termopar ajustado, o circuito é alimentado com $12 \mathrm{~V}$ e a corrente é medida com um multímetro de precisão (foi usado um multímetro Fluke modelo 89 IV). A seguir regulam-se os 2 potenciômetros até conseguir-se uma corrente de $4 \mathrm{~mA}$. Para ajustar a corrente máxima (20 mA) 
seleciona-se uma temperatura de máximo (no caso $300^{\circ} \mathrm{C}$ ). O ajuste da corrente máxima também é feito através dos potenciômetros. Este procedimento é repetido algumas vezes para refinar os ajustes, de modo que a corrente mínima fique em torno de $4 \mathrm{~mA}$ e a máxima em torno de $20 \mathrm{~mA}$. O refinamento é necessário, pois um potenciômetro interfere no ajuste do outro, quando se ajusta a corrente mínima existe um pequeno desajuste da corrente máxima e vice versa.

A segunda etapa foi o levantamento da curva de calibração do termopar e da sua respectiva placa de circuito eletrônico. Isto foi necessário, pois a máquinaferramenta usada nos experimentos não é completamente isolada. Esta máquina introduz no sinal do termopar um pequeno ruído elétrico que não poderia ser ignorado. Então, esta segunda calibração necessariamente teria que ser feita na máquina. A maneira de levantar a curva de calibração foi através do monitoramento do resfriamento, ao ar parado, de dois blocos de superficies planas aquecidos em um forno próximo a máquina até a temperatura de $400^{\circ} \mathrm{C}$. Uma vez atingida a temperatura, esperou-se durante 60 minutos para homogeneização da temperatura nos blocos. Os dois termopares foram colocados entre os dois blocos aquecidos sobre o cabeçote móvel do torno.

A leitura $\left(\mathrm{em}^{\circ} \mathrm{C}\right)$ da temperatura do termopar calibrado foi feita através do mesmo multímetro Fluke citado acima. O outro termopar foi monitorado (medição da tensão em Volts) pelo próprio sistema de aquisição de temperatura (bloco de conectores BNC, placa e programa de aquisição - LabView). A partir de $340^{\circ} \mathrm{C}$ faziase a medição da tensão do termopar. Isto foi repetido em intervalo regulares de $20^{\circ} \mathrm{C}$ até próximo a temperatura ambiente. Este procedimento foi repetido 3 vezes. Para cada ponto de temperatura fez-se a média dos 3 valores de tensão medidos. A FIGURA 3.8 mostra a curva de calibração do termopar, representada pela equação da reta $(y=123,04 x-84,228)$ feita através de regressão linear da planilha de cálculo do Excel. Deste modo, o programa de aquisição faz a leitura da temperatura em Volts e posteriormente em uma planilha de cálculo estes dados são convertidos em temperatura $\left({ }^{\circ} \mathrm{C}\right)$, através da equação da reta de calibração. $\mathrm{O}$ tempo de amostragem selecionado para a medição da temperatura da ferramenta foi relativo ao comprimento usinado. 


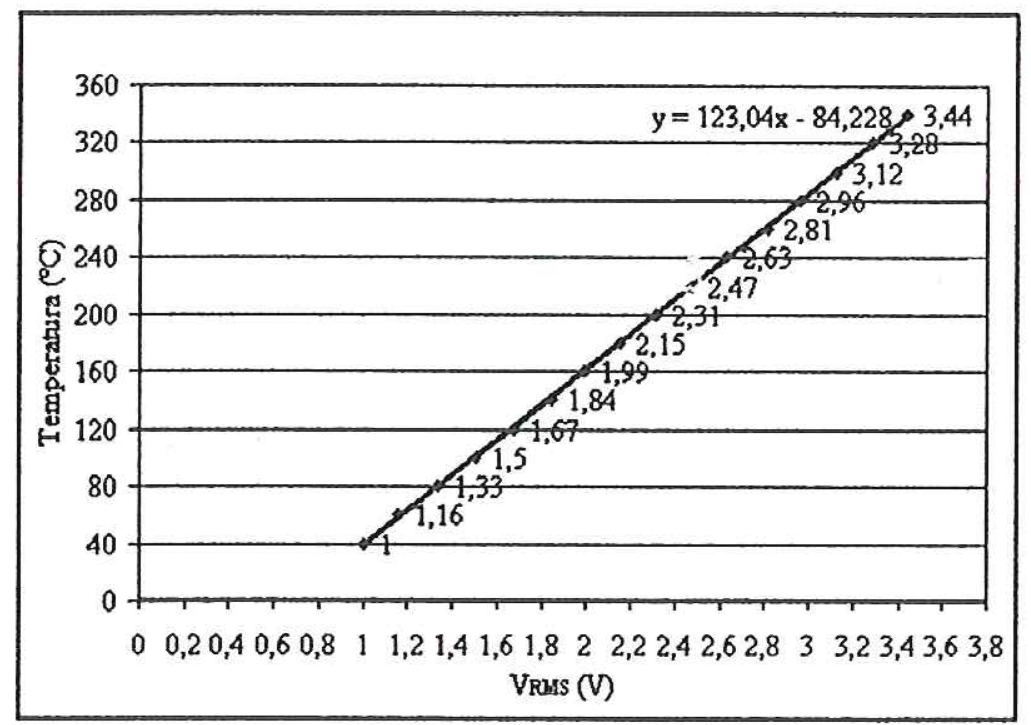

FIGURA 3.8 - Curva de Calibração do Termopar Tipo K.

\subsubsection{Medição da força de corte}

Para a medição da força de corte, foi necessário construir um portaferramenta especial para o alojamento da célula de carga piezoeléctrica, assim como também, alguns dispositivos para a fixação do conjunto de pesos conforme mostra a FIGURA 3.9.

Antes ainda de iniciar os ensaios experimentais, foi necessário efetuar uma calibração estática na célula de carga do dinamômetro. Isto se fez necessário para que os dados obtidos através da utilização do dinamômetro fossem confiáveis. A célula de carga piezoeléctrica com elementos de quartzo utilizada nos experimentos tem freqüência natural alta de $180 \mathrm{kHz}$, não sendo portanto audiveis. Este valor está muito acima das freqüências de usinagem ou outros ruídos que estão envolvidos em ambiente de manufatura (FERRARESI, 1977) e neste caso não foi feita uma calibração dinâmica do dinamômetro. $\mathrm{O}$ quartzo é um material cristalino natural, o qual simboliza extrema rigidez e estabilidade, conferindo aos sensores de medida com quartzo uma freqüência natural muito alta. A atuação da força de corte sobre os elementos de quartzo é imediatamente convertida em sinais elétricos, e a resultante do valor do deslocamento origina uma deformação de pouquíssimos milésimos de milímetro, permitindo um sistema suficientemente rígido e preciso (KISTLER, 2001). Segundo FERRARESI (1977), para que o sistema seja considerado rígido, 
isto é, a deformação da ferramenta seja pequena, o deslocamento máximo da ferramenta deve ser inferior a $15 \mu \mathrm{m}$.

A força medida pela célula de carga do dinamômetro passa por sua unidade de controle onde é amplificada. A unidade de controle foi ligada no mesmo bloco de conectores do termopar e conectado a placa de aquisição interligado ao software LabView.

A FIGURA 3.10 representa a montagem para o processo de calibração da célula de carga do dinamômetro, na qual a carga foi aplicada na ponta da ferramenta mediante dispositivo construído para essa finalidade. Para efetuar o processo de calibração, foi utilizado um conjunto de pesos variando de 5,50 a 30,50 kgf. Os pesos foram colocados em intervalos de $5 \mathrm{kgf}$. Este procedimento foi repetido 3 vezes, em seguida calculou-se a média dos 3 valores de tensão medidos. Com a utilização de um programa feito no software LabView foi plotado a curva de calibração, conforme mostra a FIGURA 3.11, encontrando-se a equação da reta $(y=72,17 x+3,9147)$ através de regressão linear da planilha de cálculo do Excel. O programa de aquisição faz a leitura da força de corte em Volts e posteriormente em uma planilha de cálculo estes dados são convertidos em Newtons, através da equação da reta de calibração.

Os testes de força de corte foram realizados em todo comprimento usinado.

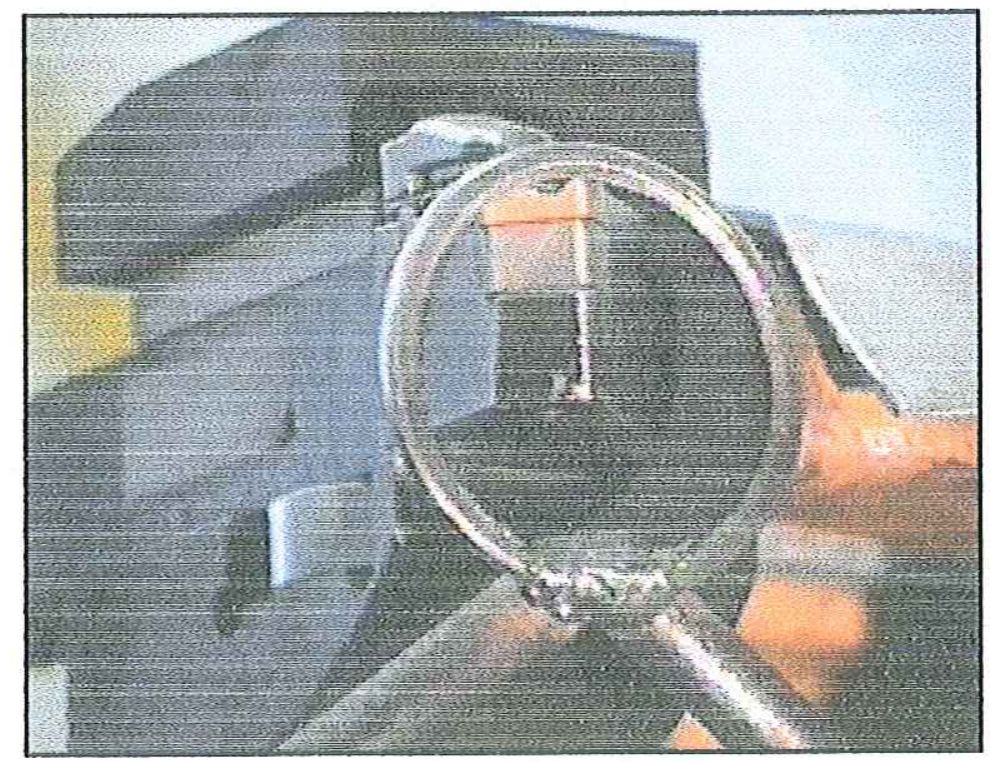

FIGURA 3.9 - Porta Ferramenta Especial para o Alojamento da Célula de Carga. 


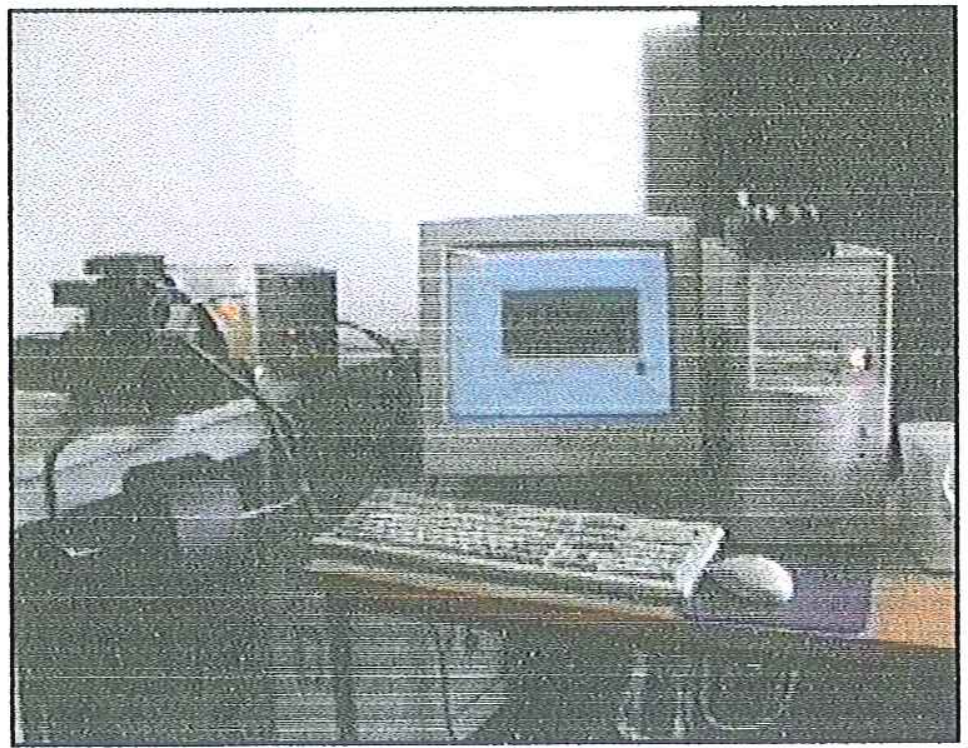

FIGURA 3.10 - Montagem para Calibração Estática da Célula de Carga.

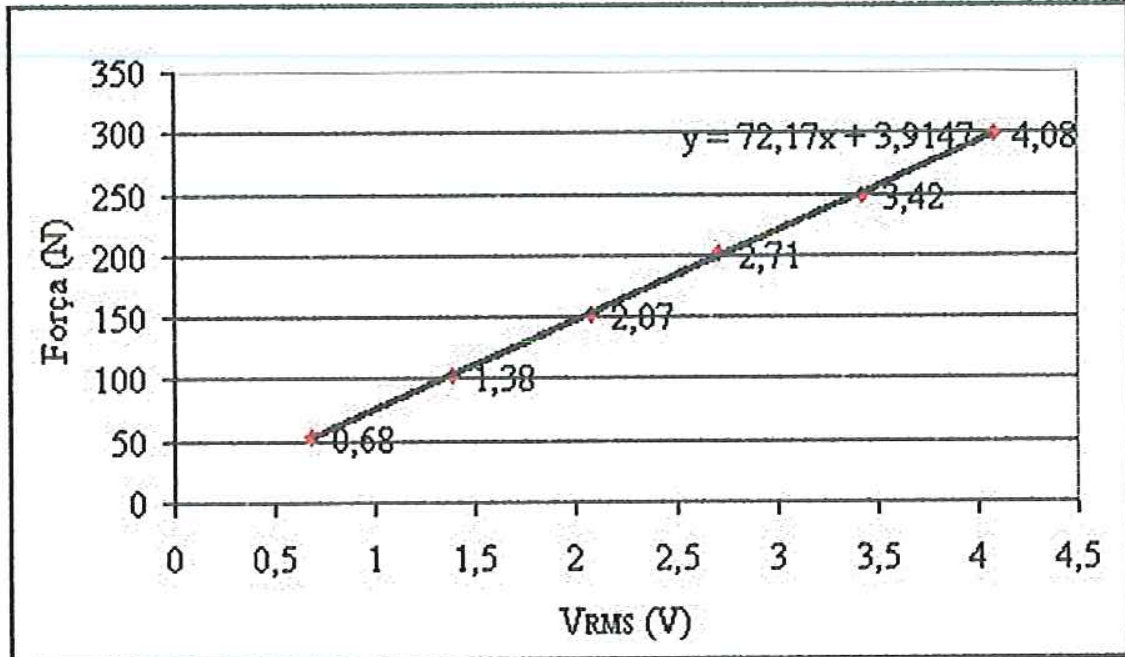

FIGURA 3.11 - Curva de Calibração Estática da Célula de Carga do Dinamômetro.

\subsubsection{Avaliação visual da microestrutura após a usinagem}

Para a análise da microestrutura, medição de microdureza e tensão residual, optou-se em construir um novo corpo de prova, com o objetivo de evitar a máxima influência na preparação das amostras conforme ilustra a FIGURA 3.12. As geometrias de melhor desempenho foram escolhidas para a análise desses parâmetros. Cada geometria foi submetida a três passadas consecutivas sob condição de corte a seco ou com MQL. O trabalho de preparação metalográfica e ataque das amostras iniciou-se com a complementação do sangramento dos canais, seguido de 
um faceamento interno a $3 \mathrm{~mm}$ abaixo da superficie a ser analisada. Em seguida foi utilizado o policorte para a execução do corte das amostras, obedecendo às dimensões da máquina de embutimento. Após o corte, foi realizado o embutimento com bakelite, seguido de lixamento das amostras com lixas que variaram de 400 à 2000 de granulação. Após o lixamento das amostras, seguiu-se o polimento, utilizando-se pasta de óxido de cromo e alumina com a granulação de 0,3 e 0,05 $\mu \mathrm{m}$. A cada troca de lixa e pasta utilizada, lava-se a amostra com detergente líquido seguido de álcool e seca imediatamente com auxílio de um secador de jato de ar quente.

$\mathrm{O}$ ataque foi realizado com uma solução de 4 partes de $\mathrm{HCl}$ (ácido clorídrico) e 1 parte de $\mathrm{HNO}_{3}$ (ácido nítrico) durante 30 segundos em média. Em seguida deu-se início à análise da microestrutura posicionando nas regiões que melhor representava a microestrutura, possibilitando uma boa focalização para retirar as fotografias.

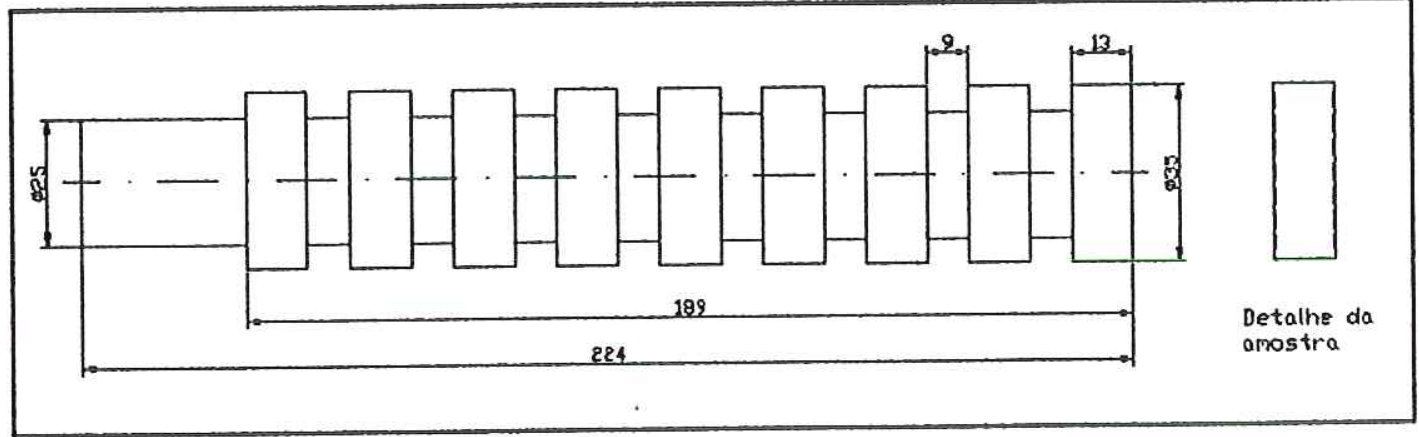

FIGURA 3.12 - Dimensões e Forma do Corpo de Prova para Análise da Integridade Superficial.

\subsubsection{Medição da tensão residual}

Para a determinação dos valores nominais de tensão residual utilizou-se o método da múltipla exposição $\left(\operatorname{sen}^{2} \Psi\right)$, segundo a norma SAE J784a. Optou-se pela análise do plano (111) do níquel, por considerações de aspecto experimental, sendo utilizados os valores do módulo de elasticidade e coeficiente de Poison do Inconel 718 para o cálculo da tensão residual. O ângulo de varredura (20) variou de 47 a 63 graus, a passos de 0,1 grau, com tempo de exposição de 1 segundo. Os ângulos de 
inclinação da amostra variaram de -60 a 60 graus, com medições efetuadas a cada 10 graus.

Para se obter as medidas de tensão residual, foi necessário ajustar as amostras possibilitando a fixação e deslocamento no difratômetro. As medidas foram realizadas aproximadamente a $10 \mu \mathrm{m}$ abaixo da superficie.

\subsubsection{Medição de microdureza}

O processo de preparação das amostras para a análise de microdureza foi o mesmo utilizado no lixamento e polimento para a análise da microestrutura. $\mathrm{O}$ embutimento no bakelite deu-se de forma que a parte convexa proporcionasse condições de executar o lixamento até obter um comprimento (l) de aproximadamente $5 \mathrm{~mm}$, o que resultaria em uma profundidade abaixo da superficie de aproximadamente de $160 \mu \mathrm{m}$, conforme mostra a FIGURA 3.13.

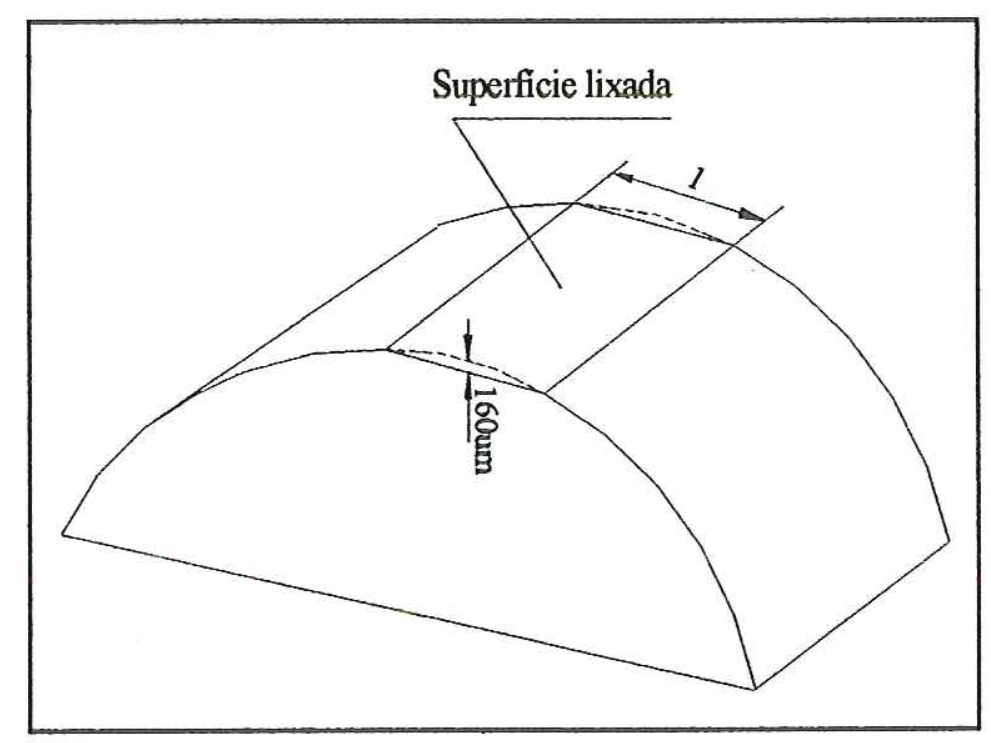

FIGURA 3.13 - Representação da Amostra para a Medição da Microdureza

A forma como foram seccionadas as amostras permitiu a obtenção de uma ampliação da região alterada metalurgicamente para a análise micrográfica demonstrado através da FIGURA 3.14. 


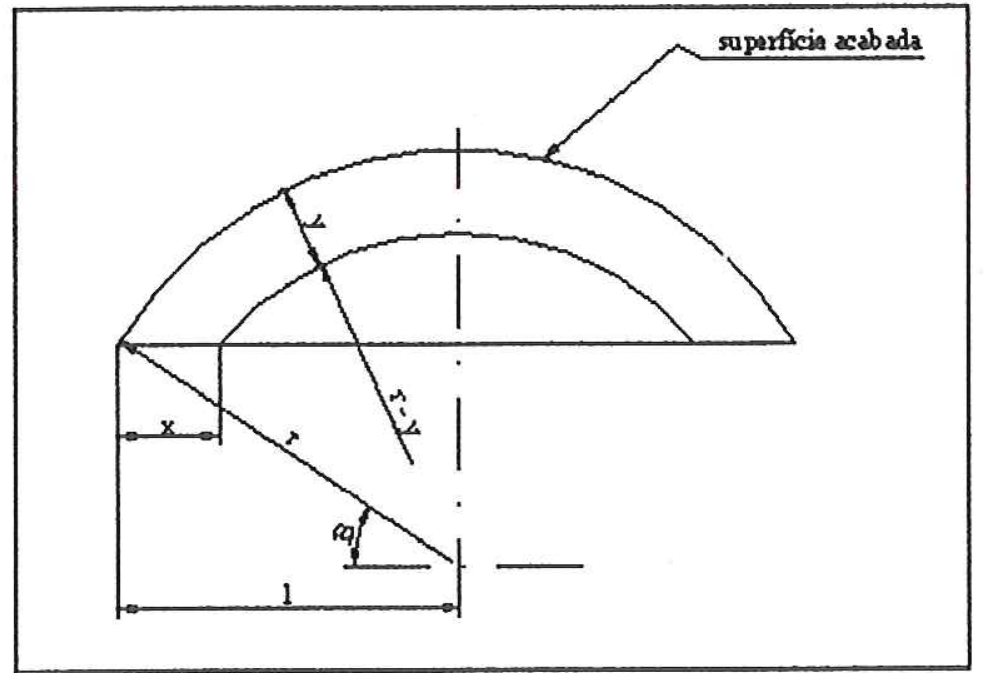

FIGURA 3.14 - Vista Lateral da Amostra

Da lei dos cossenos tem-se que:

$(r-y)^{2}=r^{2}+x^{2}-2 r x \cos B$

Como $\operatorname{cosB}=1 / \mathrm{r}$, tem-se:

$(\mathrm{r}-\mathrm{y})^{2}=\mathrm{r}^{2}+\mathrm{x}^{2}-2 \mathrm{xl}$

$r^{2}-2 r y+y^{2}=r^{2}+x^{2}-2 x 1$

$y^{2}-2 r y+\left(21 x-x^{2}\right)=0$

finalmente,

$\mathrm{y}=\mathrm{r}-\sqrt{r^{2}-\left(2 l x-x^{2}\right)}$; onde $\mathrm{x} / \mathrm{y}$ representa a taxa de ampliação da área a ser observada.

Como se pode notar pelo esquema, o comprimento $\mathrm{x}$ será maior que o comprimento y, logo a razão entre essas duas medidas será maior que um, provando assim que se tem uma ampliação da área a ser observada. 0 deslocamento de $\mathrm{x}$, em cada medição, foi de $250 \mu \mathrm{m}$, o que proporciona, após o cálculo de y, uma profundidade de 4 a $30 \mu \mathrm{m}$. Quando a profundidade da subsuperficie atingia aproximadamente $150 \mu \mathrm{m}$, utilizavam-se as amostras da análise da microestrutura para a complementação da medição até alcançar a profundidade de $300 \mu \mathrm{m}$. As medidas encontradas em ambas amostras foram compatíveis.

Para a definição da carga a ser utilizada nos ensaios, experimentaram-se cargas de 25, 50, 100 e 200 gramas. A carga de 100 gramas proporcionou a melhor 
relação entre as medidas das diagonais, obedecendo a norma que estabelece uma distância de no mínimo $2 x$ o valor da diagonal.

\subsection{Descrição dos ensaios}

O sistema de fixação dos corpos de prova (CDP) foi através de placa e contraponto conforme mostra a FIGURA 3.2. O comprimento de corte utilizado foi de aproximadamente $185 \mathrm{~mm}$, com pré-chanframento no início do corte de $10^{\circ}$, proporcionando uma entrada progressiva da ferramenta, o que é muito benéfico para evitar falha catastrófica. Dois programas CNC foram elaborados para a usinagem dos materiais, os quais são mostrados no Apêndice I.

As condições de corte selecionadas para a realização dos testes definitivos para as ferramentas cerâmicas (CC670 e CC650) e PCBN (CB7050/CB7020/CB50) nos formatos (quadrado, triangular e redondo) em todas as geometrias de aresta de corte foram: $V_{c}=500 \mathrm{~m} / \mathrm{min} ; \mathrm{f}=0,10 \mathrm{~mm} / \mathrm{rev}$; e $a_{p}=0,35 \mathrm{~mm}$ sob condição de corte a seco. A técnica de mínima quantidade de lubrificante (MQL) foi utilizada com as ferramentas de melhor desempenho no corte sem refrigeração, utilizando vazões de $15 \mathrm{ml} / \mathrm{h}$ de lubrificante e $9 \mathrm{~m}^{3} / \mathrm{h}$ de ar à pressão constante de $6,0 \mathrm{kgf} / \mathrm{cm}^{2}$. A medição da dureza foi monitorada durante os experimentos.

A vida da ferramenta era referente a uma passada, no qual consistia o experimento, para a medição de força de corte, temperatura e emissão acústica. $O$ critério de limite de vida da ferramenta foi estabelecido em função da alta taxa de desgaste da ferramenta, não sendo possível a realização de mais um passe. A cada passada foi realizada também a medição da rugosidade superficial. Após cada passe, o inserto foi retirado e identificado para posterior análise dos mecanismos de desgaste. Para a análise e medição da tensão residual, microestrutura e microdureza construiu-se um novo corpo de prova conforme ilustra a FIGURA 3.12.

O software LabView 5.1 é utilizado para comunicação com a placa de aquisição de sinais. Através de programa, escrito em linguagem LabView, pode-se visualizar os sinais de força de corte, temperatura e emissão acústica. Isto foi possível, pois todos os sinais estão em Volts. Estes sinais são convertidos para RMS 
(Root Mean Square) antes da aquisição. O programa que faz o monitoramento dos sinais adquiridos pela placa de aquisição é apresentado no Apêndice II.

Deve-se salientar que, optou-se em medir a emissão acústica com o intuito de aproveitar o sensor montado no centro da torre de ferramentas, não sendo o alvo principal da pesquisa. Entretanto, analisando-se os resultados apresentados na medição da emissão acústica com alta velocidade de corte nas diversas geometrias, verificou-se que os mesmos não apresentaram novidades com relação aos trabalhos existentes. Por este motivo, os resultados não foram apresentados.

$O$ procedimento de aquisição dos sinais consiste em inicializar o software de aquisição junto com o programa de usinagem. Durante a usinagem, os sinais de força de corte, temperatura e emissão acústica são levados a um bloco de conectores BNC. Deste bloco, o sinal analógico de tensão é levado via cabo até uma placa de aquisição instalada em um microcomputador. Assim que a usinagem foi encerrada a aquisição também foi interrompida. Os sinais foram adquiridos com a taxa de aquisição de 200 pontos/segundos. Os pontos plotados nas figuras representam a $\mathrm{RMS}\left(\mathrm{V}_{\mathrm{Rms}}\right)$ desses pontos já filtrados e amplificados. Os dados foram armazenados em arquivos da planilha eletrônica "Excel", para posterior análise e apresentação de resultados. Na planilha, os dados em Volts (temperatura e força de corte) são convertidos em graus Celsius e em Newtons. 


\section{RESULTADOS E DISCUSSÕES}

Neste capítulo são apresentados os resultados obtidos e as discussões para a temperatura da ferramenta, força de corte, emissão acústica, mecanismos de desgaste, rugosidade superficial, análise da microestrutura, microdureza e tensão residual.

\subsection{Medição da força de corte e temperatura}

Os resultados a seguir, referem-se à melhor condição de corte $\left(\mathrm{V}_{\mathrm{c}}=\right.$ $500 \mathrm{~m} / \mathrm{min} ; \mathrm{f}=0,10 \mathrm{~mm} / \mathrm{rev}$ e $a_{p}=0,35 \mathrm{~mm}$ ) e geometrias de aresta de corte encontradas no torneamento com alta velocidade de corte de superligas à base de níquel (Inconel 718 e Waspaloy) para os parâmetros avaliados. Foram testadas 21 modificações na geometria da aresta de corte, conforme mostrado na TABELA 3.6. Dentre as geometrias modificadas, somente a geometria 2 (chanfro de $0,15 \times 15^{\circ} \mathrm{com}$ raio de aresta de $0,03 \mathrm{~mm}$ ) apresentou melhor desempenho com relação às geometrias 1 e 7 (padrão).

A temperatura da ferramenta foi medida pelo método de termopar do tipo $\mathrm{K}$ fixado na superficie de saída da ferramenta, a uma distância de $1,5 \mathrm{~mm}$ da aresta de corte. $\mathrm{O}$ uso da técnica do termopar implantado utilizado da forma descrita, embora não possa fornecer a temperatura na zona de corte, este método pode ser usado com o propósito comparativo.

\subsubsection{Inconel 718}

As FIGURAS 4.1 a 4.5 representam a comparação dos valores de força de corte e temperatura com ferramentas cerâmicas (CC650 e CC670) e ferramenta de PCBN (CB7050) de geometria triangular na condição a seco e com a utilização da técnica de MQL. Os valores foram obtidos após 20 segundos e também no tempo relativo ao comprimento usinado. 
Não foram encontradas publicações relacionadas à usinagem de superligas à base de níquel utilizando a tecnologia MQL, principalmente com alta velocidade de corte, o que indica que a mesma ainda não foi suficientemente pesquisada. Com os resultados apresentados neste trabalho, pode-se esperar ganhos econômicos e tecnológicos também com este material quando se utiliza MQL.

$\mathrm{O}$ drift da célula de carga do dinamômetro foi removido através do cálculo da inclinação da curva, multiplicado pelos pontos da planilha eletrônica. Isto se fez necessário para que os valores de força de corte fossem mais confiáveis.

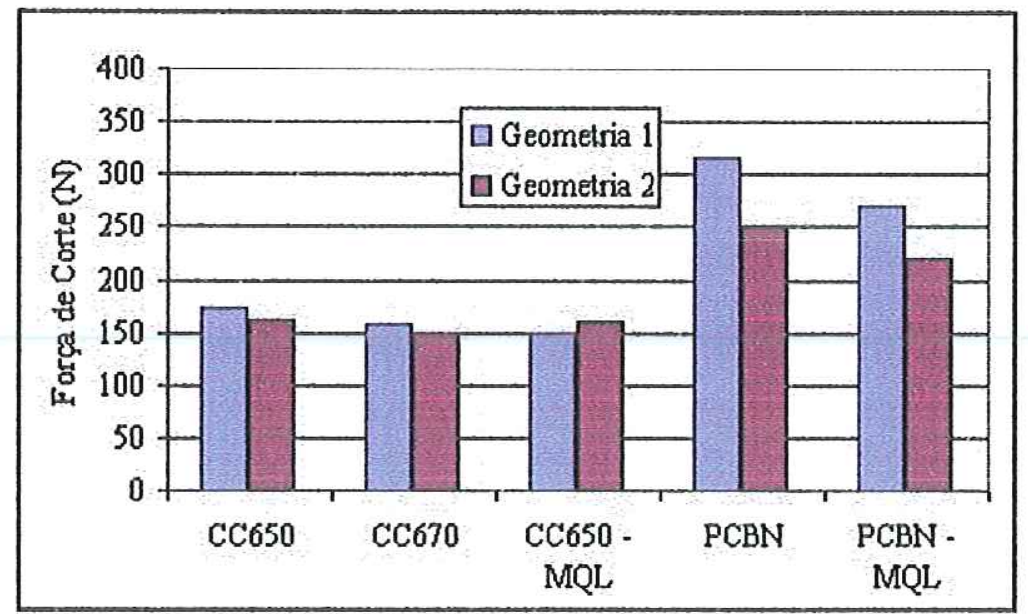

FIGURA 4.1 - Resultados da Força de Corte após 20 Segundos com Ferramentas Triangulares $\left(V_{c}=500 \mathrm{~m} / \mathrm{min} ; \mathrm{f}=0,10 \mathrm{~mm} / \mathrm{rev}\right.$ e $\left.a_{p}=0,35 \mathrm{~mm}\right)$.

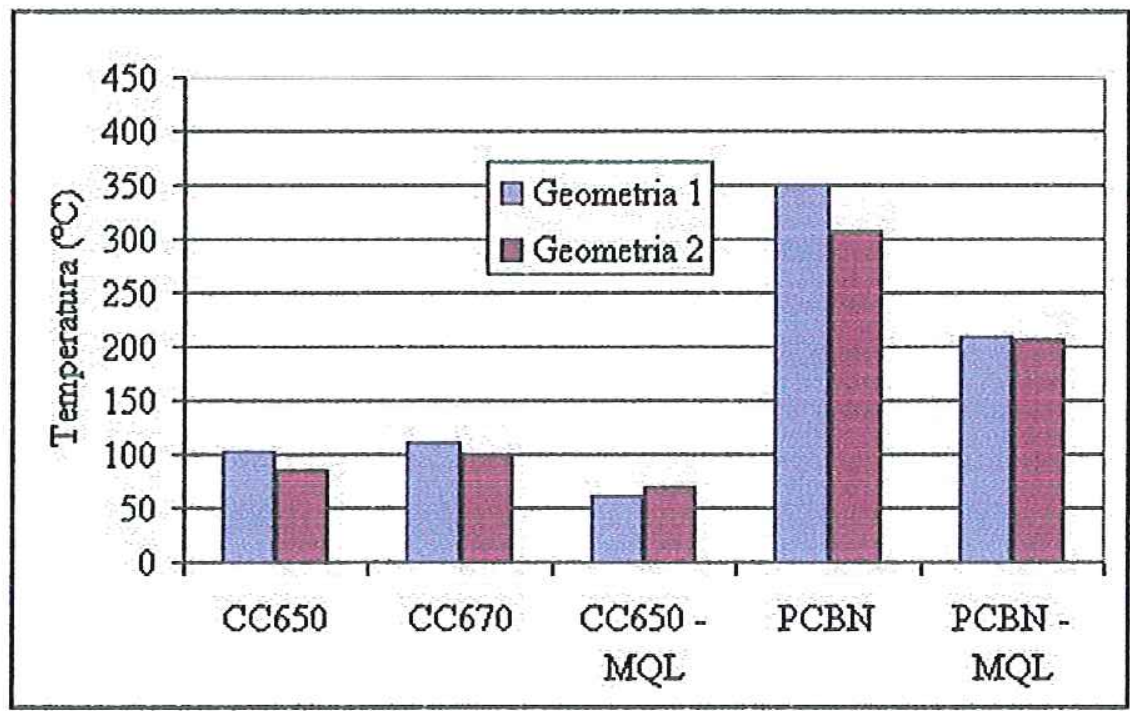

FIGURA 4.2 - Medição da Temperatura após 20 Segundos com Ferramentas Triangulares a uma Distância de 1,5mm da Aresta de Corte $\left(V_{c}=500 \mathrm{~m} / \mathrm{min} ; f=0,10 \mathrm{~mm} / \mathrm{rev}\right.$ e $\left.a_{p}=0,35 \mathrm{~mm}\right)$ 


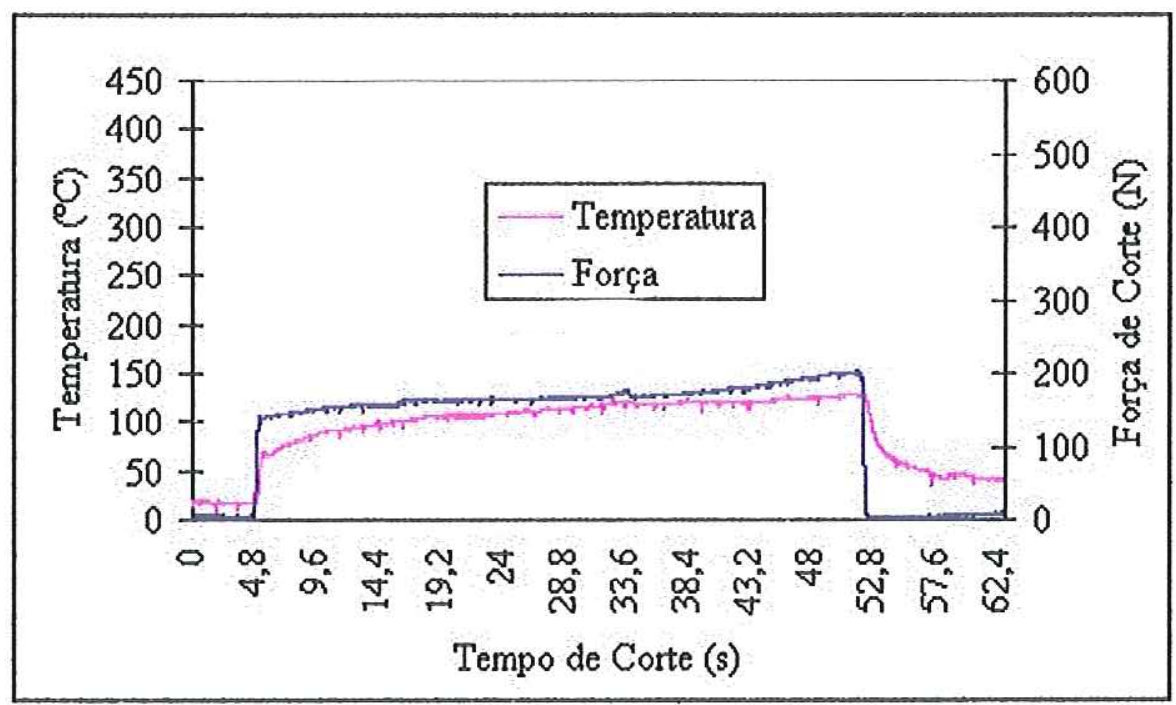

FIGURA 4.3 - Medição da Temperatura a uma Distância de 1,5mm da Aresta de Corte e da Força de Corte em Função do Tempo com Ferramenta Cerâmica CC670/Geometria 2 no Corte a Seco $\left(V_{c}=500 \mathrm{~m} / \mathrm{min} ; f=0,10 \mathrm{~mm} / \mathrm{rev}\right.$ e $\left.a_{p}=0,35 \mathrm{~mm}\right)$.

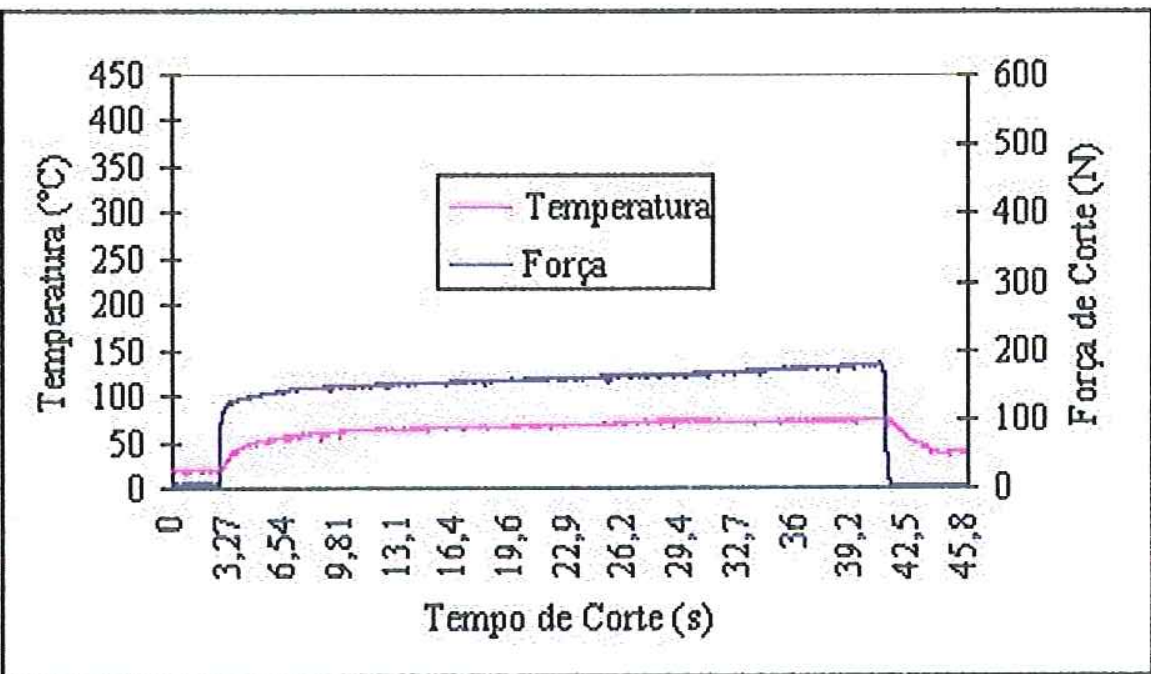

FIGURA 4.4 - Medição da Temperatura a uma Distância de 1,5mm da Aresta de Corte e da Força de Corte em Função do Tempo com Ferramenta Cerâmica CC670/Geometria 2 Utilizando MQL $\left(V_{c}=500 \mathrm{~m} / \mathrm{min} ; f=0,10 \mathrm{~mm} / \mathrm{rev}\right.$ e $\left.a_{p}=0,35 \mathrm{~mm}\right)$. 


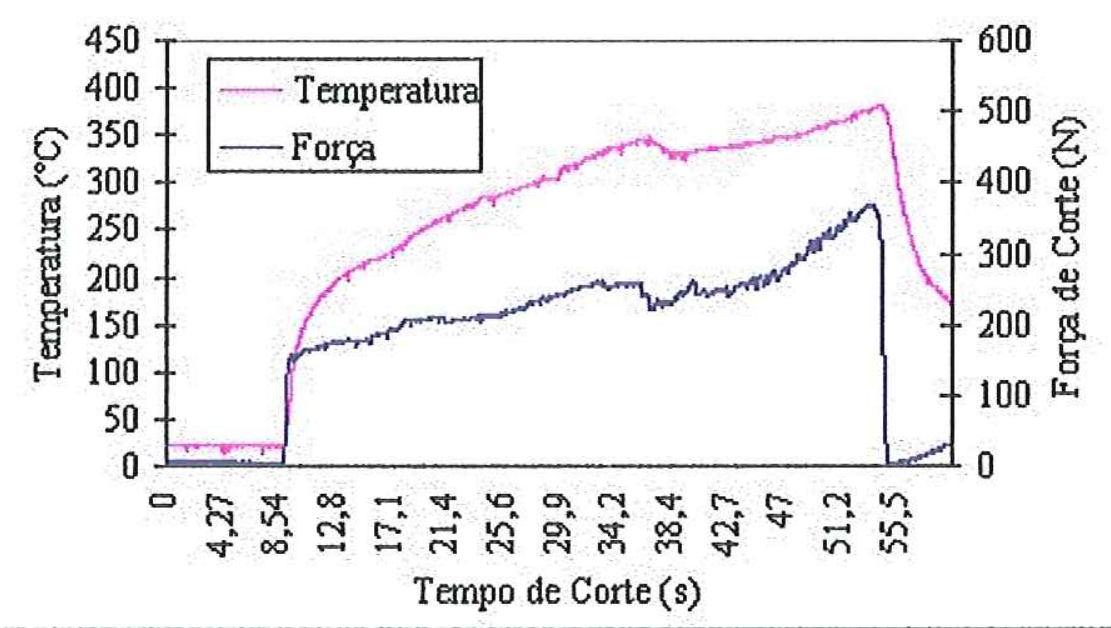

FIGURA 4.5 - Medição da Temperatura a uma Distância de 1,5mm da Aresta de Corte e da Força de Corte em Função do Tempo com Ferramenta de PCBN/Geometria 2 no Corte a Seco

$$
\left(V_{c}=500 \mathrm{~m} / \mathrm{min} ; f=0,10 \mathrm{~mm} / \mathrm{rev} \text { e } a_{p}=0,35 \mathrm{~mm}\right)
$$

Os gráficos das FIGURAS 4.3 a 4.5 foram mostrados como exemplo típico da forma de aquisição do sinal, que consiste em inicializar o software de aquisição junto com o programa $\mathrm{CNC}$ da usinagem do corpo de prova.

Os valores da força de corte e temperatura aumentam com o tempo de corte, em razão do aumento progressivo do desgaste da ferramenta. Este aumento foi observado desde o início do corte, comprovando a alta taxa de desgaste na usinagem das superligas.

Da análise comparativa das geometrias 1 e 2 (FIGURAS 4.1 e 4.2), pôde-se observar que os valores de força de corte e temperatura apresentaram alterações significativas dentro da mesma classe de material da ferramenta. De uma maneira geral, a geometria 2 proporcionou redução nos valores de força de corte e temperatura. Entretanto, quando da utilização da técnica de MQL com ferramenta cerâmica (CC650), constatou-se um aumento na força de corte e temperatura com a geometria 2. Deve-se salientar que, devido à pequena área de atuação do fluxo de ar/óleo no sistema MQL, o posicionamento do bico aspersor pode afetar significativamente a capacidade de refrigeração e consequentemente os valores de força de corte e temperatura. Por outro lado, a utilização da técnica MQL proporcionou uma redução na temperatura de aproximadamente $40 \%$ em ambas 
geometrias, mostrando efeitos notáveis de refrigeração e lubrificação, diminuindo as tensões causadas por grandes gradientes de temperatura. A redução da temperatura na ferramenta resulta da parcela de calor absolvida pelo meio lubri-refrigerante. Isso reduz o comprimento de contato influenciando na redução da força de corte. KLOCHE \& EISENBLÄTER (1997) relataram redução na temperatura e força de corte com o emprego da técnica MQL comparado com a condição a seco no processo de furação. A mesma conclusão chegaram HEISEL et al. (1998) e WAKABAYASHI et al. (1998), no torneamento contínuo de diversos tipos de aços.

A inclinação das curvas para temperatura e força de corte apresenta aproximadamente a mesma tendência para as ferramentas cerâmicas.

A influência da utilização da técnica MQL foi mais representativa nos valores de força de corte e temperatura nas ferramentas de PCBN (CB7050) em comparação com as ferramentas cerâmicas. Isto demonstra a efetiva capacidade de refrigeração dos componentes ar-óleo utilizados nos experimentos. A técnica MQL apresenta menor dispersão nos valores de força de corte e temperatura. Observa-se também que a inclinação da curva da temperatura e força de corte foi mais acentuada em relação às ferramentas cerâmicas em todas as geometrias e condições testadas. Devido à superioridade da condutividade térmica, a inferioridade do coeficiente de expansão térmica e evidências da alta taxa de desgaste, as ferramentas de PCBN apresentaram maior valor da temperatura em comparação às ferramentas cerâmicas. Uma ferramenta com maior condutividade térmica, faz com que o calor seja retirado da zona de corte sem causar o amolecimento do material da peça ao seu redor, o que facilitaria o corte, contribuindo para a diminuição da força de corte. Verifica-se que as mesmas, apresentaram valores de força de corte maiores que as ferramentas cerâmicas. Embora não representados graficamente todos os testes, as ferramentas de PCBN com concentração de $20 \%$ de CBN apresentaram valores de força de corte e temperatura bem inferior as de $50 \%$ de $\mathrm{CBN}$, provavelmente por ter condutividade térmica inferior e ter proporcionado menor taxa de desgaste. Por outro lado, o acabamento superficial foi muito inferior, por este motivo desprezou-se a apresentação dos gráficos por tratar-se de uma operação de acabamento. O tópico de rugosidade superficial será abordado mais à frente. 
As FIGURAS 4.6 a 4.10 representam a comparação dos valores de força de corte e temperatura com ferramentas cerâmicas (CC650 e CC670) e ferramenta de PCBN (CB50) de geometria redonda na condição a seco e com a utilização da técnica de MQL. Devido aos resultados insatisfatórios na condição a seco e o alto custo da ferramenta de PCBN redonda (superior aproximadamente 20 vezes em relação à ferramenta cerâmica CC650) optou-se em não testá-la na condição de MQL.

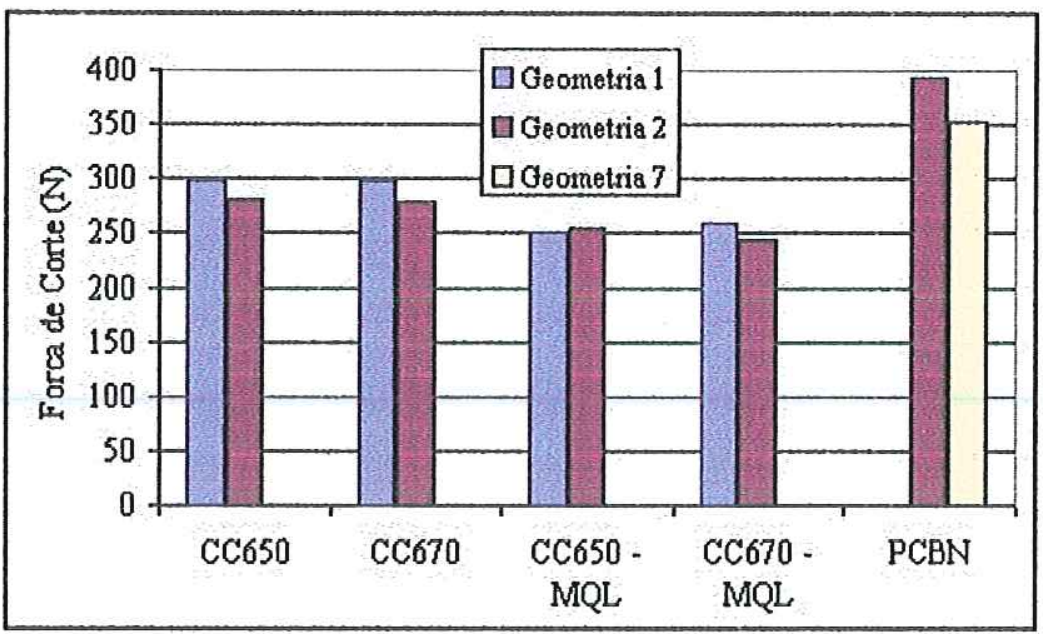

FIGURA 4.6 - Resultados da Força de Corte após 20 Segundos com Ferramentas

Redondas $\left(V_{c}=500 \mathrm{~m} / \mathrm{min} ; f=0,10 \mathrm{~mm} / \mathrm{rev}\right.$ e $\left.a_{p}=0,35 \mathrm{~mm}\right)$

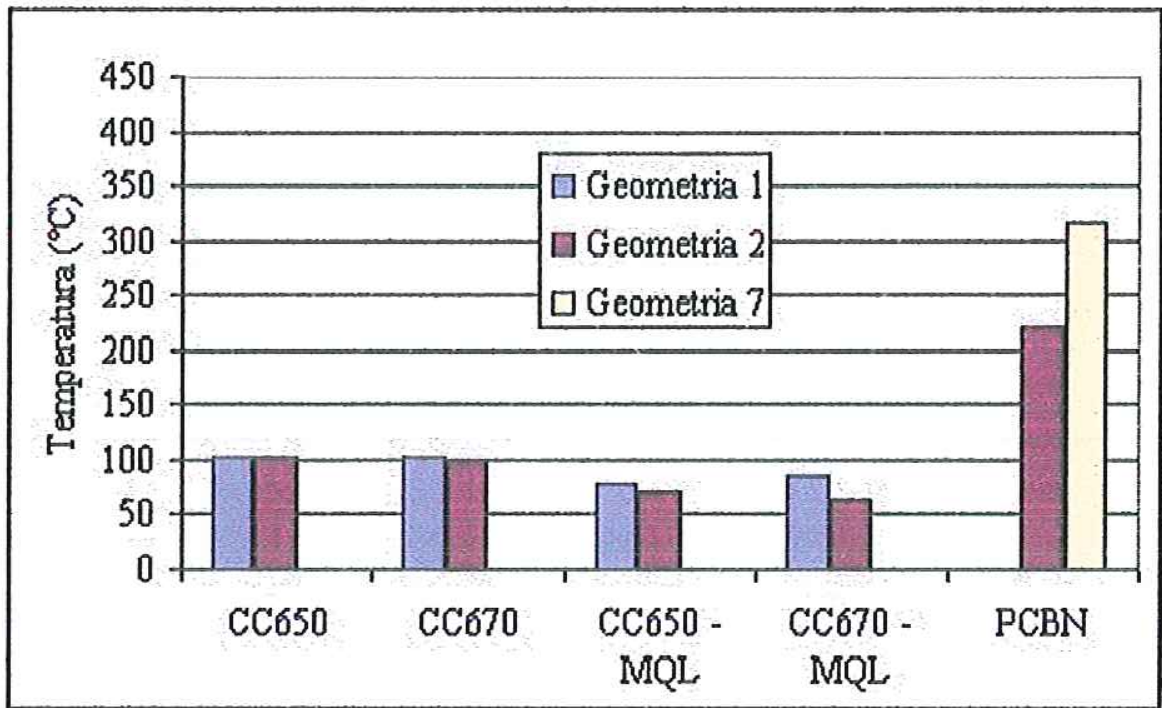

FIGURA 4.7 - Medição da Temperatura após 20 Segundos com Ferramentas

Redondas a uma Distância de $1,5 \mathrm{~mm}$ da Aresta de Corte

$\left(V_{c}=500 \mathrm{~m} / \mathrm{min} ; \mathrm{f}=0,10 \mathrm{~mm} / \mathrm{rev}\right.$ e $\left.a_{p}=0,35 \mathrm{~mm}\right)$. 


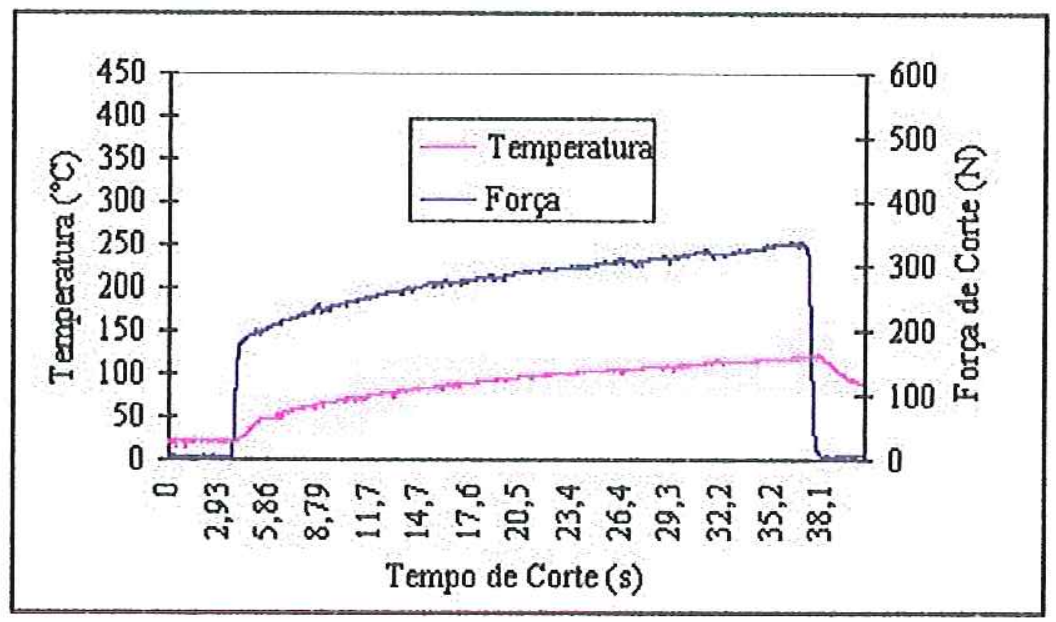

FIGURA 4.8 - Medição da Temperatura a uma Distância de 1,5mm da Aresta de

Corte e da Força de Corte em Função do Tempo com Ferramenta Cerâmica

CC650/Geometria 1 no Corte a Seco

$\left(V_{c}=500 \mathrm{~m} / \mathrm{min} ; \mathrm{f}=0,10 \mathrm{~mm} / \mathrm{rev}\right.$ e $\left.a_{p}=0,35 \mathrm{~mm}\right)$.

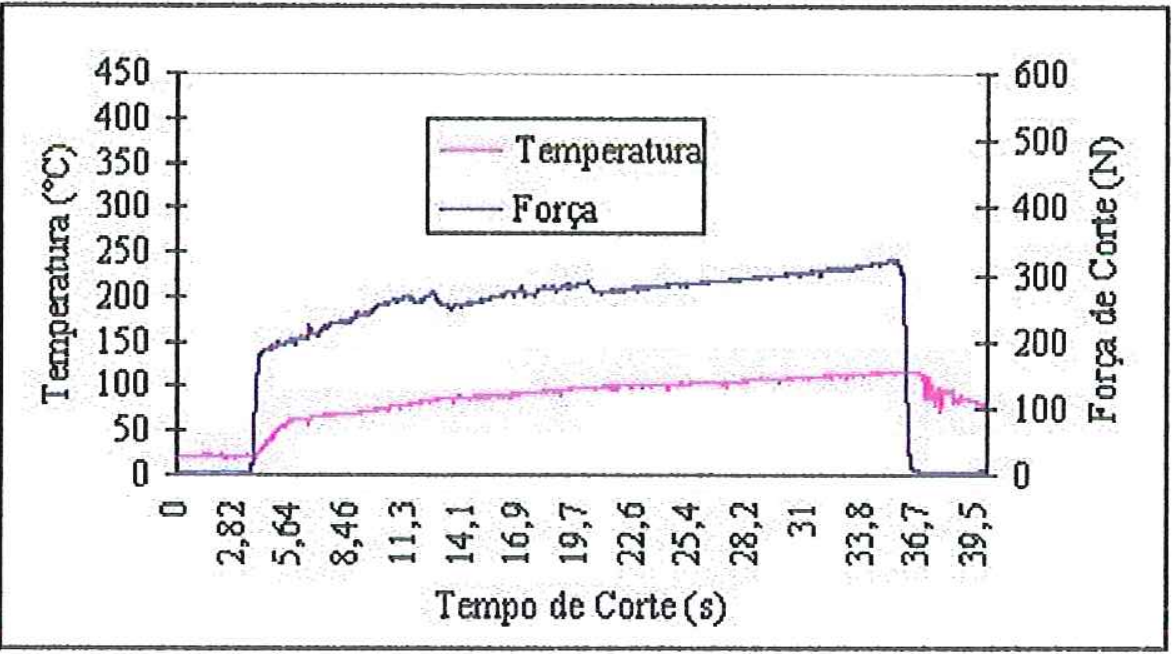

FIGURA 4.9 - Medição da Temperatura a uma Distância de 1,5mm da Aresta de

Corte e da Força de Corte em Função do Tempo com Ferramenta Cerâmica

CC650/Geometria 2 no Corte a Seco

$$
\left(V_{c}=500 \mathrm{~m} / \mathrm{min} ; \mathrm{f}=0,10 \mathrm{~mm} / \mathrm{rev} \text { e } a_{p}=0,35 \mathrm{~mm}\right) \text {. }
$$




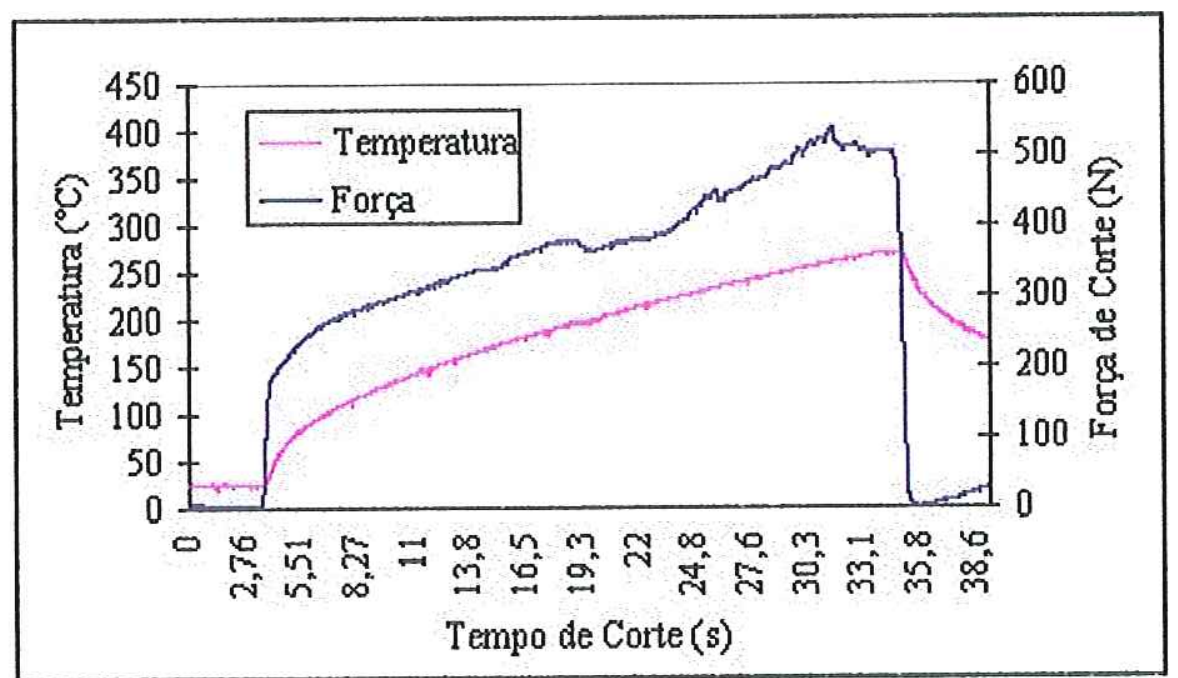

FIGURA 4.10 - Medição da Temperatura a uma Distância de 1,5mm da Aresta de Corte e da Força de Corte em Função do Tempo com Ferramenta de

\section{PCBN/Geometria 2 no Corte a Seco}

$$
\left(V_{c}=500 \mathrm{~m} / \mathrm{min} ; f=0,10 \mathrm{~mm} / \mathrm{rev} \text { e } a_{p}=0,35 \mathrm{~mm}\right) \text {. }
$$

As ferramentas redondas proporcionaram maior valor de força de corte devido à maior área de contato e equivalente ângulo de posição. Apesar do maior valor de força, não ocorreu vibração no sistema peça-ferramenta, conforme confirmam as medições de rugosidade superficial. A alta rigidez da máquina utilizada e da peça foram responsáveis pelo sucesso da utilização da ferramenta redonda, oferecendo um bom desempenho no acabamento superficial.

Analisando-se o comportamento apresentado pelas ferramentas cerâmicas de formato redondo, observa-se a mesma tendência ocorrida com as ferramentas de formato triangular, ou seja, os valores de força de corte e temperatura apresentaram alterações significativas dentro da mesma classe de material da ferramenta. A geometria 2 apresenta redução na força de corte, exceto com a ferramenta cerâmica CC650 com MQL quando da comparação com a geometria 1.

De uma maneira geral, com as ferramentas redondas repetiram-se as vantagens da técnica $\mathrm{MQL}$, ou seja, a utilização de MQL proporcionou uma redução de aproximadamente $10 \%$ na força de corte e $30 \%$ na temperatura para as ferramentas cerâmicas em ambas geometrias, mostrando mais uma vez efeitos notáveis de refrigeração e lubrificação. A técnica MQL mostrou-se novamente menor 
dispersão nos valores de força de corte e temperatura, indicando maior estabilidade durante o corte.

A inclinação da curva apresenta também a mesma tendência das ferramentas de formato triangular para força de corte e temperatura.

Considerando-se os resultados obtidos na medição da temperatura e força de corte, pode-se afirmar de maneira geral que, uma maior redução da temperatura da ferramenta levou-a a redução da força de corte, variando a intensidade de acordo com a geometria e classe de material da ferramenta. Se a condução de calor é reduzida pela ferramenta, este calor tende a se represar na zona de cisalhamento facilitando o corte.

WAKABAYASHI et al. (1998) investigaram o desempenho da técnica MQL com relação ao coeficiente de atrito no torneamento contínuo. $\mathrm{O}$ coeficiente de atrito é próximo da condição com fluido de corte, porém comparado com o corte a seco, a ação de lubrificação é evidente com a aplicação de MQL.

A ferramenta de PCBN (CB50) com geometria 2 apresentou um aumento na força de corte e uma redução na temperatura comparando com a geometria 7 (aresta sem chanfro). $\mathrm{O}$ aumento da força de corte é devido ao chanfro de aresta de corte, o qual provoca um aumento nas forças de usinagem. Por outro lado, o chanfro diminui o comprimento de contato dificultando a propagação de calor na ferramenta reduzindo a temperatura em $30 \%$ aproximadamente.

Observa-se que os valores de temperatura na ferramenta de PCBN foram de aproximadamente 2,5 vezes os valores encontrados nas ferramentas cerâmicas, possivelmente pela alta condutividade térmica e o baixo coeficiente de expansão térmica das ferramentas de PCBN e também pela presença de níquel como ligante, reagindo com o material da peça causando um desgaste acelerado resultando em altas temperaturas. Este comportamento procede para as ferramentas de PCBN triangular e quadrada.

Observando-se os resultados apresentados na temperatura para as ferramentas triangular e redonda, ambas de PCBN, nota-se que o calor propaga-se mais facilmente na ferramenta triangular, apresentando um aumento na temperatura de aproximadamente $30 \%$ em relação à ferramenta redonda com geometria 2 , resultando na redução da transmissão de calor que iria para a peça, dificultando o cisalhamento. 
Este fato explica o motivo pelo qual, o valor da força de corte, usando-se ferramenta redonda de PCBN não é muito superior a aquele da ferramenta triangular de PCBN, como acontece com as ferramentas cerâmicas.

Novamente, a inclinação da curva da temperatura e força de corte com ferramentas de PCBN foi mais acentuada em relação às ferramentas cerâmicas em todas as geometrias e condições testadas. Este aumento súbito na temperatura e força são evidências da alta taxa de desgaste que aconteceram nas ferramentas de PCBN e da sua alta condutividade térmica.

As FIGURAS 4.11 a 4.15 representam a comparação dos valores de força de corte e temperatura com ferramenta cerâmica (CC650) e ferramenta de PCBN (CB7050) de geometria quadrada na condição a seco e com a técnica de MQL. De uma maneira geral, o mesmo comportamento apresentado pela variação do chanfro e raio de aresta nas ferramentas cerâmicas, repetiu-se para as ferramentas de PCBN.

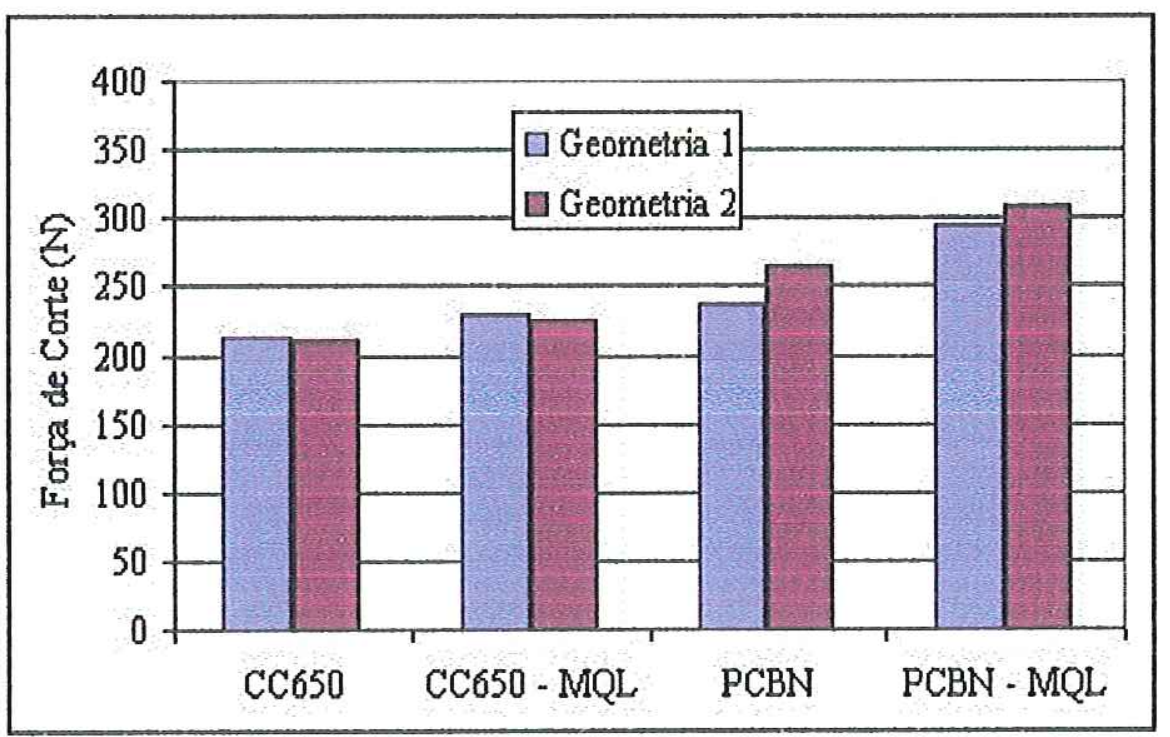

FIGURA 4.11 - Resultados da Força de Corte após 20 Segundos com Ferramentas Quadradas $\left(V_{c}=500 \mathrm{~m} / \mathrm{min} ; f=0,10 \mathrm{~mm} / \mathrm{rev}\right.$ e $\left.a_{p}=0,35 \mathrm{~mm}\right)$. 


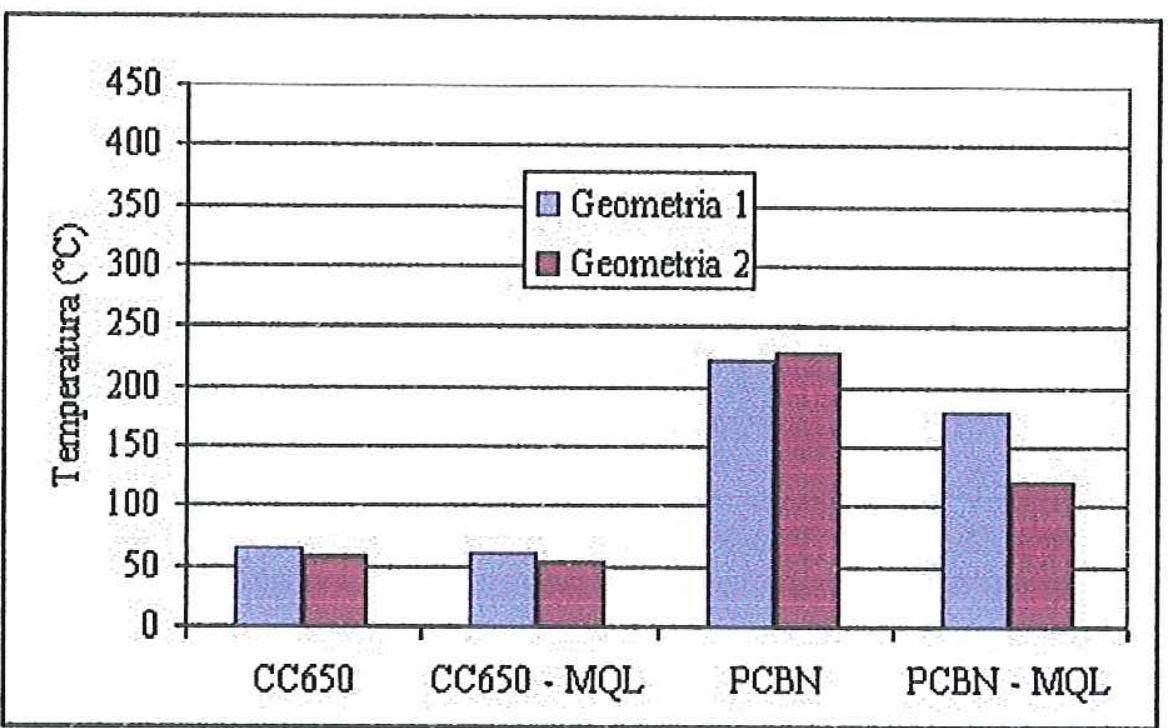

FIGURA 4.12 - Medição da Temperatura após 20 Segundos com Ferramentas Quadradas a uma Distância de 1,5mm da Aresta de Corte $\left(V_{c}=500 \mathrm{~m} / \mathrm{min} ; f=0,10 \mathrm{~mm} / \mathrm{rev}\right.$ e $\left.a_{p}=0,35 \mathrm{~mm}\right)$.

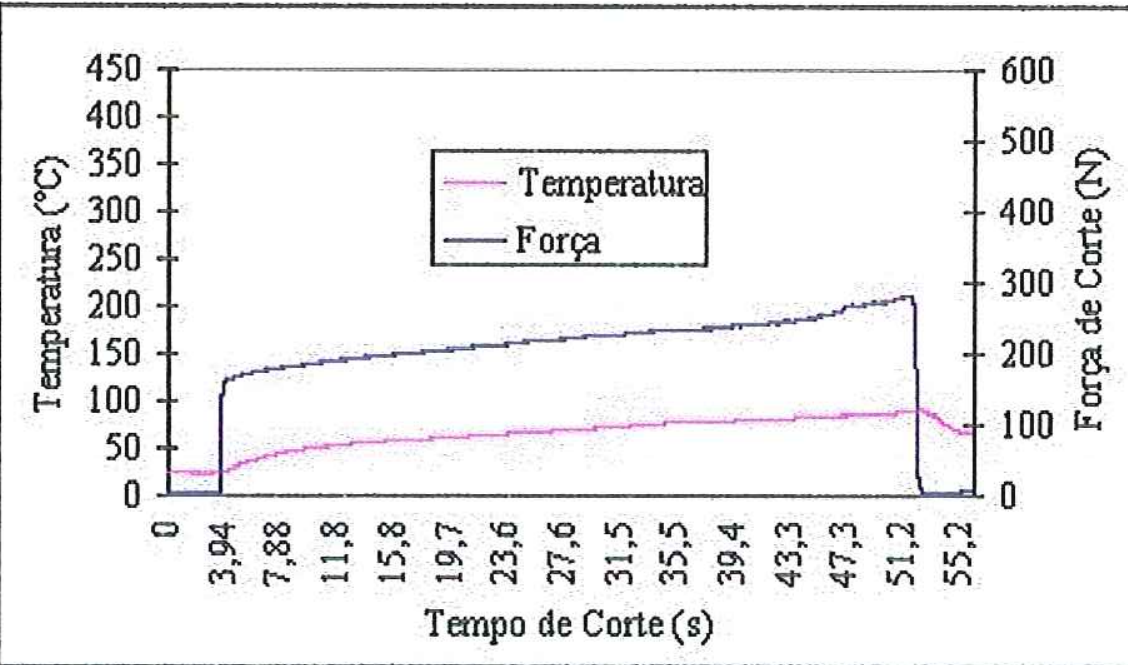

FIGURA 4.13 - Medição da Temperatura a uma Distância de 1,5mm da Aresta de Corte e da Força de Corte em Função do Tempo com Ferramenta Cerâmica CC650/Geometria 1 no Corte a Seco $\left(\mathrm{V}_{\mathrm{c}}=500 \mathrm{~m} / \mathrm{min} ; \mathrm{f}=0,10 \mathrm{~mm} / \mathrm{rev}\right.$ e $\left.\mathrm{a}_{\mathrm{p}}=0,35 \mathrm{~mm}\right)$. 


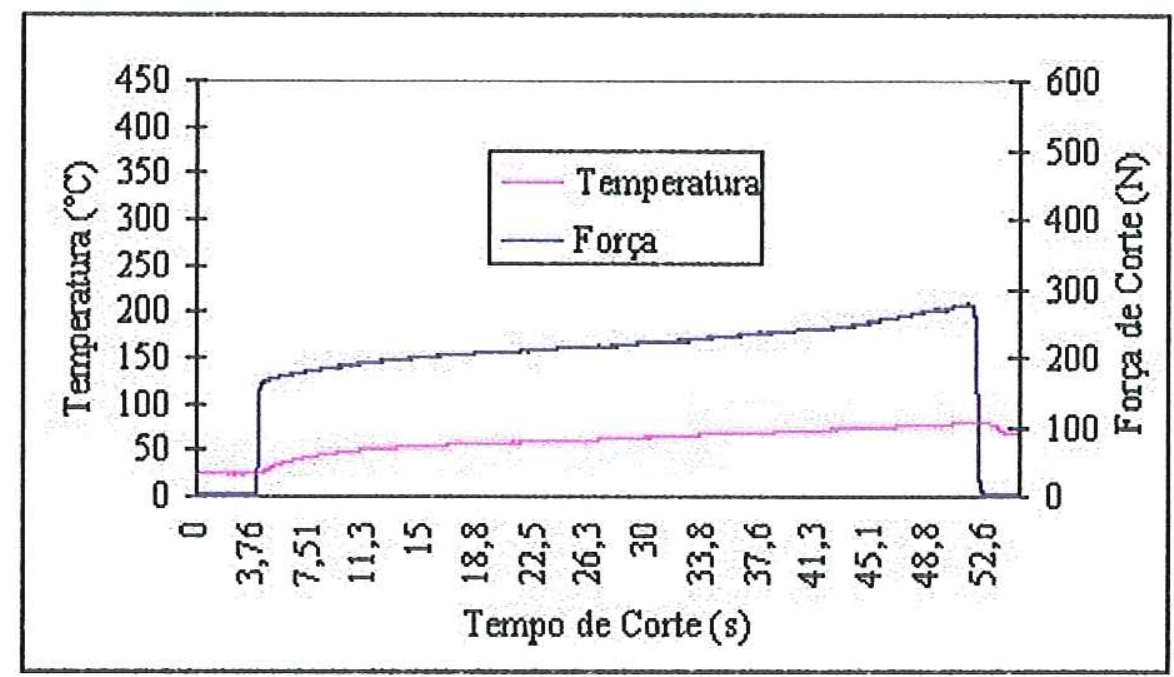

FIGURA 4.14 - Medição da Temperatura a uma Distância de 1,5mm da Aresta de

Corte e da Força de Corte em Função do Tempo com Ferramenta Cerâmica

CC650/Geometria 2 no Corte a Seco

$\left(V_{c}=500 \mathrm{~m} / \mathrm{min} ; f=0,10 \mathrm{~mm} / \mathrm{rev}\right.$ e $\left.a_{p}=0,35 \mathrm{~mm}\right)$.



FIGURA 4.15 - Medição da Temperatura a uma Distância de 1,5mm da Aresta de

Corte e da Força de Corte em Função do Tempo com Ferramenta de

PCBN/Geometria 2 Utilizando MQL

$\left(V_{c}=500 \mathrm{~m} / \mathrm{min} ; f=0,10 \mathrm{~mm} / \mathrm{rev}\right.$ e $\left.a_{p}=0,35 \mathrm{~mm}\right)$.

Observando-se os resultados apresentados pelas ferramentas quadradas, confirma-se o mesmo comportamento ocorrido pelas ferramentas triangular e redonda. As ferramentas cerâmicas quadradas apresentaram menor valor da temperatura em comparação com as ferramentas triangular e redonda. A força de 
corte das ferramentas cerâmica apresenta valores intermediários às ferramentas triangular e redonda. Por outro lado, a ferramenta de PCBN com geometria 2 indica valores de temperatura semelhantes à ferramenta redonda da mesma classe e geometria. Embora não representados graficamente todos os testes, as ferramentas com maior chanfro de aresta $\left(>20^{\circ}\right)$ apresentaram maior valor de força de corte em todas as ferramentas utilizadas. De uma maneira geral, o raio de aresta (hone) não afeta os valores de força de corte e de temperatura nas condições testadas. Entretanto, o aumento do raio de ponta da pastilha ocasiona um aumento significativo na força de corte.

A eficiência da técnica de MQL foi também confirmada nas ferramentas quadradas, principalmente com ferramentas de $\mathrm{PCBN}$, proporcionando refrigeração e lubrificação. Novamente, a técnica MQL apresenta menor dispersão nos valores de força de corte e temperatura. Em comparação com as ferramentas de PCBN triangular, confirma-se o mesmo comportamento quando da utilização da ferramenta de PCBN com concentração de $20 \%$ de $\mathrm{CBN}$, ou seja, menor concentração de CBN proporciona uma redução nos valores de força de corte e temperatura. Este comportamento pode ser explicado devido à inferioridade da condutividade térmica $\mathrm{e}$ presença de material cerâmico na segunda fase da ferramenta com $20 \%$ de CBN. Embora os valores de força de corte e temperatura tenham aumentado conforme aumenta o desgaste da ferramenta, a mudança mais dramática foi observada quando da utilização de ferramentas de PCBN, tendo uma inclinação bem mais acentuada.

As FIGURAS 4.16 a 4.20 revelam o efeito da velocidade de corte sobre a temperatura nas ferramentas cerâmicas (CC650 e CC670) nos formatos triangular, redondo e quadrado com geometria 1 sob condição de corte a seco. 


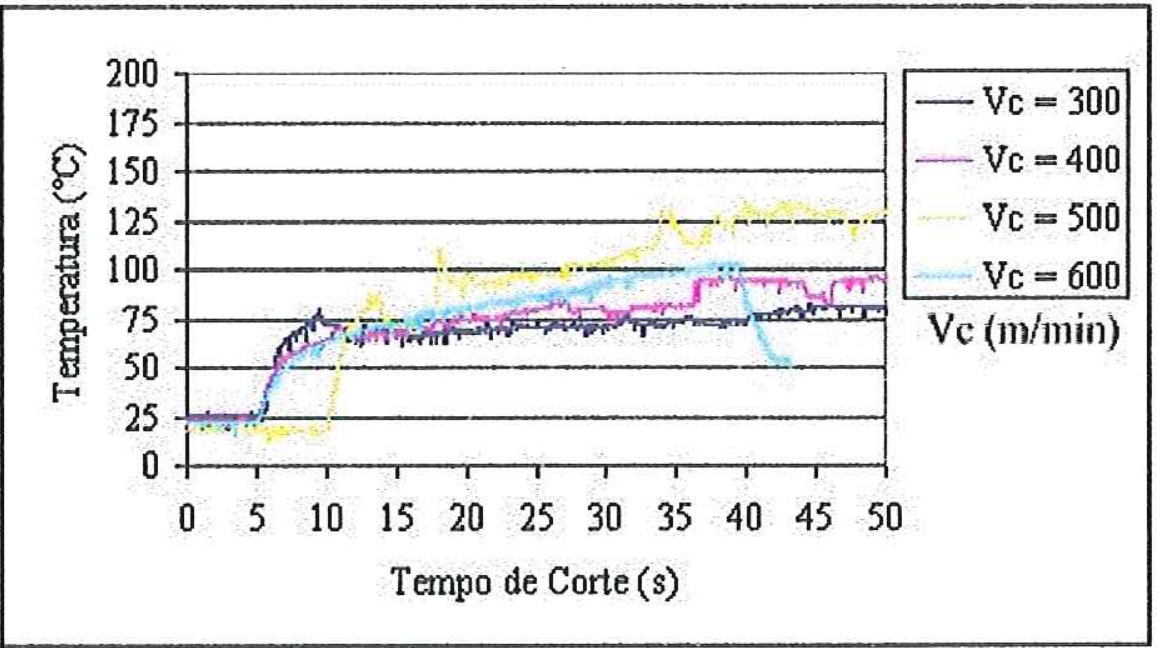

FIGURA 4.16 - Efeito da Velocidade de Corte Sobre a Temperatura, a uma Distância de 1,5mm da Aresta de Corte com Ferramenta Cerâmica CC650 Triangular $\left(V_{c}=\mathrm{m} / \mathrm{min} ; f=0,10 \mathrm{~mm} /\right.$ rev e $\left.a_{p}=0,35 \mathrm{~mm}\right)$.

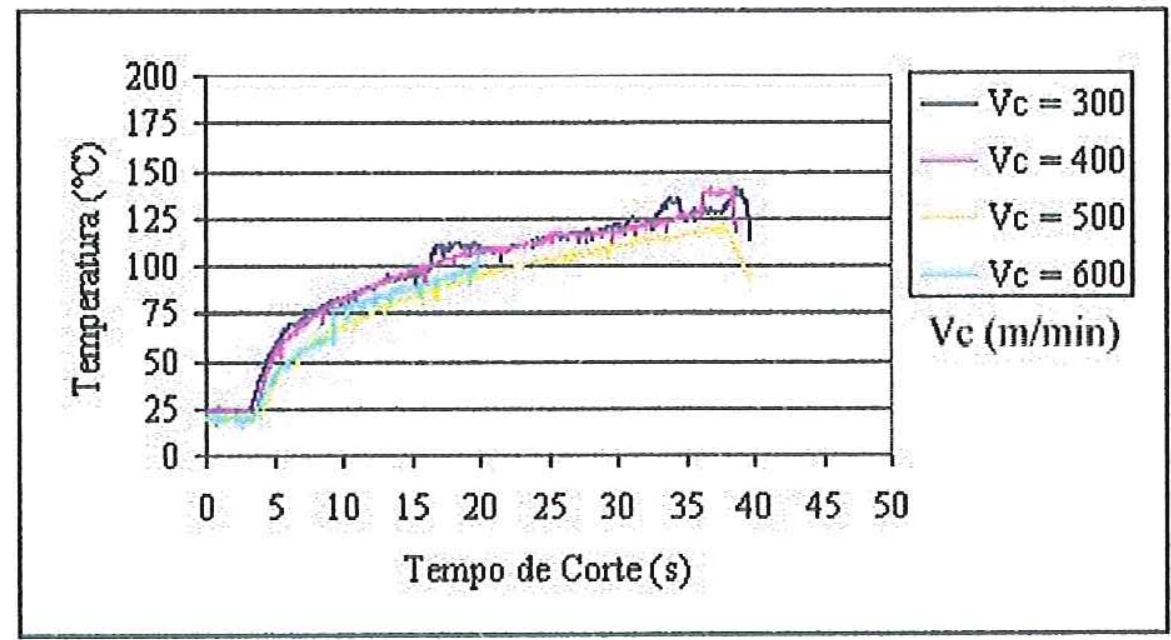

FIGURA 4.17 - Efeito da Velocidade de Corte Sobre a Temperatura, a uma Distância de 1,5mm da Aresta de Corte com Ferramenta Cerâmica CC650 Redonda

$$
\left(V_{c}=\mathrm{m} / \mathrm{min} ; \mathrm{f}=0,10 \mathrm{~mm} / \mathrm{rev} \text { e } a_{p}=0,35 \mathrm{~mm}\right) \text {. }
$$

Resultados não esperados ocorreram na análise do efeito da velocidade de corte sobre a temperatura da ferramenta durante o torneamento com alta velocidade de corte no Inconel 718. Esperava-se que quando alterasse a velocidade de corte nas faixas de $300-400-500-600 \mathrm{~m} / \mathrm{min}$, houvesse um aumento da temperatura, o que não foi constatado nas ferramentas cerâmicas. Este comportamento contradiz os resultados apresentados por diversos pesquisadores na usinagem de aços em geral, 
onde a temperatura de corte aumenta continuamente com o aumento da velocidade de corte. Novamente, a ferramenta quadrada apresenta menor valor de temperatura.

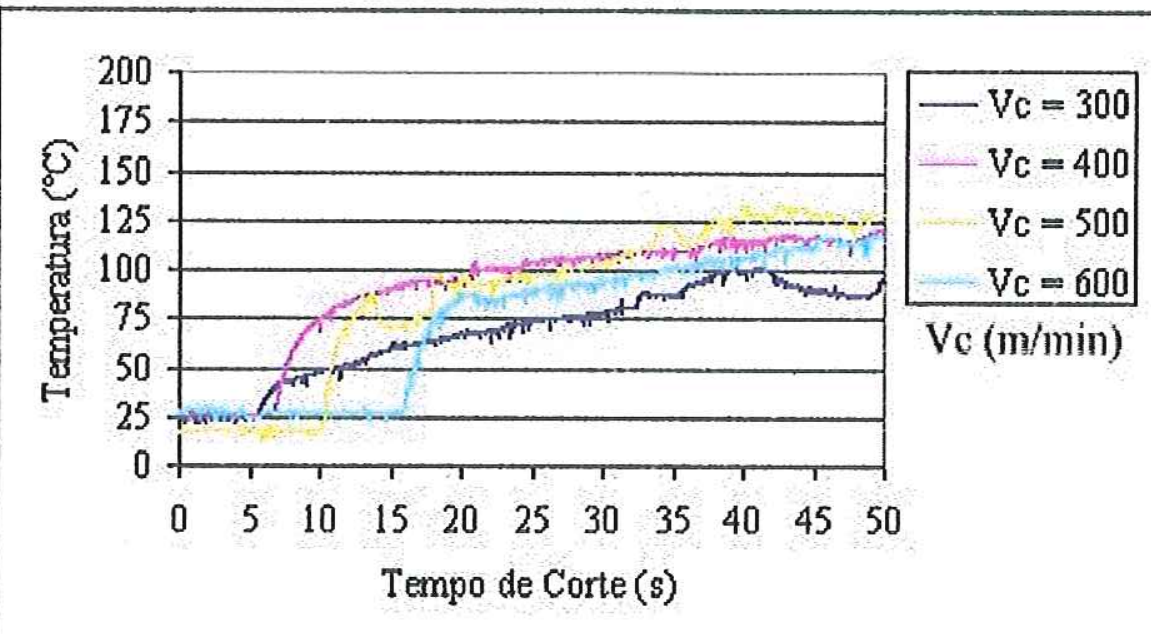

FIGURA 4.18 - Efeito da Velocidade de Corte Sobre a Temperatura, a uma Distância de 1,5mm da Aresta de Corte com Ferramenta Cerâmica CC670 Triangular $\left(V_{c}=\mathrm{m} / \mathrm{min} ; f=0,10 \mathrm{~mm} / \mathrm{rev}\right.$ e $\left.a_{p}=0,35 \mathrm{~mm}\right)$.

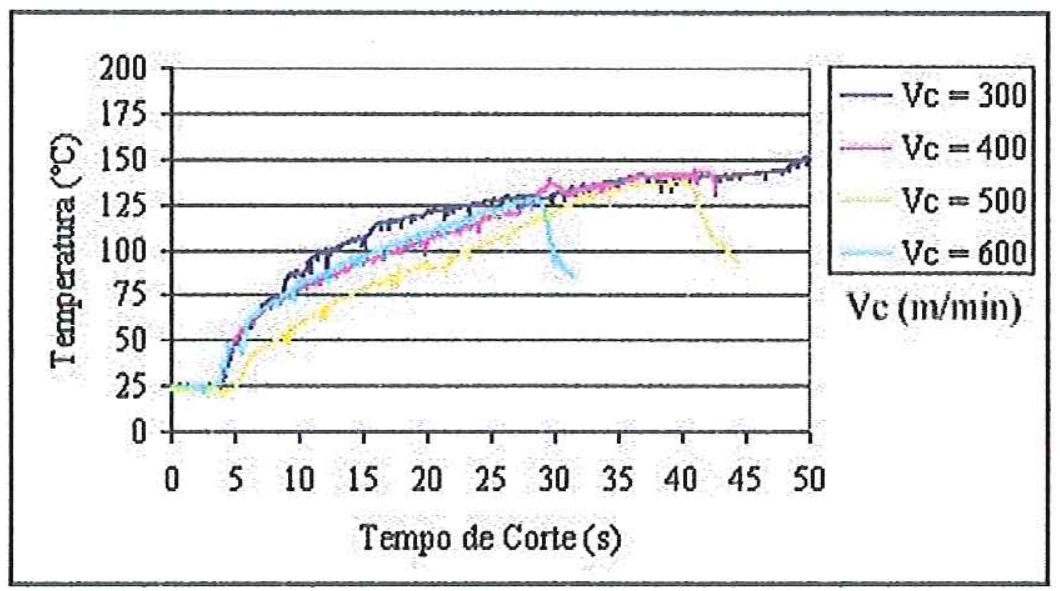

FIGURA 4.19 - Efeito da Velocidade de Corte Sobre a Temperatura, a uma Distância de 1,5mm da Aresta de Corte com Ferramenta Cerâmica CC670 Redonda $\left(V_{c}=\mathrm{m} / \mathrm{min} ; f=0,10 \mathrm{~mm} / \mathrm{rev}\right.$ e $\left.a_{p}=0,35 \mathrm{~mm}\right)$. 


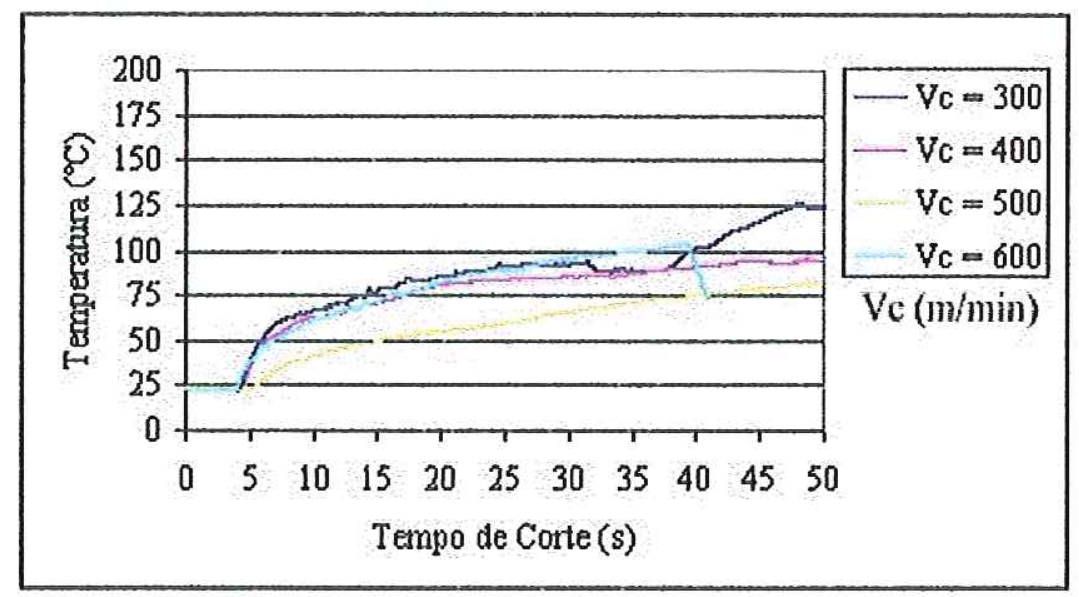

FIGURA 4.20 - Efeito da Velocidade de Corte Sobre a Temperatura, a uma Distância de 1,5mm da Aresta de Corte com Ferramenta Cerâmica CC670 Quadrada

$$
\left(V_{c}=\mathrm{m} / \mathrm{min} ; \mathrm{f}=0,10 \mathrm{~mm} / \mathrm{rev} \text { e } a_{p}=0,35 \mathrm{~mm}\right) \text {. }
$$

De uma maneira geral, inicialmente com o aumento da velocidade de corte de 300 para $500 \mathrm{~m} / \mathrm{min}$, a temperatura da ferramenta é reduzida. Quando aumenta a velocidade de corte para $600 \mathrm{~m} / \mathrm{min}$, a temperatura aumenta ficando na faixa de valores das velocidades de 300 e $400 \mathrm{~m} / \mathrm{min}$. A temperatura com velocidade de corte de $500 \mathrm{~m} / \mathrm{min}$ foi o menor valor registrado na maioria das geometrias testadas. As ferramentas CC670 apresentaram maior valor de temperatura em comparação às ferramentas CC650, devido principalmente à maior condutividade térmica. O comportamento da temperatura com o aumento da velocidade de corte encontrado nos experimentos assemelham-se com os testes dos pesquisadores ELWARDANY et al. (1996). Eles definiram a velocidade de corte de $510 \mathrm{~m} / \mathrm{min}$ como velocidade de transição, sugerindo como velocidade de corte ótima no que diz respeito à temperatura na aresta de corte. Segundo os pesquisadores, as características térmicas, mecânicas e metalúrgicas do Inconel 718 representam uma posição importante na explicação deste fenômeno. A temperatura na interface peça-ferramenta depende da natureza do material da ferramenta e da peça, bem como sobre a difusividade térmica de ambos. A condutividade térmica do Inconel 718 aumenta linearmente com a temperatura. Como a difusividade térmica aumentará com a temperatura, é esperado que o calor durante o corte com alta velocidade difundirá rapidamente através da peça. Este alto valor da difusividade térmica do Inconel 718 é acompanhado pelo baixo valor da difusividade térmica da ferramenta, consequentemente a dissipação do 
calor gerado com alta velocidade de corte será superior por intermédio da peça do que da ferramenta, assegurando baixos valores da temperatura na ponta da ferramenta. Eles afirmam que é necessário realizar um maior número de experimentos para avaliar quantitativamente a posição das características térmicas, mecânicas e metalúrgicas do Inconel 718 sobre a usinabilidade com altas velocidades de corte.

As FIGURAS 4.21 a 4.24 revelam o efeito da velocidade de corte sobre a força de corte nas ferramentas cerâmicas (CC650 e CC670) nos formatos triangular e redondo com geometria 1 sob condição de corte a seco.

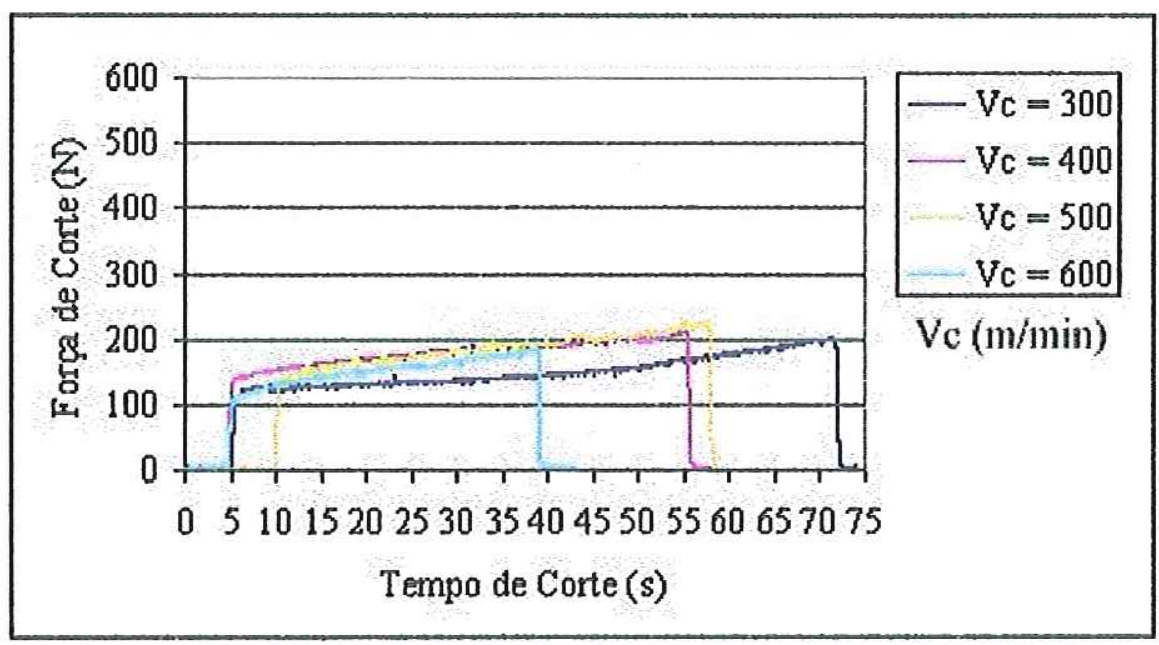

FIGURA 4.21 - Efeito da Velocidade de Corte Sobre a Força com Ferramenta

Cerâmica CC650 Triangular $\left(V_{c}=m / m i n ; f=0,10 \mathrm{~mm} /\right.$ rev e $\left.a_{p}=0,35 \mathrm{~mm}\right)$.

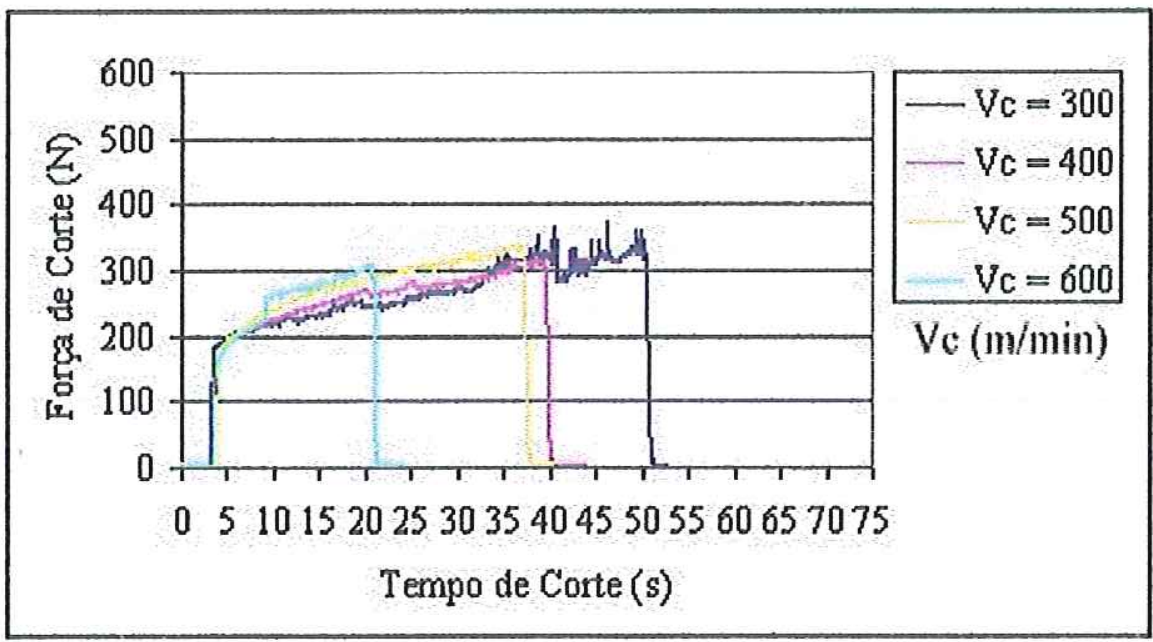

FIGURA 4.22 - Efeito da Velocidade de Corte Sobre a Força com Ferramenta Cerâmica CC650 Redonda $\left(V_{c}=\mathrm{m} / \mathrm{min} ; \mathrm{f}=0,10 \mathrm{~mm} / \mathrm{rev}\right.$ e $\left.a_{p}=0,35 \mathrm{~mm}\right)$. 


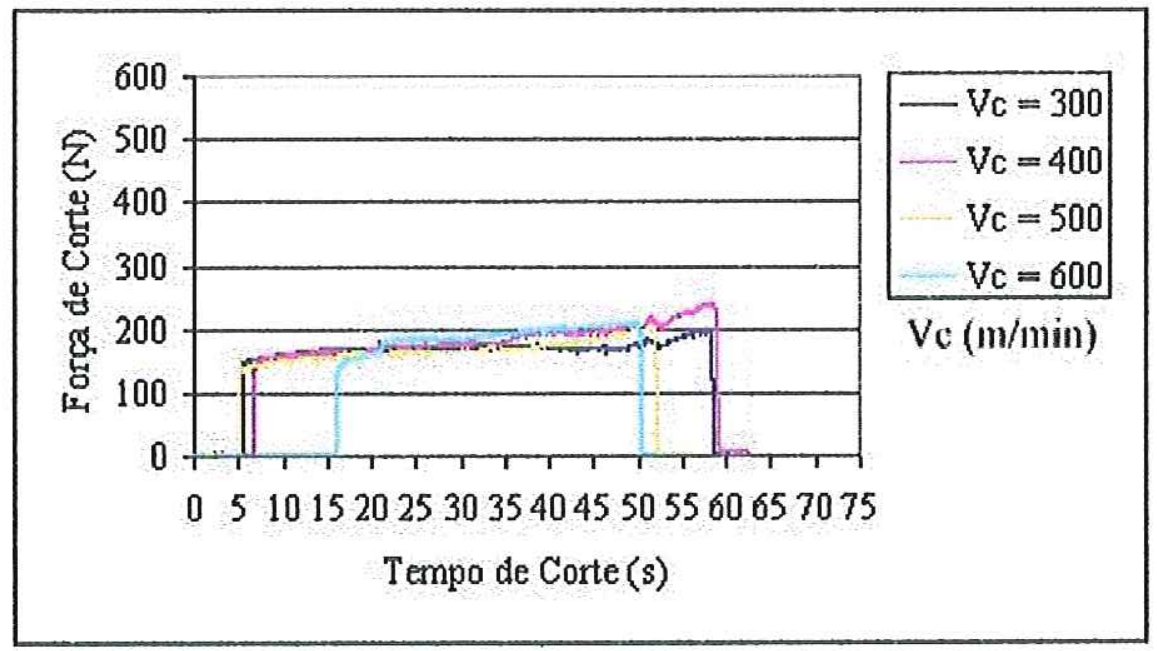

FIGURA 4.23 - Efeito da Velocidade de Corte Sobre a Força com Ferramenta

Cerâmica CC670 Triangular $\left(V_{c}=\mathrm{m} / \mathrm{min} ; \mathrm{f}=0,10 \mathrm{~mm} / \mathrm{rev}\right.$ e $\left.a_{p}=0,35 \mathrm{~mm}\right)$.

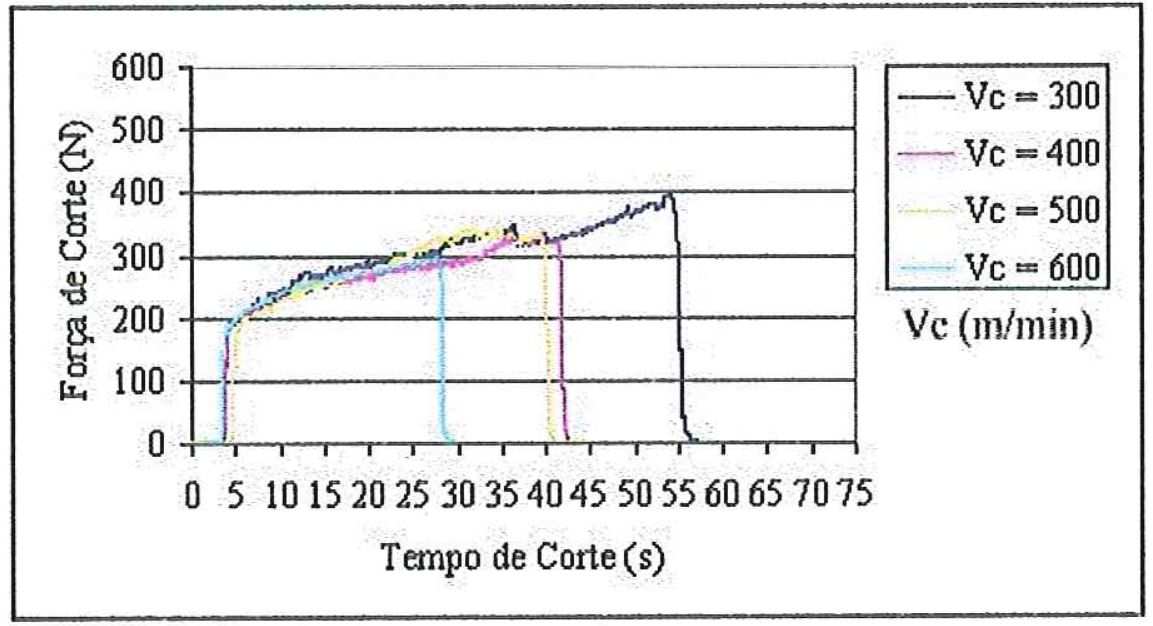

FIGURA 4.24 - Efeito da Velocidade de Corte Sobre a Força com Ferramenta

Cerâmica CC670 Redonda $\left(V_{c}=\mathrm{m} / \mathrm{min} ; \mathrm{f}=0,10 \mathrm{~mm} / \mathrm{rev}\right.$ e $\left.a_{p}=0,35 \mathrm{~mm}\right)$.

Analisando-se os resultados apresentados, conclui-se que o aumento da velocidade de corte não altera significativamente os valores da força de corte. Provavelmente, isto ocorre devido a baixa condutividade térmica do Inconel 718 $(11,4 \mathrm{~W} / \mathrm{mK})$, reduzindo a transferência de calor para a peça e mantendo a resistência ao cisalhamento. A mesma conclusão chegaram THANGARAJ \& WEINMANN (1992), afirmando que não encontraram variação expressiva na força de corte quando a velocidade de corte passa de $456 \mathrm{~m} / \mathrm{min}$ para $762 \mathrm{~m} / \mathrm{min}$ com ferramentas cerâmicas de geometria redonda. Segundo os pesquisadores, a força de corte é independente da velocidade de corte nas condições testadas, enquanto que a força de avanço aumenta 
com o aumento da velocidade de corte. De uma maneira geral, existe um consenso entre os diversos pesquisadores de que as forças na usinagem tendem a ser menores quando aumenta a velocidade de corte e não há desgaste da ferramenta. Possivelmente a redução se dá pela maior geração de calor, facilitando o cisalhamento. Novamente, as ferramentas redondas apresentam valores de força de corte superiores em relação às ferramentas triangular e quadradas.

\subsubsection{Waspaloy}

A partir de um considerável número de experimentos realizados com a superliga Inconel 718, optou-se por escolher as melhores condições de corte e geometrias de arestas de corte encontradas e testá-las no torneamento com alta velocidade de corte da superliga Waspaloy. Os parâmetros de corte utilizados foram: $\left(V_{c}=500 \mathrm{~m} / \mathrm{min} ; \mathrm{f}=0,1 \mathrm{~mm} / \mathrm{rev}\right.$ e $\left.a_{p}=0,35 \mathrm{~mm}\right)$, sob condição de corte a seco.

Existe uma carência enorme de publicações relacionada a usinagem da superliga Waspaloy, principalmente com alta velocidade de corte, pois não foi encontrada nenhuma publicação.

O comportamento da força de corte e da temperatura na usinagem do Waspaloy foi semelhante ao do Inconel 718, quando da utilização de ferramentas cerâmicas. De forma que, as discussões a seguir serão resumidas, para evitar repetições de comentários.

As FIGURAS 4.25 a 4.28 referem-se a comparação dos valores de força de corte e temperatura com ferramentas cerâmicas (CC650 e CC670) e ferramenta de PCBN (CB7050) de geometria triangular na condição a seco.

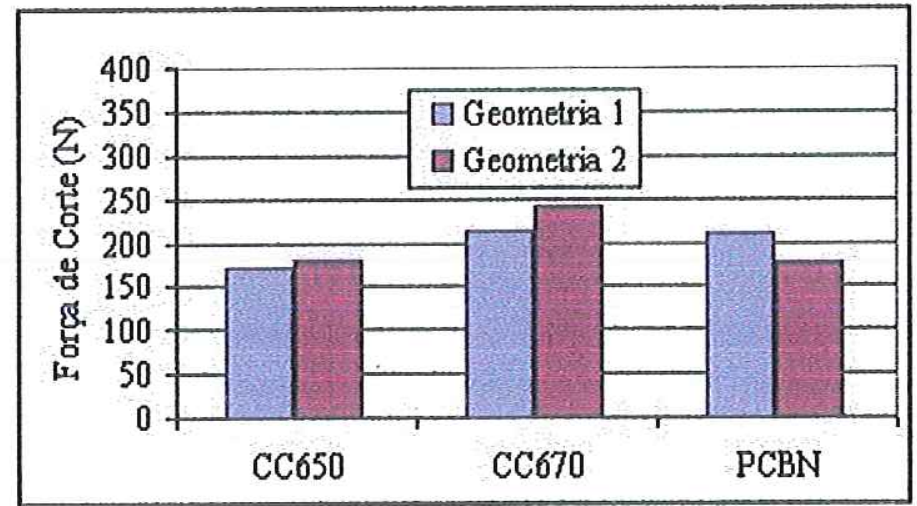

FIGURA 4.25 - Resultados da Força de Corte após 20 Segundos com Ferramentas Triangular $\left(V_{c}=500 \mathrm{~m} / \mathrm{min} ; \mathrm{f}=0,10 \mathrm{~mm} / \mathrm{rev}\right.$ e $\left.a_{p}=0,35 \mathrm{~mm}\right)$. 


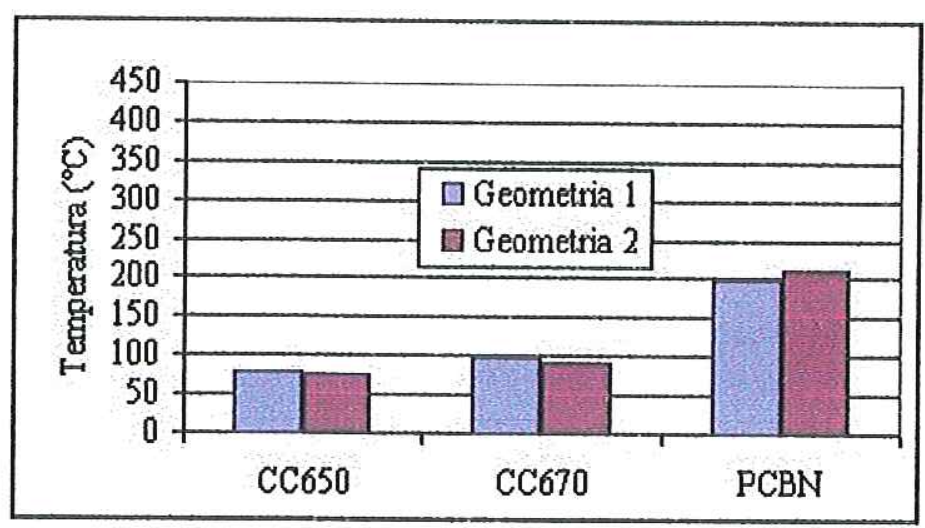

FIGURA 4.26 - Medição da Temperatura após 20 Segundos com Ferramentas Triangular a uma Distância de 1,5mm da Aresta de Corte

$\left(V_{c}=500 \mathrm{~m} / \mathrm{min} ; f=0,10 \mathrm{~mm} / \mathrm{rev}\right.$ e $\left.a_{p}=0,35 \mathrm{~mm}\right)$.

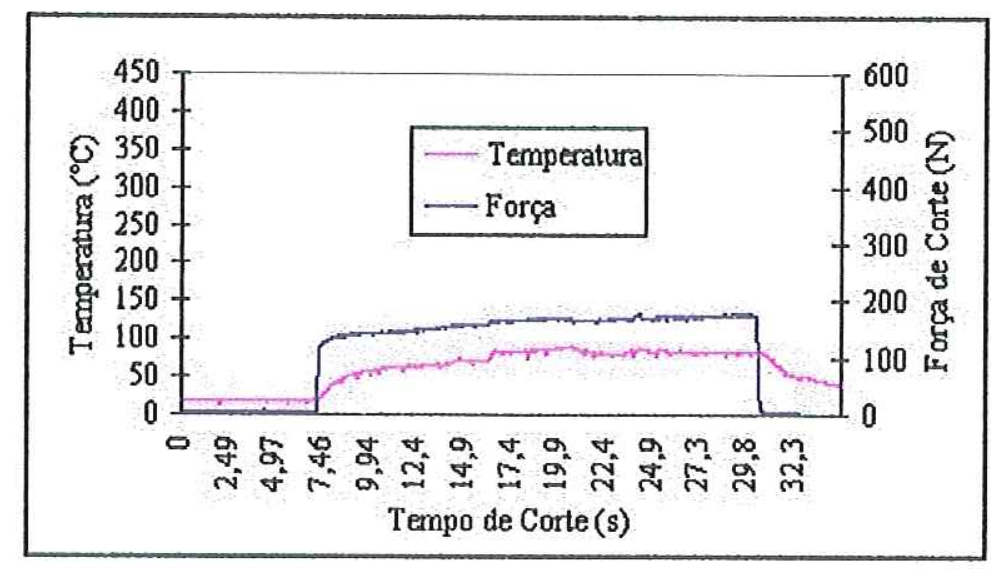

FIGURA 4.27 - Medição da Temperatura a uma Distância de 1,5mm da Aresta de Corte e da Força de Corte em Função do Tempo com Ferramenta Cerâmica CC650/Geometria $1\left(V_{c}=500 \mathrm{~m} / \mathrm{min} ; \mathrm{f}=0,10 \mathrm{~mm} / \mathrm{rev}\right.$ e $\left.a_{p}=0,35 \mathrm{~mm}\right)$.

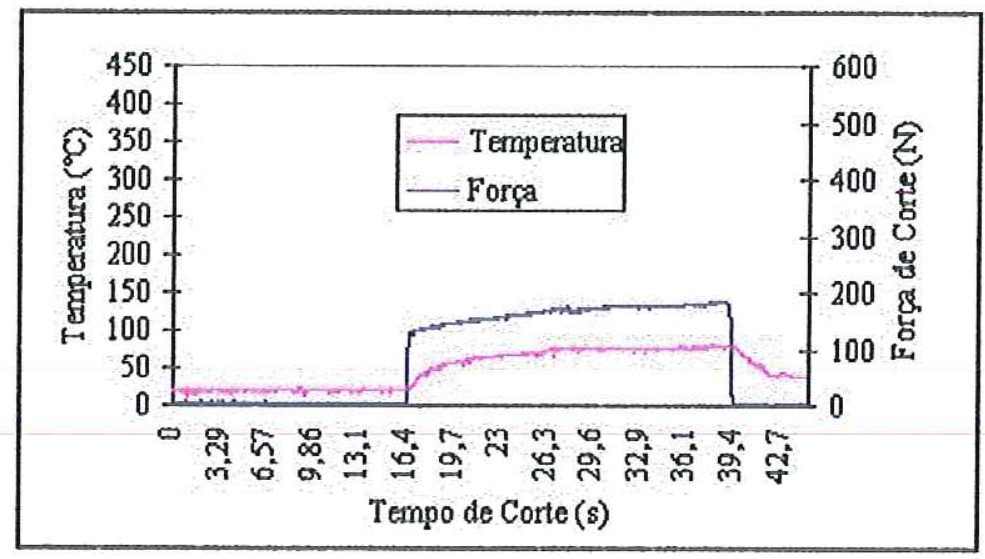

FIGURA 4.28 - Medição da Temperatura a uma Distância de 1,5mm da Aresta de Corte e da Força de Corte em Função do Tempo com Ferramenta Cerâmica CC650/Geometria $2\left(V_{c}=500 \mathrm{~m} / \mathrm{min} ; f=0,10 \mathrm{~mm} / \mathrm{rev}\right.$ e $\left.a_{p}=0,35 \mathrm{~mm}\right)$. 
Mediante análise comparativa das geometrias 1 e 2, pôde-se observar que os valores de força de corte e temperatura apresentaram alterações dentro da mesma classe de material da ferramenta, porém com menor intensidade quando comparado com o Inconel 718. Os valores de temperatura apresentados na usinagem do Waspaloy foram aproximadamente $20 \%$ inferiores aos apresentados com o Inconel 718 quando da utilização de ferramentas cerâmicas e de $40 \%$ com ferramenta de PCBN. Quanto à força de corte, as ferramentas cerâmicas apresentaram pequenas alterações em relação ao Inconel 718. Por outro lado, a ferramenta de PCBN proporcionou uma redução de aproximadamente $35 \%$ nos valores de força de corte. Provavelmente, este comportamento está relacionado à diferença de composição química e condutividade térmica das superligas. A ferramenta CC650 apresenta menor dispersão em ambas geometrias de aresta de corte, devido provavelmente à melhor estabilidade química em relação à CC670. Entretanto, a ferramenta CC670 registra maior valor de temperatura e consequentemente maior valor de força de corte. Observa-se que as ferramentas de PCBN apresentam valores de força de corte semelhantes às ferramentas cerâmicas, o que não aconteceu com a usinagem do Inconel 718. A geometria 2 proporciona melhor estabilidade durante a usinagem, por apresenta menor dispersão.

As FIGURAS 4.29 a 4.32 representam a comparação dos valores de força de corte e temperatura com ferramentas cerâmicas (CC650 e CC670) e ferramenta de PCBN (CB50) de geometria redonda.

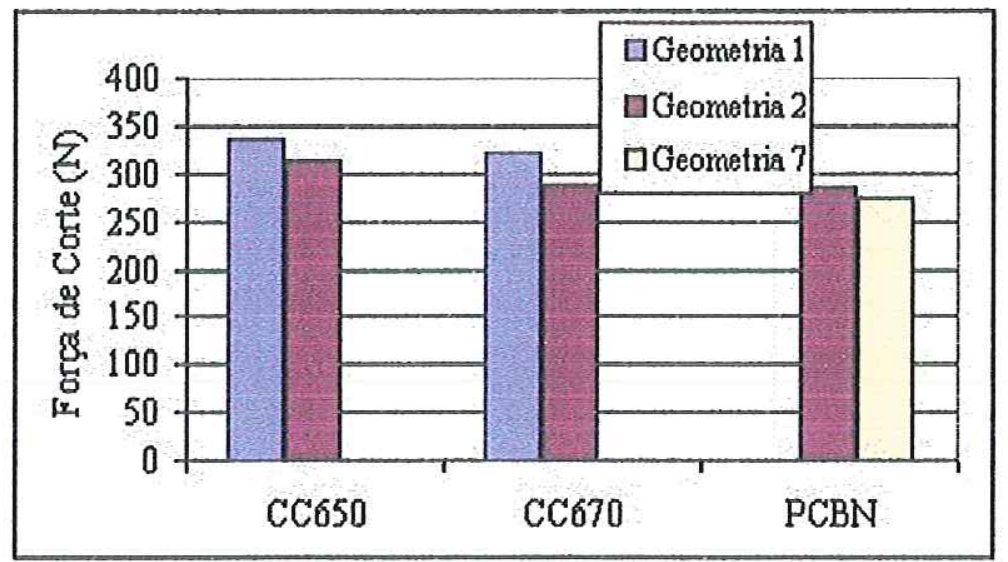

FIGURA 4.29 - Resultados da Força de Corte após 20 Segundos com Ferramentas Redondas $\left(V_{c}=500 \mathrm{~m} / \mathrm{min} ; \mathrm{f}=0,10 \mathrm{~mm} / \mathrm{rev}\right.$ e $\left.a_{p}=0,35 \mathrm{~mm}\right)$. 


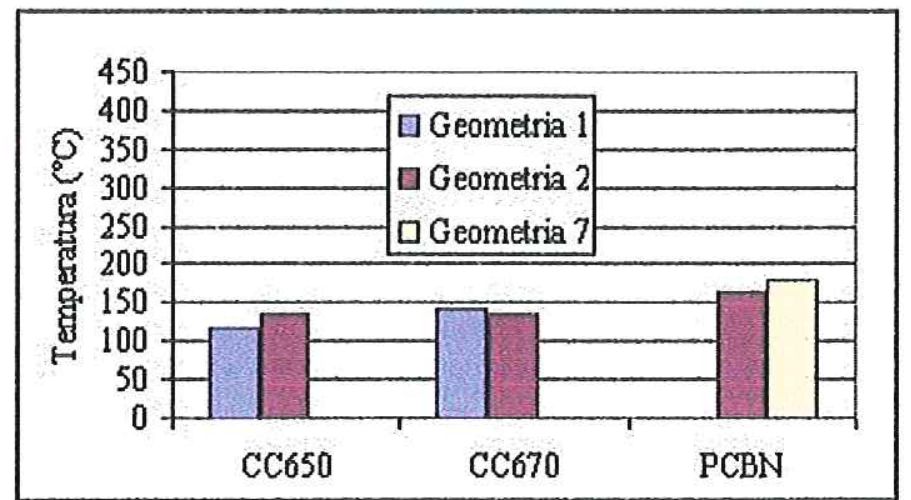

FIGURA 4.30 - Medição da Temperatura após 20 Segundos com Ferramentas

Redondas a uma Distância de 1,5mm da Aresta de Corte

$\left(V_{c}=500 \mathrm{~m} / \mathrm{min} ; \mathrm{f}=0,10 \mathrm{~mm} / \mathrm{rev}\right.$ e $\left.a_{p}=0,35 \mathrm{~mm}\right)$.

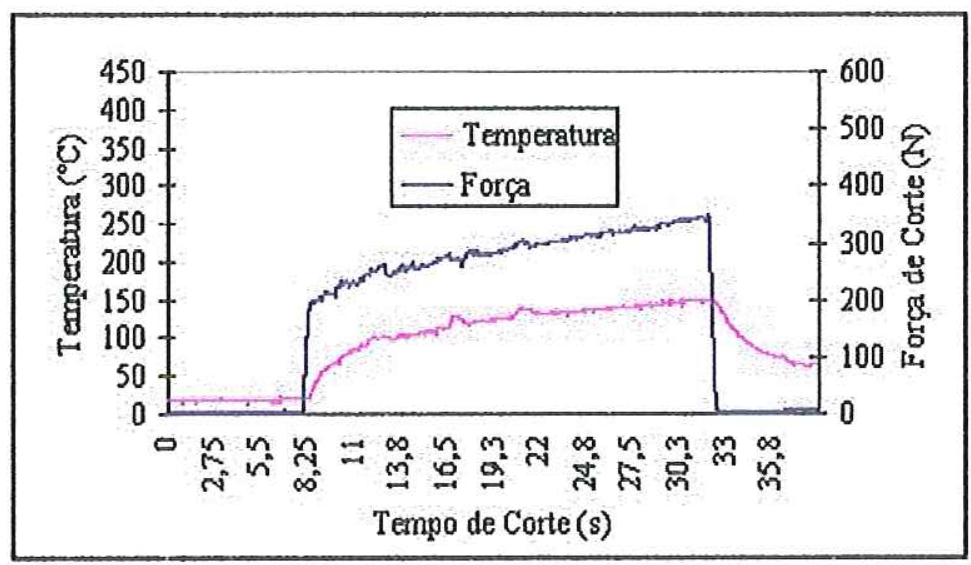

FIGURA 4.31 - Medição da Temperatura a uma Distância de 1,5mm da Aresta de Corte e da Força de Corte em Função do Tempo com Ferramenta Cerâmica CC670/Geometria $1\left(V_{c}=500 \mathrm{~m} / \mathrm{min} ; \mathrm{f}=0,10 \mathrm{~mm} / \mathrm{rev}\right.$ e $\left.a_{p}=0,35 \mathrm{~mm}\right)$.

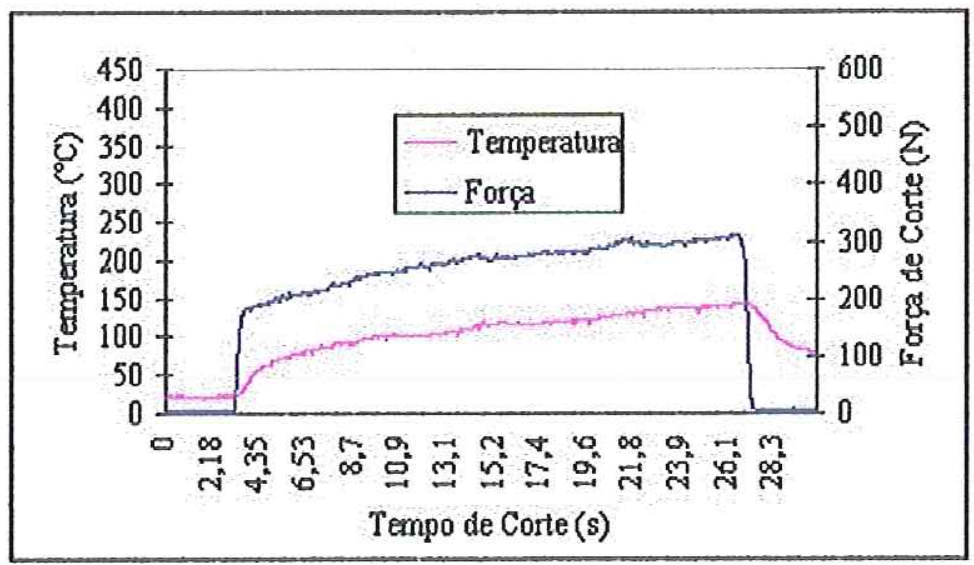

FIGURA 4.32 - Medição da Temperatura a uma Distância de 1,5mm da Aresta de Corte e da Força de Corte em Função do Tempo com Ferramenta Cerâmica CC670/Geometria $2\left(V_{c}=500 \mathrm{~m} / \mathrm{min} ; f=0,10 \mathrm{~mm} / \mathrm{rev}\right.$ e $\left.a_{p}=0,35 \mathrm{~mm}\right)$. 
As ferramentas redondas proporcionam maior valor de força de corte em comparação com as ferramentas triangular e quadrada. De uma maneira geral, a geometria 2 apresenta redução nos valores de força de corte e temperatura, repetindo o comportamento quando da usinagem do Inconel 718. Resultados não esperados ocorreram com os valores de força de corte e temperatura, pois utilizando ferramentas de cerâmica triangular, os mesmos apresentaram valores inferiores quando comparados com a usinagem do Inconel 718, o que não ocorre com as ferramentas cerâmicas redondas. Os valores de força de corte e temperatura foram ligeiramente superiores aos encontrados na usinagem do Inconel 718.

As alterações dos valores de força de corte e temperatura com ferramentas de PCBN foram insignificante quando da utilização das geometrias 2 e 7 , o que não ocorreu quando da usinagem do Inconel 718. Os valores de força de corte e temperatura foram inferiores em aproximadamente $25 \%$ e $35 \%$ aos apresentados na usinagem do Inconel 718. Observa-se que as ferramentas de PCBN apresentam valores de força de corte inferiores as ferramentas cerâmicas, o que não acontece com a usinagem do Inconel 718. O comportamento das ferramentas redondas e triangular de PCBN são muito semelhantes. As características térmicas, mecânicas e metalúrgicas de ambas superligas representam uma posição importante na explicação deste fenômeno, necessitando de análise mais detalhada.

As FIGURAS 4.33 a 4.36 representam a comparação dos valores de força de corte e temperatura com ferramentas cerâmicas (CC650 e CC670) e ferramenta de PCBN (CB7050) de geometria quadrada.

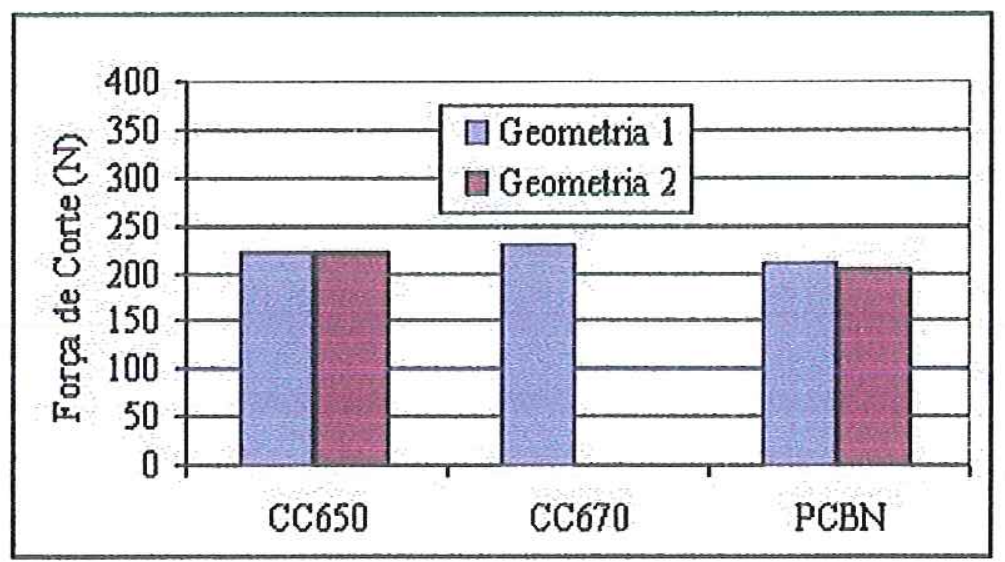

FIGURA 4.33 - Resultados da Força de Corte após 20 Segundos com Ferramentas

Quadradas $\left(V_{c}=500 \mathrm{~m} / \mathrm{min} ; f=0,10 \mathrm{~mm} / \mathrm{rev}\right.$ e $\left.a_{p}=0,35 \mathrm{~mm}\right)$. 




FIGURA 4.34 - Medição da Temperatura após 20 Segundos com Ferramentas Quadradas a uma Distância de 1,5mm da Aresta de Corte $\left(V_{c}=500 \mathrm{~m} / \mathrm{min} ; f=0,10 \mathrm{~mm} / \mathrm{rev}\right.$ e $\left.a_{p}=0,35 \mathrm{~mm}\right)$.

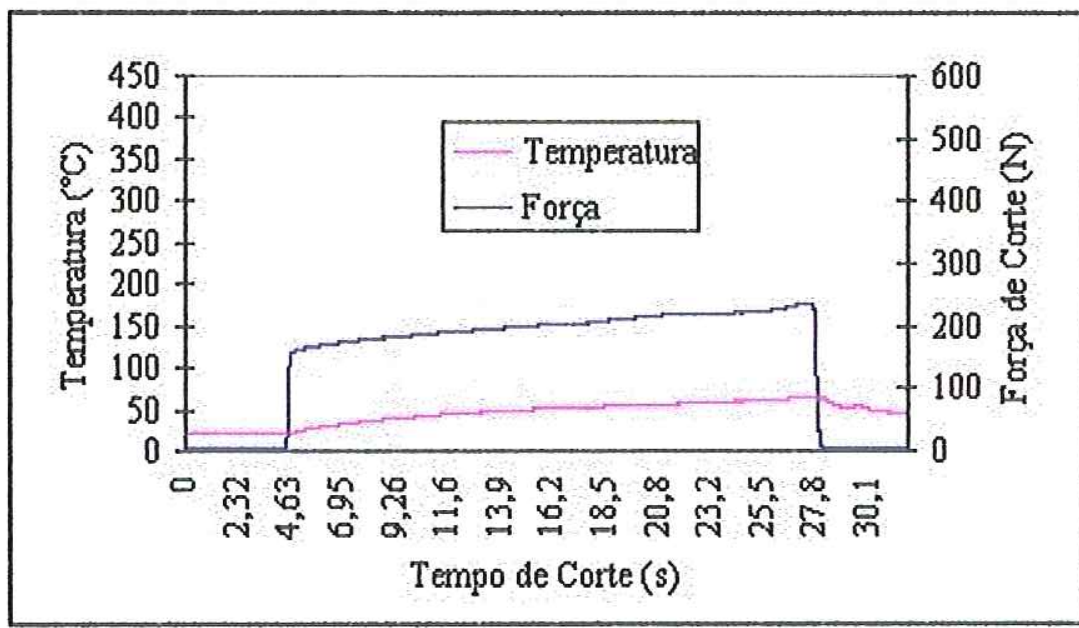

FIGURA 4.35 - Medição da Temperatura a uma Distância de 1,5mm da Aresta de Corte e da Força de Corte em Função do Tempo com Ferramenta Cerâmica CC650/Geometria $1\left(V_{c}=500 \mathrm{~m} / \mathrm{min} ; \mathrm{f}=0,10 \mathrm{~mm} / \mathrm{rev}\right.$ e $\left.a_{p}=0,35 \mathrm{~mm}\right)$. 


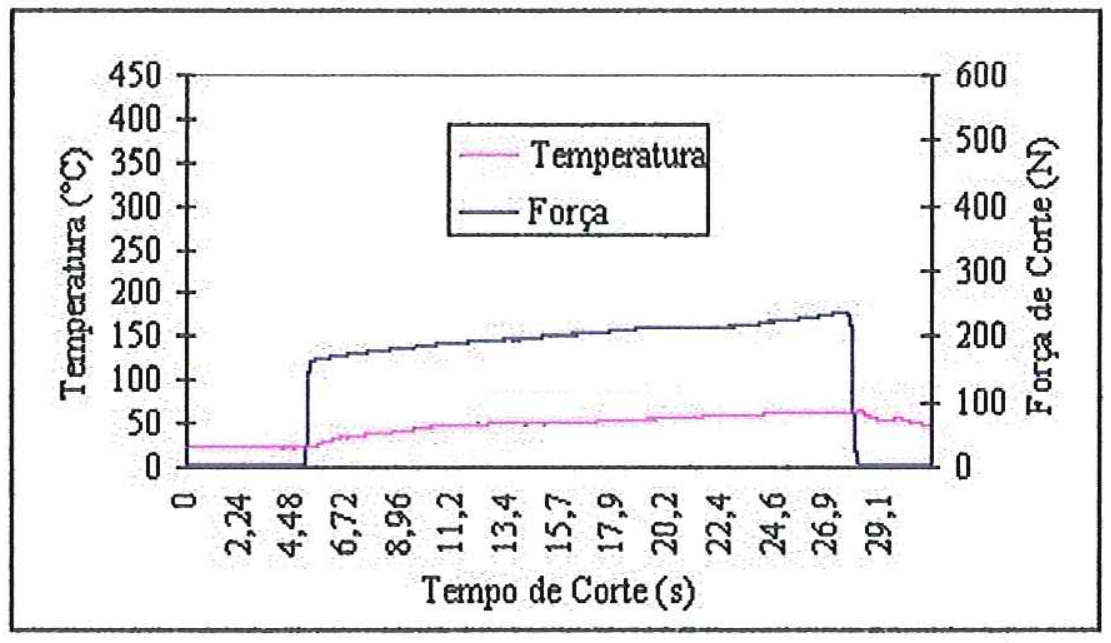

FIGURA 4.36 - Medição da Temperatura a uma Distância de 1,5mm da Aresta de

Corte e da Força de Corte em Função do Tempo com Ferramenta Cerâmica CC650/Geometria $2\left(V_{c}=500 \mathrm{~m} / \mathrm{min} ; f=0,10 \mathrm{~mm} / \mathrm{rev}\right.$ e $\left.a_{p}=0,35 \mathrm{~mm}\right)$.

Mediante análise comparativa das geometrias 1 e 2, pôde-se observar que os valores de força de corte e temperatura não sofreram alterações significativas dentro da mesma classe de material. Os valores de força de corte e temperatura apresentados na usinagem do Waspaloy com ferramentas de PCBN foram aproximadamente $20 \%$ e $40 \%$ inferiores aos apresentados com o Inconel 718. Para as ferramentas cerâmicas os valores foram praticamente os mesmos. A influência das geometrias 1 e 2 nos parâmetros avaliados com ferramentas quadradas foram mínimas em relação as demais ferramentas.

As ferramentas cerâmicas quadradas apresentaram menor valor da temperatura em comparação com as ferramentas triangular e redonda. As forças de corte das ferramentas cerâmicas apresentam valores intermediários às ferramentas triangular e redonda. Este mesmo comportamento aconteceu na usinagem do Inconel 718. A superioridade da condutividade térmica das ferramentas de PCBN é confirmada em relação às ferramentas cerâmicas. 


\subsection{Mecanismos de desgaste}

\subsubsection{Inconel 718}

As características deste material (fragilidacie, baixa condưiividade térmica, presença de carbetos, resistência à alta temperatura e tendência ao endurecimento por deformação) ocasionaram intenso desgaste nas ferramentas proporcionando um tempo de vida reduzido. A presença de APC não foi observada em nenhuma geometria, apesar de alguns pesquisadores comentarem que ela é freqüente. Em geral diferentes tipos de desgastes são evidentes em todas figuras. Em nenhuma ferramenta ocorreu falha catastrófica nas condições testadas. Entretanto, nota-se indícios de desgaste de cratera na superfície de saída, muito embora em proporção bem inferior ao desgaste de entalhe.

A identificação dos mecanismos e tipos de desgaste que atuaram sobre as ferramentas é efetuada com base em fotografias feitas em microscópio eletrônico de varredura.

O aspecto do desgaste encontrado nas ferramentas cerâmicas (CC650 e CC670) de geometria triangular na condição a seco e com a utilização da técnica de MQL pode ser observado nas FIGURAS 4.37 a 4.40 .

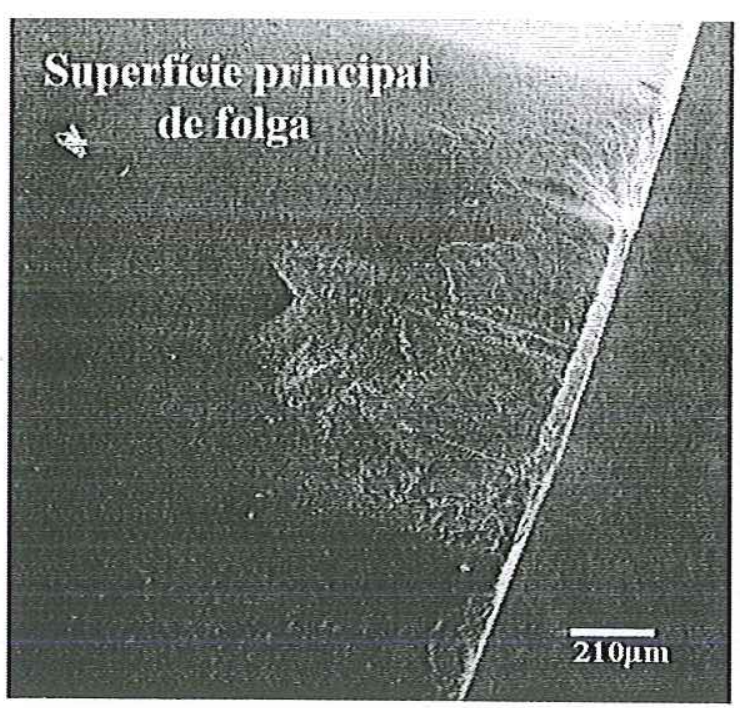

(a) Geometria 1 - 50X (após 49 segundos)

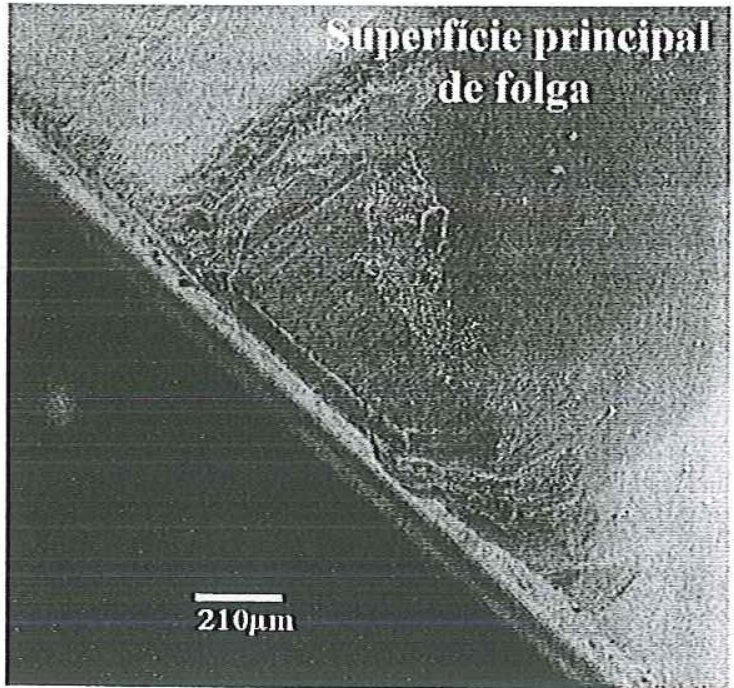

(b) Geometria 2 - 50X (após 47 segundos)

FIGURA 4.37 - Condição de Desgaste da Ferramenta Cerâmica CC650 Triangular sem Refrigeração $\left(V_{c}=500 \mathrm{~m} / \mathrm{min} ; f=0,10 \mathrm{~mm} /\right.$ rev e $\left.a_{p}=0,35 \mathrm{~mm}\right)$. 


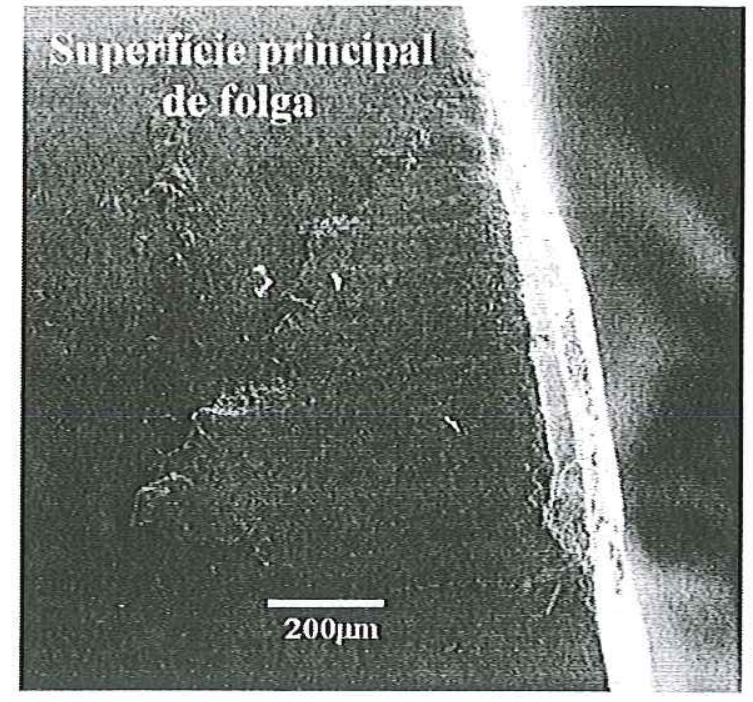

(a) Geometria 1 - 70X (após 40 segundos)

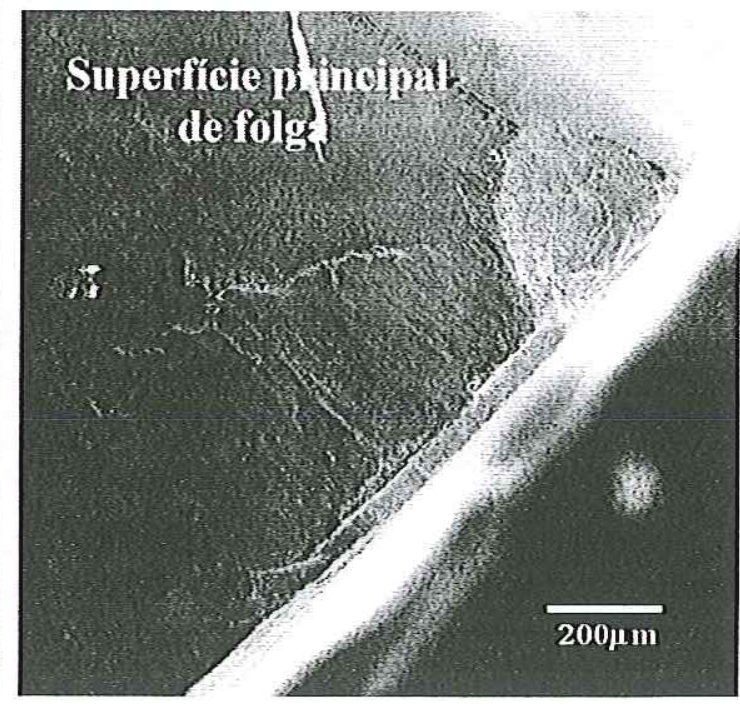

(b) Geometria 2 - 70X (após 37 segundos)

FIGURA 4.38 - Condição de Desgaste da Ferramenta Cerâmica CC650 Triangular Utilizando MQL $\left(V_{c}=500 \mathrm{~m} / \mathrm{min} ; \mathrm{f}=0,10 \mathrm{~mm} / \mathrm{rev}\right.$ e $\left.\mathrm{a}_{\mathrm{p}}=0,35 \mathrm{~mm}\right)$.

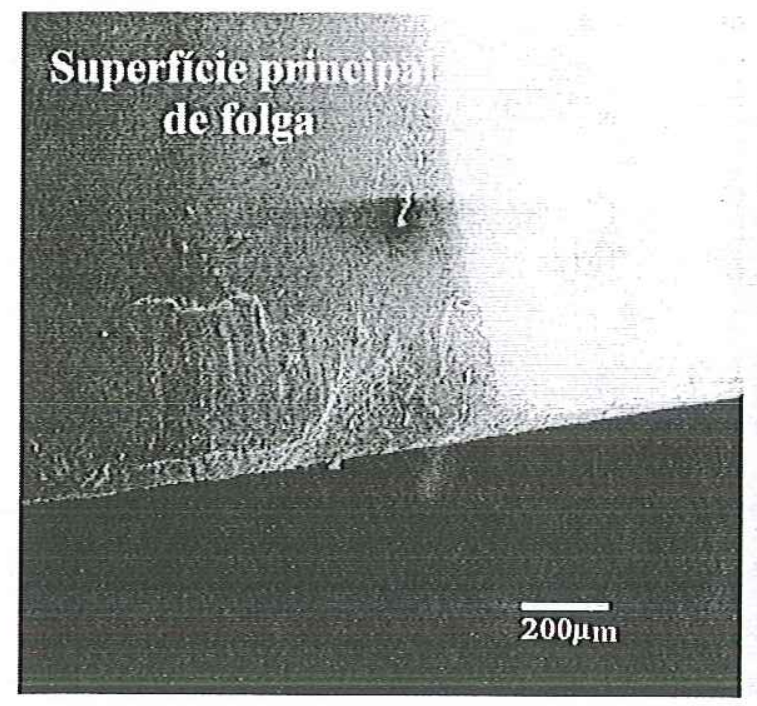

(a) Geometria 1 - 50X (após 47 segundos)

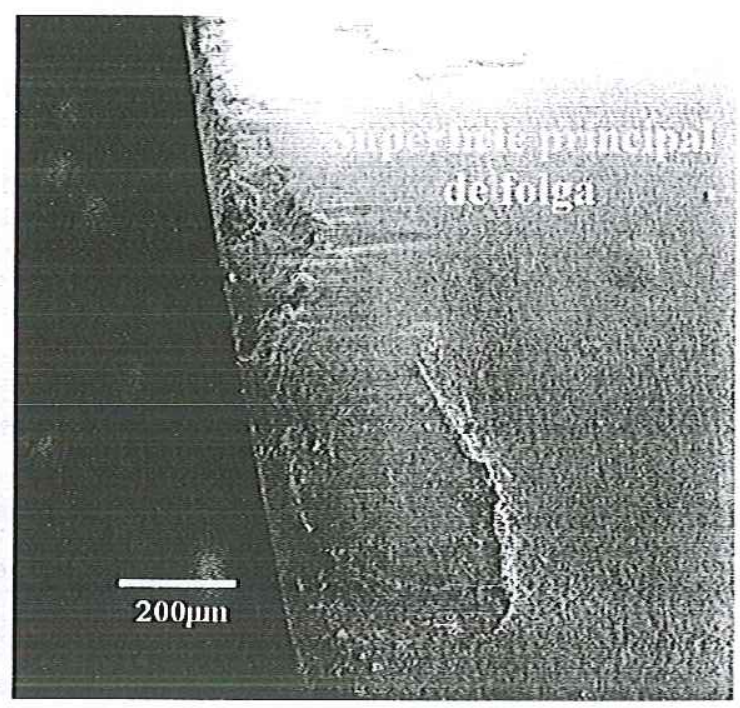

(b) Geometria 2 - 70X (após 49 segundos)

FIGURA 4.39 - Condição de Desgaste da Ferramenta Cerâmica CC670 Triangular sem Refrigeração $\left(V_{c}=500 \mathrm{~m} / \mathrm{min} ; \mathrm{f}=0,10 \mathrm{~mm} / \mathrm{rev}\right.$ e $\left.\mathrm{a}_{\mathrm{p}}=0,35 \mathrm{~mm}\right)$.

De uma maneira geral, os desgastes que ocorreram no torneamento com alta velocidade de corte não são provenientes de um único mecanismo de desgaste, mas sim de uma combinação de vários deles. 


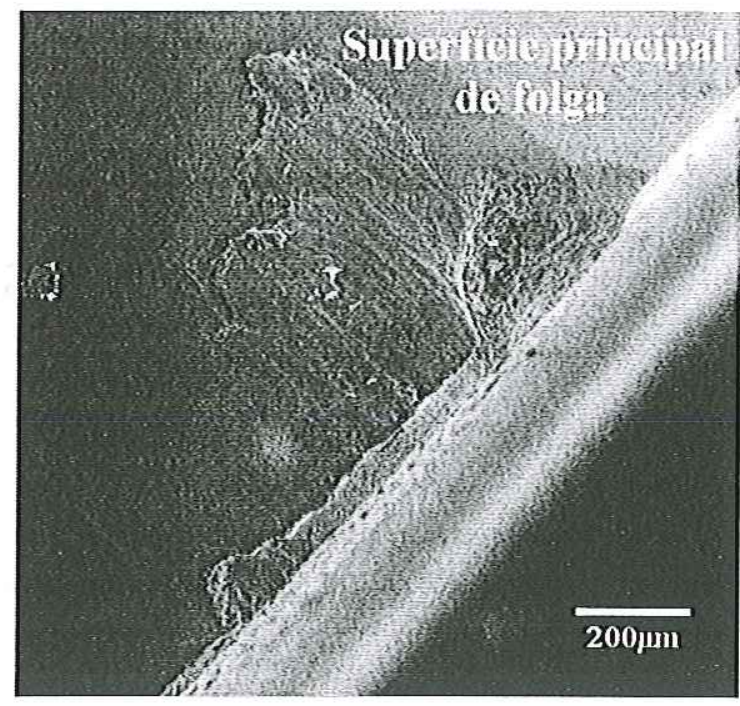

(a) Geometria 1 - 70X (após 40 segundos)

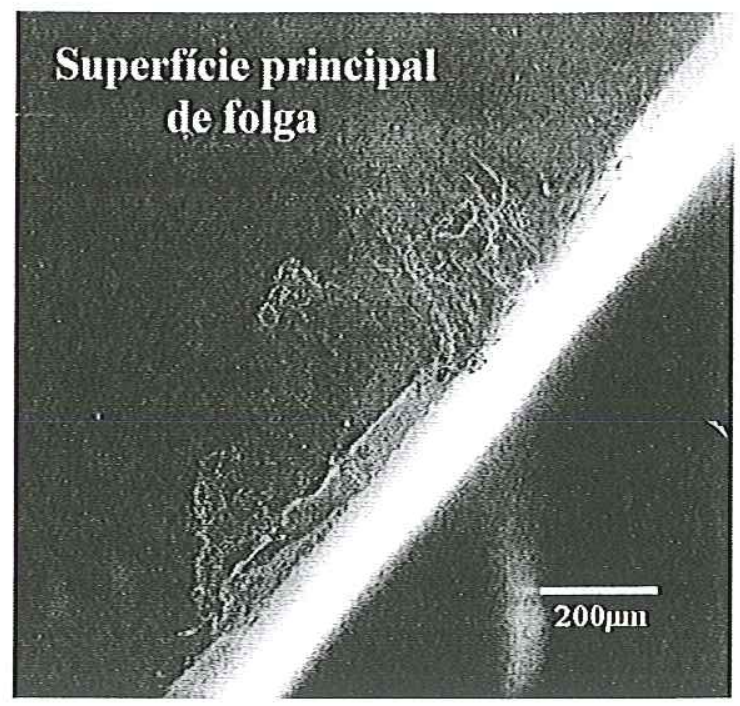

(b) Geometria 2 - 70X (após 38 segundos)

FIGURA 4.40 - Condição de Desgaste da Ferramenta Cerâmica CC670 Triangular Utilizando MQL $\left(V_{c}=500 \mathrm{~m} / \mathrm{min} ; \mathrm{f}=0,10 \mathrm{~mm} / \mathrm{rev}\right.$ e $\left.a_{p}=0,35 \mathrm{~mm}\right)$.

O sulco na profundidade de corte na usinagem de superligas à base de níquel tem sido vista como um dos principais fatores limitadores da vida das ferramentas cerâmicas. Isto é causado pela combinação de alta temperatura, alta resistência do material da peça, alta deformação plástica, endurecimento da camada superficial durante a usinagem, alta tensão na interface cavaco-ferramenta e cavacos abrasivos (RICHARDS \& ASPINWALL, 1989; GATTO \& IULIANO, 1994 e EZUGWU et al. 1999). Contudo, em nenhuma condição a usinagem com alta velocidade resultou em quebra catastrófica das ferramentas cerâmicas e de PCBN. Isto se deve provavelmente ao aumento da velocidade de corte, resultando no aumento da temperatura e presumivelmente na redução do nível de tensões mecânicas e térmicas desenvolvidas na região do corte e da capacidade do material da ferramenta suportar essas tensões sem microfraturas. Além disso, o torno utilizado desempenhou um papel muito importante, por ter alta rigidez e potência.

É notável a presença de material aderido ao longo da aresta de corte. O efeito abrasivo do material aderido é que causa o arrastamento para trás da aresta de corte. A adesão não tem muita influência sobre a deterioração da ferramenta quando comparado com outros mecanismos. O endurecimento do cavaco aumenta as características abrasivas aumentando a formação do desgaste de entalhe. Desgaste de adesão ao longo da aresta de corte pode ser observado tanto na condição a seco como na utilização de 
MQL. Na condição de MQL, o esfriamento do cavaco devido ao fluxo de ar e à convecção faz com que a ferramenta esteja sujeita à alta dureza do material durante o corte, o que aumenta o seu desgaste. A expectativa era de que a condição com MQL apresentasse um menor desgaste devido ao efeito lubrificante do fluido de corte, que atuaria no sentido de reduzir a abrasão entre ferramenta-peça-cavaco. Porém, acreditase que a tensão gerada durante o corte prejudicou a ação do jato pulverizado de fluido de corte, impedindo-o de chegar na região do corte. Além disso, existe o efeito refrigerante do ar comprimido, que reduz a temperatura do cavaco e mantém a dureza alta. Por esses motivos, a condição com MQL não apresenta um desempenho superior à condição a seco no aspecto relacionado com o desgaste na maioria das ferramentas utilizadas. Isto sugere que, o mecanismo de desgaste "attrition" (aderência com arrastamento) é o tipo de desgaste dominante conduzindo para o desgaste de cratera. $\mathrm{Na}$ condição a seco, o aspecto do desgaste em ambas geometrias foi semelhante. Entretanto, quando da utilização da técnica de MQL, observa-se que a geometria 2 apresenta menor taxa de desgaste, sendo mais representativo com a ferramenta cerâmica CC670.

Observa-se a intensa presença de microlascamento e aderência no raio da ferramenta até a extremidade da profundidade de corte, região de contato com a superfície usinada, devido provavelmente à alta deformação plástica. A região onde se concentram esses mecanismos é muito importante, devido ao contato íntimo com a superfície da peça acabada durante o corte, influenciando consequentemente na rugosidade superficial da peça. As inclusões de fibras de $\mathrm{SiC}_{\mathrm{w}}$ aumentam a condutividade térmica, tenacidade e a dureza, mas, infelizmente a estabilidade química é reduzida, influenciando na taxa de desgaste.

$\mathrm{O}$ aspecto do desgaste encontrado nas ferramentas de PCBN (CB7050) de geometria triangular na condição a seco pode ser observado na FIGURA 4.41. A ocorrência dos tipos de desgastes apresentados nas ferramentas cerâmicas com geometria triangular, também esteve presente nas ferramentas de PCBN limitando a vida, mas com combinação e intensidade diferente. 


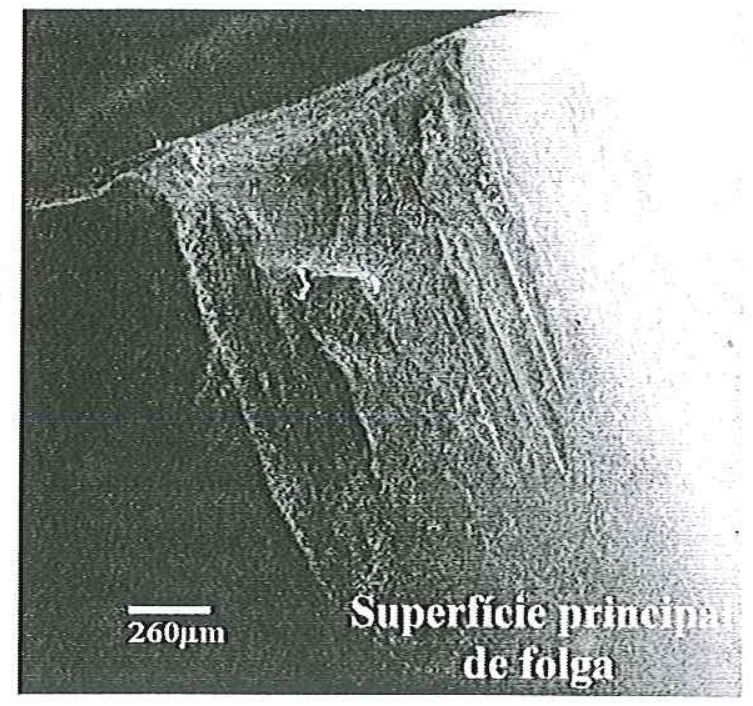

(a) Geometria 1 - 40X (após 45 segundos)

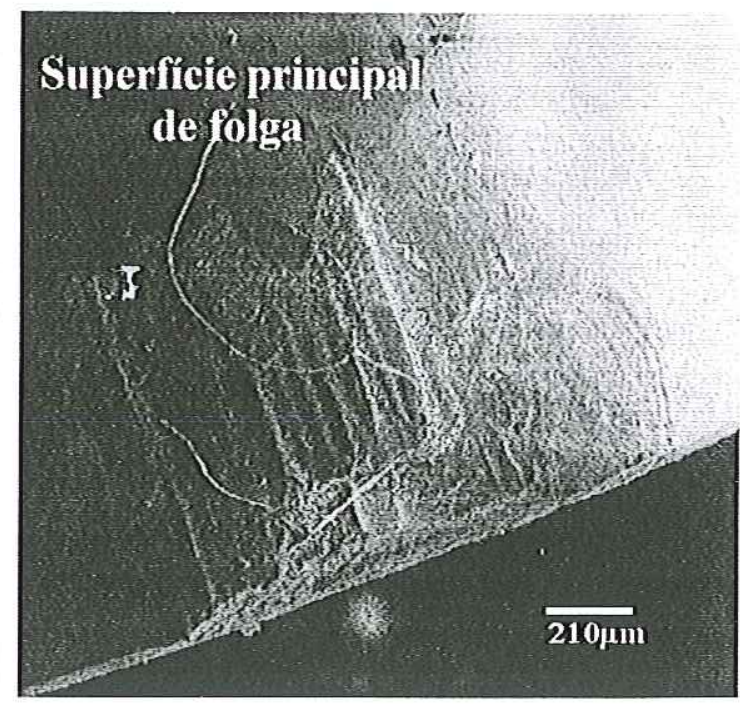

(b) Geometria 2 - 50X (após 46 segundos)

FIGURA 4.41 - Condição de Desgaste da Ferramenta de PCBN Triangular $\left(V_{c}=500 \mathrm{~m} / \mathrm{min} ; \mathrm{f}=0,10 \mathrm{~mm} / \mathrm{rev}\right.$ e $\left.a_{p}=0,35 \mathrm{~mm}\right)$.

Um resultado surpreendentemente negativo foi obtido com as ferramentas de PCBN com concentração de 20 e $50 \%$ de CBN, pois vários pesquisadores as indicaram como uma alternativa de grande potencial para a usinagem das superligas Inconel 718 e Waspaloy, o que não foi comprovado em nenhuma geometria sob condição de corte a seco ou com a técnica de MQL. Os pesquisadores afirmam que o melhor desempenho das ferramentas de PCBN é devido em grande parte à sua maior dureza a quente. Embora não representado, as ferramentas de PCBN com 20 e $50 \%$ de CBN apresentaram comportamento totalmente diferente. $O$ desgaste predominante na ferramenta de baixa concentração foi do tipo abrasão.

Os efeitos das possíveis reações químicas ocorridas com as ferramentas de PCBN são difíceis de identificar, especialmente por causa da complexidade das superligas, devido à grande quantidade de elementos químicos presentes, sendo que qualquer elemento pode estar envolvido na reação. Por outro lado, o material da $2^{\mathrm{a}}$ fase da ferramenta de PCBN pode reagir com os elementos das superligas, principalmente o níquel.

Analisando-se os tipos de mecanismos de desgaste predominante nas ferramentas de PCBN, é considerado mais provável que tenha ocorrido os mecanismos por difusão, abrasão e attrition (aderência com arrastamento) na superfície de folga e saída causado por partículas de carboneto da peça ou por grãos de CBN liberados 
durante o corte, devido à deterioração do material ligante, principalmente pela alta temperatura e interações químicas contribuindo para o desgaste da ferramenta. Estes tipos de desgastes têm sido revelados por muitos pesquisadores quando da usinagem de superligas à base de níquel. Quando são comparados os tipos de desgaste das geometrias 1 e 2, observa-se que o aspecto do desgaste é semelhante.

Segundo LIAO \& SHIUE (1996), o diagrama de fase Co-Ni e Co-Fe mostra que o $\mathrm{Ni}$ e o Fe podem ser dissolvidos quase completamente com o Co em altas temperaturas implicando em partículas da peça difundir para dentro do material ligante da ferramenta. As fases intermetálicas (TiC, TaC e WC) também podem ser dissolvidas na existência de Ni. Deste modo, a resistência do ligante entre os grãos de CBN poderá ser destruída ou destacada da superfície da ferramenta.

As FIGURAS 4.42 a 4.45 representam os tipos de desgaste encontrados nas ferramentas cerâmicas (CC650 e CC670) de geometria redonda na condição a seco e com a utilização da técnica de MQL.

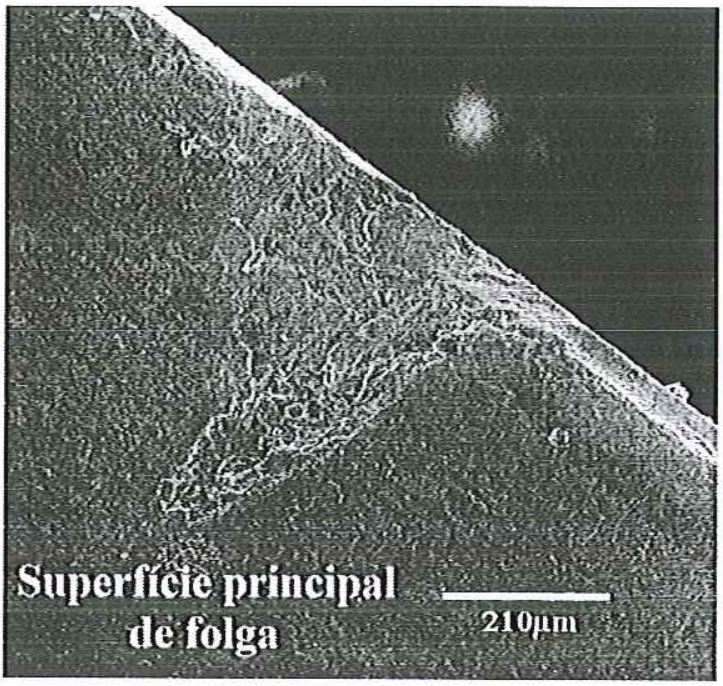

(a) Geometria 1 - 100X (após 35 segundos)

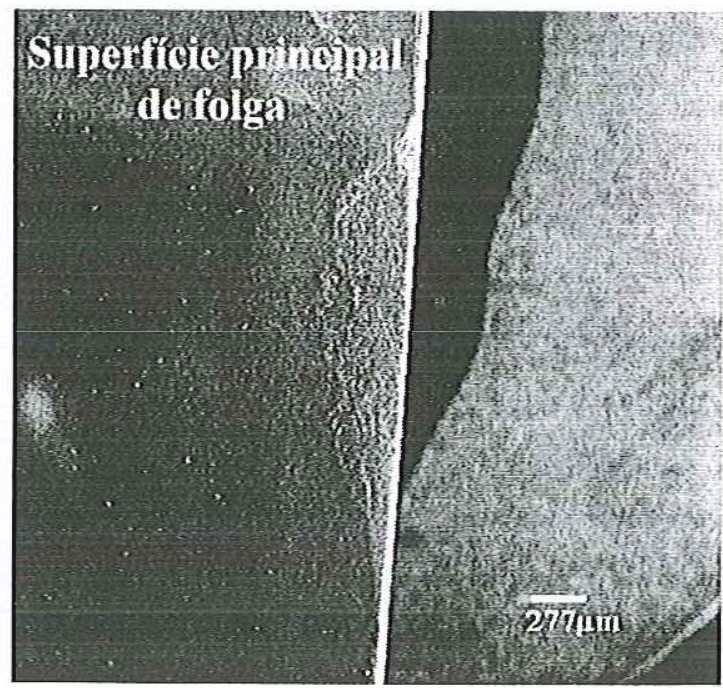

(b) Geometria 2 - 25X (após 33 segundos)

FIGURA 4.42 - Condição de Desgaste da Ferramenta Cerâmica CC650 Redonda sem Refrigeração $\left(V_{c}=500 \mathrm{~m} / \mathrm{min} ; \mathrm{f}=0,10 \mathrm{~mm} / \mathrm{rev}\right.$ e $\left.\mathrm{a}_{\mathrm{p}}=0,35 \mathrm{~mm}\right)$. 


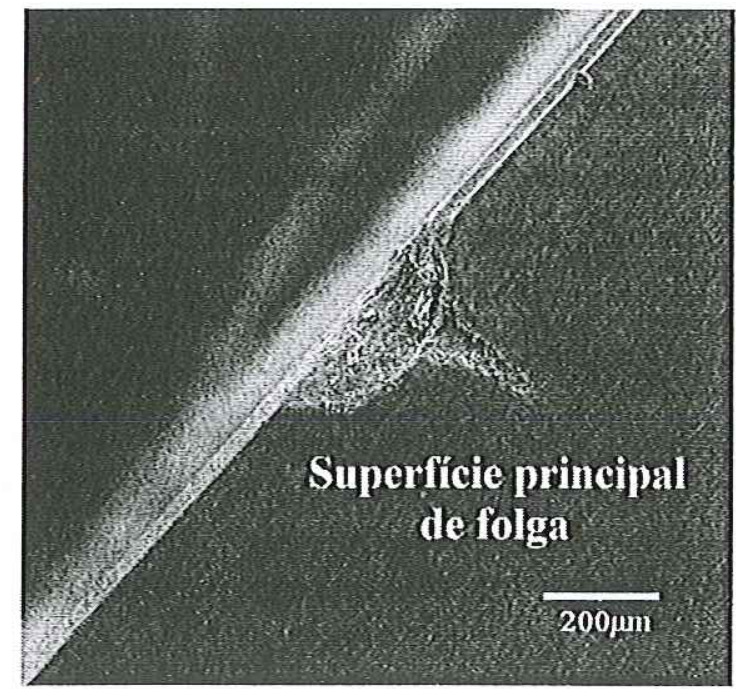

(a) Geometria 1 - 70X (após 33 segundos)

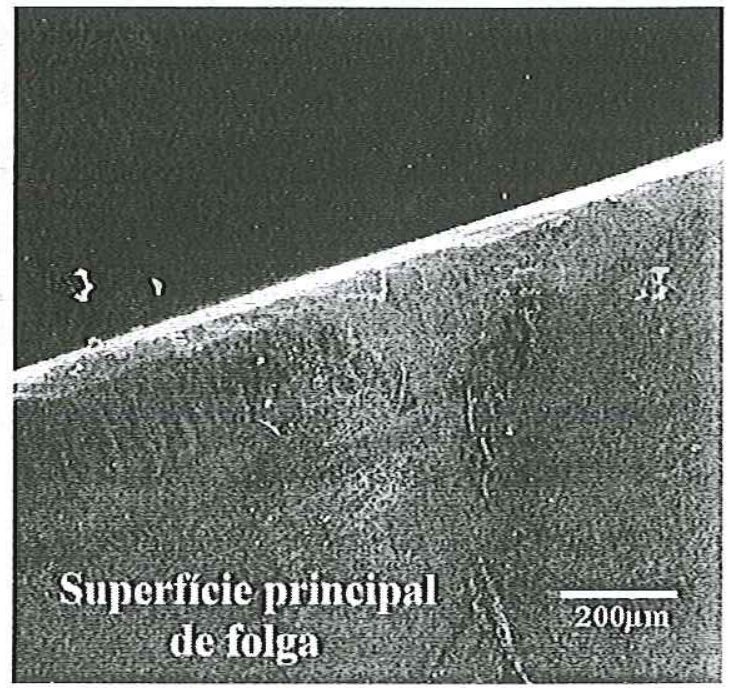

(b) Geometria 2 - 70X (após 31 segundos)

FIGURA 4.43 - Condição de Desgaste da Ferramenta Cerâmica CC650 Redonda Utilizando MQL $\left(V_{c}=500 \mathrm{~m} / \mathrm{min} ; \mathrm{f}=0,10 \mathrm{~mm} / \mathrm{rev}\right.$ e $\left.\mathrm{a}_{\mathrm{p}}=0,35 \mathrm{~mm}\right)$.

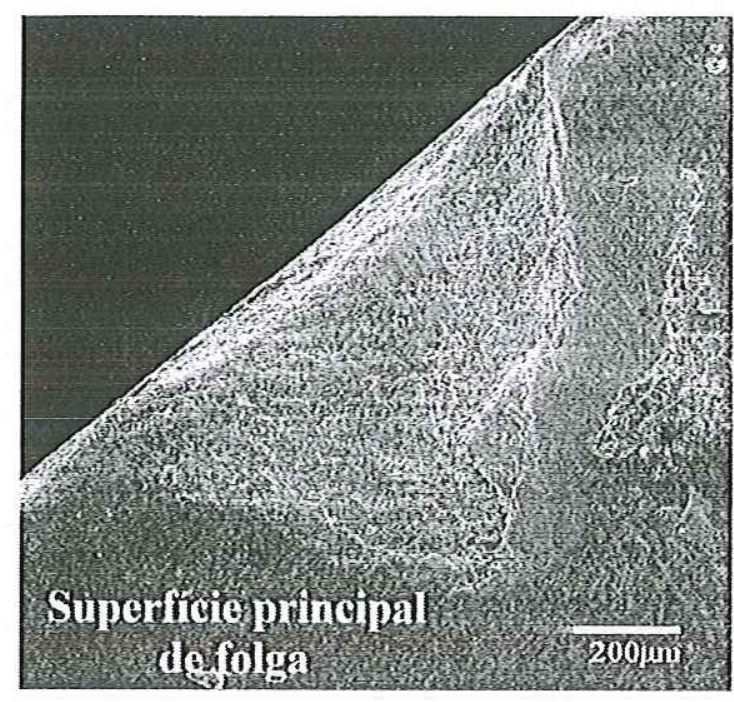

(a) Geometria 1-70X (após 37 segundos)

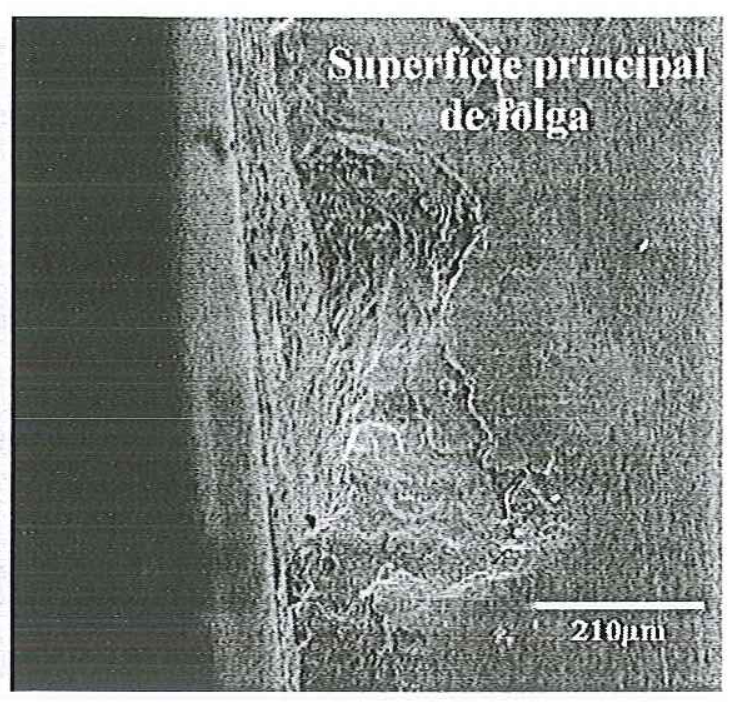

(b) Geometria 2 - 100X (após 35 segundos)

FIGURA 4.44 - Condição de Desgaste da Ferramenta Cerâmica CC670 Redonda sem

Refrigeração $\left(V_{c}=500 \mathrm{~m} / \mathrm{min} ; \mathrm{f}=0,10 \mathrm{~mm} /\right.$ rev e $\left.a_{p}=0,35 \mathrm{~mm}\right)$.

Em geral, as ferramentas redondas obtiveram melhor desempenho em comparação com as triangulares e quadradas em todas as classes de material da ferramenta, por apresentar aresta de corte mais resistente auxiliando na redução da taxa de desgaste e na dissipação de calor. 


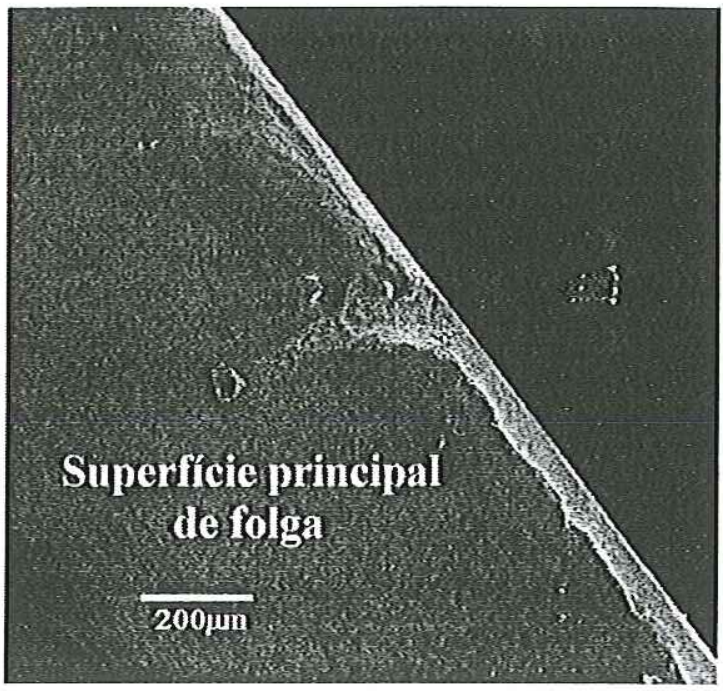

(a) Geometria 1 - 70X (após 31 segundos)



(b) Geometria 2 - 70X (após 30 segundos)

FIGURA 4.45 - Condição de Desgaste da Ferramenta Cerâmica CC670 Redonda Utilizando MQL $\left(V_{c}=500 \mathrm{~m} / \mathrm{min} ; \mathrm{f}=0,10 \mathrm{~mm} / \mathrm{rev}\right.$ e $\left.\mathrm{a}_{\mathrm{p}}=0,35 \mathrm{~mm}\right)$.

A ocorrência dos tipos de desgastes apresentados na geometria triangular, novamente apresentou indícios na vida das ferramentas redondas. O desgaste de entalhe na altura da profundidade de usinagem é originado pela alta deformação plástica na extremidade da profundidade de corte ocasionando aumento na temperatura, o que favorece a adesão de material da peça na ferramenta. Em todas condições, a limitação do desgaste se deu por desgaste de entalhe na altura da profundidade de usinagem associado aos mecanismos por abrasão, difusão e attrition (aderência e arrastamento) envolvendo a perda de material por microsulcamento ou sulcos causada por partículas de elevada dureza. Consequentemente, o mecanismo do tipo attrition é transferido para o desgaste de cratera e entalhe. O desgaste do tipo entalhe é muito comum em materiais que endurecem ao serem trabalhados, uma vez que a camada superficial é sempre mais dura que o material abaixo da superfície (SMITH, 1994). Segundo WAYNE \& BULJAN (1990), o desgaste de entalhe na altura da profundidade de usinagem é conseqüência de interação química entre a ferramenta e o cavaco, tendo grande influência com o aumento da temperatura e tensão de cisalhamento. A ferramenta cerâmica CC670 mostra menos flutuação do desgaste de entalhe.

As ferramentas cerâmicas redondas apresentaram menor evidência de lascamentos em relação às ferramentas triangulares da mesma classe. Naturalmente, o 
aumento da temperatura registrado para as ferramentas redondas pode ocasionar uma redução na probabilidade de microlascamento.

As ferramentas cerâmicas (CC650 e CC670) de geometria 2 apresentaram taxa de desgaste inferior em relação à geometria 1, numa proporção 1 por 2 aproximadamente. A mesma proporção ocorreu quando da utilização da técnica de MQL em comparação com a condição a seco em ambas geometrias de aresta de corte. A técnica de MQL proporciona o mesmo nível de desgaste nas geometrias 1 e 2 . Observa-se que a técnica MQL reduz a abrasão, o que diminui o desgaste. De uma maneira geral, existe um consenso entre os diversos pesquisadores de que a técnica de MQL reduz a taxa de desgaste em comparação com a condição a seco.

Segundo PASHBY \& KHAMSEHZADEH (1990), as inclusões de $\mathrm{SiC}_{\mathrm{w}}$ aumentam a condutividade térmica e a dureza, mas, infelizmente a estabilidade química é reduzida, e há evidência de que isto influencia a taxa de desgaste. A taxa de desgaste da ferramenta CC670 foi superior em relação à ferramenta CC650, confirmando a inferioridade de estabilidade química e a resistência à abrasão. $\mathrm{O}$ desgaste por difusão foi considerado o desgaste predominante nas ferramentas CC670.

De acordo com NARUTAKI et al. (1993); ELBESTAWI et al. (1993) e JUN et al. (1997), o desgaste por difusão que pode acontecer na usinagem com alta velocidade utilizando ferramenta de $\mathrm{Al}_{2} \mathrm{O}_{3}+\mathrm{SiC}_{\mathrm{w}}$, no qual, o níquel e o ferro difundem para dentro do material da ferramenta reagindo quimicamente com $\mathrm{SiC}_{\mathrm{w}}$ produzindo $\mathrm{FeSi}$ e $\mathrm{NiSi}$. Isto significa que as fibras de $\mathrm{SiC}_{\mathrm{w}}$ desaparecem da superfície da ferramenta sob condição de alta velocidade de corte, diminuindo a resistência e a dureza da ferramenta e aumentando a taxa de desgaste. Isso confirma a notável presença do desgaste por difusão nas ferramentas de cerâmica (CC670). Por outro lado, JIANXIN \& XING (1997) revelaram que níquel e cromo foram difundidos para a superfície de saída da ferramenta acelerando a taxa de desgaste. Em algumas fotografias, o desgaste de flanco pode ser considerado como difusão ou abrasão na superfície de folga, principalmente nas ferramentas de cerâmica (CC670).

Nos testes de difusão, NARUTAKI et al. (1993) afirmam que não existe difusão quando utiliza ferramentas de cerâmica $\mathrm{Al}_{2} \mathrm{O}_{3}+\mathrm{TiC}$ (CC650), tornando-a mais estável na usinagem do Inconel 718 em relação às outras cerâmicas. Deste modo, as ferramentas cerâmicas $\left(\mathrm{Al}_{2} \mathrm{O}_{3}+\mathrm{TiC}\right)$ têm mais resistência ao desgaste por reação 
química na usinagem com alta velocidade de corte, o que foi confirmado também no presente trabalho. A boa estabilidade química das ferramentas cerâmicas CC650, aliada a uma melhoria da resistência ao choque térmico e mecânico através da adição de TiC, são características que, sem dúvida, beneficiam a situação com alta velocidade de corte.

GATTO \& IULIANO (1994), através de observações no microscópio eletrônico de varredura encontraram fibras de $\mathrm{SiC}$ fraturada na região dos lascamentos da ferramenta cerâmica CC670. Provavelmente, não ocorreu desgaste por difusão na ferramenta cerâmica CC650, mas nota-se a presença mais acentuada do mecanismo do tipo abrasão em comparação com a ferramenta cerâmica CC670.

$\mathrm{O}$ aspecto do desgaste encontrado na ferramenta de PCBN (CB50) de geometria redonda sob condição a seco pode ser observado na FIGURA 4.46. Devido ao baixo desempenho e o alto custo da ferramenta de PCBN redonda não foi possível realizar experimentos com a utilização da técnica de MQL. Desta forma, a confiabilidade na análise dos resultados pode ficar comprometida, pois não foram realizados repetições nos experimentos.

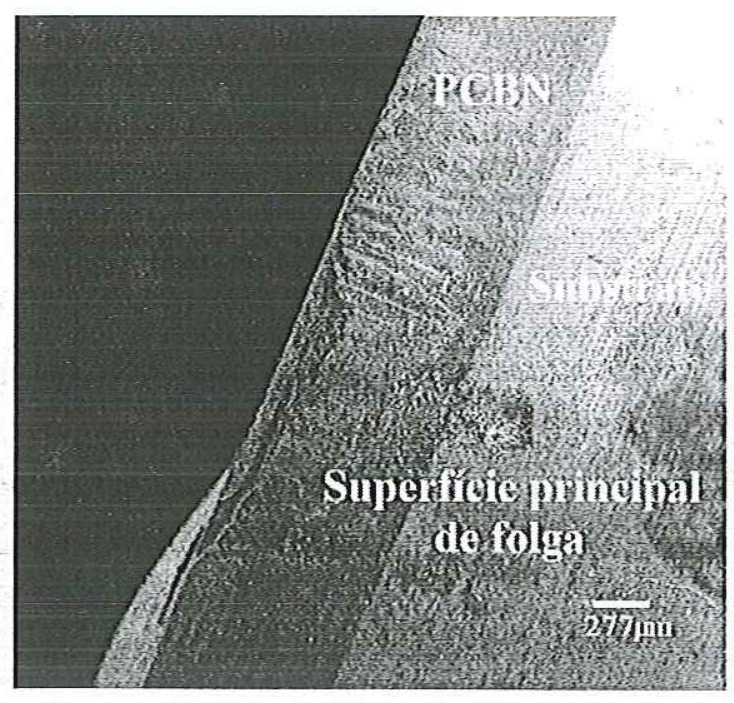

(a) Geometria 7 - 25X (após 32 segundos)

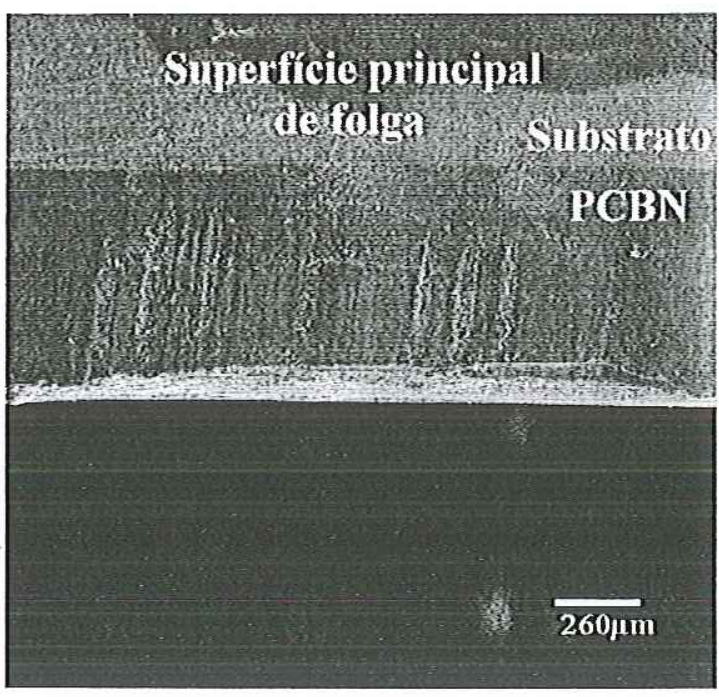

(b) Geometria 2 - 40X (após 31 segundos)

FIGURA 4.46 - Condição de Desgaste da Ferramenta de PCBN Redonda

$$
\left(V_{c}=500 \mathrm{~m} / \mathrm{min} ; \mathrm{f}=0,10 \mathrm{~mm} / \mathrm{rev} \text { e } a_{p}=0,35 \mathrm{~mm}\right) \text {. }
$$

Os efeitos das reações químicas ocorridas nas ferramentas de PCBN redonda foram diferentes dos efeitos das apresentadas nas geometrias triangular e quadrada. 
Para tal comportamento, ainda não foi encontrada uma justificativa, havendo necessidade de realizar mais uma série de experimentos para explicar tal fenômeno. É notável a diferença dos tipos de mecanismos de desgaste em comparação com as ferramentas de formato triangular e quadrado. O desgaste por difusão e entalhe, fortemente presente nas outras geometrias, na ferramenta redonda não foram apresentados.

A ferramenta de PCBN redonda apresenta menor evidência de lascamentos em relação às ferramentas triangular e quadrada da mesma classe. A geometria 2 apresenta desgaste inferior à geometria 7 (padrão). Para a maioria dos especialistas em ferramentas de corte, o processo de preparação de aresta, quando administrado corretamente, aumenta a resistência mecânica e de impacto da aresta de corte da ferramenta prolongando a sua vida.

As FIGURAS 4.47 a 4.49 representam os tipos de desgastes encontrados nas ferramentas cerâmicas (CC650 e CC670) e PCBN (CB7050) de geometria quadrada na condição a seco e com a utilização da técnica de MQL. Embora não representadas, as geometrias 1 e 2 apresentaram praticamente a mesma intensidade de desgaste. A ferramenta cerâmica CC670 proporciona maior taxa de desgaste em relação à ferramenta CC650.

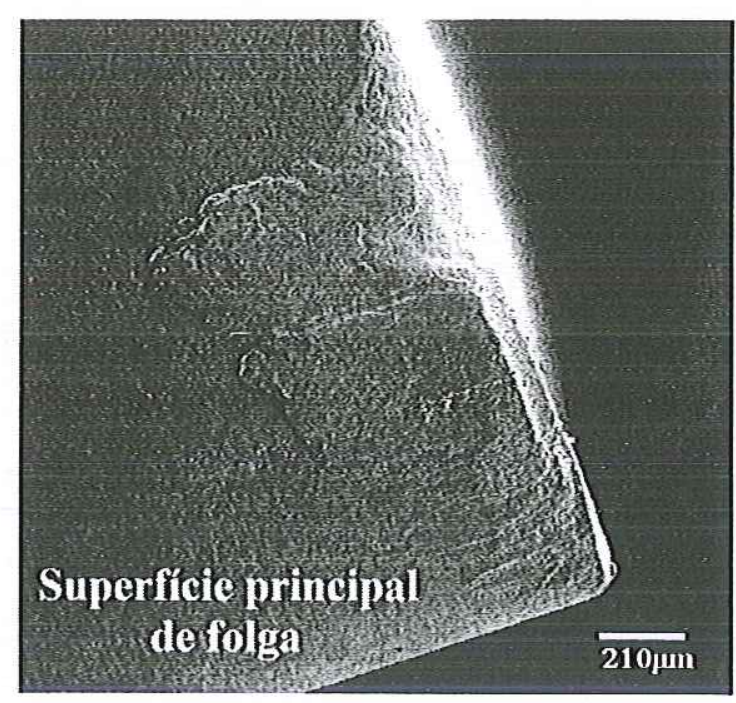

(a) Geometria 1 - 50X (após 48 segundos)

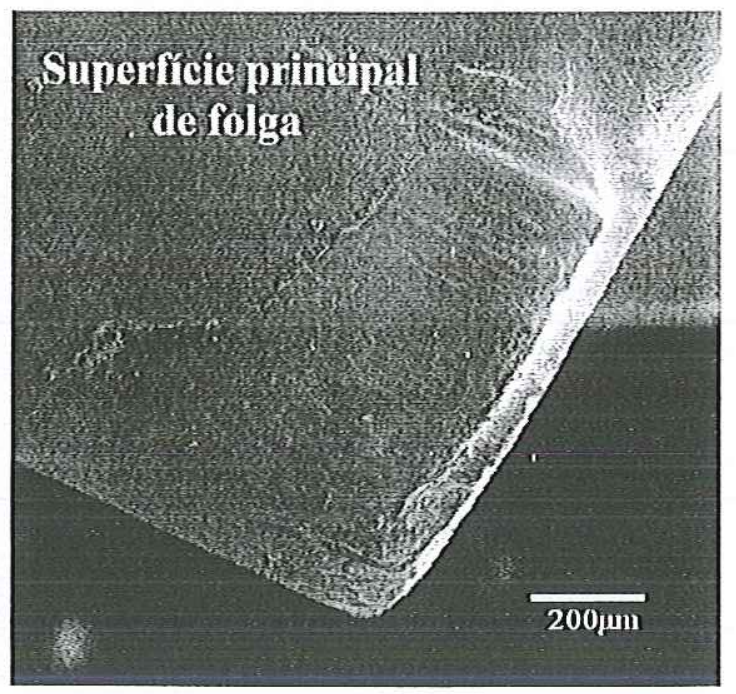

(b) Geometria 2 - 70X (após 49 segundos)

FIGURA 4.47 - Condição de Desgaste da Ferramenta Cerâmica CC650 Quadrada sem Refrigeração $\left(V_{c}=500 \mathrm{~m} / \mathrm{min} ; f=0,10 \mathrm{~mm} / \mathrm{rev}\right.$ e $\left.a_{p}=0,35 \mathrm{~mm}\right)$. 


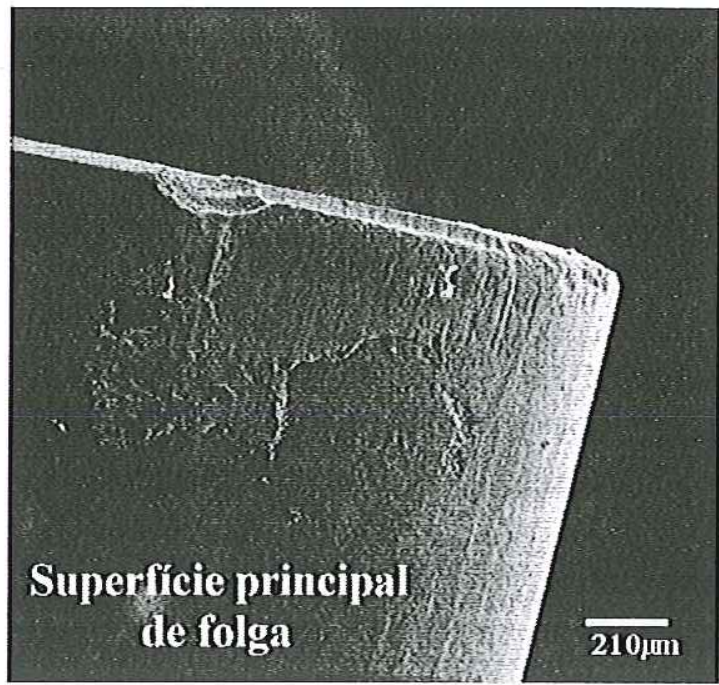

(a) Geometria 1 - CC650 (50X)

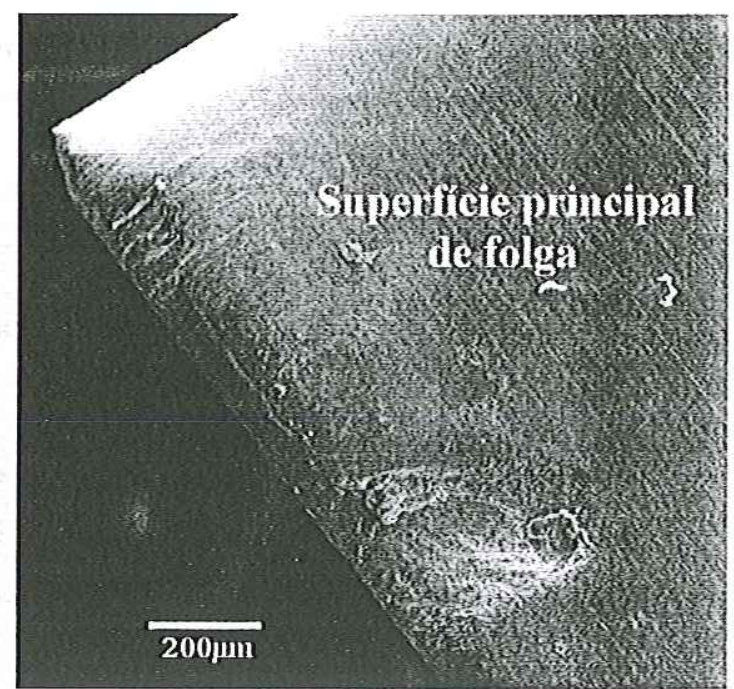

(b) Geometria 1 - CC670 (70X)

FIGURA 4.48 - Condição de Desgaste com Ferramentas de Cerâmicas Quadradas Utilizando MQL após 39 Segundos $\left(V_{c}=500 \mathrm{~m} / \mathrm{min} ; \mathrm{f}=0,10 \mathrm{~mm} / \mathrm{rev}\right.$ e $\left.\mathrm{a}_{\mathrm{p}}=0,35 \mathrm{~mm}\right)$.

Observa-se também em comparação as ferramentas cerâmicas triangulares a forte presença do desgaste de adesão ao longo da aresta de corte podendo ser observado tanto na condição a seco como na utilização de MQL. Isto sugere que o mecanismo de desgaste attrition (aderência com arrastamento) é o tipo de desgaste dominante nas ferramentas quadradas conduzindo para o desgaste de cratera e entalhe, principalmente na ferramenta CC650.

A ocorrência dos tipos de desgaste apresentados na geometria triangular esteve presente na geometria quadrada variando apenas a intensidade. Novamente, a limitação do desgaste se deu por desgaste de entalhe na altura da profundidade de corte associado aos desgastes por abrasão, difusão e "attrition" (aderência e arrastamento) envolvendo a perda de material por microsulcamento ou sulcos causado por partículas de elevada dureza. Nota-se a presença de lascamento na superfície de folga, na região de contato com a superfície usinada, devido provavelmente à alta deformação plástica favorecendo microlascamento e aderência no raio da ferramenta até a extremidade da profundidade de usinagem. Contudo, a região onde se concentram os microlascamentos é muito importante, devido ao contato íntimo com a superfície da peça acabada durante o corte, influenciando consequentemente na rugosidade superficial conforme pode ser comprovado nos gráficos de rugosidade superficial apresentado no item 4.3 . 
De acordo com GATTO \& IULIANO (1994), o aumento da deformação plástica tem grande influência do ângulo de posição, e que o ângulo de $45^{\circ}$ proporciona um aumento da deformação plástica.

Observando-se a influência da geometria sobre o desgaste de entalhe, pode-se verificar que a geometria redonda apresenta menor desgaste de entalhe seguida pela geometria triangular e quadrada.

De uma maneira geral, o desgaste de flanco das diversas ferramentas cerâmicas pode ser considerado como mecanismo por difusão. Segundo NARUTAKI et al. (1993), as ferramentas cerâmicas (CC650) têm melhor desempenho com velocidade de corte acima de $400 \mathrm{~m} / \mathrm{min}$ e alto avanço e ferramentas cerâmicas (CC670) são satisfatórias para velocidades na faixa de 100 - $400 \mathrm{~m} / \mathrm{min}$ com baixo avanço. Apesar das ferramentas cerâmicas serem conhecidas por sua estabilidade química, encontramse fortes indícios de mecanismos químicos em todas ferramentas e condições utilizadas. Este comportamento pode ser explicado pelo corte com alta velocidade gerar alta temperatura na região do corte.

Deve-se salientar que a geometria 2 apresenta menor evidência de lascamentos e desgaste de entalhe na maioria das ferramentas utilizadas. A presença do raio de aresta proporciona maior resistência mecânica e de impacto à aresta de corte.

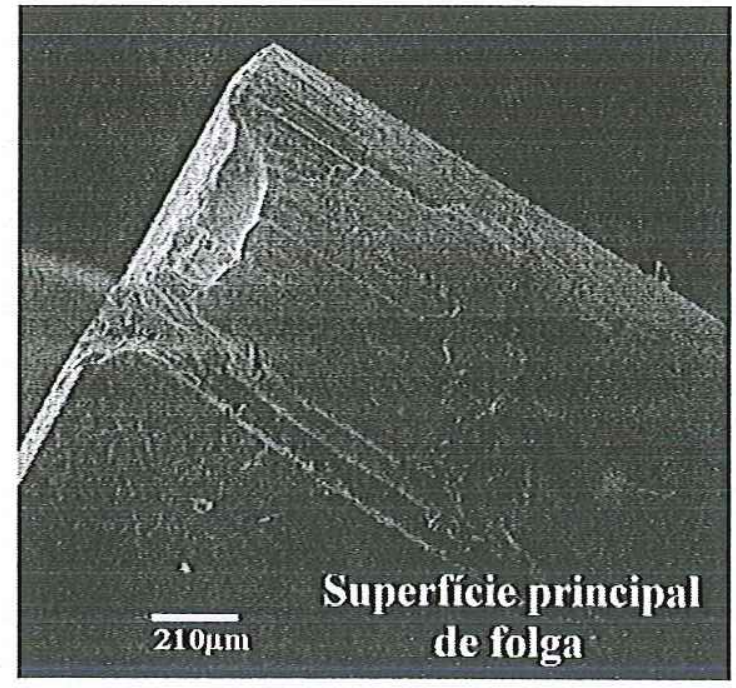

(a) Geometria 1 - 50X (após 47 segundos)

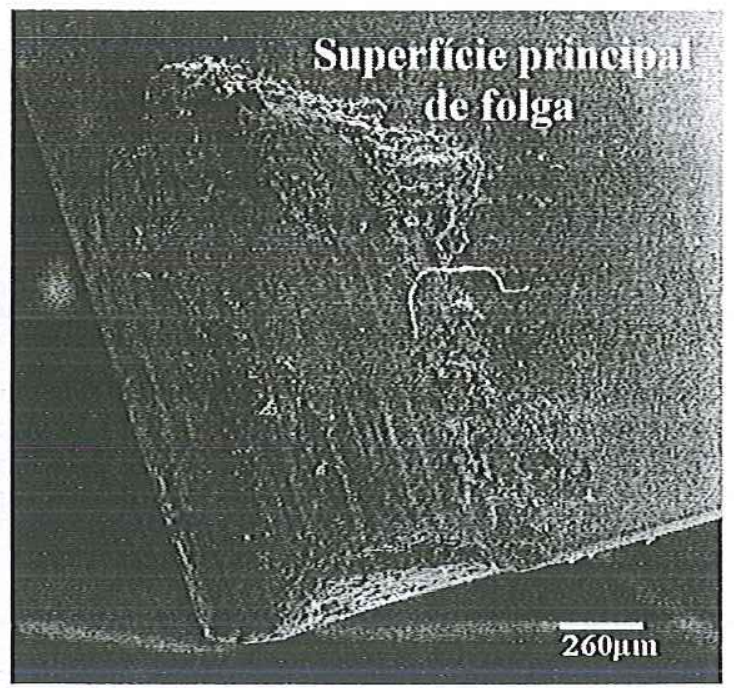

(b) Geometria 2 - 40X (após 46 segundos)

FIGURA 4.49 - Condição de Desgaste da Ferramenta de PCBN Quadrada sem Refrigeração $\left(V_{c}=500 \mathrm{~m} / \mathrm{min} ; \mathrm{f}=0,10 \mathrm{~mm} / \mathrm{rev}\right.$ e $\left.a_{p}=0,35 \mathrm{~mm}\right)$. 
$\mathrm{O}$ alto desgaste das ferramentas de PCBN pode ser atribuído à deterioração provocada pelas reações químicas que ocorrem em alta temperatura em virtude da alta velocidade. Novamente, as ferramentas de PCBN com concentração de $20 \%$ de CBN, apresentaram uma taxa de desgaste bem inferior às ferramentas com $50 \%$ de CBN. Por outro lado, o acabamento superficial foi muito inferior, por este motivo não foram apresentados resultados. De uma maneira geral, as ferramentas de PCBN com geometria 2 apresentaram menor taxa de desgaste em comparação com a geometria 1.

No geral, resultados satisfatórios são encontrados através da aplicação da tecnologia de MQL em todas as geometrias. As ferramentas cerâmicas demostraram maior resistência à difusão do que as ferramentas de PCBN.

As FIGURAS 4.50 e 4.51 revelam a influência do torneamento com rampa (conicidade de $0,1 \mathrm{~mm}$ em $185 \mathrm{~mm}$ ) sobre os mecanismos de desgaste nas ferramentas cerâmicas (CC650 e CC670) nos formatos triangular e redondo com geometria 1 sob condição de corte a seco.

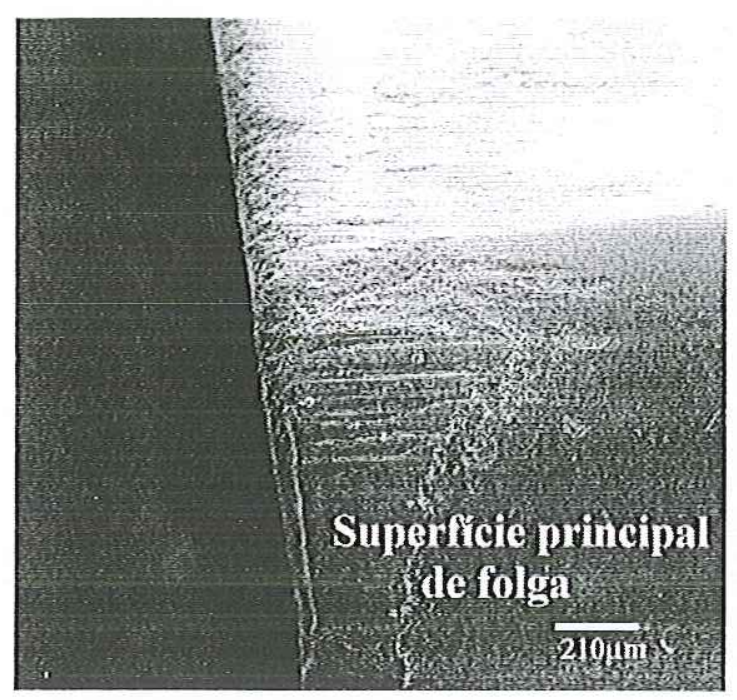

(a) Triangular - 50X (após 43 segundos)

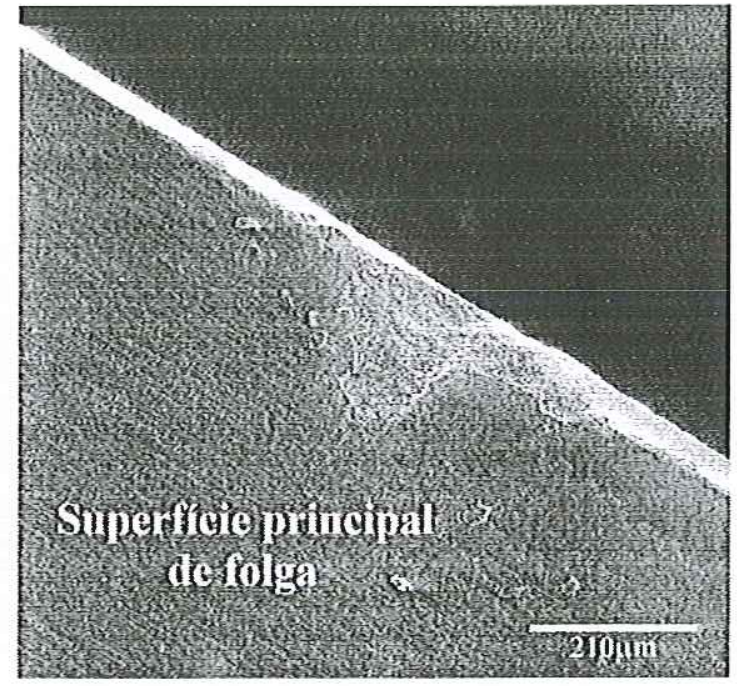

(b) Redonda - 100X (após 38 segundos)

FIGURA 4.50 - Condição de Desgaste com Ferramentas Cerâmicas (CC650) com Geometria $1\left(V_{c}=500 \mathrm{~m} / \mathrm{min} ; \mathrm{f}=0,10 \mathrm{~mm} / \mathrm{rev}\right.$ e $\left.\mathrm{a}_{\mathrm{p}}=0,35 \mathrm{~mm}\right)$. 


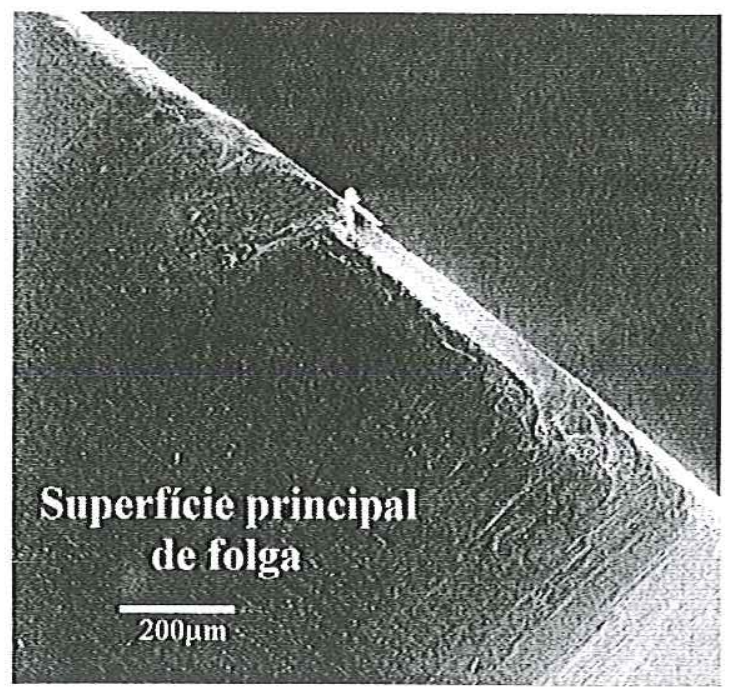

(a) Triangular - 70X (após 40 segundos)

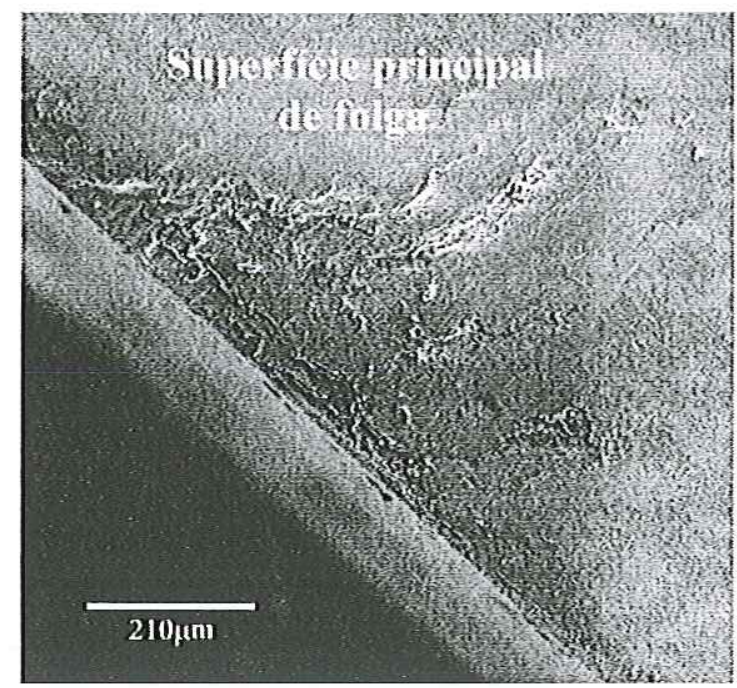

(b) Redonda - 100X (após 36 segundos)

FIGURA 4.51 - Condição de Desgaste de Ferramentas Cerâmicas (CC670) com Geometria $1\left(V_{c}=500 \mathrm{~m} / \mathrm{min} ; \mathrm{f}=0,10 \mathrm{~mm} / \mathrm{rev}\right.$ e $\left.\mathrm{a}_{\mathrm{p}}=0,35 \mathrm{~mm}\right)$.

O torneamento em rampa reduz grandemente ou elimina o desgaste do tipo entalhe atribuído como principal mecanismo de falha da ferramenta. Quando se aplicam técnicas de usinagem em rampa, os efeitos mais severos de desgaste da camada superficial mais dura, ainda estão presentes, claro, mas pode-se manifestar sob a forma de desgaste de flanco propagado uniformemente pela extensão da profundidade de usinagem acarretada pela ação de rampa. Esta técnica conduz para a troca constantemente da profundidade de corte ao longo da aresta de corte, distribuindo deste modo à concentração do desgaste de entalhe (SMITH, 1994 e EZUGWU et al. 1999).

Analisando-se os resultados apresentados pelo torneamento em paralelo, conclui-se que a usinagem em rampa reduziu o desgaste de entalhe e em alguns casos transformou-o em desgaste de flanco na extensão da profundidade de corte independentemente do material da ferramenta e da geometria utilizada.

\subsubsection{Waspaloy}

Considerando-se os melhores resultados obtidos na usinagem do Inconel 718, pôde-se apresentar objetivamente algumas fotografias por microscopia eletrônica de varredura das ferramentas desgastadas quando da usinagem da superliga Waspaloy. 
De uma maneira geral, existe um consenso entre os mecanismos de desgaste que ocorreram com as ferramentas utilizadas na usinagem da superliga Inconel 718, ou seja, os tipos de desgaste não são provenientes de um único mecanismo, mas sim de uma combinação de vários deles, variando apenas a intensidade. Assim também pensa ADDHOUM \& BROUSSAUD (1989), observando o mesmo comportamento do desgaste na usinagem das duas superligas. Devido à semelhança no comportamento dos mecanismos de desgaste, as discussões a seguir serão resumidas, para evitar repetições de comentários.

O aspecto do desgaste encontrado nas ferramentas cerâmicas (CC650 e CC670) de geometria triangular pode ser observado nas FIGURAS 4.52 e 4.53 . Devido à dificuldade de encontrar essa superliga, não foi possível repetir os testes na análise dos mecanismos de desgaste. Todos os testes foram realizados sob condição a seco. A taxa de desgaste apresentada pelo waspaloy foi inferior em relação a usinagem do Inconel $718 \mathrm{em}$ todos formatos e geometrias de aresta de corte. Provavelmente, o menor percurso de corte e a diferença de composição química foram responsáveis por tal fenômeno.

De uma maneira geral, resultados satisfatórios também foram encontrados através da utilização da ferramenta com geometria modificada (chanfro em $\mathrm{T}$ de $0,15 \mathrm{x}$ $15^{\circ}$ com raio de aresta de $\left.0,03 \mathrm{~mm}\right)$.

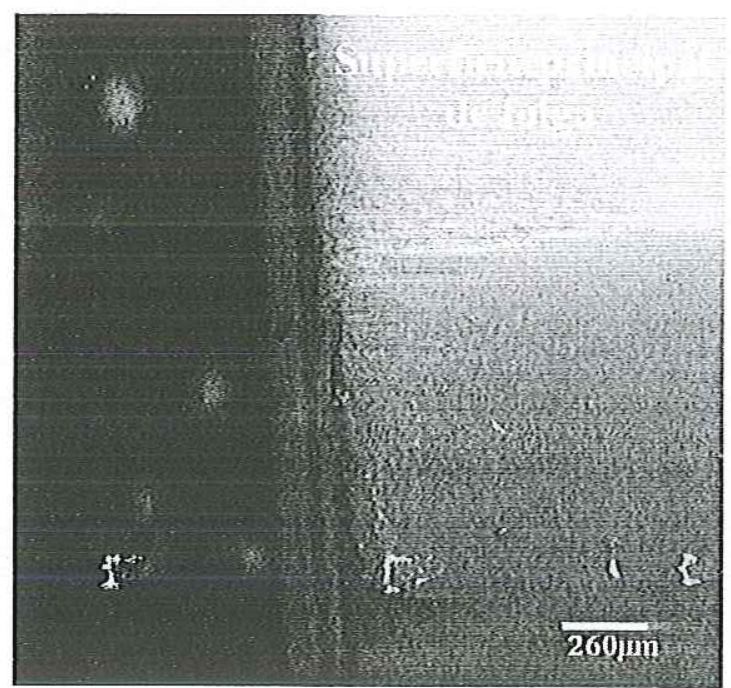

(a) Geometria 1 - 40X (após 23 segundos)

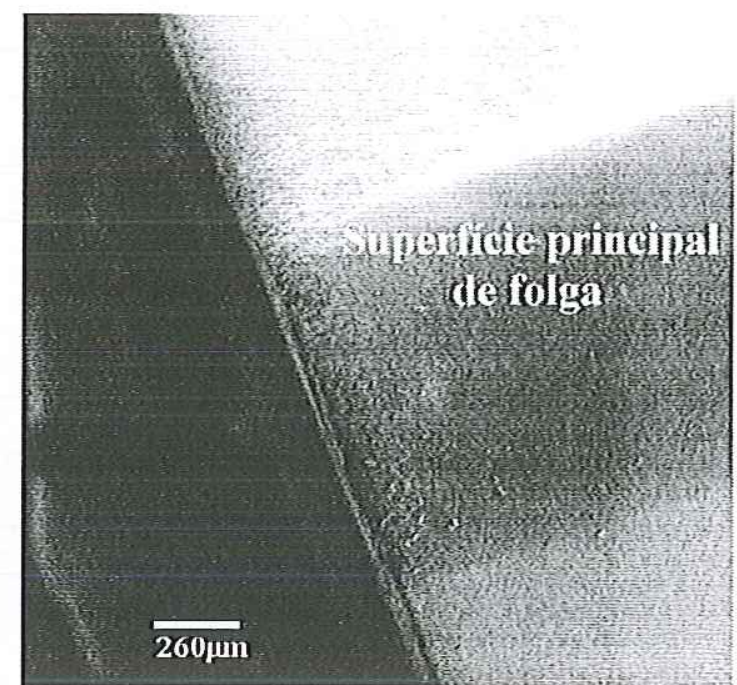

(b) Geometria 2 - 40X (após 23 segundos)

FIGURA 4.52 - Condição de Desgaste da Ferramenta Cerâmica CC650 Triangular $\left(V_{c}=500 \mathrm{~m} / \mathrm{min} ; \mathrm{f}=0,10 \mathrm{~mm} / \mathrm{rev}\right.$ e $\left.a_{p}=0,35 \mathrm{~mm}\right)$. 


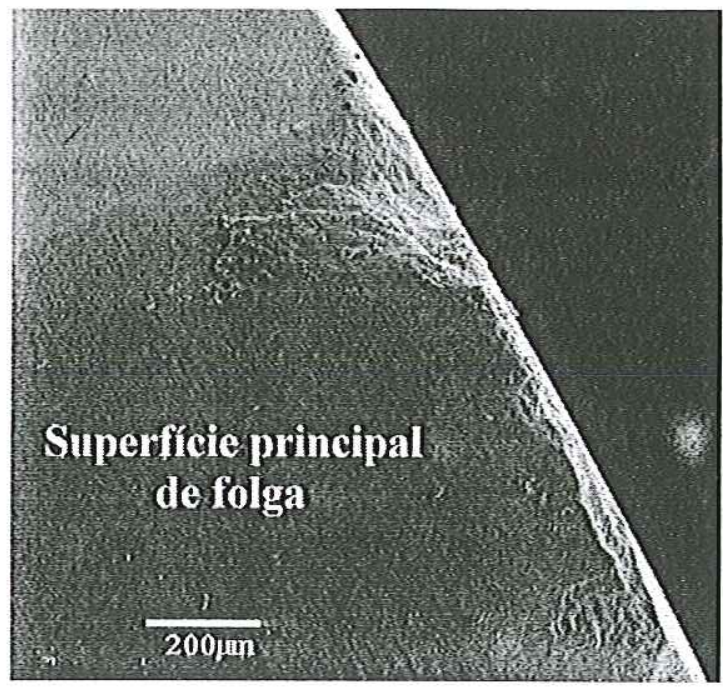

(a) Geometria 1 - 70X (após 25 segundos)

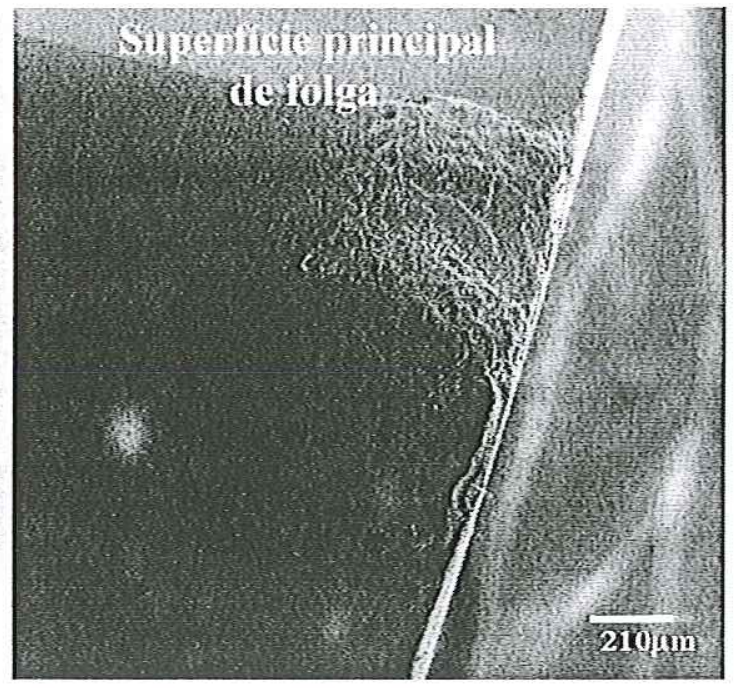

(b) Geometria 2 - 50X (após 24 segundos)

FIGURA 4.53 - Condição de Desgaste da Ferramenta Cerâmica CC670 Triangular $\left(V_{c}=500 \mathrm{~m} / \mathrm{min} ; \mathrm{f}=0,10 \mathrm{~mm} / \mathrm{rev}\right.$ e $\left.\mathrm{a}_{\mathrm{p}}=0,35 \mathrm{~mm}\right)$.

Não ocorreu fratura das ferramentas, onde, pode-se detectar uma boa estabilidade da aresta de corte quanto ao nível de tensões mecânica e térmica desenvolvidas na região do corte e da capacidade do material da ferramenta suportar essas tensões sem microfraturas em ambas superligas.

As geometrias 1 e 2 apresentaram praticamente o mesmo aspecto de desgaste em ambas cerâmicas. Novamente, a ferramenta cerâmica (CC650) mostra superioridade na usinagem com alta velocidade de corte em superligas, apresentando apenas desgaste de abrasão. As ferramentas CC670 apresentaram desgaste de difusão e microlascamento ao longo da aresta de corte. Provavelmente, ocorreu primeiramente desgaste de cratera e entalhe nas ferramentas cerâmicas CC670 seguido do mecanismo de difusão. De uma maneira geral, o aspecto do desgaste foi bem inferior em relação a usinagem do Inconel 718 em todas ferramentas.

Considerando-se o aspecto do desgaste obtido na usinagem do Inconel 718 e Waspaloy, pode-se sugerir objetivamente que as ferramentas de PCRN mostram-se competitivas no torneamento com alta velocidade da superliga Waspaloy quanto ao parâmetro mecanismos de desgaste. A presença forte do mecanismo de difusão na usinagem do Inconel 718 não foi observada no Waspaloy. Provavelmente, os mecanismos de desgaste por abrasão e difusão aparecem juntos nas ferramentas de PCBN. As geometrias 1 e 2 apresentaram praticamente o mesmo aspecto de desgaste. 
A FIGURA 4.54 representa os tipos de desgastes encontrados na ferramenta cerâmica (CC650) de geometria redonda.



(a) Geometria 1 - 70X (após 24 segundos)

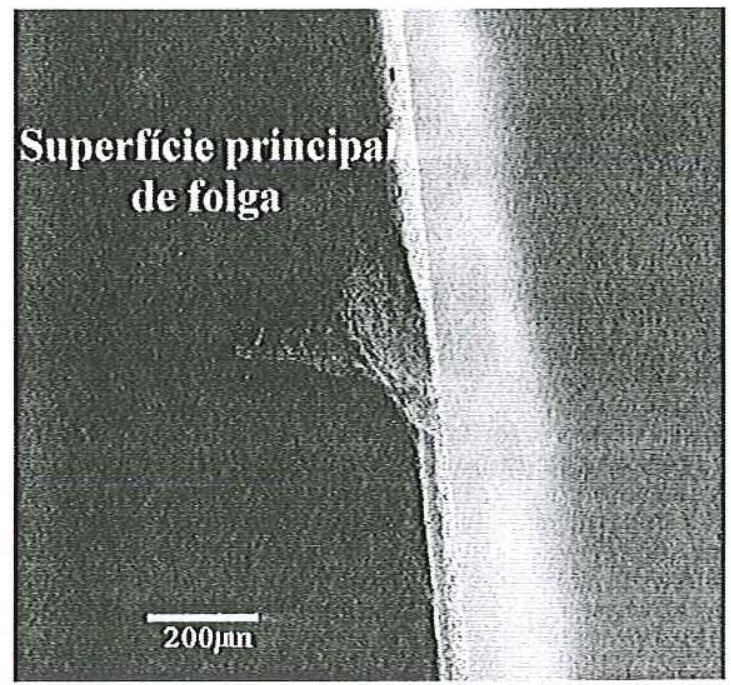

(b) Geometria 2 - 70X (após 23 segundos)

FIGURA 4.54 - Condição de Desgaste da Ferramenta Cerâmica CC650 Redonda $\left(V_{c}=500 \mathrm{~m} / \mathrm{min} ; \mathrm{f}=0,10 \mathrm{~mm} /\right.$ rev e $\left.a_{p}=0,35 \mathrm{~mm}\right)$.

Novamente, a associação dos desgastes por abrasão, "attrition" (aderência e arrastamento) e difusão esteve presente, mas em menor intensidade. A limitação da vida da ferramenta se deu por desgaste de entalhe na altura da profundidade de corte associados aos mecanismos citados. A geometria 1 apresentou maior indício de desgaste por difusão.

$\mathrm{O}$ aspecto do desgaste encontrado na ferramenta cerâmica (CC650) e na ferramenta de PCBN (CB7050) de geometria quadrada pode ser observado nas FIGURAS 4.55 e 4.56. 


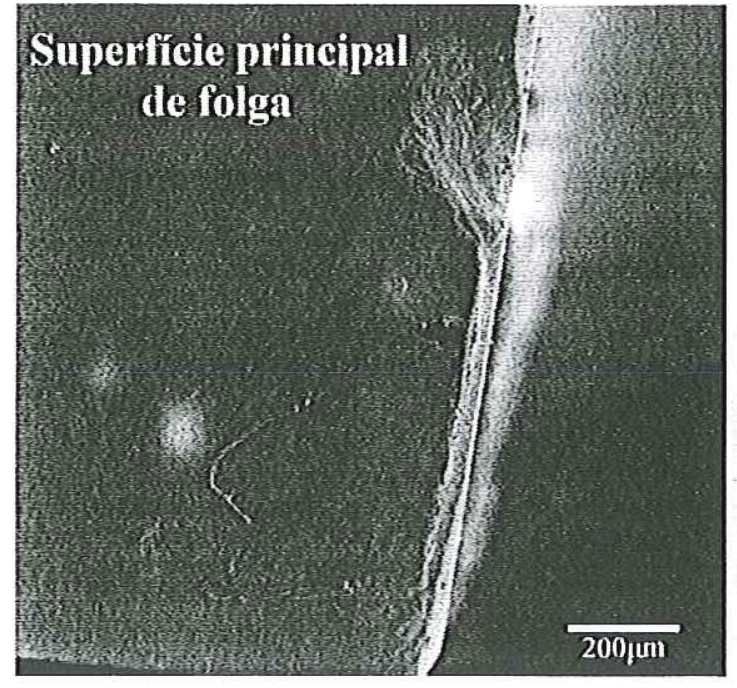

(a) Geometria 1 - 70X (após 24 segundos)

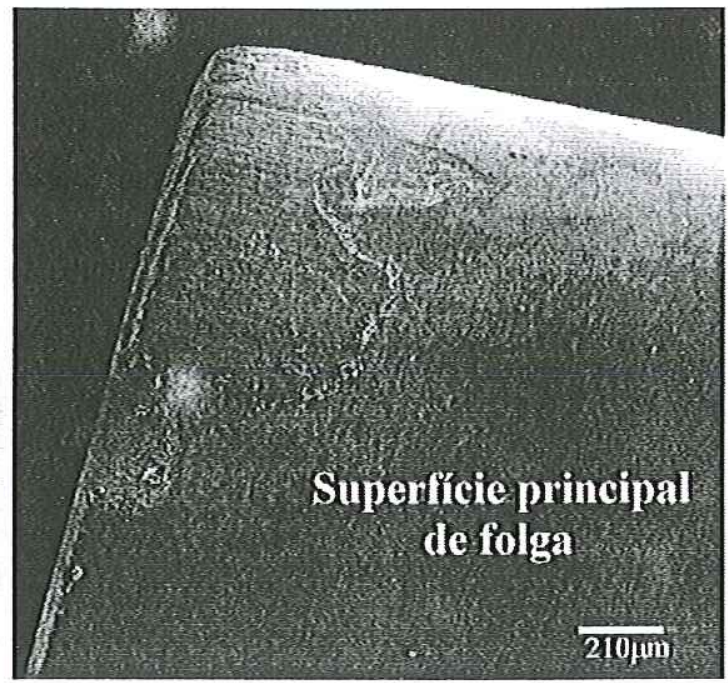

(b) Geometria 2 - 50X (após 23 segundos)

FIGURA 4.55 - Condição de Desgaste da Ferramenta Cerâmica CC650 Quadrada $\left(V_{c}=500 \mathrm{~m} / \mathrm{min} ; \mathrm{f}=0,10 \mathrm{~mm} / \mathrm{rev}\right.$ e $\left.\mathrm{a}_{\mathrm{p}}=0,35 \mathrm{~mm}\right)$.

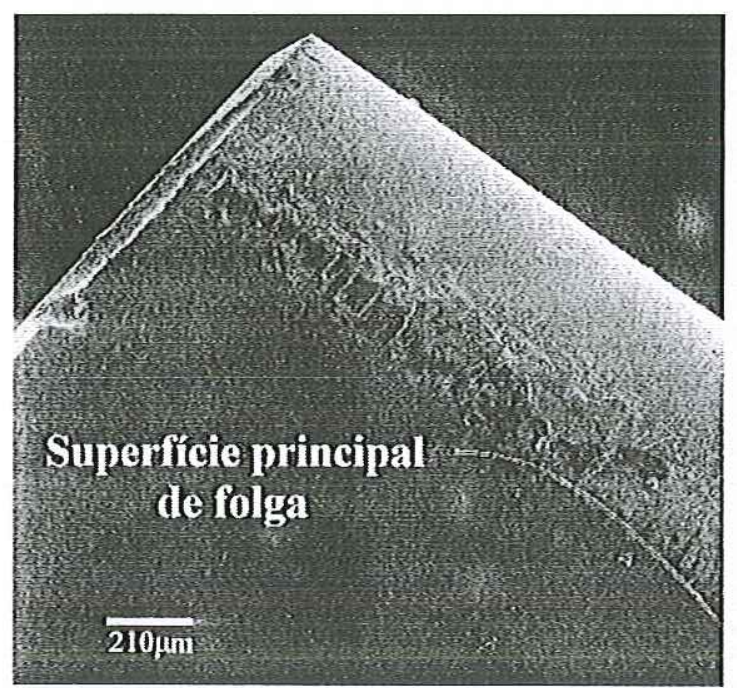

(a) Geometria 1 - 50X (após 22 segundos)

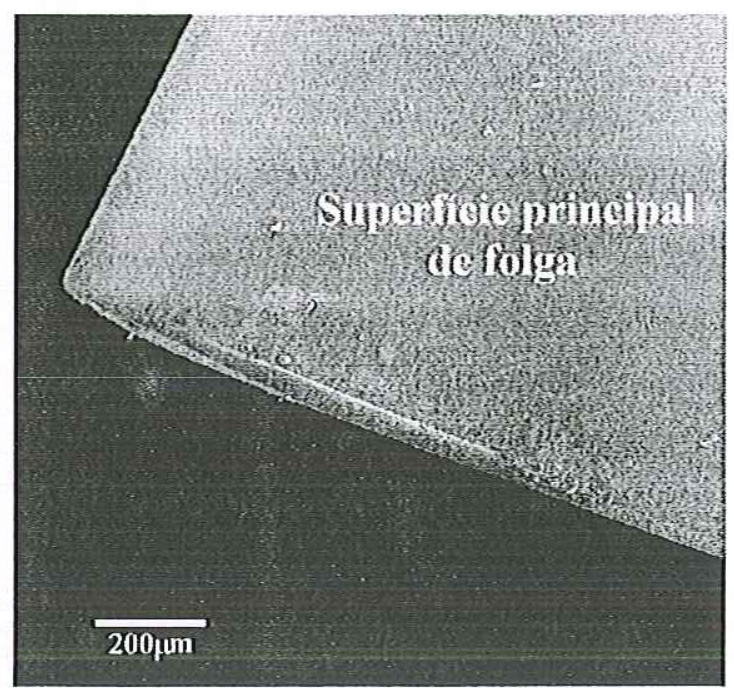

(b) Geometria 2 - 70X (após 22 segundos)

FIGURA 4.56 - Condição de Desgaste da Ferramenta de PCBN (CB7050) Quadrada $\left(V_{c}=500 \mathrm{~m} / \mathrm{min} ; \mathrm{f}=0,10 \mathrm{~mm} / \mathrm{rev}\right.$ e $\left.a_{p}=0,35 \mathrm{~mm}\right)$.

Em comparação com a usinagem do Inconel 718, observa-se também a forte presença do desgaste de adesão ao longo da aresta de corte podendo ser observado em ambas geometrias quando utilização da ferramenta cerâmica quadrada. Possivelmente, o mecanismo de desgaste attrition (aderência com arrastamento) é o tipo de desgaste dominante nas ferramentas quadradas conduzindo para o desgaste de cratera. De uma 
maneira geral, o aspecto final do desgaste de entalhe em todas ferramentas é do tipo difusão, tornando limitação dominante para a vida da ferramenta. A ocorrência dos tipos de desgaste apresentados na usinagem do Inconel 718 esteve presente no Waspaloy variando apenas a intensidade. Todavia, a boa estabilidade química das ferramentas cerâmicas não foi suficiente para evitar fortes indícios de mecanismo químico gerado pelas altas temperaturas na região do corte em ambas superligas.

A geometria 2 apresenta menor taxa de desgaste em comparação com a geometria 1. Novamente, a presença forte do mecanismo de difusão e microlascamento apresentados na usinagem do Inconel 718, não foi observada no Waspaloy. Provavelmente, a diferença de composição química e das propriedades mecânicas das superligas influenciaram nos mecanismos de desgaste das diversas ferramentas e geometrias testadas. 


\subsection{Rugosidade Superficial}

\subsubsection{Inconel 718}

Já é bastante conhecido que o acabamento superficial pode afetar significativamente a resistência dos componentes quando os mesmos são submetidos a ciclos de fadiga. Em geral, as superligas à base de níquel são utilizadas em componentes que exigem alta confiabilidade no que diz respeito ao limite de fadiga.

As FIGURAS 4.57 a 4.59 mostram a influência das geometrias nos valores médios do parâmetro $R_{a}(\mu \mathrm{m})$ em três pontos eqüidistantes do comprimento usinado para as ferramentas cerâmicas (CC650 e CC670) e PCBN nas geometrias triangular, redonda e quadrada na condição sem fluido e com utilização da técnica de MQL. Os gráficos a seguir, representam as geometrias que proporcionaram o melhor acabamento superficial. Foram efetuadas 09 medições na variação de $R_{a}$ no comprimento de $185 \mathrm{~mm}$, em seguida calculou-se a média representada nos gráficos seguintes.

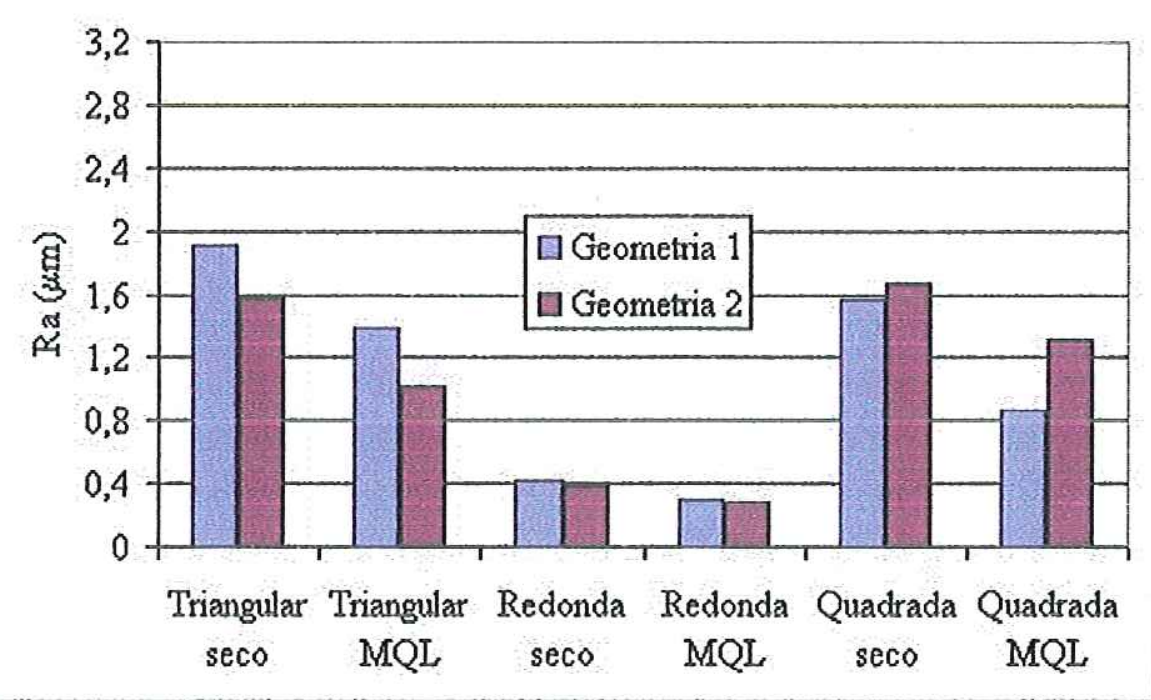

FIGURA 4.57 - Rugosidade Superficial $\mathrm{R}_{\mathrm{a}}$ Utilizando Ferramentas Cerâmicas CC650 - $\left(V_{c}=500 \mathrm{~m} / \mathrm{min} ; f=0,10 \mathrm{~mm} / \mathrm{rev}\right.$ e $\left.a_{p}=0,35 \mathrm{~mm}\right)$. 


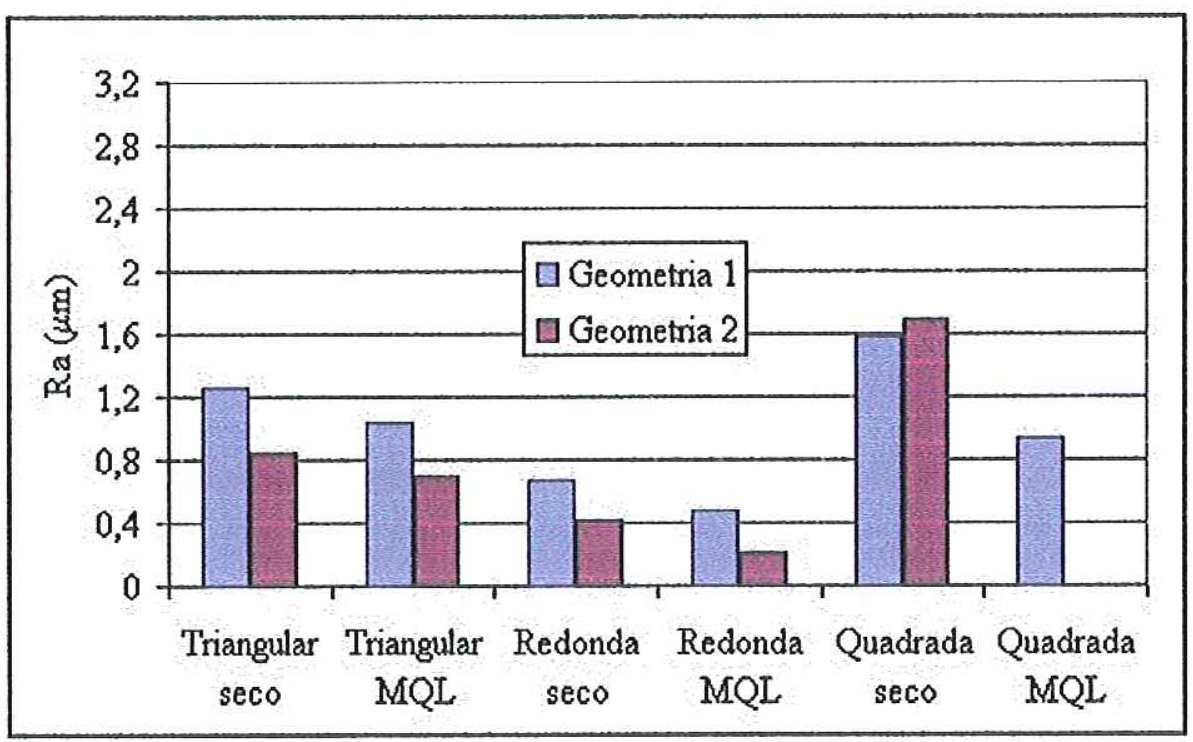

FIGURA 4.58 - Rugosidade Superficial $R_{a}$ Utilizando Ferramentas Cerâmicas CC670 - $\left(V_{c}=500 \mathrm{~m} / \mathrm{min} ; f=0,10 \mathrm{~mm} /\right.$ rev e $\left.a_{p}=0,35 \mathrm{~mm}\right)$.

Observando-se os resultados apresentados na condição sem fluido, é possível perceber que a ferramenta cerâmica redonda (CC650) obteve-se o menor valor de $\mathrm{R}_{\mathrm{a}}$ $(0,38 \mu \mathrm{m})$ seguida da ferramenta redonda CC670, ambas com geometria 2.

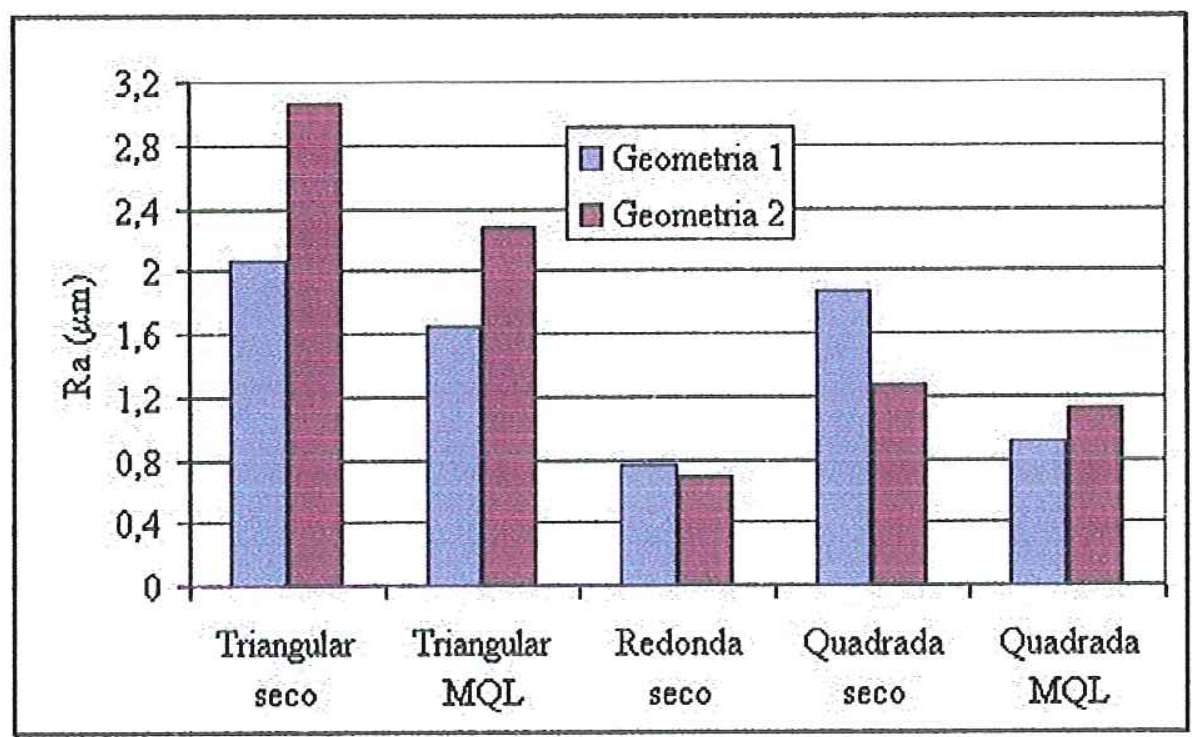

FIGURA 4.59 - Rugosidade Superficial $R_{a}$ Utilizando Ferramentas de PCBN $\left(V_{c}=500 \mathrm{~m} / \mathrm{min} ; f=0,10 \mathrm{~mm} / \mathrm{rev}\right.$ e $\left.a_{p}=0,35 \mathrm{~mm}\right)$.

Devido aos resultados insatisfatórios na condição de corte a seco e o alto custo da ferramenta de PCBN redonda, optou-se em não testá-la na utilização da técnica de MQL. 
Considerando-se os resultados obtidos nos diversos testes realizados no torneamento com alta velocidade, pode-se afirmar objetivamente que as ferramentas cerâmicas (CC650 e CC670) de formato quadrado com geometria 2 apresentaram pior desempenho quando comparada com a geometria 1 sob condição de corte sem fluido e com MQL. Todavia, quando da utilização de ferramentas de PCBN, não se obteve um comportamento padrão sob condição sem fluido e com MQL. Para tais resultados, ainda não foi encontrada uma justificativa.

Resultados satisfatórios na qualidade superficial são encontrados através da aplicação da técnica de MQL, nos quais os valores da rugosidade média ficaram na faixa de $0,29 \mu \mathrm{m}$ para a ferramenta cerâmica CC650 e $0,21 \mu \mathrm{m}$ para ferramenta cerâmica CC670, ambas com a geometria 2. Os valores alcançados de rugosidade superficial com MQL são comparáveis ao processo de retificação. A técnica de MQL proporciona uma melhoria na rugosidade de $30 \%$ nas ferramentas cerâmicas redondas com geometria 1 e de 25 a $50 \%$ na geometria 2 em relação à condição sem fluido. As demais geometrias também obtiveram ganhos na redução do parâmetro $R_{a}$ com a utilização da técnica de mínima quantidade de lubrificante, confirmando os efeitos significativos de refrigeração e lubrificação. A ferramenta cerâmica CC670 triangular com geometria 2 alcançou valor de $R_{a}$ de $0,69 \mu$ m com a técnica de $M Q L$, podendo atender a usinagem de algumas formas de peças que não fosse possível executar com a ferramenta redonda. Ferramentas de PCBN com geometria 2 apresenta pior desempenho em relação à geometria 1 quando da utilização da técnica de MQL. Deve-se salientar que, devida à pequena área de atuação do fluxo de ar/óleo no sistema MQL, o posicionamento do bico aspersor pode afetar significativamente a capacidade de lubrificação e consequentemente os valores da rugosidade superficial. Melhoria da qualidade superficial foi também alcançada por DÖRR \& SAHM (2000), utilizando a tecnologia HSM e MQL no fresamento de aço austenítico de níquel cromo trabalhando com $20 \mathrm{ml} / \mathrm{h}$ de lubrificante. WAKABAYASHI et al. (1998) revelaram eficiência da técnica de MQL quanto ao parâmetro $R_{a}$ no torneamento convencional do aço S45C. Observaram-se nos seus experimentos que $\mathrm{R}_{\mathrm{a}}$ permaneceu praticamente constante, o que não ocorreu sob condição sem fluido $\mathrm{e}$ com a refrigeração convencional. 
As ferramentas cerâmicas demonstraram melhor acabamento superficial em todas as geometrias utilizadas sob condição de corte sem fluido e com MQL quando comparadas com as ferramentas de PCBN. Possivelmente, os maiores valores de $\mathbf{R}_{\mathbf{a}}$ para as ferramentas de PCBN são devido aos maiores esforços de corte, proveniente da menor temperatura na região do corte, dificultando o cisalhamento do cavaco. DARWISH (1997) também afirma a superioridade do acabamento superficial da ferramenta cerâmica (CC680) com relação à ferramenta de PCBN (CB50), principalmente utilizando avanço para operação de acabamento.

Os valores de $R_{a}$ mostram uma tendência de crescimento com relação ao tempo de corte, ou seja, à medida que aumenta o comprimento usinado, os mesmos aumentam com a presença do desgaste. No início do corte os valores de $R_{a}$ foram bem inferiores ao final do corte, e algumas geometrias indicaram fusão superficial no material da peça no final do corte. As ferramentas redondas apresentaram um comportamento mais uniforme da rugosidade em todo comprimento usinado. De uma maneira geral, nota-se que a rugosidade superficial demonstra uma relação com o desgaste, o que está de consenso com vários pesquisadores. As ferramentas que obtiveram maior valor de rugosidade foram às ferramentas que apresentaram maior taxa de desgaste. Este comportamento está ligado à capacidade de cada ferramenta em manter a geometria da aresta de corte, à medida que o desgaste progride.

A ferramenta de PCBN triangular apresenta maior valor de rugosidade superficial tanto na condição sem fluido como na de MQL. Os valores de rugosidade superficial $R_{a}$ ficaram na faixa de 2,07 a 3,06 $\mu$ m sob condição sem fluido e 1,65 a $2,27 \mu \mathrm{m}$ com MQL. É notável a diferença entre as ferramentas de PCBN com concentração de 20 e $50 \%$ de $\mathrm{CBN}$, sendo esta última a melhor opção para o acabamento superficial.

Embora não representados graficamente todos os testes, as ferramentas com chanfro de aresta $\left(>20^{\circ}\right)$ apresentaram maior valor de rugosidade superficial em todas as ferramentas utilizadas. Chanfro de aresta $\left(\geq 30^{\circ}\right)$ proporciona alta taxa de fusão/adesão de material na superfície da peça. $O$ chanfro de aresta com $15^{\circ}$ teve melhor representação nos parâmetros avaliados. Todavia, raio de aresta $\geq 0,05 \mathrm{~mm}$ afeta negativamente $o$ acabamento superficial na usinagem das superligas. $O$ raio de aresta de melhor desempenho foi de aproximadamente $0,03 \mathrm{~mm}$. O raio de ponta $\left(\mathrm{r}_{\varepsilon}\right)$ 
da pastilha não influencia no acabamento superficial, provavelmente pelos baixos valores de profundidade de usinagem e avanço utilizados.

\subsubsection{Waspaloy}

As FIGURAS 4.60 e 4.61 mostram a influência das geometrias nos valores médios do parâmetro $R_{a}$ em três pontos eqüidistantes do comprimento usinado para as ferramentas cerâmicas (CC650 e CC670) e PCBN nas geometrias triangular, redonda e quadrada sob condição de corte sem fluido.

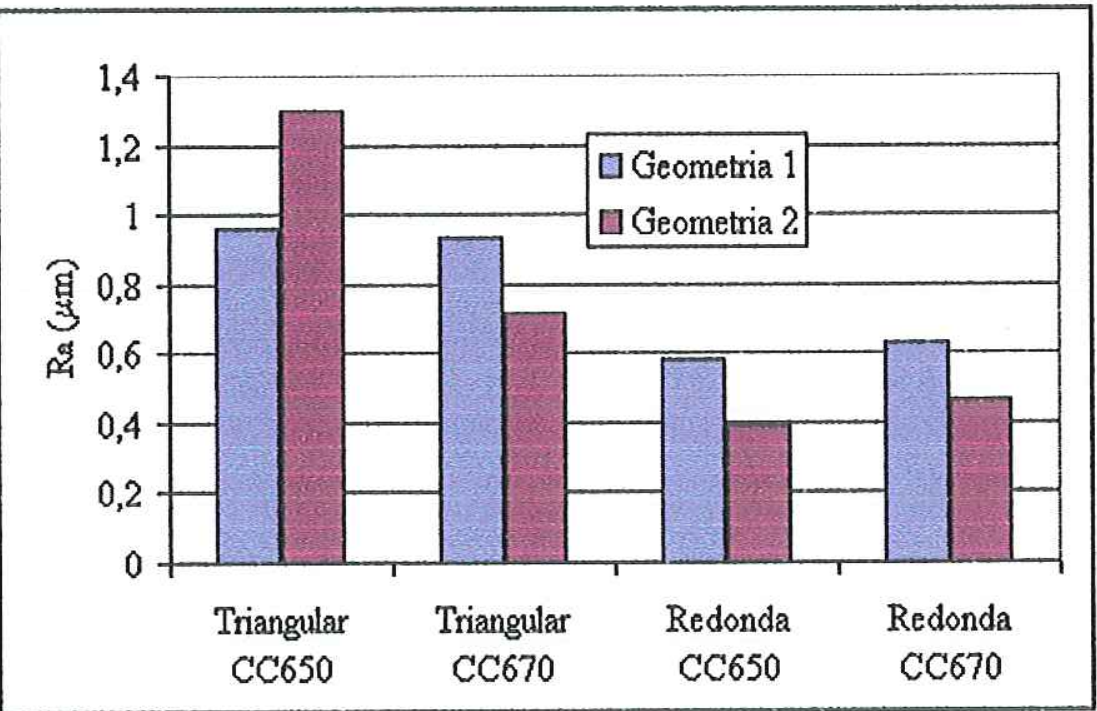

FIGURA 4.60 - Rugosidade Superficial $R_{a}$ Utilizando Ferramentas Cerâmicas $\left(\right.$ CC650 e CC670) - $\left(V_{c}=500 \mathrm{~m} / \mathrm{min} ; \mathrm{f}=0,10 \mathrm{~mm} / \mathrm{rev}\right.$ e $\left.a_{p}=0,35 \mathrm{~mm}\right)$.

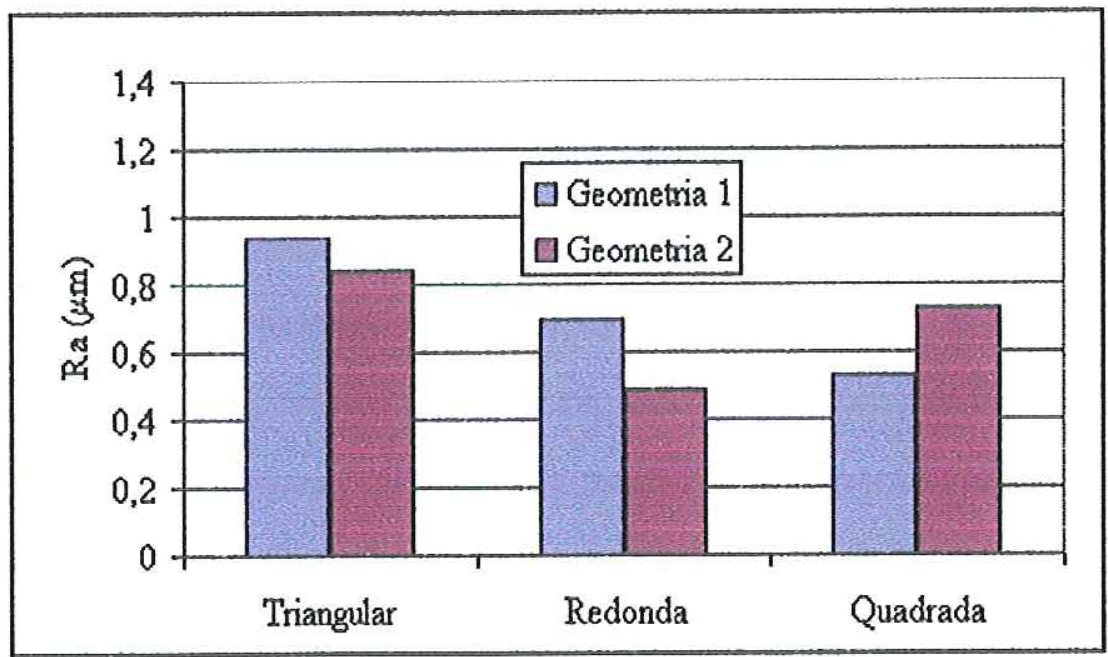

FIGURA 4.61 - Rugosidade Superficial $R_{a}$ Utilizando Ferramentas de PCBN $\left(V_{c}=500 \mathrm{~m} / \mathrm{min} ; f=0,10 \mathrm{~mm} / \mathrm{rev}\right.$ e $\left.a_{p}=0,35 \mathrm{~mm}\right)$. 
Observando-se os resultados apresentados, nota-se que a ferramenta cerâmica redonda (CC650) obteve o menor valor de $R_{a}(0,39 \mu \mathrm{m})$, seguida pela ferramenta cerâmica redonda (CC670) com $0,47 \mu \mathrm{m}$ e da ferramenta de PCBN redonda com $\mathrm{R}_{\mathrm{a}}=$ $0,49 \mu \mathrm{m}$ todas com geometria 2 . As ferramentas cerâmicas quadradas, apresentam um desempenho bem inferior em ambas geometrias de aresta de corte, por este motivo e devido à escassez da superliga Waspaloy, não foi apresentado graficamente. A ferramenta cerâmica triangular (CC650) com geometria 2, apresenta maior valor de rugosidade em relação a geometria 1 . O mesmo acontece com a ferramenta de PCBN quadrada. A geometria 2 foi superior nos demais formatos e classe de material.

O comportamento na usinagem do Inconel 718 foi diferente em relação as geometrias de melhor desempenho quando comparadas com o Waspaloy. As ferramentas triangular e quadrada apresentam menor valor de rugosidade superficial. Por outro lado, com ferramentas redondas os valores foram praticamente os mesmos. Provavelmente, a diferença do percurso de corte, da composição química e da dureza teve influência nos valores de rugosidade superficial.

A exemplo do Inconel 718 , os valores de $\mathrm{R}_{\mathrm{a}}$ mostram uma tendência de crescimento com relação ao tempo de corte. No início do corte, os valores de $R_{a}$ foram bem inferiores ao final do corte. As ferramentas redondas apresentam também um comportamento mais uniforme da rugosidade superficial. 


\subsection{Medição da tensão residual}

Os resultados a seguir referem-se às melhores condições de corte e geometria de arestas de corte encontradas no torneamento com alta velocidade de corte da superliga Inconel 718. Devido ao custo elevado das inspeções e o baixo desempenho das ferramentas de geometria quadrada, da ferramenta cerâmica CC650 triangular e das ferramentas de PCBN, quanto ao parâmetro rugosidade superficial, optou-se em não testá-las para a análise de tensão residual, microestrutura e microdureza. As condições de corte para a análise desses parâmetros foram: $V_{c}=500 \mathrm{~m} / \mathrm{min}, \mathrm{f}=$ $0,1 \mathrm{~mm} / \mathrm{rev}$ e $a_{p}=0,35 \mathrm{~mm}$. Novamente, por limitação da superliga Waspaloy, não foi possível realizar testes para a análise dos parâmetros citados para este material.

No decorrer dos testes, optou-se em testar a condição de $V_{c}=70 \mathrm{~m} / \mathrm{min}$, com o intuito de comparar o comportamento da velocidade de corte na integridade superficial. A análise desses parâmetros foi realizada após um percurso de corte de 43 metros.

A FIGURA 4.62 apresenta os valores de tensão residual obtidos nas amostras com ferramentas cerâmicas (CC650 e CC670) nas diversas geometrias sob condição a seco e com utilização da técnica de MQL.

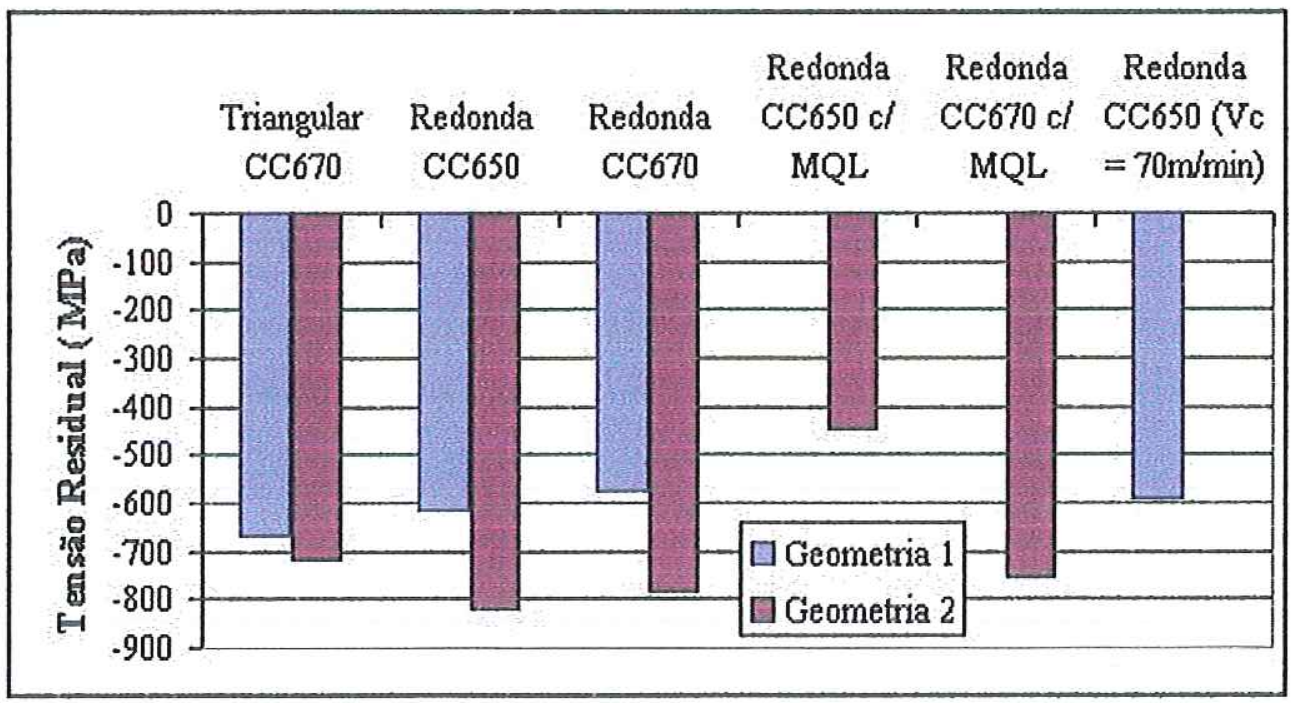

FIGURA 4.62 - Resultado Comparativo da Tensão Residual com Ferramentas

Cerâmicas a uma Profundidade Abaixo da Superficie de Aproximadamente $10 \mu \mathrm{m}$

$$
\left(V_{c}=500 \mathrm{~m} / \mathrm{min} ; \mathrm{f}=0,10 \mathrm{~mm} / \mathrm{rev} \text { e } a_{p}=0,35 \mathrm{~mm}\right) \text {. }
$$


Uma análise comparativa dos valores de tensão residual mostra que, em todas ferramentas, geometrias e condições de corte, obteve-se tensões residuais de compressão. Normalmente, o processo de torneamento conduz tensão de compressão principalmente quando da utilização de ferramentas desgastadas. Tensões residuais de compressão são consideradas benéficas nas propriedades mecânicas dos materiais, aumentando a resistência à fadiga tendo um grande impacto na vida dos componentes. Essas propriedades são importantes quando da utilização de superligas. Observa-se, que a geometria 2 (chanfro em T de $0,15 \times 15^{\circ}$ com raio de aresta de $0,03 \mathrm{~mm}$ ) proporciona maior valor de tensão de compressão em comparação com a geometria 1, o que é benéfico. Essa diferença é mais representativa quando da utilização de ferramentas redondas, sendo que as mesmas revelam um acréscimo de $35 \%$ em relação a geometria 1 . Deve-se salientar que, a utilização da superliga Inconel 718 está concentrada em componentes que trabalham à altas temperaturas, requerendo excelente resistência mecânica, onde as propriedades da superficie são suscetíveis à fadiga, tensão residual e corrosão revelando um grande impacto na vida dos componentes em serviço. MATSUMOTO et al. (1999) e THIELE \& MELKOTE (1999) revelaram resultados semelhantes no torneamento de aço endurecido, encontrando maior valor de tensão de compressão quando da utilização da ferramenta com raio de aresta em relação à ferramenta com quina viva. A geometria da aresta de corte é um fator determinante no perfil da tensão residual.

Em comparação com a usinagem a seco, confirma-se uma redução nos valores de tensão residual com o emprego da técnica de MQL, principalmente para a ferramenta cerâmica CC650. O maior valor da tensão residual foi apresentado pela ferramenta redonda seguido pela ferramenta triangular, todas com geometria 2 .

Analisando os resultados apresentados para baixa e alta velocidade de corte, pode-se afirmar que a usinagem com alta velocidade não afeia negativamente a integridade superficial. Nota-se que não ocorreram alterações significativas nos valores de tensão residual, quando da utilização das duas classes de cerâmica.

\subsection{Avaliação visual da microestrutura após a usinagem}

As FIGURAS 4.63 a 4.66 mostram os resultados referentes às observações de alterações subsuperficiais produzidas com ferramentas cerâmicas (CC650 e CC670) 
de formato redondo na condição a seco e com utilização da técnica de MQL após um percurso de corte de 43 metros.

Observa-se que as alterações subsuperficiais causadas com as diversas geometrias foram mínimas, não havendo diferenças significativas entres as geometrias 1 e 2 e a classe de material da ferramenta. Devido à elevada dureza do material, encontrou-se certa dificuldade durante o lixamento e polimento manual de forma à garantir a planicidade das amostras para a ampliação desejada. Dificuldades também foram encontradas para a realização do ataque, no qual foram testados diversos tipos de ataque. Uma discreta diferença de tempo e concentração já apresentava ataques diferenciados.

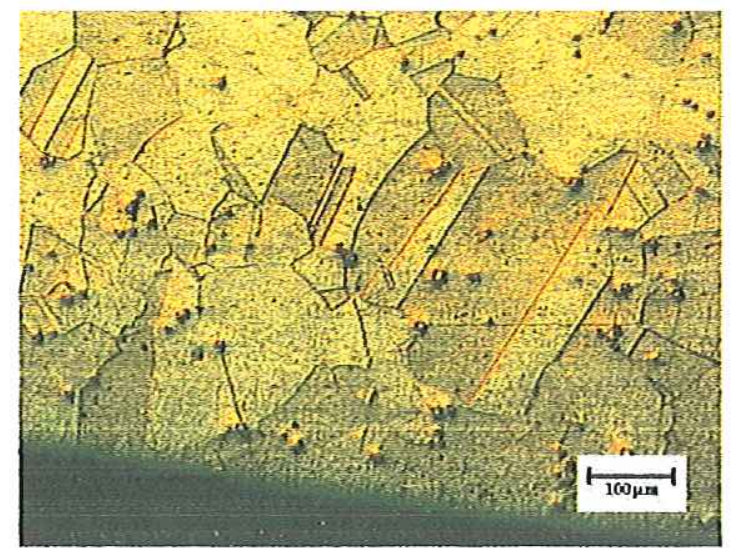

(a) Geometria 1

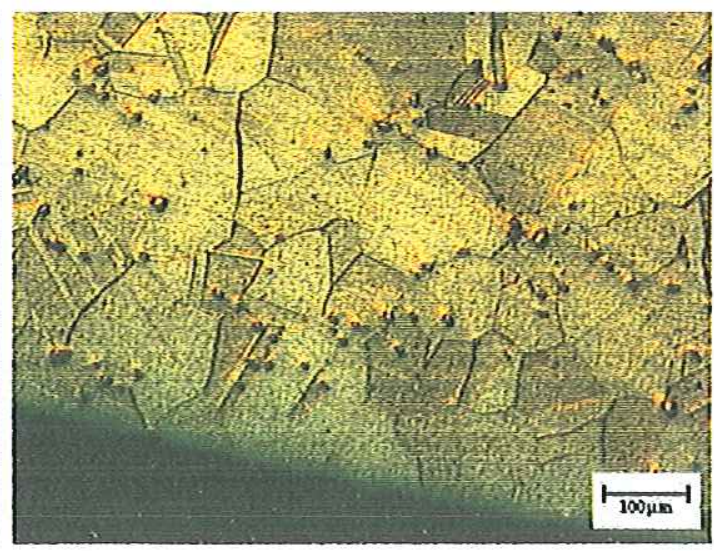

(b) Geometria 2

FIGURA 4.63 - Microestruturas Subsuperficiais Obtidas com Ferramenta Cerâmica Redonda CC670 sem Refrigeração (x100)

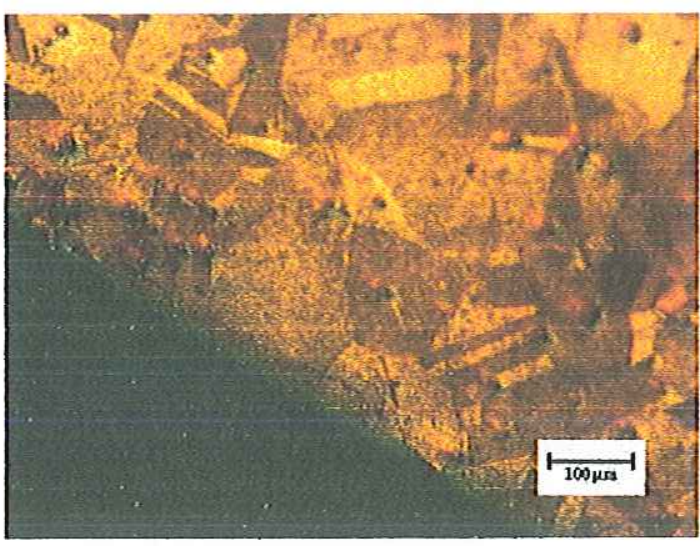

(a) Geometria 1

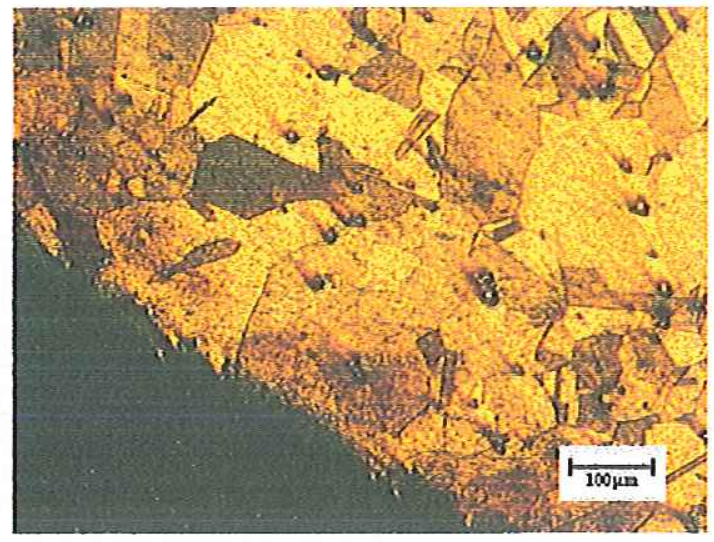

(b) Geometria 2

FIGURA 4.64 - Microestruturas Subsuperficiais Obtidas com Ferramenta Cerâmica Redonda CC650 sem Refrigeração (x100). 
As alterações metalúrgicas evidentes com as diversas ferramentas redondas sob condição a seco ficaram essencialmente restritas às variações na microestrutura. Nota-se que não foram observadas alterações subsuperficiais significativas, quando da utilização das classes de cerâmicas e das geometrias 1 e 2. Segundo EZUGWU et al. (1999), melhoria do acabamento superficial e mínima camada danificada podem ser obtidos com utilização de insertos redondos, o que foi confirmado no presente trabalho.



(a) Cerâmica CC670

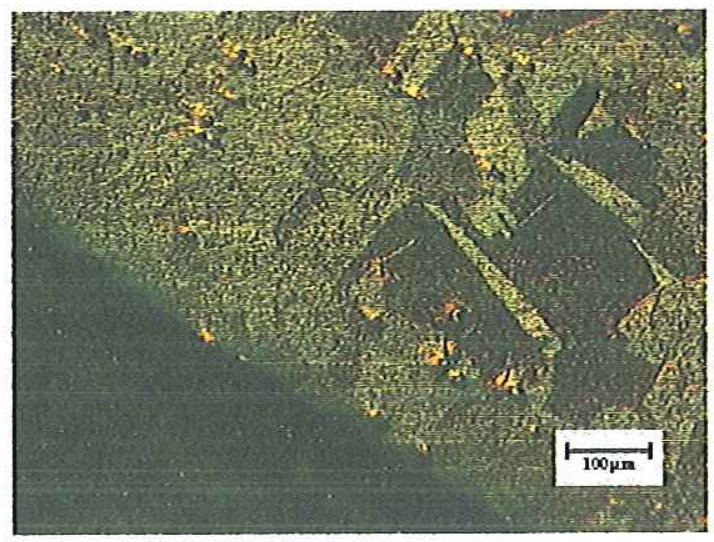

(b) Cerâmica CC650

FIGURA 4.65 - Microestruturas Subsuperficiais Obtidas com Ferramentas Redondas de Cerâmica/Geometria 2 Utilizando MQL (x100).

Analisando-se as microestruturas quando da usinagem a seco, não se nota indícios de alterações subsuperficiais na microestrutura com o emprego da técnica de MQL. Este comportamento pode ser explicado pela fadiga térmica, ou seja, a ação do refrigerante/lubrificante objetiva atuar no sentido de evitar o aquecimento da ferramenta, uma vez que o bico aspersor foi direcionado para a superfície de saída/interface. Além disso, devida à pequena área de atuação do fluxo de ar/óleo no sistema MQL, o posicionamento do bico aspersor pode afetar significativamente a capacidade de refrigeração. Provavelmente, a influência da técnica de MQL foi mínima em relação à peça, sugerindo a utilização de mais um bico aspersor para o resfriamento da peça. 


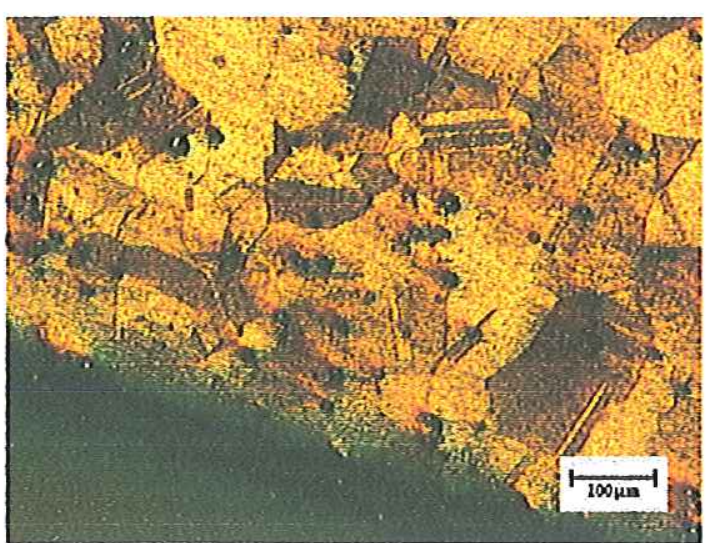

(a) Alterações subsuperficiais

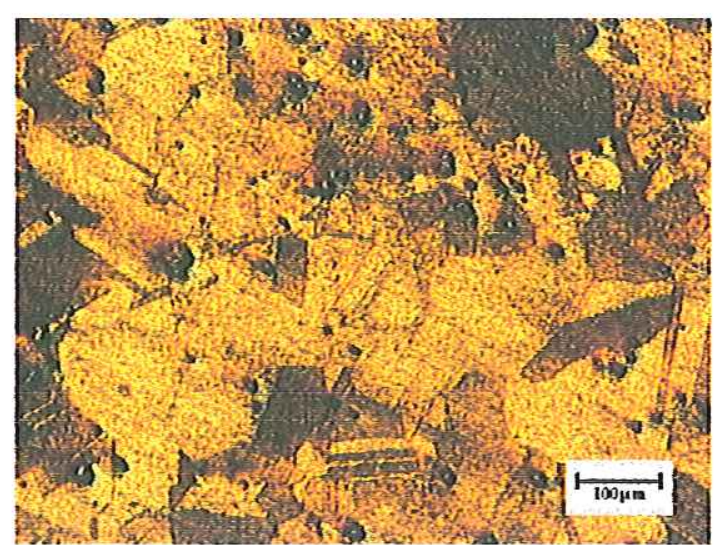

(b) Região central da amostra

FIGURA 4.66 - Microestruturas Subsuperficiais Causadas com Ferramenta Cerâmica CC650/Geometria 1 sem Refrigeração com $V_{c}=70 \mathrm{~m} / \mathrm{min}(\mathrm{x} 100)$.

Devido ao menor custo da ferramenta cerâmica CC650 redonda em comparação com outras ferramentas e o bom desempenho nos parâmetros avaliados anteriormente, optou-se testá-la na condição de baixa velocidade de corte. A microestrutura apresentada quando se utiliza baixa velocidade de corte, assemelha-se com a usinagem com alta velocidade. Isto, novamente, confirma que HSM não afeta negativamente a integridade superficial, reforçando o resultado da análise de tensão residual.

A FIGURA 4.67 representa as alterações subsuperficiais produzidas com ferramenta cerâmica CC670 de geometria triangular na condição a seco.

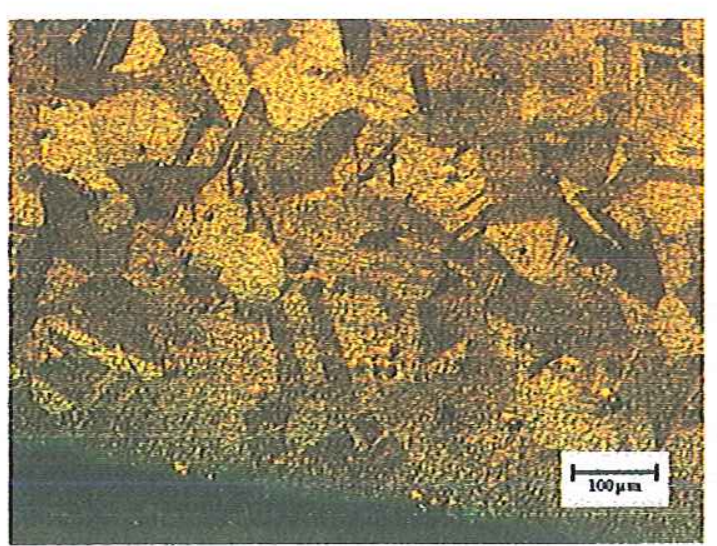

(a) Geometria 1

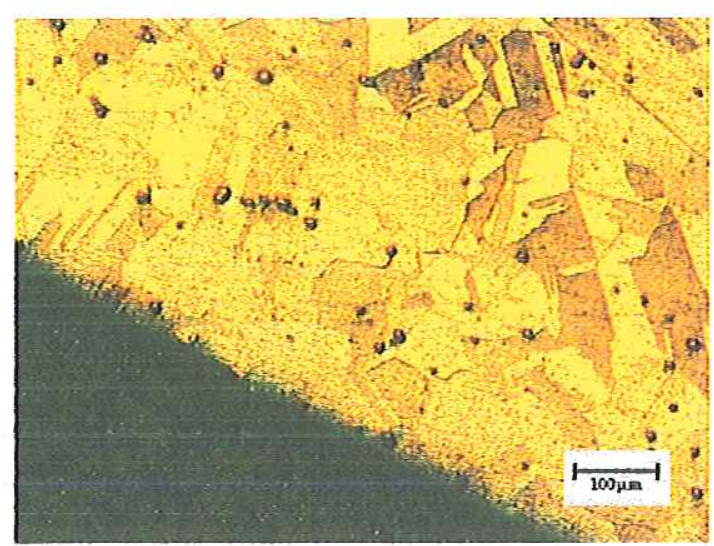

(b) Geometria 2

FIGURA 4.67 - Microestruturas Subsuperficiais Obtidas com Ferramenta Cerâmica Triangular CC670 sem Refrigeração (x100). 
Novamente, não foi possível detectar alterações subsuperficiais quando da utilização das geometrias 1 e 2 . As ferramentas redondas e triangulares apresentaram praticamente as mesmas microestruturas. Analisando-se finalmente os resultados apresentados nas figuras anteriores, pode-se afirmar que as alterações subsuperficiais causadas durante a usinagem com alta velocidade foram mínimas quando comparadas com informações publicadas por diversos pesquisadores na usinagem com velocidade convencional. Provavelmente, a ordem de grandeza do calor ou deformação plástica que foi para a peça, se tratando de operação de acabamento, não foi suficiente para produzir alterações subsuperficiais na microestrutura do material. Deve-se salientar que a baixa condutividade térmica do Inconel 718 tem influência direta na microestrutura. Além disso, a incidência de danos térmicos no torneamento com alta velocidade de corte é mínima.

\subsection{Medição da microdureza}

De forma a reforçar as informações apresentadas nas micrografias, foram realizadas medições de microdureza. As FIGURAS 4.68 a 4.71 representam a variação da microdureza com a profundidade abaixo da superficie usinada utilizando ferramentas cerâmicas (CC670 e CC650) redonda na condição a seco e com utilização da técnica de MQL.

Os valores médios encontrados na medição da microdureza sob condição a seco com ferramenta redonda foram de $511 \mathrm{HV}_{0,10}$ para a ferramenta cerâmica CC670 com geometria 1 e $500 \mathrm{HV}_{0,10}$ para a geometria 2. A ferramenta cerâmica CC650 apresentou valor médio de $529 \mathrm{HV}_{0,10}$ para a geometria 1 e $512 \mathrm{HV}_{0,10}$ para a geometria 2. Quando da utilização da $V_{c}=70 \mathrm{~m} / \mathrm{min}$, o valor médio encontrado foi de $531 \mathrm{HV}_{0,10}$. Os valores encontrados com o uso da técnica de MQL foram de 528 $\mathrm{HV}_{0,10}$ para a ferramenta CC670 e $519 \mathrm{HV}_{0,10}$ para CC650, ambas com geometria 2. A ferramenta triangular CC670 apresentou valores médios de $533 \mathrm{HV}_{0,10}$ com geometria 1 e $525 \mathrm{HV}_{0,10}$ para a geometria 2. Embora não representado graficamente, as medições de microdureza foram até a profundidade de $700 \mu \mathrm{m}$, com o intuito de encontrar alterações subsuperficiais, não revelando a partir de $350 \mu \mathrm{m}$ variações significativas. Por outro lado, deve-se observar que, todos os valores encontrados na 
medição da microdureza foram superiores a média da dureza do material base no início da usinagem (425 HV).

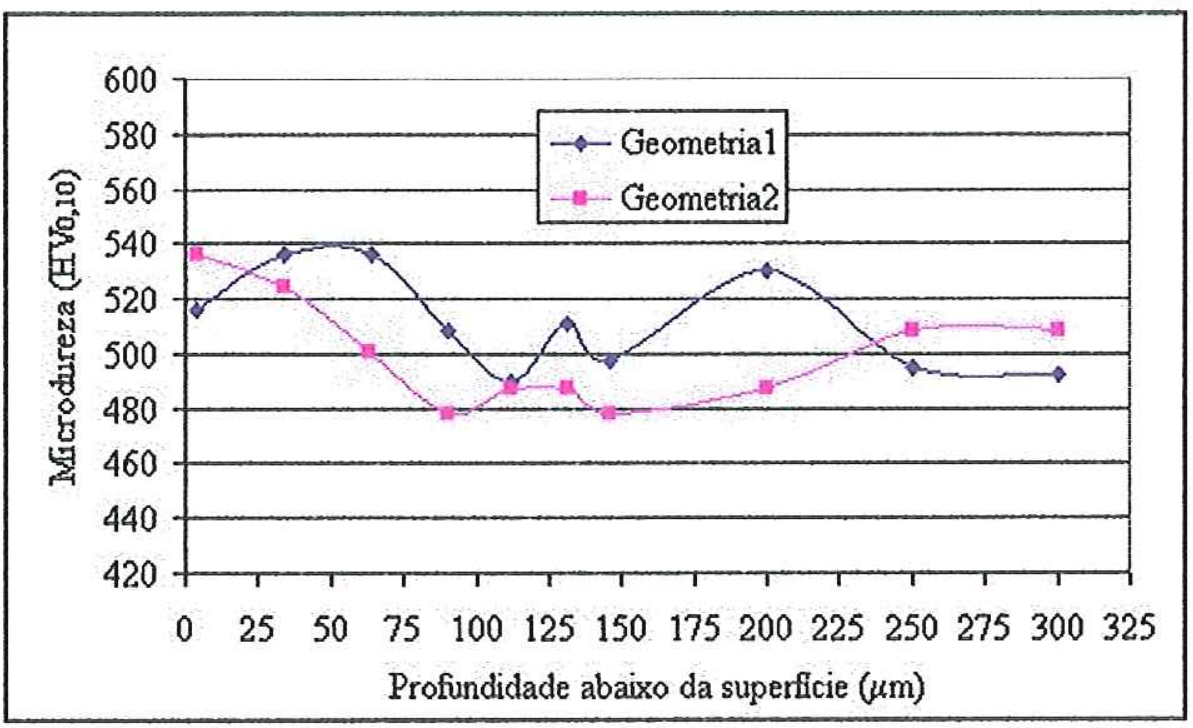

FIGURA 4.68 - Variação da Microdureza em Função da Profundidade Abaixo da Superficie com Ferramenta Cerâmica Redonda CC670 sem Refrigeração $\left(V_{c}=500 \mathrm{~m} / \mathrm{min} ; f=0,10 \mathrm{~mm} / \mathrm{rev}\right.$ e $\left.a_{p}=0,35 \mathrm{~mm}\right)$.

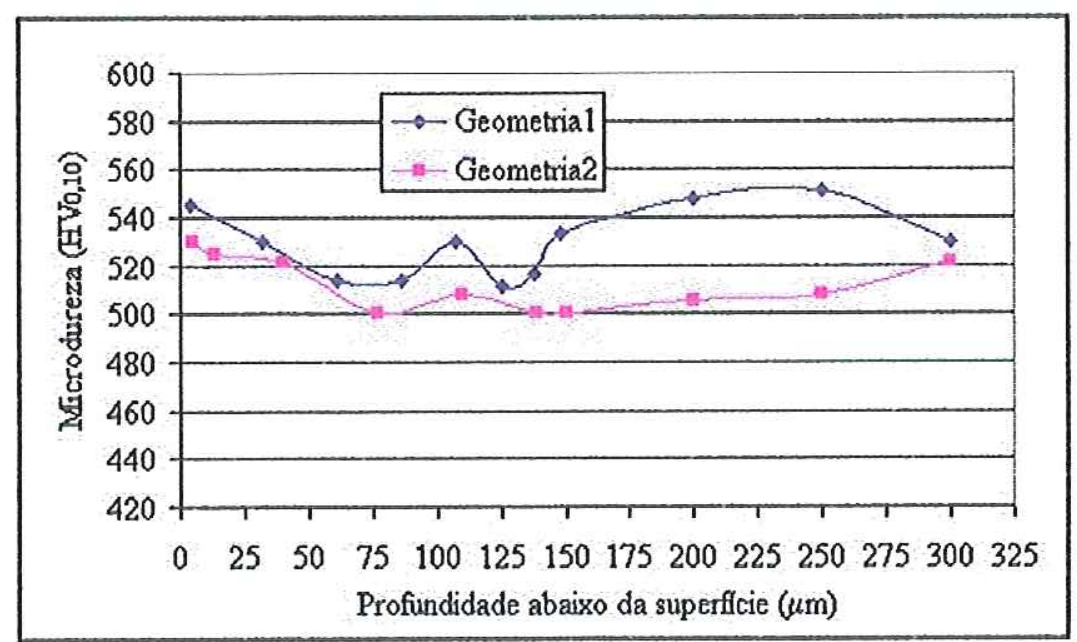

FIGURA 4.69 - Variação da Microdureza em Função da Profundidade Abaixo da Superficie com Ferramenta Cerâmica Redonda CC650 sem Refrigeração $\left(V_{c}=500 \mathrm{~m} / \mathrm{min} ; \mathrm{f}=0,10 \mathrm{~mm} / \mathrm{rev}\right.$ e $\left.a_{p}=0,35 \mathrm{~mm}\right)$. 


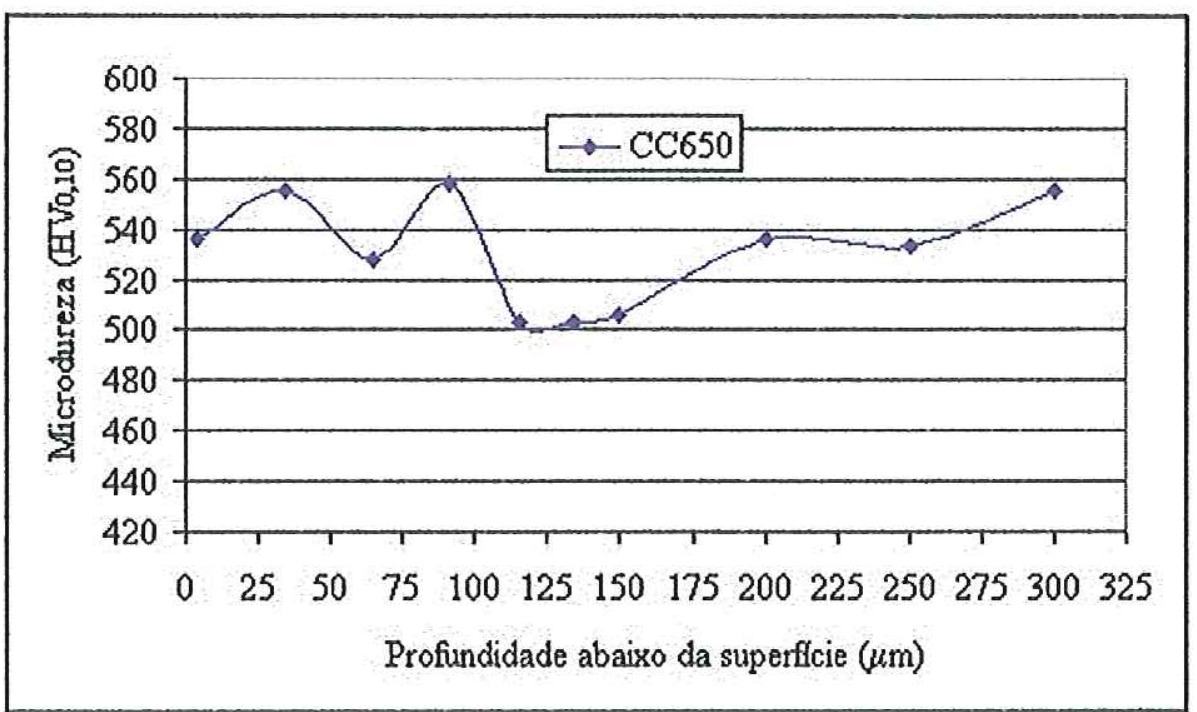

FIGURA 4.70 - Variação da Microdureza em Função da Profundidade Abaixo da Superficie com Ferramenta Cerâmica Redonda CC650/Geometria 1 sem Refrigeração $\left(V_{c}=70 \mathrm{~m} / \mathrm{min} ; f=0,10 \mathrm{~mm} / \mathrm{rev}\right.$ e $\left.a_{p}=0,35 \mathrm{~mm}\right)$.

Os resultados obtidos na medição de microdureza para as diversas geometrias e classe de material da ferramenta não indicaram alterações subsuperficiais significativas. Estes dados ratificam as observações feitas nas análises das microestruturas subsuperficiais. Novamente, a confirmação que HSM não afeta negativamente a integridade superficial. Resultados semelhantes dos valores de microdureza, foram encontrados por EZUGWU \& TANG (1995) no torneamento do Inconel 718 com ferramenta cerâmica $\left(\mathrm{Al}_{2} \mathrm{O}_{3}+\mathrm{TiC}\right)$ de geometria redonda na condição de $V_{c}=152 \mathrm{~m} / \mathrm{min}, \mathrm{f}=0,125 \mathrm{~mm} / \mathrm{rev}$ e $a_{p}=2 \mathrm{~mm}$. Os pesquisadores também não encontraram alterações significativas nos valores de microdureza com tempo de corte inferior a 1 minuto. Contudo, alterações subsuperficiais foram observadas quando o tempo de corte excedeu 3 minutos, ocasionando alta deformação plástica e alta temperatura quando da usinagem prolongada. Usinagem prolongada tende a aumentar a dureza da camada da superficie e também deteriorar a superficie usinada. EZUGWU \& TANG (1995) demonstraram também que, as ferramentas de geometria romboidal/losangular $\left(80^{\circ}\right)$, independente do tipo de cerâmica, apresentaram variações significativas nos valores de microdureza quando da comparação com a geometria redonda. As variações foram observadas desde o início do corte, sendo mais representativas com ferramenta cerâmica pura $\left(\mathrm{Al}_{2} \mathrm{O}_{3}\right)$. 
A análise comparativa entre os valores médios da microdureza com baixa e alta velocidade de corte apresenta diferença de $2 \mathrm{HV}_{0,10}$, sendo considerado desprezível, principalmente se for convertido para HRC.

A usinagem convencional registra valores superiores da microdureza e maior dispersão em comparação com HSM dentro das mesmas condições. Observa-se que a condição de baixa velocidade de corte apresenta uma tendência de endurecimento logo abaixo da superficie, o que não acontece com HSM em ambas geometrias.

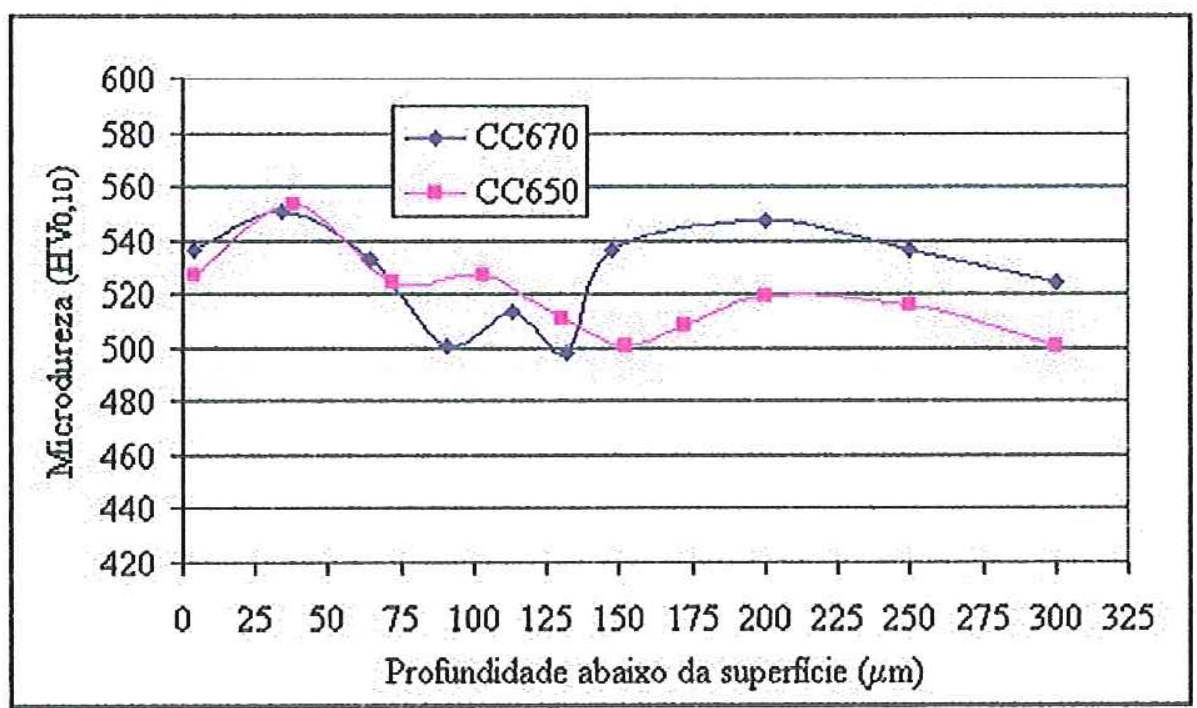

FIGURA 4.71 - Variação da Microdureza em Função da Profundidade Abaixo da Superficie com Ferramentas Redondas de Cerâmica/Geometria2 Utilizando MQL $\left(V_{c}=500 \mathrm{~m} / \mathrm{min} ; \mathrm{f}=0,10 \mathrm{~mm} / \mathrm{rev}\right.$ e $\left.a_{p}=0,35 \mathrm{~mm}\right)$.

A técnica de MQL apresentou uma maior dispersão dos valores de microdureza em relação à condição a seco quando da utilização da ferramenta cerâmica (CC650). Nota-se que a utilização de MQL apresenta uma tendência de endurecimento da camada subsuperficial. Provavelmente, a temperatura na interface ferramenta-peça-cavaco atingiu níveis suficientes que pudesse alterar levemente a integridade superficial.

A modificação na dureza da camada subsuperficial, devido ao endurecimento da peça durante a usinagem com relação à dureza inicial do material base, citada por diversos pesquisadores na usinagem com velocidade de corte convencional, foi confirmada no trabalho nas diversas condições testadas. 
A FIGURA 4.72 representa a variação da microdureza com a profundidade abaixo da superficie usinada utilizando ferramenta cerâmica CC670 triangular na condição a seco. Novamente, não foi possível detectar alterações significativas quando da utilização das geometrias 1 e 2 .

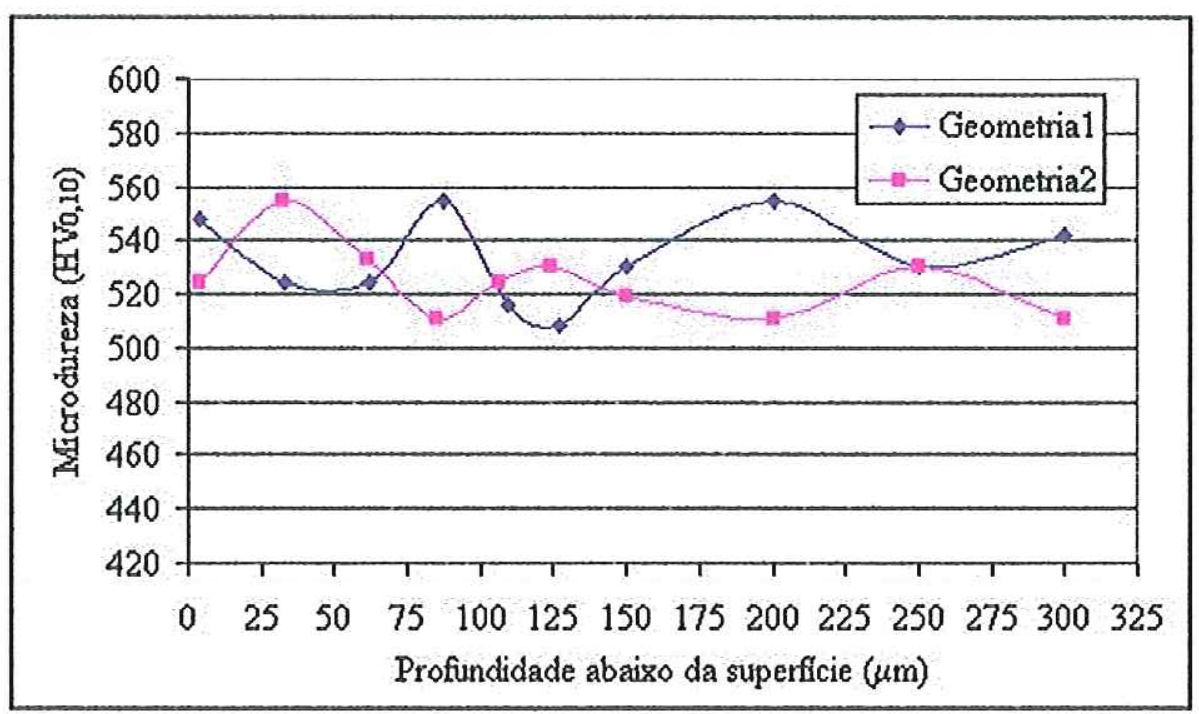

FIGURA 4.72 - Variação da Microdureza em Função da Profundidade Abaixo da Superfície com Ferramenta Cerâmica Triangular CC670

$$
\left(V_{c}=500 \mathrm{~m} / \mathrm{min} ; f=0,10 \mathrm{~mm} / \mathrm{rev} \text { e } a_{p}=0,35 \mathrm{~mm}\right) \text {. }
$$

A camada mais próxima à superficie apresenta maior dureza, quando utiliza ferramenta cerâmica (CC650) redonda e ferramenta cerâmica (CC670) triangular, ambas com geometria 1 sob condição a seco.

A dispersão nas medidas de microdureza pode ser devido principalmente à presença de precipitados ou não homogeneidade da microestrutura. Por outro lado, a aferição do padrão de microdureza permite um erro de $\pm 2 \%$. De uma maneira geral, observa-se que não houve um comportamento padrão nos valores da microdureza, ou seja, os valores oscilam para cima e para baixo, não apresentando uma tendência definida. Provavelmente, a baixa condutividade térmica do Inconel 718 contribuiu para o bom comportamento das alterações subsuperficiais, evitando que o calor fosse para a peça favorecendo a fadiga térmica. 
O resultado final da avaliação da microdureza comprova as informações das micrografias, permitindo também concluir sobre a não ocorrência de alterações microestruturais do material usinado quando da utilização das classes de cerâmicas (CC650 e CC670). A geometria 2 apresentou ligeiramente menor dispersão dos valores de microdureza na maioria das ferramentas utilizadas. Provavelmente, a menor dispersão está relacionada ao maior valor de tensão residual de compressão apresentado pela geometria 2. A variação máxima dos valores médios encontrados nas diversas condições foi de $33 \mathrm{HV}_{100}$, o que corresponde a uma variação máxima de dureza de $\pm 1 \mathrm{HRC}$ para uma dureza de valor nominal de $521 \mathrm{HV}_{0,10}$, podendo ser desprezada essa variação.

De uma maneira geral, as alterações subsuperficiais causadas durante a usinagem com alta velocidade de corte foram mínimas, quando comparadas com as informações publicadas sobre a usinagem com velocidade de corte convencional em superligas à base de níquel. 


\section{CONCLUSÕES}

Com base nos resultados dos experimentos realizados com as diversas geometrias de ferramentas, material da ferramenta e sob as condições de usinagem descritas, pôde-se concluir, para o torneamento com alta velocidade em superligas à base de níquel endurecidas sob condição de corte a seco e com MQL que:

* Na usinagem do Inconel 718, as ferramentas cerâmicas (CC650 e CC670) de geometria triangular apresentaram o menor valor de força de corte, seguida da geometria quadrada e redonda. Para as ferramentas de PCBN, a seqüência foi quadrada, triangular e redonda. De uma maneira geral, a geometria 2 (chanfro em $\mathrm{T}$ de $0,15 \times 15^{\circ}$ com raio de aresta de $0,03 \mathrm{~mm}$ ), apresentou redução nos valores de força de corte. Para o Waspaloy, uma discreta diferença ocorreu nos valores de força de corte com ferramenta de PCBN de geometria triangular e quadrada. $O$ comportamento das ferramentas cerâmicas foi semelhante quando da usinagem do Inconel 718. As ferramentas de PCBN com concentração de $20 \%$ de CBN apresentaram valores de força de corte e temperatura inferior às ferramentas com $50 \%$ de $\mathrm{CBN}$ em ambas superligas. A força de corte diminui com a redução da temperatura da ferramenta;

$\therefore$ As ferramentas com chanfro de aresta $\left(>20^{\circ}\right)$ apresentaram maior valor de força de corte em todas as ferramentas utilizadas. De uma maneira geral, o raio de aresta não afeta os valores de força de corte e temperatura. Entretanto, o aumento do raio de ponta da pastilha ocasiona um aumento significativo na força de corte;

* A força de corte permaneceu praticamente constante com o aumento da velocidade de corte na faixa de valores utilizados em tedas as geometrias;

* A técnica MQL reduziu razoavelmente a força de corte na maioria das ferramentas utilizadas. Os resultados de temperatura mostraram uma redução expressiva comprovando eficiência de refrigeração e lubrificação. Os valores de $\mathrm{R}_{\mathrm{a}}$ foram reduzidos significativamente com o emprego da técnica; 
Da análise da temperatura para as ferramentas cerâmicas sob condição a seco, quando da usinagem do Inconel 718, verifica-se que o menor valor de temperatura foi registrado pela ferramenta quadrada. As ferramentas triangular e redonda apresentaram praticamente os mesmos valores de temperatura. Para as ferramentas de PCBN, a maior temperatura foi apresentada pela ferramenta triangular com geometria 1. De uma maneira geral, a geometria 2 indicou redução nos valores de temperatura em relação a geometria 1 em ambas superligas. A variação do chanfro e raio de aresta não teve influência significativa nos valores de temperatura. $\mathrm{O}$ aumento da velocidade de corte não altera significativamente os valores da temperatura. Para o Waspaloy, verifica-se que a menor temperatura foi registrada pela ferramenta quadrada, seguida da ferramenta triangular e redonda para ambas classes de ferramentas cerâmicas. Para as ferramentas de PCBN, o comportamento foi diferente, sendo que a maior temperatura foi revelada pela ferramenta triangular em ambas geometrias de aresta. As ferramentas de PCBN apresentaram maior valor de temperatura em comparação com as ferramentas cerâmicas, devido principalmente à superioridade da condutividade térmica;

- Uma análise comparativa da temperatura e força de corte apresentada pelas duas superligas mostra que a temperatura e a força de corte das ferramentas de PCBN na usinagem do Waspaloy foi inferior com relação ao Inconel 718. O mesmo comportamento não foi observado com as ferramentas cerâmicas;

- As análises dos resultados diversos indicam que a técnica MQL pode ser aplicada com eficiência no torneamento com alta velocidade de corte de superligas à base de níquel;

De uma maneira geral, o tipo de desgaste dominante foi o de entalhe e os mecanismos foram abrasão, "attrition” (aderência com arrastamento) e provável difusão na maioria das ferramentas utilizadas em ambas superligas. Entretanto, a presença do desgaste de entalhe na profundidade de usinı!gem foi mais fortemente influenciada em diversas condições de corte. $\mathrm{O}$ desgaste de flanco foi mais prevalecente ao longo da aresta de corte com uma provável combinação dos mecanismos de desgaste do tipo abrasão e "attrition". O alto desgaste das ferramentas de PCBN pode ser atribuído à deterioração provocada pelas reações 
químicas que ocorrem em alta temperatura em virtude da alta velocidade. As ferramentas de PCBN com concentração de 20 e 50\% de CBN apresentaram taxa de desgaste superior às ferramentas cerâmicas. A concentração de CBN altera completamente o comportamento dos mecanismos de desgaste. A geometria 2 apresentou menor taxa de desgaste em comparação com a geometria 1, na maioria das ferramentas utilizadas. No geral, existe um consenso entre os mecanismos de desgaste que ocorreram com as ferramentas utilizadas na usinagem de ambas superligas. $\mathrm{O}$ aspecto do desgaste na usinagem do Waspaloy apresenta menor intensidade em relação ao Inconel 718;

* Apesar das ferramentas cerâmicas serem conhecidas por sua boa estabilidade química, encontram-se fortes indícios de mecanismos químicos em todas ferramentas e condições utilizadas;

* A boa estabilidade química das ferramentas cerâmicas CC650, aliada a uma melhoria da resistência ao choque térmico e mecânico através da adição de TiC, são características que, sem dúvida, beneficiam a situação com alta velocidade de corte;

* Observando-se a influência da geometria sobre o desgaste de entalhe, pode-se verificar que a geometria redonda apresenta menor desgaste de entalhe seguida pela geometria triangular e quadrada. A geometria 2 apresentou menor evidência de lascamentos e desgaste de entalhe;

* O torneamento com rampamento proporciona redução no desgaste de entalhe, e em algumas situações transformou-o em desgaste de flanco na extensão da profundidade de usinagem, independentemente da geometria utilizada;

* A usinabilidade das superligas à base de níquel é fortemente influenciada pela geometria e material da ferramenta. A estruturação da geometria da aresta de corte desempenha um papel importante sobre o resultado da usinagem. As características térmicas, mecânicas e metalúrgicas das superligas dificultam demasiadamente a u:inagem, proporcionando elevado nível de desgaste;

* O melhor desempenho global foi fornecido pela ferramenta cerâmica redonda CC650 seguida pela CC670, ambas com geometria 2. As ferramentas de PCBN não apresentaram bom desempenho em nenhuma geometria sob os parâmetros analisados em ambas superligas; 
As ferramentas cerâmicas apresentaram melhor acabamento superficial com relação às ferramentas de PCBN em ambas superligas. Quando da usinagem do Inconel 718, a ferramenta cerâmica CC650 redonda apresenta $R_{a}=0,38 \mu \mathrm{m}$ sob condição a seco e $\mathrm{R}_{\mathrm{a}}=0,29 \mu \mathrm{m}$ com a utilização da técnica de $\mathrm{MQL}$, ambas com geometria 2. A rugosidade superficial $R_{a}$ da ferramenta cerâmica CC670 redonda ficou na faixa de $R_{a}=0,41 \mu \mathrm{m}$ sob condição a seco e $R_{a}=0,21 \mu \mathrm{m}$ com a utilização da técnica de MQL, todas com geometria 2. Esse valor é comparável aos valores encontrados no processo de retificação. Os menores valores de $R_{a}$ foram alcançados para as ferramentas cerâmicas redonda (CC650 e CC670), seguidas da ferramenta de PCBN redonda e da ferramenta cerâmica triangular CC670, todas com geometria 2. As ferramentas de PCBN com concentração de $50 \%$ de CBN apresentaram acabamento superficial superior às ferramentas com $20 \%$ de CBN. O chanfro da aresta de corte influencia no acabamento superficial, sendo que as ferramentas com maior chanfro de aresta $\left(>20^{\circ}\right)$ apresentaram maior valor de $R_{a}$ em todas as ferramentas utilizadas;

* O comportamento da rugosidade superficial na superliga Waspaloy foi semelhante ao Inconel 718. A ferramenta cerâmica CC650 redonda apresenta melhor acabamento superficial com $R_{a}=0,39 \mu$ m seguida da ferramenta redonda CC670 com $R_{a}=0,47 \mu \mathrm{m}$ e da ferramenta de PCBN redonda com $R_{a}=0,49 \mu \mathrm{m}$ todas com geometria 2. Uma análise comparativa da qualidade superficial obtida no torneamento com alta velocidade das duas superligas, mostra que, de uma maneira geral, existiu uma tendência do Inconel 718 apresentar melhor acabamento superficial;

* A análise comparativa dos valores de tensão residual mostra que, em todas ferramentas, geometrias e condições de corte, obteve-se tensão residual de compressão. A geometria 2 proporcionou maior valor de tensão de compressão em comparação com a geometria 1 , comprovando que a geometria da aresta de corte tem influência no valor da tensão residual. ( emprego da técrica de MQL reduziu os valores de tensão residual principalmente com a ferramenta cerâmica CC650. HSM não afeta negativamente a integridade superficial. O maior valor da tensão residual foi apresentado pela ferramenta redonda seguido pela ferramenta triangular todas com geometria 2 ; 
Não foram observadas alterações subsuperficiais na microestrutura quando da utilização das geometrias 1 e 2 e da classe de material da ferramenta. Em comparação com a usinagem a seco, não se notam indícios de alterações subsuperficiais na microestrutura com o emprego da técnica de MQL. A microestrutura apresentada quando se utilizou baixa velocidade de corte, assemelha-se com a usinagem com alta velocidade. Pela análise da microestrutura, pode-se afirmar que HSM não afeta negativamente a integridade superficial;

* Os resultados obtidos na medição de microdureza para as diversas geometrias e classe de material da ferramenta não indicaram alterações subsuperficiais significativas. Estes dados ratificam as observações feitas na análise da microestrutura, e confirma novamente que HSM não afeta negativamente a integridade superficial. A usinagem convencional registra valores superiores da microdureza e maior dispersão em comparação com HSM;

Mediante os resultados obtidos nos parâmetros: rugosidade superficial, tensão residual, microestrutura, microdureza e mecanismos de desgaste, pode-se afirmar que as ferramentas cerâmicas redonda (CC650 e CC670) com geometria 2 são aceitáveis no torneamento com alta velocidade das superligas ensaiadas. Entretanto, a ferramenta cerâmica CC650 representa melhor relação custo beneficio.

Ao finalizar, pode-se afirmar que dentro dos objetivos previstos, este trabalho trouxe importantes contribuições no sentido de elucidar o torneamento com alta velocidade de superligas à base de níquel. Porém, as superligas só podem ser usinadas com grandes dificuldades, necessitando de mais investigações com altas velocidades e avanços para que se tenha um melhor desempenho, principalmente quanto a vida da ferramenta. 


\section{SUGESTÕES PARA TRABALHOS FUTUROS}

Baseando-se no trabalho experimental realizado, pode-se indicar algumas sugestões para trabalhos futuros, com intuito de obter um aprofundamento do conhecimento do torneamento com alta velocidade de corte em superligas à base de níquel:

Análise econômica e ambiental do emprego da técnica de mínima quantidade de lubrificante (MQL) com relação aos fluidos de corte tradicionais;

* Medição da temperatura na interface cavaco-ferramenta-peça para que se possa estimar a quantidade de calor que vai para a peça, cavaco e através da ferramenta na condição de alta velocidade;

: Investigação dos fatores químicos nos mecanismos de desgaste, para que se possa afirmar as principais reações químicas ocorridas nos mecanismos, pois somente com a utilização do MEV torna-se dificil estas análises;

* Utilização de diferentes tipos de fluidos de corte e vazões de ar para comprovar a eficiência da tecnologia MQL em diversos materiais;

* Experimentar ferramentas de diversos fabricantes, principalmente de PCBN, (variando teor de $\mathrm{CBN}$, ligante e granulometria do $\mathrm{CBN}$ ) para que se possa ter uma análise mais detalhada do emprego de ferramentas cerâmicas e de PCBN;

Investigação do comportamento da geometria 2 (modificada) para os parâmetros de corte tradicionais em diversos materiais. 


\section{BIBLIOGRAFIA}

\subsection{Bibliografia Citada}

ABRÃO, A. M.; ASPINWALL, D. K.; WISE, M. L. (1993). A review of policrystalline cubic boron nitride tool developments and aplication. In: Proceding of the Thirtieth Internacional Matador Conference, Manchester, UK, p.1-11, Apr.

ABRÃO, A.M.; ASPINWALL, D.K. (1996). The surface integrity of turned and ground hardened bearing steel. Wear, v.196, p. 279-284.

ADDHOUM, H.; BROUSSAUD, D. (1989). Interaction of ceramic cutting tools with nickel-based alloys. Materials Science and Engineering, n.109, p. 379-387.

AGBA, E. (1999). High speed machining of unsupported thin-walled structures. In: $3^{\text {rd }}$ Internacional Machining \& Grinding Conference, Cincinnati, Ohio, P.121132 , Oct.

ANDRAE, P. (1999). Chip formation in high speed cutting HSC. In: $3^{\text {rd }}$ Internacional Machining \& Grinding Conference, Cincinnati, Ohio, P.107-120, Oct.

ANDRAE, P. (1999b). Tool \& process design for high-efficient machining. In: $3^{\text {rd }}$ Internacional Machining \& Grinding Conference, Cincinnati, Ohio, P.133-148, Oct.

ANDREASEN, J. L.; CHIFFRE, L. (1993). Automatic chip-brealing detection in turning by frequency analysis of cutting force. In: Annals of the CIRP, v. 42, n.1, p. $45-48$.

ASHLEY, S. (1995). High-speed machining goes mainstream. Mechanical Engineering, p.56-61, May. 
BECK, W. H. (1998). Alta velocidade e ferramentas de alto desempenho reduzem o tempo de usinagem. Máquinas e Metais, n.388, p.40-47, abr.

BECK, W. H. (2000). Tecnologias e ferramentas para o corte a alta velocidade. Máquinas e Metais, n.409, p.34-38, fev.

BERT, P. E. (1997). O impacto da usinagem de precisão a alta velocidade na produção. Máquinas e Metais, n.375, p.36-41, mar.

BOEHS, L.; PEIXOTO, F. L.; REZENDE, D. F. (1995). Fresamento do Inconel 625 com diferentes formas e materiais de ferramentas. In: XIII CONGRESSO BRASILEIRO DE ENGENHARIA MECÂNICA - COBEM, Belo Horizonte MG.

BRANDT, G.; GERENDAS, A.; MIKUS, M. (1990). Wear mechanisms of ceramic cutting tools when machining ferrous and non-ferrous alloys. Journal of the European Ceramic Society, n.6, p.273-290.

BRINKSMEIER, E.; CAMMETT, J. T.; KÖNIG, W.; LESKOVAR, P.; PETERS, J.; TÖNSHOFF, H. K. (1982). Residual stresses - Measurement and causes in machining processes. In: Annals of the CIRP, v. 31, n.2, p. 491-510.

BROCKHOFF, T.; WALTER, A. (1998). Fluid minimization in cutting and grinding. Abrasives Magazine, p.38-42, Oct./Nov.

BYRNE, G.; DORNFELD, D.; INASAKI, I.; KETTELER, G.; KÖNIG, W.; TETI, R. (1995). Tool Condition Monitoring (TCM) - The Status of Research and Industrial Application. In: Annals of the CIRP, v. 44, n.2, p. 541-561.

CAPELLO, E; DAVOLI, P.; BASSANINI, G.; BISI, A. (1999). Residual stresses and surface roughness in turning. Journal of Engineering Materials and Technology, v.121, p.346-351, July.

CARPINETTI, L. C. R. (2000). Planejamento e análise de experimentos. EESC USP, São Carlos - SP, 205p. 
CHANDRASEKARAN, H.; JOHANSSON, J. O. (1994). Chip flow and notch wear mechanism during the machining of high austenitic stainless steels. Annals of the CIRP, v.43, n.1, p.101-105.

CHOUDHURY, I. A; BARADIE, M. A. (1998). Machinability of nickel-base super alloys: a general review. Journal of Materials Processing Technology, v.77, p.278-287.

CHRISTOFFEL, K. (2001). High-speed machining - from a tool manufacturer's perspective. In: Anais do $6^{\circ}$ Seminário International de Alta Tecnologia Mamufatura Avançada, Universidade Metodista de Piracicaba, Unimep, Piracicaba, SP, out.

COELHO, R. T; ASPINWALL, D. K.; WISE, M. L. (1995). Aplicação de materiais ultraduros como ferramentas de corte de geometria definida. Máquinas e Metais, n.357, p.70-80, maio.

COELHO, R. T; SOUZA, A. F.; SCHÜTZER, K. (2001). The application of highspeed cutting technology in Brazil - first results. In: Anais do $6^{\circ}$ Seminário International de Alta Tecnologia - Manufatura Avançada, Universidade Metodista de Piracicaba, Unimep, Piracicaba, SP out.

DAN, L.; MATHEW, J. (1990). Tool wear and failure monitoring techniques for turning - a review. International Journal of Machine Tools and Mamufacture, v. 30 , p. $579-598$.

DARWISH, S. M. (1997). The impact of tool material and cutting parameters on surface roughness of a nickel-base superalloy. Materials and Mamufacturing Processes, v.12, n.6, p.1017-1035.

DESTEFANI, J. D. (1997). Spindles key to high speed machining. Mamufacturing Engineering, p.68-77, Oct.

DEWES, R. C.; ASPINWALL, D. K. (1995). High speed machining - cutting tools and machine requirements. In: Proceding of the Thirtieth Internacional Matador Conference, Manchester, UK, p.455-461, Apr. 
DEWES, R. C.; ASPINWALL, D. K. (1997). A review of ultra high speed milling of hardened steels. Journal of Materials Processiong Technology, n.69, p.1-17.

DINIZ, A. E.; MARCONDES, F. C.; COPPINI, N.L. (1999). Tecnologia da usinagem dos materiais. mmeditora, São Paulo, 242p.

DINIZ, A. E. (1999). Minimal lubrification in the drilling process of aluminum silicion alloy. In: $3^{\text {rd }}$ Internacional Machining \& Grinding Conference, Cincinnati, Ohio, P.683-697, Oct.

DISTLER, H. (1996). Computer numerical control systems that master high speed cutting. In: Anais do $1^{\circ}$ Seminário Internacional de Alta Tecnologia - Usinagem com altíssima velocidade de corte e alta precisão, Universidade Metodista de Piracicaba, Unimep, Santa Bárbara d'Oeste, SP, out.

DORNFELD, D. (1999). Monitoração de processos por emissão acústica. Máquinas e Metais, n.401, p.64-81, maio.

DÖRR, J. (1999). New perspectives in dry machining. In: Anais do $4^{o}$ Seminário International de Alta Tecnologia - Inovações tecnológicas na mamufatura para o ano 2000, Universidade Metodista de Piracicaba, Unimep, Santa Bárbara d'Oeste, SP, ago.

DÖRR, J.; SAHM, A. (2000). A mínima quantidade de lubrificante avaliada pelos usuários. Máquinas e Metais, n.418, p.20-39, nov.

DUNLAP, C. (1997). Should you try dry? Cutting Tool Engineering, v. 49, n.1, p. 22-33, Feb.

ELBESTAWI, M. A.; ELWARDANY, I.; TAN, M. (1993). Performance of whiskerreinforced ceramic tools in milling nickel-based superalloy. In: Annals of the CIRP, v.42, n.1, p.99-102.

ELBESTAWI, M. A.; CHEN, L.; BECZE, E. C.; WARDANY, I. (1997). High-speed milling of dies and molds in their hardened state. In: Annals of the CIRP, v.46, n.1, p.57-62. 
ELWARDANY, T. I.; MOHAMMED, E.; ELBESTAWI, M. A. (1996). Cutting temperature of ceramic tools in high speed machining of difficult to cut materials. Internacional Journal Machine Tools Manufacturing, v.36, n.5, p.611-634.

ELWARDANY, T. I.; KISHAWY, H. A.; ELBESTAWI, M. A. (2000). Surface integrity of die material in high speed hard machining, Part 2: microhardness variations and residual stresses. Transactions of the ASME, Journal of Mamufacturing Science and Engineering, v. 122, p.632-641, Nov.

ENDERLE, K.D.; KNUSZYNSKI, J. (1998). A tecnologia de corte a alta velocidade produz furos de melhor qualidade. Máquinas e Metais, n.386, p.16-20, fev.

ERRICO, G. E.; CALZAVARINI, R. (1995). Advanced ceramic tools: an experimental assessment in turning tests. Journal of Materials processing Technology, n.54, p.34-39.

EZUGWU, E. O.; WALLBANK, J. (1988). Propriedades e fabricação de ferramentas cerâmicas. Máquinas e Metais, n.271, p.14-22, mar.

EZUGWU, E. O.; MACHADO, A. R.; PASHBY, I. R.; WALLBANK, J. (1990). The effect of high-pressure coolant supply when machining a heat-resistant nickel-based superalloy. Journal of the Society of Tribologist and Lubrification Engineers. v.47, n.9, p.751-757.

EZUGWU, E. O.;TANG, S. H. (1995). Surface abuse when machining cast iron (G17) and nickel-base superalloy (Inconel 718) with ceramic tools. Journal of Materials Processing Technology, n.55, p.63-69.

EZUGWU, E. O.; WANG, Z. M. (1996). Performance of PVD and CVD coated carbide tools when machining nickel based Inconel 718 alloy, In: Progress of Cutting and Grinding - ICPCG, v.3, p.102-107.

EZUGWU, E. O.; WANG, Z. M.; MACHADO, A. R. (1999). The machinability of nickel-basead alloys: a review. Journal of Materials Processing Technology, n.86, p.1-16. 
EZUGWU, E. O.; WANG, Z. M.; OKEKE, C. I. (1999a). Tool life and surface integrity when machining Inconel 718 with PVD and CVD coated tools. Tribology Transactions, v.42, n.2, p.353-360.

FALlBÖHMER, C. A.; RODRÍGUEZ, T.; ÖZEL, T.; ALTAN, T. (2000). Highspeed machining of cast iron and alloy steels for die and mold manufacturing. Journal of Materials Processing Technology, n.98, p.104-115.

FERRARESI, D. (1977). Fundamentos da usinagem dos metais. 9.ed. v.1, São Paulo, Editora Edgard Blücher Ltda., 751p.

FINZER, T. (1997). High-speed machining (HSC) in die and mold manufacturing. In: Anais do $2^{\circ}$ Seminário Internacional de Alta Tecnologia - Usinagem com altíssima velocidade de corte e alta precisão, Universidade Metodista de Piracicaba, Unimep, Santa Bárbara d'Oeste, SP, July.

FLOM, D.G.; KOMANDURI, R. (1989). High-speed machining. In: American Society for Metals, Metals handbook, 9.ed., Metals Park, Ohio, USA, v.16, Machining, p.597-606.

GATTO, A., IULIANO, L. (1994). Chip formation analysis in high speed machining of a nickel base superalloy with silicon carbide whisker-reinforced alumina. Internacional Journal Machine Tools Mamufacturing, v.34, n.8, p.1147-1161.

GATTO, A., IULIANO, L. (1997). Advanced coated ceramic tools for machining superalloys. Internacional Journal Machine Tools Mamufacturing, v.37, n.5, p.591-605.

GEIST, J. (1999). Influence of HSC-appropriate machining parameters on NC programming. In: Anais do $4^{o}$ Seminário International de Alta Tecnologia Inovações tecnológicas na mamufatura para o ano 2000, Universidade Metodista de Piracicaba, Unimep, Santa Bárbara d'Oeste, SP, ago.

GRUNDLER, E. (1994). HSC = High speed cutting. European Production Engineering (EPE), v.18, n.1-2, p.30-32. 
HANASAKI, S.; FUJIWARA, J.; MIYAMOTO, T. (1996). Mechanism of groove wear formation in cutting of hi-nickel alloy. In: Progress of Cutting and Grinding, v.3, ICPCG, p.114-119.

HAMANN, J. C.; MAÎTRE, F.; GUILLOT, D. (1994). Selective transfer built-up layer displacement in high-speed machining - Consequences on tool wear and cutting forces. In: Annals of the CIRP, v.43, n.1, p.69-72.

HEISEL, U.; GRINGEL, M. (1996). Machine tool design requirements for highspeed machining. In: Annals of the CIRP, v.45, n.1, p.389-392.

HEISEL, U.; LUTZ, D.; WASSMER, R.; WALTER, U. (1998). A técnica da quantidade mínima de fluidos e sua aplicação nos processos de corte. Máquinas $e$ Metais, n.386, p.22-38, fev.

HOCK, L.; JAJENSKI, J. (1996). NC programming for high speed machining. Modern Machine Shop, v.69, n.6, p.88-94, Nov.

INASAKI, I. (1998). Application of acoustic emission sensor for monitoring machining processes. Ultrasonics, v.36, p.273-281.

INTERNATIONAL ORGANIZATION FOR STANDARDIZATION (1993), ISO 3685 - Tool life testing with single-point turning tools.

JACK, D. H. (1987). Hard materials for metal cutting. Metals and Materials, v.3, p.516-520, Sept.

JEMIELNIAK, K.; OTMAN, O. (1998). Catastrophic tool failure detection based on acoustic emission signal analysis. In: Annals of the CIRP, v.47, n.1, p.31-34.

JIANXIN, D.; XING, A. (1997). Wear behavior and mechanisms of alumina-based ceramic tools in machining of ferrous and non-ferrous alloys. Tribology International, v.30, n.11, p.807-813.

JUN, Z,; JIANXIN, D.; JIANHUA, Z.; XING, A. (1997). Failure mechanisms of a whisker-reinforced ceramic tool when machining nickel-based alloys. Wear, n.208, p.220-225. 
KAHLES, J. F.; FIELD, M.; HARVEY, S. M. (1978). High speed machining possibilities and needs. In: Annals of the CIRP, v.27, n.2, p.551-560.

KALDOR, S.; MALKIN, S. (1986). A common denominator for optimal cutting tool geometry. Annals of the CIRP, v.35, n.1, p.41-44.

KALHÖFER, E. (1997). Dry machining - Priniples and applications. In: Anais do $2^{o}$ Seminário Internacional de Alta Tecnologia - Usinagem com altíssima velocidade de corte e alta precisão, Universidade Metodista de Piracicaba, Unimep, Santa Bárbara d'Oeste, SP, july.

KANKAANPÄÄ, H.; KORHONEN, A. S. (1987). Effets of cutting geometry in turning with TiN-coated tools. Internacional Journal Machine Tools Manufacturing. v.27, n.3, p.305-310.

KATTAN, I. A.; CURRIE, K. R. (1996). Developing new trends of cutting tool geometry. Journal of Materials Processing Technology, n.61, p.231-237.

KIRSCHNIK, M. (1997). Comando numérico computadorizado para aplicações HSC. In: Anais do $2^{\circ}$ Seminário Internacional de Alta Tecnologia - Usinagem com altíssima velocidade de corte e alta precisão, Universidade Metodista de Piracicaba, Unimep, Santa Bárbara d'Oeste, SP, jul.

KISTLER. (2001). General force measurement one component force measurement http://www.kistler.ch/force_lcomponent.htm (22 dec.).

KITAGAWA, T.; KUBO, A.; MAEKAWA, K. (1997). Temperature and wear of cutting tools in high-speed machining of Inconel 718 and Ti-6Al-6V-2Sn. Wear, n.202, p.142-148.

KLOCKE, F.; EISENBLÄTTER, G. (1997). Dry cutting. In: Annals of the CIRP, v. 46, n.2, p.519-526.

KLOCKE, F.; PÖHLS, M. (1998). Broaching with cermets - Exploiting the potentials of moderm cutting materials. Production Engineering. v.5, n.1, p.1316. 
KLOCKE, F.; SCHULZ, A.; GERSCHWILER, K.; REHSE, M. (1998). Clean manufacturing technologies - The competitive edge of tomorrow? The Internacional Journal of Mamufacturing Science \& Production. v.1, n.2, p.77-86.

KLOCKE, F.; KNODT, S.; WÜRTZ, C. (1999). Fresamento HSC de cavidades em aço temperado. Máquinas e Metais, n.402, p.20-26, jul.

KOMANDURI, R; SCHROEDER, T. A. (1986). On shear instability in machining a nickel-iron base superalloy. Journal of Engineering for Industry, v.108, p.93-100, May.

KÖNIG, W.; GERSCHWILER, K. (1999). Machining nickel-based superalloys. Mamufacturing Engineering. n.3, p.102-108.

KRAMER, B. M. (1987). On tool materials for high-speed machining. Journal of Engineering for Industry, v.109, p.87-91.

KRESS, K. G. (1996). HSC and high performance tools reduce workpiece machining times. In: Anais do $1^{o}$ Seminário Internacional de Alta Tecnologia. Usinagem com altíssima velocidade de corte e alta precisão, Universidade Metodista de Piracicaba, Unimep, Santa Bárbara d'Oeste, SP, out.

LAYNE, M. H. (2001). Deteç̧ão e correção do desbalanceamento em suportes de ferramentas. Máquinas e Metais, n.424, p.128-147, maio.

LÉON, P. (1997). High speed milling for engineers. In: Anais do $2^{o}$ Seminário Internacional de Alta Tecnologia - Usinagem com altíssima velocidade de corte $e$ alta precisão, Universidade Metodista de Piracicaba, Unimep, Santa Bárbara d'Oeste, SP, jul.

LIAO, S. Y.; SHIUE, R. H. (1996). Carbide tool wear mechanism in turning of Inconel 718 superalloy. Wear, n.193, p.16-24.

LIN, J.; LEE, S.; WENG, C. (1992). Estimation of cutting temperature in high speed machining. Journal of Engineering Materials and Technology, v.114, p.289-296, July. 
LIU, C. R.; BARASH, M. M. (1976). The mechanical state of the sublayer of a surface generated by chip-removal process, part 2: Cutting with a tool with flank wear. Journal of Engineering for Industry, v.98, p.1202-1208, Nov.

LO, H. W.; KALDOR, S.; VENUVINOD, P. K. (1998). A broad-brush approach to the selection of general purpose cutting tool geometry for maximum tool life. Internacional Journal Machine Tools Mamufacturing, v.38, n.1-2, p.1-14.

LUO, S. Y.; TSAI, Y. Y. (1996). Wear characteristics in turning high hardness alloy steel by ceramic and cbn tools. Progress of Cutting and Grinding, v.III, p.120125.

MACHADO, A. R; SILVA, M. B. (1999). Usinagem dos metais. 4. Ed. Editora da Universidade Federal de Uberlândia.

MACHADO, A. R.; DINIZ, A. E. (2000). Vantagens e desvantagens do uso (ou não) de fluidos de corte. In: CONGRESSO DE USINAGEM 2000, São Paulo - SP.

MAJIMA, T. (1996). A produção de moldes e matrizes é melhor com fresadoras de ultravelocidade. Máquinas e Metais, n.365, p.22-43, maio.

MATSUMOTO, Y.; BARASH, M. M.; LIU, C. R. (1986). Effect of hardness on the surface integrity of AISI 4340 steel. Journal of Engineering for Industry, v.108, p.169-175, Aug.

MATSUMOTO, Y.; HASHIMOTO, F.; LAHOTI, G. (1999). Surface integrity generated by precision hard turning. In: Annals of the CIRP, v.48, n.1, p.59-62.

MÜLLER, P.; ICE, M. S. (1999). Usinagem sem refrigeração de furos e roscas. In: Anais do $4^{\circ}$ Seminário International de Alta Tecnologia - Inovações tecnológicas na mamufatura para o ano 2000, Universidade Metodista de Piracicaba, Unimep, Santa Bárbara d'Oeste, SP, ago.

NARUTAKI, N.; YAMANE, Y.; KAYASHI, K. (1993). High-speed machining of Inconel 718 with ceramic tools. In: Annals of the CIRP, v.42, n.1, p.103-106.

NARUTAKI, N.; YAMANE, Y.; TASHIMA, S.; KUROKI, H. (1997). A new advanced ceramic for dry machining. In: Annals of the CIRP, v.46, n.1, p.43 - 48. 
NOAKER, M. P. (1991). Super speeds for superalloys. Mamufacturing Engineering, p.63-68, Oct.

NOVASKI, O.; CORRÊA, M. (1998). A HSC como vantagem competitiva. Máquinas e Metais, n.394, p.74-89, nov.

NOVASKI, O; DÖRR, J. (1999). Usinagem sem refrigeração. Máquinas e Metais, n.399, p.18-27, mar.

PASHBY, I. R.; KHAMSEHZADEH, H. (1990). A usinagem de waspaloy com diferentes pastilhas cerâmicas. Máquinas e Metais, n.296, p.30-39, set.

RAHMAN, M.; SEAH, W. K. H.; TEO, T. T. (1997). The machinability of Inconel 718. Journal of Materials Processing Technology, n.63, p.199-204.

REN, H.; ALTINTAS, Y. (2000). Mechanics of machining with chamfered tools. Transactions of the ASME, Journal of Mamufacturing Science and Engineering, v. 122, p.650-659, Nov.

RICHARDS, N.; ASPINWALL, D. (1989). Use of ceramic tools for machining nickel basead alloys. Internacional Journal Machine Tools Mamufacturing, v.29, n. 4 , p. $575-588$.

RUFFINO, R. T. (1977). Fluidos de corte. In: FERRARESI, D. Fundamentos $d a$ usinagem dos metais. Ed. Edgard Blücher, São Paulo, Cap. 11, p.512-565.

SADAT, A. B. (1987). Surface characteristics of machined Inconel 718 nickel-base superalloy using natural and controlled contact length tools. Internacional Journal Machine Tools Mamufacturing, v.27, n.3, p.333-342.

SAHM, D. (1996). The technology of high speed cutting. In: Anais do $I^{o}$ Seminário Internacional de Alta Tecnologia - Usinagem com altíssima velocidade de corte e alta precisão, Universidade Metotista de Piracicaba, Unimep, Santa Bárbara d'Oeste, SP, out.

SAHM, D.; SCHNEIDER, T. (1996). A produção sem refrigerante é interessante e deve ser mais conhecida. Máquinas e Metais, n.367, p. 38-55, ago. 
SANCHEZ, L.E.; LOSNAK, C.; PEREZ, F. R. C. (2000). Efeito da lapidação de pastilhas de metal duro sobre o seu desgaste. In: $1^{\circ}$ CONGRESSO NACIONAL DE ENGENHARIA MECÂNICA - CONEM, Natal - RN.

SCHMITT, T. (1996). High speed milling machines. In: Anais do $I^{o}$ Seminário Internacional de Alta Tecnologia - Usinagem com altíssima velocidade de corte e alta precisão, Universidade Metodista de Piracicaba, Unimep, Santa Bárbara d'Oeste, SP, out.

SCHMITT, T. (1997). As máquinas-ferramentas acionadas por motores lineares são mais rápidas e precisas. Máquinas e Metais, n.373, p.48-58, jan.

SCHOCK, J. (1998). Usos potenciais da HSC na usinagem de matrizes. Máquinas e Metais, n.394, p.28-33, nov.

SCHULZ, H.; MORIWAKI, T. (1992). High speed machining. Annals of the CIRP, v.41, n.2, p.637-645.

SCHULZ, H. (1994). O estado-da-arte das máquinas de usinagem a alta velocidade. Máquinas e Metais, n.341, p.46-57, jan.

SCHULZ, H.; HOCK, St. (1995). High-speed milling of dies and moulds - cutting conditions and technology. In: Annals of the CIRP, v.44, n.1, p.35-38.

SCHULZ, H. (1996). High-speed machining. In: Anais do $I^{o}$ Seminário Internacional de Alta Tecnologia - Usinagem com altíssima velocidade de corte e alta precisão, Universidade Metodista de Piracicaba, Unimep, Santa Bárbara d'Oeste, SP, out.

SCHULZ, H. (1997). Start of art and trends of high-speed machining. In: Anais do $2^{o}$ Seminário Internacional de Alta Tecnologia - Usinagem com altíssima velocidade de corte e alta precisão, Universidade Metodista de Piracicaba, Unimep, Santa Bárbara d'Oeste, SP, July. 
SCHULZ, H. (1999). Trends in manufacturing technology at the threshold of the millennium. In: Anais do $4^{o}$ Seminário International de Alta Tecnologia Inovações tecnológicas na mamufatura para o ano 2000, Universidade Metodista de Piracicaba, Unimep, Santa Bárbara d'Oeste, SP, ago.

SCHULZ, H. (1999b). The history of high speed machining. Revista de Ciência \& Tecnologia, Universidade Metodista de Piracicaba, Unimep, v.7, n.13, p.9-18, jun.

SCHULZ, H.; ABELE, E.; SAHM, A. (2001). High-speed machining - fundamentals and industrial application. In: Anais do $6^{\circ}$ Seminário International de Alta Tecnologia - Mamufatura Avançada, Universidade Metodista de Piracicaba, Unimep, Piracicaba, SP, out.

SCHÜTZER, K.; SOUZA, A. F.; DEONISIO, C. C. C. (2000). Introdução do processo HSC na indústria brasileira. In: Anais do $4^{o}$ Seminário International de Alta Tecnologia - Inovações tecnológicas na mamufatura para o ano 2000, Universidade Metodista de Piracicaba, Unimep, Santa Bárbara d'Oeste, SP, ago.

SCHÜTZER, K.; SOUZA, A. F.; STANIK, M. (2001). A usinagem HSC na manufatura de moldes e matrizes. Máquinas e Metais, n.420, p.92-103, jan.

SHAFFER, W. (1999). Cutting tool edge preparation. In: $3^{\text {rd }}$ Internacional Machining \& Grinding Conference, Cincinnati, Ohio, P.799-808, Oct.

SHARMAN, A.; DEWES, R. C.; ASPINWALL, D. K. (1999). Tool life when high speed ball nose end milling. In: Internacional Conference in Advances in Materials and Processing Technologies - AMPT. Dublin, Irlanda, p.437-445, Aug.

SHAW, M.C. (1984). Metal cutting principles, New York, USA, Oxford Science Publications, 594p.

SHINTANI, K.; UEKI, M.; FUJIMURA, Y. (1989). Optimum tool geometry of cbn tool for continuous turning of carburized steel. Internacional Journal Machine Tools Mamufacturing, v.29, n.3, p.403-413. 
SIKDAR, C.; PAUL, S.; CHATTOPADHYAY, A. (1992). Effect of variation in edge geometry on wear and life of coated carbide face milling inserts. Wear, n.157, p.111-116.

SILVA, L. R. (1998). Torneamento e retificação do aço ABNT 4340 temperado. Belo Horizonte. 83p. Dissertação (Mestrado) - Escola de Engenharia da Universidade Federal de Minas Gerais.

SIMON, A. T. (2001). O estágio atual do segmento de máquinas-ferramenta. Máquinas e Metais, n.420, p.108-112, jan.

SINHOFF, V.; ALTMÜLLER, S.; EISENBLÄTTER, G. (1999). A usinagem a seco em alta velocidade: revolução ou evolução? Máquinas e Metais, n.404, p.22-37, set.

SMITH, H. K. (1994). O uso de ferramentas reforçadas com whiskers em ligas de níquel. Máquinas e Metais, n.343, p.70-80, mar.

SMITH, S.; TLUSTY, J. (1997). Current trends in high-speed machining. Transactions of the ASME, Journal of Mamufacturing Science and Engineering v.119, p.664-666, Nov.

STIER, H. (1988). The rewards and demands of hard-part turning. Modern Machine Shop, v.60, n.11, p.88-94.

STOCKINGER, F.; BECK, W.; ENDERL, D. (1998). Desenvolvimento em ferramentas de corte a alta velocidade. Máquinas e Metais, n.389, p.28-39, maio.

THANGARAJ, A. R; WEINMANN, K. J. (1992). On the wear mechanisms and cutting performance of silicon carbide whisker-reinforced alumina. Journal of Engineering for Industry, v.114, p.301-308, Aug.

THIELE, J. D.; MELKOTE, S. N. (1999). The effect of tool edge geometry on workpiece sub-surface deformation and through-thickness residual stresses for hard-turning of AISI 52100 steel. In: XXVII Conference North American Mamufacturing Research Institution - SME, Berkeley, california, MR99-167, p.16, May. 
TÖNSHOFF, H. K.; WULFSBERG, J. P; KALS, H. J.; KÖNIG, W; LUTTERVELT, C. A. (1988). Developments and trends in monitoring and control of machining processes. In: Annals of the CIRP, v.37, n.2, p.610-622.

TÖNSHOFF, H. K.; WOBKER, C. (1994). Wear characteristics of cermets cutting tools. In: Annals of the CIRP, v.43, n.1, p.89-92.

TRENT, E.M. (1984). Metal cutting, 2.ed. London, England, Butterworths, 245p.

VIGNEAU. J.; BOULANGER, J. (1982). Behaviour of ceramic tools during the machining of nickel base alloys. In: Annals of the CIRP, v.31, n.1, p.35-39.

VIGNEAU. J.; BORDEL, P.; LÉONARD, A. (1987). Influence of the microstructure of the composite ceramic tools on their performance when machining nickel alloys. In: Annals of the CIRP, v.36, n.1, p.13-16.

VIGNEAU. J. (1997). Obtendo alta produtividade na usinagem de ligas de titânio e superligas. Máquinas e Metais, n.380, p.16-31, set.

ZHANG, Y. Z. (1986). Groove wear of tools in NC turning of pure nickel. In: Annals of the CIRP, v.35, n.1, p.71-74.

WAKABAYASHI, T.; SATO, H.; INASAKI, I. (1998). Turning using extremely small amounts of cutting fluids. JSME Internacional Journal. v.41, n.1, p.143148.

WALZ, T. (1996). Experience in high speed machines with direct drives. In: Anais do $1^{o}$ Seminário Internacional de Alta Tecnologia - Usinagem com altíssima velocidade de corte e alta precisão, Universidade Metodista de Piracicaba, Unimep, Santa Bárbara d'Oeste, SP, out.

WATANABE, K. (1996). Exemplos de projeto de fusos de alta velocidade e os métodos de balanceamento. Máquinas e Metais, n. 367, p.74-86. jul.

$\times$ WAYNE, S. F.; BULJAN, S. T. (1990). Wear of ceramic cutting tools in Ni-based superalloy machining. Tribology Transactions, v.33, n.4, p.618-626.

WECK, M.; SCHUMACHER, M.; QUEINS, M. (1999). Nova geração de máquinasferramenta de alta velocidade. Máquinas e Metais, n.402, p.16-40, jun. 
WEINGAERTNER, W. L.; SCHROETER, R. B.; CÚRCIO, F. (1994). Comparação das ligas de $\mathrm{Al}$ e $\mathrm{Cu}$ quanto às forças de usinagem. Máquinas e Metais, n.341, p.72-80, maio.

WEINGAERTNER, W.; GOMES, O. (1997). Avaliação da usinabilidade dos aços inox austeníticos SAE 304 e SAE 316. Máquinas e Metais, n.374, p.108-116, fev.

WERTHEIM, J.; ROTBERG, J.; BER, A. (1997). Efeitos do fluido a alta pressão através da superficie de saída da ferramenta. Máquinas e Metais, n.383, p.58-79, dez.

WILCOX, S. J.; REUBEN, R. L.; SOUQUET, P. (1997). The Use of Cutting Force and Acoustic Emission Signals for the Monitoring of Tool Insert Geometry During Rough Face Milling. International Journal of Machine Tools and Mamufacturing, v.37, n.4, p.481-494.

YOUNG, P.; BYRNE, G.; COTTERELL, M. (1997). Manufacturing and the environment. The Internacional Journal of Advanced Mamufacturing Technology, v. 13, p. $488-493$. 


\subsection{Bibliografia Consultada}

ABRÃO, A. M.; ASPINWALL, D. K. (1996). A utilização de ferramentas cerâmicas na usinagem de metais. In: IV CONGRESSO DE ENGENHARIA MECÂNICA CEM - NNE, Recife - Pe, p.243-247.

ARONSON, R. B. (1999). Ceramics: A tool material worth trying. Mamufacturing Engineering, n.7, p.66-71.

DAGILOKE, I.F.; KALDOS, A.; DOUGLAS, S.; MILLS, B. (1995). High-speed machining: na approach to process analysis. Journal of Materials processing Technology, n.54, p.82-87.

DEWES, R. C.; ASPINWALL, D.K. (1996). The use of high speed machining for the manufacture of hardened steel dies. Transactions of the north American Manufacturing Research Institution of SME, v.24, p.21-26, May.

EZUGWU, E. O.; PASHBY, I. R. (1992). High speed milling of nickel-based superalloys. Journal of Materials processing Technology, n.33, p.429-437.

FERREIRA, J. R.; SANTOS, J. N.; FILHO, F.T.; DINIZ, A. E.; BRAGA, D. U. (2000). Usinagem de aços endurecidos com mínima lubrificação. In: $1^{\circ}$ CONGRESSO NACIONAL DE ENGENHARIA MECÂNICA - CONEM, Natal $-\mathrm{RN}$.

FIELD, R; BEARD, T. (1996). High speed machining of dies and molds. Modern Machine Shop, v.69, n.6, p.76-83, Nov.

GALLIST, R. (1989). High-speed machining: Where it's headed. Modern Machine Shop, v.62, n.5, p.66-78, Oct.

GRIFFITH, W. H. (1994). Check-list para usinagem de alta velocidade e alta precisão. Máquinas e Metais, n.339, p.82-88, mar.

HAMANN, J.C.; GROLLEAU, F.; MAÎTRE, F. (1996). Machinability improvement of steels at high cutting speeds - Study of tool/work material interaction. In: Annals of the CIRP, v.45, n.1, p.87-92. 
HYATT, G. (1997). High-speed dry machining can cut cycle times and cost. Mamufacturing Engineering, n.9, p.82-87.

KAKINO, Y.; MATSUBARA, A.; KOHNO, Y.; NOGUCHI, K.; MURAKAMI, D.; TAKATA, Y. (1995). High speed, high produtive machining of automobile parts by machining center with high speed and high accelertion rate. In: Progress of Cutting and Grinding, v.3, ICPCG, p.192-197.

KISHAWY, H. A.; ELBESTAWI, M.A. (1999). Effects of process parameters on material side flow during hard turning. Internacional Journal of Machine tools \& Mamufacture. v.39, p.1017-1030.

KLOCKE, F.; EISENBLÄTTER, G. (1997). Machinability investigation of the drilling process using minimal cooling lubrification techniques. Prodution Engineering, v.4/1, p.19-24.

LETELLIER, J.; SAIN-CHELY, J. (1993). Como tornear materiais dificeis: Inconel, inox e titânio. Máquinas e Metais, n.331, p.70-73, ago.

LEWIS, D. L. (1997). A que velocidade andará a usinagem no século 21, lá pelo ano 2005. Máquinas e Metais, n.374, p.24-33, fev.

MÖLLER, B. (1998). Aplicações e limites dos fusos de alta rotação. Máquinas e Metais, n.392, p.52-57, set.

NASCIMENTO, G.; ABRÃO, A. M. (2000). Influência da geometria da ferramenta de corte na usinabilidade do aço ABNT 1045. In: $1^{\circ}$ CONGRESSO NACIONAL DE ENGENHARIA MECÂNICA - CONEM, Natal - RN.

NG, E.G.; LEE, D. W.; SHARMAN, R. C.; DEWES, R.C.; ASPINWALL, D. K. (2000). High speed ball nose end milling of Inconel 718. In: Annals of the CIRP, v. 49, n. 1, p. $41-46$.

NIEMINEN, I.; PARO, J.; KAUPPINEN, V. (1996). High-speed milling of advanced materials. Journal of Materials processing Technology, n.56, p.24-36. 
NOVASKI, O.; CORRÊA, M; FINZER, Th. (1998). A tecnologia da usinagem em altíssima velocidade de corte - HSC. In: $8^{\circ}$ CONGRESO CHILENO DE INGENIERIA MECÁNICA, p.677-679.

NOVASKI, O; DÖRR, J. (1999). Usinagem quase a seco. Máquinas e Metais, n. 406, p. 34-41, nov.

SCHNEIDER, J. (1999). Ceramics and CBN. Mamufacturing Engineering, n. 1, p.6673.

TLUSTY, J. (1993). High-speed machining. In: Annals of the CIRP, v.42, n.2, p.733738.

TLUSTY, J.; SMITH, S.; WINFOUGH, R. (1996). Techniques for the use of long slender end mills in high-speed milling. In: Annals of the CIRP, v.45, n.1, p.393396.

TOMITA, K. (1999). O atual estágio da HSM e dos materiais de ferramentas de corte. Máquinas e Metais, n.405, p.20-39, out.

VENKATESH, V. C.; KATTAN, I. A. (1996). An analysis of cutting tools with negative side cutting edge angles. Journal of Materials processing Technology, n.58, p.351-361.

WEINGAERTNER, W.L.; SCHROETER, R.B.; TEIXEIRA, C.R. (2000). As influências da minimização do fluido de corte. Máquinas e Metais, n.408, p.5259 , jan. 


\section{Apêndice I}

Programa de usinagem utilizado nos experimentos com Inconel 718.

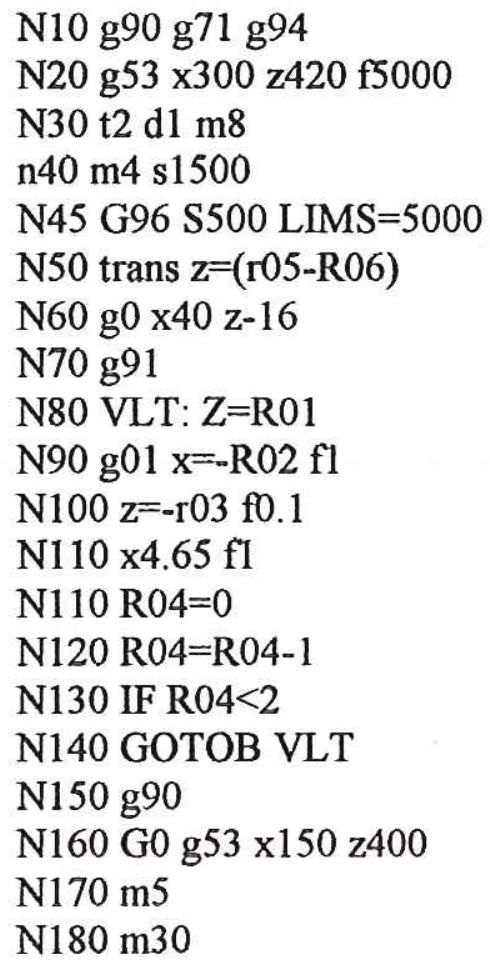

Programa de usinagem utilizado nos experimentos com Waspaloy.

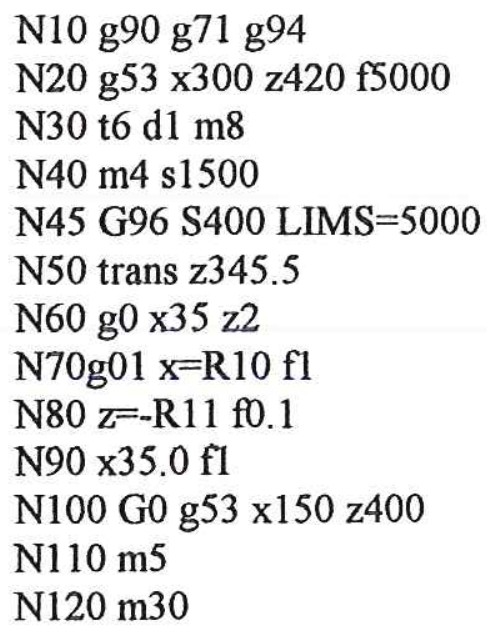




\section{Apêndice II}

Tela do software de aquisição de dados (LabView 5.1).

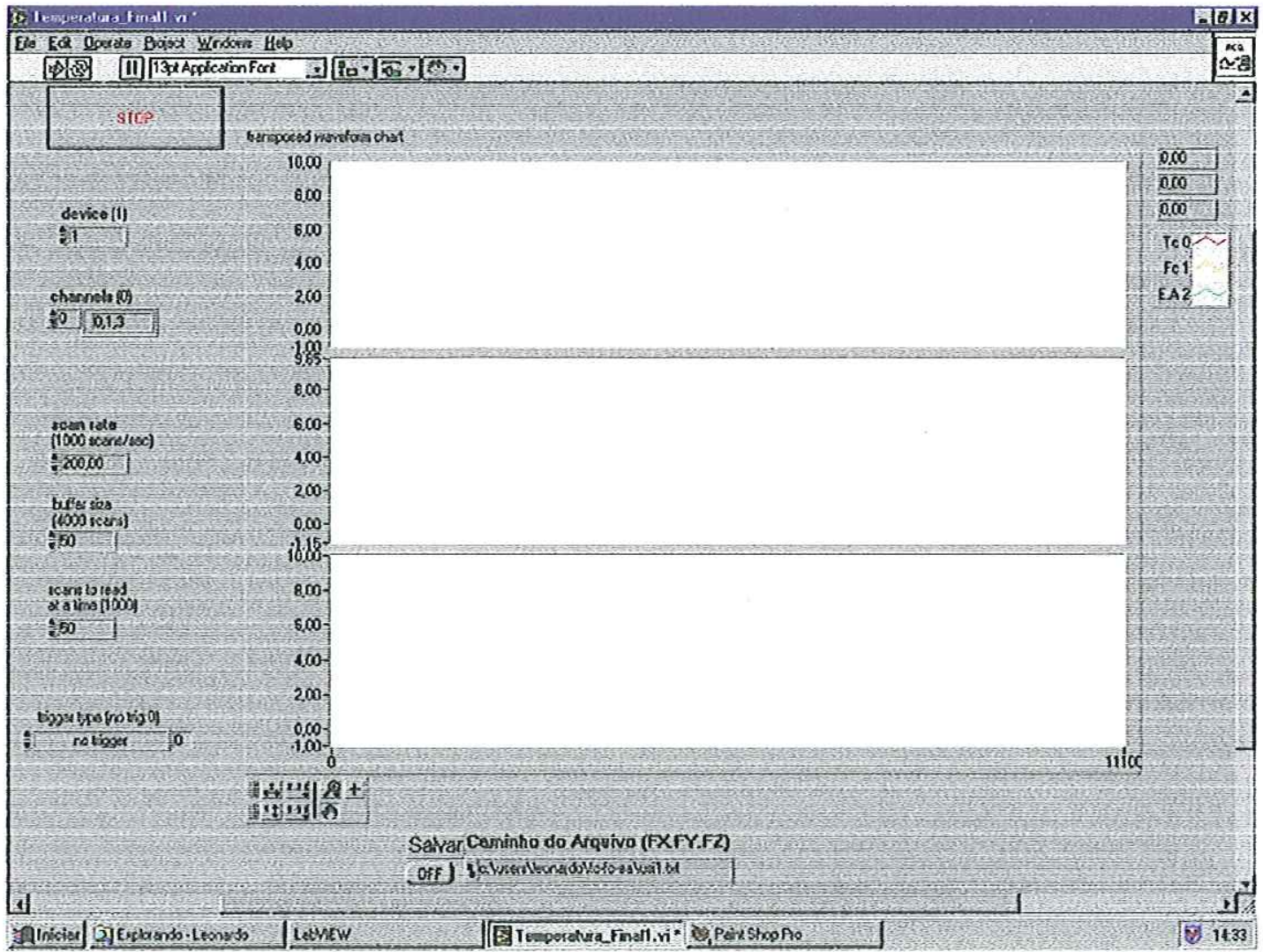


Diagrama interno do programa de aquisição de dados.

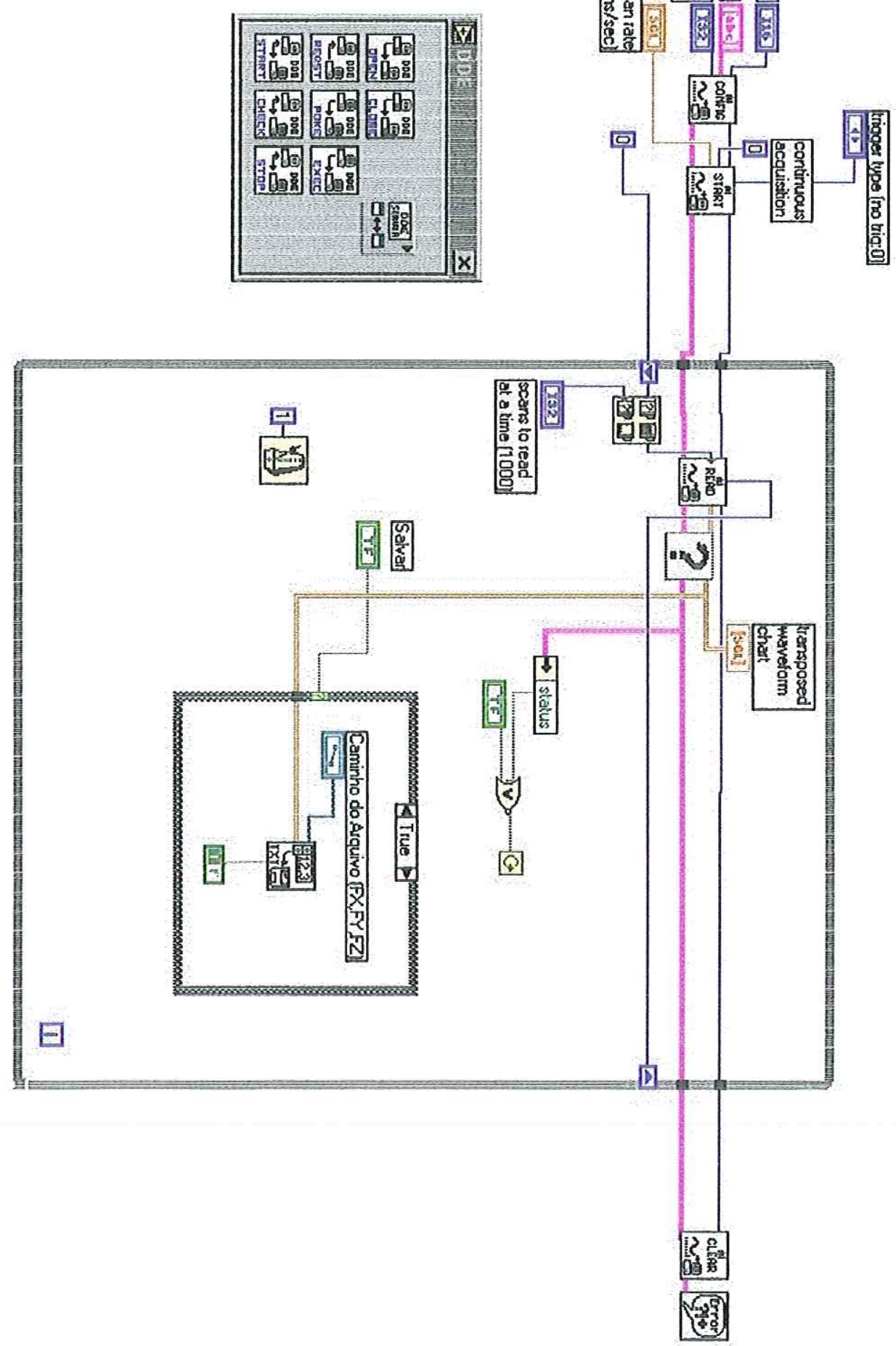

